\title{
Extração de Informações de Desempenho em GPUs NVIDIA
}

\author{
Paulo Carlos Ferreira dos Santos
}

\author{
DissERTAÇÃO APRESENTADA \\ $\mathrm{AO}$ \\ Instituto de Matemática E EstatísticA \\ DA \\ Universidade DE SÃo PaUlo \\ PARA \\ OBTENÇÃO DO TÍTULO \\ $\mathrm{DE}$ \\ Mestre em CiÊnCIAS
}

\begin{abstract}
Programa: Ciência da Computação
Orientador: Prof. Dr. Marco Dimas Gubitoso (orientador) - IME-USP
\end{abstract}




\title{
Extração de Informações de Desempenho em GPUs NVIDIA
}

\author{
Esta dissertação contém as correções e alterações \\ sugeridas pela Comissão Julgadora durante a defesa \\ realizada por Paulo Carlos Ferreira dos Santos em 15/03/2013. \\ O original encontra-se disponível no Instituto de \\ Matemática e Estatística da Universidade de São Paulo.
}

Comissão Julgadora:

- Prof. Dr. Marco Dimas Gubitoso (orientador) - IME-USP

- Prof. Dr. Marcel Parolin Jackowski - IME-USP

- Profa. Dra. Liria Matsumoto Sato - EP-USP 


\section{Agradecimentos}

Contei durante este trabalho com muita ajuda, mas gostaria de salientar o suporte, a paciência quase infinita e a disponibilidade do meu orientador, o Prof. Dr.Marco Dimas Gubitoso. Por vezes, quando eu via um caminho sem saída, ele mostrava que um pouco mais de persistência e paciência resolveriam.

Também gostaria de agradecer à minha filha, Luíza, que além de me acompanhar durante o trajeto, sempre achou que eu poderia ir além.

O Prof. Dr. Marcel Parolin Jackowski, com a sua visão crítica sobre o texto e seu incentivo, colaborou muito com a melhoria do texto final.

Aos tantos amigos com quem dividi os meus pensamentos, gostaria de deixar um grande obrigado, com a certeza de que essas amizades perdurarão. 


\section{Resumo}

Santos, P. C. F. Extração de Informações de Desempenho em GPUs NVIDIA. 2013. 154 f. Dissertação (Mestrado)- Instituto de Matemática e Estatística, Universidade de São Paulo, São Paulo, 2013.

O recente crescimento da utilização de Unidades de Processamento Gráfico (GPUs) em aplicações científicas, que são voltadas ao desempenho, gerou a necessidade de otimizar os programas que nelas rodam. Uma ferramenta adequada para essa tarefa é o modelo de desempenho que, por sua vez, se beneficia da existência de uma ferramenta de extração de informações de desempenho para GPUs.

Este trabalho cobre a criação de um gerador de microbenchmark para instruções PTX $^{1}$ que também obtém informações sobre as características do hardware da GPU.

Os resultados obtidos com o microbenchmark foram validados através de um modelo simplificado que obteve erros entre $6,11 \%$ e $16,32 \%$ em cinco kernels de teste. Também foram levantados os fatores de imprecisão nos resultados do microbenchmark.

Utilizamos a ferramenta para analisar o perfil de desempenho das instruções e identificar grupos de comportamentos semelhantes. Também testamos a dependência do desempenho do pipeline da GPU em função da sequência de instruções executada e verificamos a otimização do compilador para esse caso.

Ao fim deste trabalho concluímos que a utilização de microbenchmarks com instruções PTX é factível e se mostrou eficaz para a construção de modelos e análise detalhada do comportamento das instruções.

Palavras-chave: microbenchmark, linguagem PTX, desempenho de GPU, modelo de desempenho, paralelismo.

\footnotetext{
${ }^{1}$ Parallel Thread eXecution, Execução Paralela de Linhas. Conjunto de instruções para GPUs da NVIDIA.
} 


\section{Abstract}

Santos, P. C. F. Performance Information Extraction on NVIDIA GPUs. 2013. $154 \mathrm{f}$. Dissertação (Mestrado) - Instituto de Matemática e Estatística, Universidade de São Paulo, São Paulo, 2013.

The recent growth in the use of tailored for performance Graphics Processing Units (GPUs) in scientific applications, generated the need to optimize GPU targeted programs. Performance models are the suitable tools for this task and they benefits from existing GPUs performance information extraction tools.

This work covers the creation of a microbenchmark generator using PTX ${ }^{2}$ instructions and it also retrieves information about the GPU hardware characteristics.

The microbenchmark results were validated using a simplified model with errors rates between $6.11 \%$ and $16.32 \%$ under five diferent GPU kernels. We also explain the imprecision factors present in the microbenchmark results.

This tool was used to analyze the instructions performance profile, identifying groups with similar behavior. We also evaluated the corelation of the GPU pipeline performance and instructions execution sequence. Compiler optimization capabilities for this case were also verified.

We concluded that the use of microbenchmarks with PTX instructions is a feasible approach and an effective way to build performance models and to generate detailed analysis of the instructions' behavior.

Keywords: microbenchmark, PTX language, GPU performance, performance model, parallelism.

${ }^{2}$ Parallel Thread eXecution, instruction set for NVIDIA GPUs. 


\section{Sumário}

Lista de Abreviaturas $\quad$ xi

Lista de Figuras $\quad$ Xv

Lista de Tabelas $\quad$ xxi

1 Introdução $\quad 1$

1.1 Organização do Trabalho . . . . . . . . . . . . . . . . . . . . . 3

2 Conceitos de Paralelismo $\quad 5$

2.1 Taxonomia de Flynn . . . . . . . . . . . . . . . . . . . . . . . 6

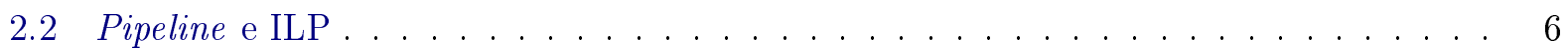

2.3 Modelos . . . . . . . . . . . . . . . . . . . . . . . . . 9

3 Conceitos de GPU $\quad 11$

3.1 Fundamentos . . . . . . . . . . . . . . . . . . . . . 13

3.2 Arquitetura GPU . . . . . . . . . . . . . . . . . . . . . . . . . . . . . . . . . . . . .

3.2 .1 Compute Capability . . . . . . . . . . . . . . . 16

3.2 .2 Stream Multi Processor . . . . . . . . . . . . . . . . 16

3.2 .3 Gerenciamento de Memória . . . . . . . . . . . . . . . . . . . 17

3.2 .4 Arquitetura SIMT . . . . . . . . . . . . . . . . 20

3.3 Arquitetura Fermi . . . . . . . . . . . . . . . . . . 23

4 Conceitos de Cuda $\quad 27$

4.1 Modelo de Programação . . . . . . . . . . . . . . . . . . . . . 27

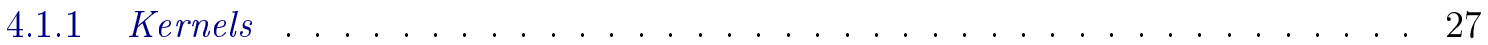

4.1 .2 Hierarquia de Threads . . . . . . . . . . . . . . . . 28

4.1 .3 Hierarquia de Memória . . . . . . . . . . . . . . . . . . 30

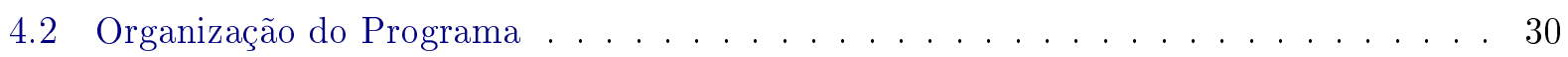

$4.2 .1 \quad$ Formas de Transferência . . . . . . . . . . . . . . . . . . . . . 32

4.3 Etapas de Criação do Programa . . . . . . . . . . . . . . . . . . . . 32

$4.3 .1 \quad \mathrm{NVCC} \ldots \ldots \ldots \ldots \ldots \ldots \ldots$

4.3.2 Arquitetura Virtual e Arquitetura Real . . . . . . . . . . . . . . . 34

4.3 .3 Compilação por Demanda . . . . . . . . . . . . . . . . . 36

4.3 .4 Emulação . . . . . . . . . . . . . . . . . . . . . . . 36 
4.3.5 Repositórios . . . . . . . . . . . . . . . . . . 37

4.3.6 Informações sobre Utilização de Memória . . . . . . . . . . . . . . . . 38

5 Trabalhos Relacionados 39

5.1 An Analytical Model for a GPU Architecture with Memory-Level and Thread-Level Parallelism Awareness . . . . . . . . . . . . . . . . . . 39

5.2 A Performance Prediction Model for the CUDA GPGPU Platform . . . . . . . . . 42

5.3 An Adaptive Performance Modeling Tool for GPU Architectures . . . . . . . . . . . . 43

5.4 A Quantitative Performance Analysis Model for GPU Architectures . . . . . . . . . . 44

5.5 Demystifying GPU Microarchitecture Through Microbenchmarking . . . . . . . . . . 45

5.6 Resumo das Formas de Contabilizar o Tempo de Execução . . . . . . . . . . . . . . . . 46

6 Microbenchmark $\quad 47$

6.1 Gerador de Microbenchmark . . . . . . . . . . . . . ........ 48

6.1.1 Gerador de Instruções em PTX . . . . . . . . . . . . . . . . . . . . . . 48

6.1 .2 Linguagem de Definição de Instruções ． . . . . . . . . . . . . . . . . . . 50

6.1.3 Gerador de Código de Teste . . . . . . . . . . . . . . . . . . . . 52

6.1.4 Opções de Configuração do Gerador de Microbenchmark . . . . . . . . . . . . 55

6.1.5 Compilação do Microbenchmark . . . . . . . . . . . . . . . . . 58

6.2 Executável do Microbenchmark . . . . . . . . . . . . . . . . . . . 60

6.2.1 Opções de Configuração do Executável do Microbenchmark . . . . . . . . . . 60

6.2.2 Arquivo de Saída do Microbenchmark . . . . . . . . . . . . . . . . 61

6.3 Pós Processamento do Microbenchmark . . . . . . . . . . . . . . . . . . 63

6.3 .1 Obtenção do Tempo Médio . . . . . . . . . . . . . . . . . . . . 63

6.3.2 Perfil de Desempenho das Instruções . . . . . . . . . . . . . . . . . . . 65

6.3.3 Arquivo de Saída do Pós Processamento . . . . . . . . . . . . . . . . . 65

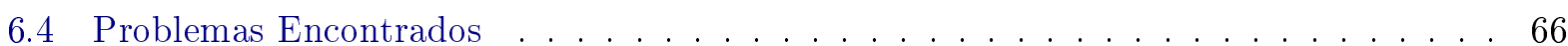

6.4 .1 Interferência da Geração de Vídeo . . . . . . . . . . . . . . . . . . . . 67

6.4 .2 Análise de Código Morto . . . . . . . . . . . . . . . . . . . . 67

6.4 .3 Código PTX e Código de Máquina . . . . . . . . . . . . . . . . . . 68

6.4 .4 Variações no Tempo de Execução . . . . . . . . . . . . . . . . . . . . 68

6.5 Escolhas do Projeto . . . . . . . . . . . . . . . . . . 70

7 Experimentos e Resultados $\quad 71$

7.1 Análises Preliminares . . . . . . . . . . . . . . . . . . . . . . . 71

7.1 .1 Análise de Dispersão . . . . . . . . . . . . . . . . . . . . . . 72

7.1 .2 Análise do Escalonamento . . . . . . . . . . . . . . . . . . . . . 72

7.1 .3 Análise do Trecho de Teste . . . . . . . . . . . . . . . . . . . . 76

7.1.4 Análise da Distribuição Após Alteração na Forma de Contabilizar o Tempo . 84

7.1.5 Análise do Sistema de Medição . . . . . . . . . . . . . . . . . . . . . . . 86

7.1.6 Análise do Perfil da Instrução . . . . . . . . . . . . . . . . . . . . . . . . . 89

7.1.7 Resumo e Conclusões das Análises Preliminares . . . . . . . . . . . . . . . . 98

7.2 Validação . . . . . . . . . . . . . . . . . . . . . . . . . 100

7.2.1 Kernels de Teste . . . . . . . . . . . . . . . . . 100 
7.2 .2 Modelo Simplificado . . . . . . . . . . . . . . . . . . . . . . . . . 101

7.2 .3 Resultados . . . . . . . . . . . . . . . . . . . . 101

7.2 .4 Análise das Rechamadas . . . . . . . . . . . . . . . . . . . . . . . . . . . . 104

7.3 Pipeline, Sequência de Instruções e Tempo de Execução . . . . . . . . . . . . . . 104

7.4 Comparativo com Valores de Referência da NVIDIA . . . . . . . . . . . . . . . 109

7.4.1 Resumo e Conclusões da Validação . . . . . . . . . . . . . . . . . . . . 109

8 Conclusões $\quad 111$

8.1 Sugestões para Pesquisas Futuras . . . . . . . . . . . . . . . . . . . . 113

A Compute Capability 115

B Desempenho Instruções fornecido pela NVIDIA 117

$\begin{array}{lr}\text { C Código Fonte } & 119\end{array}$

D Desmontagem de Instruções PTX 121

D.1 Instrução de Divisão de 64 bits . . . . . . . . . . . . . . . . . . . . . . . . 121

$\begin{array}{ll}\text { Referências Bibliográficas } & 125\end{array}$

$\begin{array}{lr}\text { Índice Remissivo } & 129\end{array}$ 


\title{
Lista de Abreviaturas
}

\author{
ALU Unidade Lógica e Aritmética (Arithmetic Logic Unit) \\ ANSI Instituto Nacional Americano de Padrões (American National Standards Institute) \\ API Interface de Programação de Aplicativos (Application Programming Interface) \\ CFG Grafo de Controle de Fluxo (Control Flow Graph) \\ $\mathrm{Cg} \quad \mathrm{C}$ (linguagem) para Gráficos (C for Graphics) \\ CPI Ciclos de Relógio por Instrução (Clock per Instruction) \\ CPU Unidade Central de Processamento (Central Processing Unit) \\ CUDA Arquitetura de Equipamento e Computador Unificada (Computer Unified Device Architecture) \\ CWP Paralelismo de Computação do Warp (Computation Warp Parallelism) \\ DirectX Coleção de APIs da Microsoft para programação gráfica no sistema operacional Windows. \\ DLP Paralelismo ao Nível dos Dados (Data Level Parallelism) \\ DRAM Memória Dinâmica de Acesso Aleatório (Dynamic Random-Access Memory) \\ ECC Código de Correção de Erros (Error Correction Code) \\ FPU Unidade de Ponto Flutuante (Floating Point Unit) \\ GCC GNU Compiler Collection (Coleção de Compiladores GNU) \\ GNU Sigla recursiva para "GNU's Not Unix"(GNU não é Unix) \\ GPU Unidade de Processamento Gráfico (Graphics Processing Unit) \\ GPGPU GPU de Propósito Geral (General Purpose Graphics Processing Unit) \\ IEEE Instituto de Engenheiros Elétricos e Eletrônicos (Institute of Electrical and Electronic Engineers) \\ ILP Paralelismo ao Nível da Instrução (Instruction Level Parallelism) \\ ISA Arquitetura do conjunto de instruções (Instruction Set Architecture) \\ JIT Compilação por Demanda (Just in Time Compilation) \\ L1 Cache de Nível 1 (Level 1 Cache) \\ L2 Cache de Nível 2 (Level 2 Cache) \\ MPI Interface de Passagem de Mensagens (Message Passing Interface) \\ MWP Paralelismo de Memória do Warp (Memory Warp Parallelism) \\ NVCC CUDA Compiler Driver (Controlador de Compilação CUDA) \\ OpenGL Biblioteca Gráfica Aberta - API livre de computação gráfica (Open Graphics Library) \\ PCI Interconexão Expressa de Componente Periférico (Peripheral Component Interconnect Express) \\ Pixel Elemento de Imagem (Picture Element) \\ PRAM Máquina Paralela de Acesso Aleatório (Parallel Random Access Machine) \\ PTX Execução Paralela de Linhas (Parallel Thread eXecution) \\ ROP Processador de Operação de Varredura (Raster Operation Processor) \\ SDK Conjunto de Desenvolvimento de Software (Software Development Kit) \\ SFU Unidade de Função Especial (Special Function Unit)
}


SIMD Instrução única e dados múltiplos (Simple Instruction Multiple Data)

SIMT Instrução única e múltiplas threads (Simple Instruction Multiple Thread)

SM Multiprocessador de Fluxo (Stream Multiprocessor)

SMC Controlador de Multiprocessador de Fluxo (Stream Multiprocessor Controller)

SP Processador de Fluxo (Stream Processor)

SPMD Programa único e dados múltiplos (Single Program Multiple Data)

TPC Grupos de Textura/Processador (Texture/Processor Clusters)

VLIW Instrução de Palavra Muito Longa (Very Long Instruction Word)

WLP Paralelismo ao Nível do Warp (Warp Level Parallelism)

WFG Grafo de Fluxo de Trabalho (Work Flow Graph) 


\section{Lista de Figuras}

2.1 Exemplo de um pipeline com seis estágios (Stallings, 2003, p. 428) . . . . . . . . 7

2.2 Diagrama de tempos da execução de instruções no pipeline de seis estágios (Stallings,

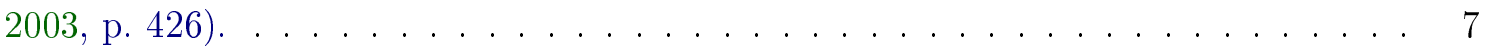

2.3 Diagrama de tempos da execução de instruções no pipeline de seis estágios com dependência de leitura após escrita na instrução $2 \ldots \ldots \ldots \ldots$

3.1 Exemplo de um pipeline gráfico (Liu et al., 2007) . . . . . . . . . . . . . 12

3.2 Fluxo de processamento utilizando GPU. . . . . . . . . . . . . . . . . . . 13

3.3 Arquitetura da GPU GeForce 8800 da NVIDIA (Lindholm et al., 2008). . . . . . . . 14

3.4 Estrutura do Stream Multi Processor CUDA com Unidade de Dupla Precisão. . . . . 16

3.5 Visão Simplificada do Sistema de Memória da GPU. . . . . . . . . . . . . . . . . 19

3.6 As várias linhas (threads) em um tear formando uma urdidura (warp) (Lindholm et al.,

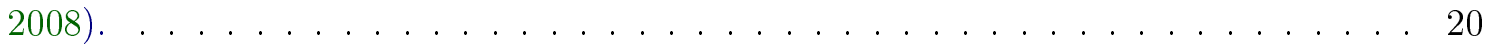

3.7 Alocação de Blocos e Warps no SM (Hong e Kim, 2009b). . . . . . . . . . . . . . . 21

3.8 SIMT: Escalonamento e Execução dos Warps (Lindholm et al., 2008). . . . . . . . . 22

3.9 A alocação do mesmo kernel em duas GPUs, uma com 2 SMs e a outra com 4 SMs.(Kirk e mei W. Hwu, 2010, p. 68) . . . . . . . . . . . . . . . . 23

3.10 Arquitetura do SM Fermi da NVIDIA.(NVIDIA, 2009) . . . . . . . . . . . . . . . 24

3.11 Escalonador Duplo da Arquitetura Fermi (NVIDIA, 2009) . . . . . . . . . . . . . . 25

3.12 Unificação do Espaço de Endereçamento da Arquitetura Fermi (NVIDIA, 2009). . . . 25

3.13 Hierarquia de Memórias da Arquitetura Fermi (NVIDIA, 2009) . . . . . . . . . . . . 26

4.1 Organização bidimensional de blocos e threads (NVIDIA, 2011d, p. 9). . . . . . . . . 29

4.2 Os tipos de memória e as permissões de acesso (NVIDIA, 2011d, p. 11) . . . . . . . . 31

4.3 Separação de código, compilação e união final feita pelo nvcc (Lanfear e Ziegler, 2009). 33

4.4 Etapas de compilação CUDA (NVIDIA, 2011f, p. 21) . . . . . . . . . . . . . 34

4.5 Os dois estágios de compilação, com a arquitetura virtual e a real. . . . . . . . . . 35

4.6 A relação entre a arquitetura virtual, a arquitetura real e a utilização de emulação

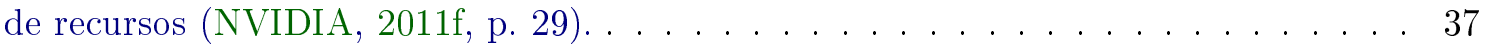

6.1 Ciclo de criação do microbenchmark . . . . . . . . . . . . . . . . . 47

6.2 Execução e Pós Processamento do microbenchmark . . . . . . . . . . . . . . . . 48

6.3 Fluxo do teste entre o computador hospedeiro e a GPU. . . . . . . . . . . . . . . . 52

6.4 Sequência de etapas da compilação do microbenchmark . . . . . . . . . . . . . . . 59

6.5 Contabilização do tempo inicial e final com a execução de quatro warps. . . . . . . . 64 
7.1 Histograma da instrução add.u32 com 10 instruções no trecho, 480 threads (15 warps) e 100 amostragens. . . . . . . . . . . . . . . . . . . . . . 73

7.2 Histograma da instrução mad.hi.u32 com 10 instruções no trecho, 480 threads (15 warps) e 100 amostragens. . . . . . . . . . . . . . . . . 73

7.3 Histograma da instrução div.rn.f64 com 10 instruções no trecho, 480 threads (15 warps) e 100 amostragens. . . . . . . . . . . . . . . . . . . 74

7.4 Histograma da instrução rsqrt.approx.ftz.f32 com 10 instruções no trecho, 512 threads (16 warps), 50 amostragens e considerando o tempo de cada warp. . . . . . . . . 76

7.5 Histograma da instrução rsqrt.approx.ftz.f32 com 10 instruções no trecho, 512 threads (16 warps), 50 amostragens e considerando o tempo total do kernel. . . . . . . . . 76

7.6 Histograma da instrução mov.s64 com 10 instruções no trecho, 480 threads (15 warps) e 100 amostragens. Os tempos se referem a cada warp sendo executado. . . . . . . 76

7.7 Histograma da instrução mov.s64 com 1 instrução no trecho, 480 threads (15 warps), 100 amostragens e considerando o tempo de cada warp. . . . . . . . . . . 77

7.8 Histograma da instrução mov.s64 com 2 instruções no trecho, 480 threads (15 warps), 100 amostragens e considerando o tempo de cada warp. . . . . . . . . . . 77

7.9 Histograma da instrução mov.s64 com 3 instruções no trecho, 480 threads (15 warps), 100 amostragens e considerando o tempo de cada warp. . . . . . . . . . . . 77

7.10 Histograma da instrução mov.s64 com 4 instruções no trecho, 480 threads (15 warps), 100 amostragens e considerando o tempo de cada warp. . . . . . . . . . . 77

7.11 Histograma da instrução mov.s64 com 5 instruções no trecho, 480 threads (15 warps), 100 amostragens e considerando o tempo de cada warp. . . . . . . . . . . 78

7.12 Histograma da instrução mov.s64 com 10 instruções no trecho, 480 threads (15 warps), 100 amostragens e considerando o tempo de cada warp. . . . . . . . . . . 78

7.13 Histograma da instrução mov.s64 com 10 instruções no trecho, 32 threads (1 warp), 100 amostragens e considerando o tempo de cada warp. . . . . . . . . . . 78

7.14 Histograma da instrução mov.s64 com 10 instruções no trecho, 64 threads (2 warps), 100 amostragens e considerando o tempo de cada warp. . . . . . . . . . . 78

7.15 Histograma da instrução mov.s64 com 10 instruções no trecho, 96 threads (3 warps), 100 amostragens e considerando o tempo de cada warp. . . . . . . . . . 78

7.16 Histograma da instrução mov.s64 com 10 instruções no trecho, 128 threads (4 warps), 100 amostragens e considerando o tempo de cada warp. . . . . . . . . . 78

7.17 Histograma da instrução mov.s64 com 10 instruções no trecho, 160 threads (5 warps), 100 amostragens e considerando o tempo de cada warp. . . . . . . . . . . 79

7.18 Histograma da instrução mov.s64 com 10 instruções no trecho, 192 threads (6 warps), 100 amostragens e considerando o tempo de cada warp. . . . . . . . . . . 79

7.19 Histograma da instrução mov.s64 com 10 instruções no trecho, 224 threads (7 warps), 100 amostragens e considerando o tempo de cada warp. . . . . . . . . . . 79

7.20 Histograma da instrução mov.s64 com 10 instruções no trecho, 256 threads (8 warps), 100 amostragens e considerando o tempo de cada warp. . . . . . . . . . . . 79

7.21 Histograma da instrução mov.s64 com 10 instruções no trecho, 288 threads (9 warps), 100 amostragens e considerando o tempo de cada warp. . . . . . . . . . . 
7.22 Histograma da instrução mov.s64 com 10 instruções no trecho, 320 threads (10 warps ), 100 amostragens e considerando o tempo de cada warp. . . . . . . . . . . . 79

7.23 Histograma da instrução mov.s64 com 10 instruções no trecho, 352 threads (11 warps ), 100 amostragens e considerando o tempo de cada warp. . . . . . . . . . . . 80

7.24 Histograma da instrução mov.s64 com 10 instruções no trecho, 384 threads (12 warps), 100 amostragens e considerando o tempo de cada warp. . . . . . . . . . . . 80

7.25 Histograma da instrução mov.s64 com 10 instruções no trecho, 416 threads (13 warps), 100 amostragens e considerando o tempo de cada warp. . . . . . . . . . . . 80

7.26 Histograma da instrução mov.s64 com 10 instruções no trecho, 448 threads (14 warps), 100 amostragens e considerando o tempo de cada warp. . . . . . . . . . . 80

7.27 Histograma da instrução mov.s64 com 1 instrução no trecho, 384 threads (12 warps), 100 amostragens e considerando o tempo de cada warp. . . . . . . . . . . . . . 81

7.28 Histograma da instrução mov.s64 com 1 instrução no trecho, 416 threads (13 warps), 100 amostragens e considerando o tempo de cada warp. . . . . . . . . . . . . . . . 81

7.29 Histograma da instrução mov.s64 com 1 instrução no trecho, 448 threads (14 warps), 100 amostragens e considerando o tempo de cada warp. . . . . . . . . . . . . . . . . 81

7.30 Histograma da instrução mov.s64 com 1 instrução no trecho, 480 threads (15 warps), 100 amostragens e considerando o tempo de cada warp. . . . . . . . . . . . . . . . . 81

7.31 Instrução add.s32, gráfico da quantidade de instruções no trecho versus a quantidade de warps onde inicia a variância diferente de zero. Executado na GPU GeForceGTX470 com 50 iterações, arquitetura virtual PTX 10 e arquitetura real SM 20. . . . . . . . . 82

7.32 Instrução mad.lo.u64, gráfico da quantidade de instruções no trecho versus a quantidade de warps onde inicia a variância diferente de zero. Executado na GPU GeForceGTX470 com 50 iterações, arquitetura virtual PTX 10 e arquitetura real SM 20. . . . . . . . . 83

7.33 Instrução mul.f64, gráfico da quantidade de instruções no trecho versus a quantidade de warps onde inicia a variância diferente de zero. Executado na GPU GeForceGTX470 com 50 iterações, arquitetura virtual PTX 10 e arquitetura real SM 20. . . . . . . . 83

7.34 Instrução add.s32, gráfico do desvio padrão versus a quantidade de instruções no trecho versus a quantidade de warps. Executado na GPU GeForceGTX470 com 50 iterações, arquitetura virtual PTX 10 e arquitetura real SM 20. . . . . . . . . . . . . 84

7.35 Histograma da instrução add.s32 com 4 instruções no trecho, 192 threads (6 warps), 100 amostragens e considerando o tempo total do kernel. Os tempos indicados possuem a calibragem descontada. . . . . . . . . . . . . . . . . . . 85

7.36 Histograma da instrução lg2.approx.ftz.f32 com 3 instruções no trecho, 96 threads (3 warps ), 100 amostragens e considerando o tempo total do kernel. Os tempos indicados possuem a calibragem descontada. . . . . . . . . . . . . . . . . . . . . . 85

7.37 Histograma da instrução mul.hi.u32 com 10 instruções no trecho, 480 threads (15 warps ), 100 amostragens e considerando o tempo total do kernel. Os tempos indicados possuem a calibragem descontada. . . . . . . . . . . . . . . . . . . . 86

7.38 Histograma da instrução mul.hi.u32 com 10 instruções no trecho, 512 threads (16 warps ), 100 amostragens e considerando o tempo total do kernel. Os tempos indicados possuem a calibragem descontada. 
7.39 Histograma da instrução mul.sat.f32 com 10 instruções no trecho, 352 threads (11 warps), 100 amostragens e considerando o tempo total do kernel. Os tempos indicados possuem a calibragem descontada. . . . . . . . . . . . . 8

7.40 Histograma da instrução mul.sat.f32 com 10 instruções no trecho, 384 threads (12 warps), 100 amostragens e considerando o tempo total do kernel. Os tempos indicados possuem a calibragem descontada. . . . . . . . . . . . . . 86

7.41 Histograma da instrução mov.f64 com 10 instruções no trecho, 480 threads (15 warps), 100 amostragens e considerando o tempo total do kernel. Os tempos indicados possuem a calibragem descontada. . . . . . . . . . . . . . . . 8

7.42 Histograma da instrução selp.f64 com 10 instruções no trecho, 480 threads (15 warps), 100 amostragens e considerando o tempo total do kernel. Os tempos indicados possuem a calibragem descontada. . . . . . . . . . . . . . . . . . 8

7.43 Calibragem, gráfico da quantidade de instruções no trecho versus a quantidade de warps onde inicia a variância diferente de zero. Executado na GPU GeForceGTX470 com 50 iterações, arquitetura virtual PTX 10 e arquitetura real SM 20. . . . . . . . .

7.44 Histograma da calibragem com 416 threads (13 warps), 50 amostragens e considerando o tempo total do kernel. . . . . . . . . . . . . . . . . . . 88

7.45 Histograma da calibragem com 448 threads (14 warps), 50 amostragens e considerando o tempo total do kernel. . . . . . . . . . . . . . . . . .

7.46 Histograma da calibragem com 736 threads (23 warps), 50 amostragens e considerando o tempo total do kernel. . . . . . . . . . . . . . . . . . . .

7.47 Histograma da calibragem com 768 threads (24 warps), 50 amostragens e considerando o tempo total do kernel. . . . . . . . . . . . . . . . . . .

7.48 Instrução add.s32, gráfico 3D do tempo médio de execução pela quantidade de instruções no trecho pela quantidade de threads. Executado na GPU GeForceGTX470 com 100 iterações, arquitetura virtual PTX 10 e arquitetura real SM 20 . . . . . . .

7.49 Instrução add.s32, gráfico do tempo médio de execução para cada quantidade de instruções no trecho pela quantidade de threads. Executado na GPU GeForceGTX470 com 100 iterações, arquitetura virtual PTX 10 e arquitetura real SM 20 . . . . . . . .

7.50 Instrução add.s64, gráfico 3D do tempo médio de execução pela quantidade de instruções no trecho pela quantidade de threads. Executado na GPU GeForceGTX470 com 100 iterações, arquitetura virtual PTX 10 e arquitetura real SM 20. . . . . . . . 91

7.51 Instrução add.s64, gráfico do tempo médio de execução para cada quantidade de instruções no trecho pela quantidade de threads. Executado na GPU GeForceGTX470 com 100 iterações, arquitetura virtual PTX 10 e arquitetura real SM 20. . . . . . . . 92

7.52 Instrução sqrt.approx.f32, gráfico 3D do tempo médio de execução pela quantidade de instruções no trecho pela quantidade de threads. Executado na GPU GeForceGTX470 com 100 iterações, arquitetura virtual PTX 10 e arquitetura real SM 20. . . . . . . . 92

7.53 Instrução sqrt.approx.f32, gráfico do tempo médio de execução para cada quantidade de instruções no trecho pela quantidade de threads. Executado na GPU GeForceGTX470 com 100 iterações, arquitetura virtual PTX 10 e arquitetura real SM 20 . . . . . . . 93 
7.54 Instrução div.rn.f64, gráfico 3D do tempo médio de execução pela quantidade de instruções no trecho pela quantidade de threads. Executado na GPU GeForceGTX470 com 100 iterações, arquitetura virtual PTX 10 e arquitetura real SM 20. . . . . . . . 93

7.55 Instrução div.rn.f64, gráfico do tempo médio de execução para cada quantidade de instruções no trecho pela quantidade de threads. Executado na GPU GeForceGTX470 com 100 iterações, arquitetura virtual PTX 10 e arquitetura real SM 20. . . . . . . . 94

7.56 Instrução sub.rn.f64, gráfico 3D do tempo médio de execução pela quantidade de instruções no trecho pela quantidade de threads. Executado na GPU GeForceGTX470 com 100 iterações, arquitetura virtual PTX 10 e arquitetura real SM 20. . . . . . . . 94

7.57 Instrução sub.rn.f64, gráfico do tempo médio de execução para cada quantidade de instruções no trecho pela quantidade de threads. Executado na GPU GeForceGTX470 com 100 iterações, arquitetura virtual PTX 10 e arquitetura real SM 20. . . . . . . . 95

7.58 Instrução mul.rn.f32, gráfico 3D do tempo médio de execução pela quantidade de instruções no trecho pela quantidade de threads. Executado na GPU GeForceGTX470 com 100 iterações, arquitetura virtual PTX 10 e arquitetura real SM 20 . . . . . . . 95

7.59 Instrução mul.rn.f32, gráfico do tempo médio de execução para cada quantidade de instruções no trecho pela quantidade de threads. Executado na GPU GeForceGTX470 com 100 iterações, arquitetura virtual PTX 10 e arquitetura real SM 20. . . . . . . 96

7.60 Calibragem, gráfico 3D do tempo médio de execução pela quantidade de instruções no trecho pela quantidade de threads. Executado na GPU GeForceGTX470 com 100 iterações, arquitetura virtual PTX 10 e arquitetura real SM 20 . . . . . . . . . . . 97

7.61 Calibragem, gráfico do tempo médio de execução para cada quantidade de instruções no trecho pela quantidade de threads. Executado na GPU GeForceGTX470 com 100 iterações, arquitetura virtual PTX 10 e arquitetura real SM 20 . . . . . . . . . . . 97

7.62 Sequência de etapas da validação. . . . . . . . . . . . . . . . . . . . . . 102

7.63 Resultado da execução de três kernels com as mesmas instruções, porém, em sequências diferentes. Compilado sem otimização e executado na GPU GeForceGTX470, com 100 iterações, arquitetura virtual PTX 10 e arquitetura real SM 20 . . . . . . . 106

7.64 Resultado da execução de dois kernels com as mesmas instruções, porém, em sequências diferentes. Compilado com otimização e executado na GPU GeForceGTX470 com 100 iterações, arquitetura virtual PTX 10 e arquitetura real SM 20. . . . . . . . . . . 108 


\section{Lista de Tabelas}

7.1 Escalonamento da instrução add.u16 com 4 warps . . . . . . . . . . . . . . . . 74

7.2 Escalonamento da instrução div.s32 com 3 warps e 2 instruções no trecho de teste. . 74

7.3 Escalonamento da instrução div.s32 com 3 warps e 4 instruções no trecho de teste. . 75

7.4 Escalonamento da instrução div.s32 com 3 warps, 5 instruções no trecho de teste e inversão no escalonamento. . . . . . . . . . . . . . . . . . 75

7.5 Tabela da quantidade de instruções no trecho versus a quantidade de warps onde inicia a variância diferente de zero, para a instrução add.s32. Executado na GPU GeForceGTX470 com 50 iterações, arquitetura virtual PTX 10 e arquitetura real

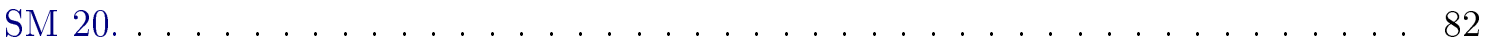

7.6 Resultados da execução dos 5 kernels comparados com os valores calculados pelo modelo usando os valores do microbenchmark. Ambos com 100 execuções. . . . . . . 103

7.7 Resultados da execução dos 5 kernels comparados com os valores calculados pelo modelo usando os valores do microbenchmark. Ambos com 100 execuções e o microbenchmark com a modificação de teste da instrução mov.

7.8 Comparação entre os resultados para os dois primeiros kernels de teste, utilizando os resultados obtidos com o modelo e utilizando os valores de referência da NVIDIA. O tempo de execução se refere à média de 100 execuções com 1024 threads. O valor do modelo foi ajustado para refletir a execução com 1024 threads. . . . . . . . . . . . . 109

A.1 Recursos e características técnicas - parte 1 (NVIDIA, 2011d, p. 158) . . . . . . . 115

A.2 Recursos e características técnicas - parte 2 (NVIDIA, 2011d, p. 158) . . . . . . . 115

A.3 Recursos e características técnicas - parte 3 (NVIDIA, 2011d, p. 159) . . . . . . . . 116

B.1 Tabela de referência da NVIDIA (NVIDIA, 2011d, p. 98) . . . . . . . . . . . 117

B.2 Tabela de emissão, pelo escalonador da compute capability 1.X, de instruções para execução (NVIDIA, 2011d, p. 162) . . . . . . . . . . . . . . . . . . 118 


\section{Lista de Algoritmos}

1 Microbenchmark de Instrução . . . . . . . . . . . . . . . . . . . . . . 54

2 Execução em Rajada da Rotina de Teste de Instrução . . . . . . . . . . . . . . . . . . . . . . . . . 55

3 Execução Intercalada da Rotina de Teste de Instrução . . . . . . . . . . . . . . . . . . . 55

4 Levantamento do Perfil de Desempenho das Instruções . . . . . . . . . . . . . . . 65 


\section{Capítulo 1}

\section{Introdução}

As placas GPU ${ }^{1}$ são uma opção barata de cálculo em ponto flutuante e estão cada vez mais comuns nos computadores de alto desempenho. Entre as listas de junho/2011 e novembro/2011 do site top $500^{2}$, o uso de GPU aumentou de 17 para 39 máquinas. Dessas 39 máquinas, 35 usam equipamento da NVIDIA ${ }^{3}$. No ano de 2012 tivemos no mês de junho, 57 sistemas com aceleradores ou coprocessadores e destes, 52 são NVIDIA ${ }^{4}$. Na lista de novembro de 2012 tivemos 62 sistemas com aceleradores e 50 deles com tecnologia NVIDIA ${ }^{5}$.

Ao lado desse crescimento da presença das GPUs em computadores de alto desempenho, temos a necessidade de otimizar as aplicações que executam nelas. A utilização de um modelo de desempenho auxilia no ajuste fino do programa e na localização dos gargalos de desempenho. Mesmo um modelo simples pode trazer grandes resultados (Sauer e Chandy, 1981, p. 3) (Kobayashi, 1978, p. 18).

Para isso, um modelo deve capturar os principais fatores que determinam o desempenho do sistema. Adicionando a esses fatores as medições executadas no equipamento alvo, o modelo poderá prever o resultado a ser obtido com a execução do programa (Sauer e Chandy, 1981, p. 2).

Porém, como comenta Gubitoso, a arte está em equilibrar a complexidade do modelo com a precisão dos resultados:

"um modelo analitico suficientemente preciso é com frequência complicado demais para ser usado. O grande desafio é a escolha do nivel de detalhe suficientemente fino para que o modelo tenha precisão, mas que não seja tão fino a ponto de tornar o modelo resultante intratável"(Gubitoso, 1996).

Considerando os modelos estudados capítulo 5 (Trabalhos Relacionados), as medições para a confecção de um modelo de desempenho, para GPU, com o mínimo detalhamento possível, poderiam ser o tempo de execução da computação e os tempos dos acessos aos distintos tipos de memória.

Este trabalho tem o seu foco no levantamento dos tempos de execução da computação para um programa para GPU. O levantamento dos dados sobre os tempos de acesso à memória já está bem coberto nos trabalhos comentados no capítulo 5, Trabalhos Relacionados.

\footnotetext{
${ }^{1}$ Graphics Processing Unit - Unidade de Processamento Gráfico

${ }^{2}$ http://www.top500.org/lists/2011/11/press-release - consultado em 28/11/2011.

${ }^{3}$ Esta e todas as outras marcas comerciais e registradas que aparecem neste trabalho são propriedade de seus respectivos donos.

${ }^{4}$ http://www.top500.org/lists/2012/06/highlights/ - consultado em 03/12/2012.

${ }^{5}$ http://www.top500.org/lists/2012/11/highlights / - consultado em 03/12/2012.
} 


\section{Objetivos}

O objetivo deste trabalho é criar ferramentas para extração de informações de desempenho que possam auxiliar no desenvolvimento de modelos de desempenho para kernels ${ }^{6}$ de GPU NVIDIA.

Os objetivos específicos são:

- A obtenção de dados sobre o o hardware da GPU;

- A criação de um microbenchmark para as instruções PTX da GPU;

- A validação dos resultados obtidos como o microbenchmark através de um modelo de desempenho, além da verificação da acurácia desses resultados, quando comparados com os resultados de desempenho fornecidos pela NVIDIA. Bem como verificar os fatores de imprecisão nos resultados obtidos;

- Verificar a dependência do desempenho do pipeline da GPU em função da sequência de instruções executada e verificar a otimização do compilador para esse caso;

- Verificar a existência de padrões de desempenho entre as diversas instruções.

\section{Metodologia}

Iniciamos o trabalho com o levantamento bibliográfico que, à época, encontrou somente o artigo de Hong e Kim (Hong e Kim, 2009b), descrevendo um interessante modelo para GPUs NVIDIA da família Tesla. Apesar de posteriormente considerarmos outros artigos, esse, em especial, foi o que motivou o trabalho.

Nesse e em outros artigos, o tempo de computação era aproximado pela quantidade de instruções dinâmicas multiplicado por uma constante, que indica a quantidade de ciclos de relógio por instrução executada. Ainda no artigo de Hong e Kim, a contagem das instruções era feita baseada no código PTX e não no código de máquina.

A motivação veio de um comentário, no artigo de Hong e Kim, sobre um dos fatores de imprecisão do modelo. Ele seria a diferença na quantidade de instruções no código PTX e no código executável.

Para auxiliar na solução desse problema, decidimos fazer o levantamento do tempo de cada instrução PTX existente e formar uma base de dados. Dessa forma, para obter o tempo total de computação de um kernel qualquer, bastaria contabilizar o tempo das instruções utilizadas nesse kernel, a partir dos valores presentes nessa base de consulta.

Escolhemos utilizar microbenchmarks para levantar os tempos de execução de cada instrução PTX. E, para evitar a codificação manual de uma grande quantidade de rotinas de teste para as instruções, optamos por criar um gerador de código.

Esse gerador recebe como entrada uma descrição das instruções a serem testadas. Dessa forma, o microbenchmark criado, faria o teste para esse conjunto definido de instruções.

Para descrever as instruções PTX, com as suas características de compatibilidade e tipos de dados, criamos uma linguagem que é interpretada pelo gerador do microbenchmark. Para cada instrução a ser testada, é criada uma rotina de teste separada, que contabiliza o tempo de execução de um trecho contendo a instrução em teste, que pode estar repetida uma ou mais vezes.

Foi escolhido o formato de texto para os arquivos de saída do microbenchmark, que possuem informações sobre a instrução executada e a contagem de ciclos de relógio, no início e fim do teste.

\footnotetext{
${ }^{6}$ Um kernel é um módulo de programa que executa na GPU
} 
Dessa forma, separamos a obtenção dos dados brutos, feita pelo microbenchmark, da obtenção do tempo médio e outras estatísticas, feita na etapa de pós processamento.

\section{Contribuições}

A ferramenta em si é a principal contribuição, pois, o seu uso auxilia na compreensão das características de execução do hardware. Além disso, juntamente com o microbenchmark de memória, constitui a base para a construção de um modelo de desempenho. Portanto, a sua disponibilidade facilitará a tarefa de criação do modelo.

Até o limite do nosso conhecimento, esta é a primeira implementação de microbenchmark utilizando a linguagem intermediária (PTX). Apenas um dos trabalhos comentados no capítulo 5, Trabalhos Relacionados, utiliza um microbenchmark para obter os tempos das instruções. Porém, esse trabalho de Zhang e Owens (Zhang e Owens, 2011), utiliza instruções executadas pelo hardware e limita a algumas instruções consideradas representativas para a modelagem do pipeline ${ }^{7}$.

Outra contribuição é a metodologia que, através de uma linguagem para descrição das instruções e um gerador de aplicação, cria o microbenchmark de acordo com as necessidades do teste.

Por fim, a análise dos resultados da execução do microbenchmark permitiu identificar algumas classes de comportamento das instruções. Baseado em diversas execuções, cobrindo todas possibilidades de repetividade da instrução e quantidades de $\operatorname{warps}^{8}$ em execução, foram criados gráficos que mostram as características de escalabilidade das diversas instruções.

\subsection{Organização do Trabalho}

Este trabalho está organizado em oito capítulos e quatro apêndices, sendo que o primeiro capítulo compreende esta introdução. No Capítulo 2, Conceitos de Paralelismo, discutimos alguns aspectos da classificação das máquinas paralelas, as características do pipeline e as penalidades de execução que mais interessam a este trabalho. Além disso, comentamos sobre o paralelismo no nível das instruções e sobre os modelos analíticos de desempenho.

No Capítulo 3, Conceitos de GPU, mostramos a estrutura de hardware da GPU, incluindo as arquiteturas Tesla e a Fermi da NVIDIA. É dada uma visão cronológica para explicar a evolução da arquitetura e suas vantagens de balanceamento de carga sobre as placas de vídeo anteriores. São abordados tópicos como a execução multi-thread, a transferência de programas, a forma de escalonamento utilizada, os tipos de memória existentes e seu gerenciamento.

O próximo capítulo, Conceitos de $C U D A^{9}$, de número 4, descrevemos o modelo de programação CUDA, utilizado em aplicações GPGPU ${ }^{10}$ com arquitetura NVIDIA. É explicada a hierarquia de threads e seus direitos de acesso à memória, o processo de compilação, os recursos de emulação de instruções e a importância da quantidade de memória utilizada.

Uma revisão dos trabalhos que possuem relação com a extração de informações de desempenho está no Capítulo 5, Trabalhos Relacionados, onde também resumimos, para esses trabalhos, as soluções utilizadas para a avaliação do tempo de execução das instruções.

A ferramenta, criada neste trabalho, está descrita no Capítulo 6, Microbenchmark, em que também são descritos alguns problemas encontrados durante o desenvolvimento da mesma.

\footnotetext{
${ }^{7}$ Tubulação ou encanamento - ver seção 2.2 para uma explicação detalhada.

${ }^{8}$ Unidade de escalonamento da GPU que corresponde a 32 threads.

${ }^{9}$ Computer Unified Device Architecture, Arquitetura de Equipamento e Computador Unificada.

${ }^{10}$ General Purpose Graphics Processing Unit - Unidade de Processamento Gráfico de Propósito Geral.
} 
A utilização da ferramenta, com os experimentos executados, está descrita no Capítulo 7, Experimentos e Resultados, onde também é comentado o processo de refino das funcionalidades dessa ferramenta. Além disso, temos a validação (efetuada através de um modelo simplificado) e alguns testes avaliando o compilador e o pipeline de execução de instruções.

As conclusões estão no Capítulo 8.

O primeiro apêndice, A, contém um resumo das características de cada revisão do hardware das GPUs NVIDIA até a arquitetura Fermi. A seguir, no Apêndice B, temos o desempenho informado pelo fabricante para os principais grupos de instruções. No Apêndice $\mathrm{C}$ temos a listagem do código fonte para algumas rotinas de teste.

No último apêndice, $\mathrm{D}$, temos a listagem da desmontagem do código de máquina de uma rotina de teste para uma instrução. 


\section{Capítulo 2}

\section{Conceitos de Paralelismo}

A busca pelo aumento de desempenho dos processadores utilizou, até aproximadamente 2003, duas técnicas básicas: aumentar o número de instruções que poderiam ser emitidas em cada ciclo de relógio, conhecido como ILP'; e aumentar a frequência do relógio (Olukotun e Hammond, 2005).

Para aumentar a frequência do processador, uma das técnicas utilizadas foi o pipeline ${ }^{2}$, que além de permitir uma maior frequência de execução ${ }^{3}$, também permite a existência de paralelismo na execução das instruções. Tanto as técnicas de ILP quanto de pipeline adicionaram circuitos aos processadores. Porém, com o aumento dos circuitos e da frequência também ocorre o aumento do consumo de energia e a consequente dissipação de calor (Olukotun e Hammond, 2005).

Por volta de 2003, a técnica de aumento de desempenho através do aumento da frequência do relógio encontrou o seu limite de aplicação devido à excessiva dissipação de calor (Kirk e mei W. Hwu, 2010, p. 1-2).

A solução adotada para continuar com o aumento de desempenho foi a adição de núcleos de processamento dentro do mesmo processador. Essa tecnologia foi chamada de multi-core ${ }^{4}$ e continua sendo explorada em 2012.

Até o aparecimento do multi-core, os ganhos de desempenho obtidos pelas técnicas comentadas anteriormente eram transparentes para o programador. Ou seja, podia-se usufruir desses ganhos sem alterar o programa. Com os vários núcleos, o programa precisaria ser convertido para esse novo paradigma de programação para obter ganhos de desempenho (Sutter e Larus, 2005).

Um ponto importante na criação de programas que possam obter melhor desempenho em processadores multi-core é a forma de expressar o seu paralelismo e a sua relação com os dados a serem manipulados.

\footnotetext{
${ }^{1}$ Instruction Level Paralelism ou paralelismo ao nível da instrução.

${ }^{2}$ Tubulação ou encanamento.

3 "Pipelining of individual instruction execution into a sequence of stages has allowed designers to increase clock rates as instructions have been sliced into larger numbers of increasingly small steps, which are designed to reduce the amount of logic that needs to switch during every clock cycle". - O enfileiramento da execução de instruções individuais em uma sequência de etapas permitiu aos projetistas aumentar as taxas de relógio, uma vez que as instruções foram divididas em um maior número de passos menores, que são concebidos para reduzir a quantidade de lógica que precisa mudar de estado durante cada ciclo de relógio (Olukotun e Hammond, 2005).

${ }^{4}$ Multi-núcleos.
} 


\subsection{Taxonomia de Flynn}

Baseado na forma como o fluxo de instruções e o fluxo de dados interagem, Flynn classificou as arquiteturas de computadores em quatro categorias: o SISD, o MISD, o SIMD e o MIND. Para essa classificação, o fluxo é considerado como sendo a sequência de itens, instruções ou dados, que são executados ou recebem operações por um processador (Flynn, 1972).

O modelo mais simples, o SISD (Single-Instruction Stream - Single-Data Stream ${ }^{5}$ ), possui um único elemento de processamento e um único fluxo de dados, que o torna similar ao modelo definido por von Neumann (Rauber e Rünger, 2010, p. 11).

No caso do MISD, Multiple-Instruction Stream - Single-Data Stream ${ }^{6}$, temos vários elementos de processamento, cada um com sua memória de programa privada e um único acesso comum à memória global (que armazena os dados). Dessa forma, temos a execução paralela das instruções, porém, nos mesmos dados. Conforme Rauber e Rünger, esse modelo de execução não possui implementação comercial (Rauber e Rünger, 2010, p. 11).

Com um único fluxo de processamento, o SIMD (Single-Instruction Stream - Multiple-Data Stream ${ }^{7}$ ) possui vários elementos de processamento que executam um mesmo programa. Além disso, eles possuem acesso à memória de dados, que pode ser compartilhada ou distribuída. A execução do programa é feita de forma que cada elemento de processamento execute a mesma instrução em dados diferentes ao mesmo tempo, ou seja, temos o paralelismo da execução da instrução desde que não haja dependência nos dados (Rauber e Rünger, 2010, p. 11). Esse modelo é utilizado em processadores vetoriais e em matrizes de processadores.

Na classificação MIMD (Multiple-Instruction Stream - Multiple-Data Stream ${ }^{8}$ ) temos vários elementos de processamento, cada um deles com acesso separado aos dados e ao programa, de forma que cada um deles pode processar instruções diferentes em dados diferentes. Ou seja, executando de forma assíncrona em dados diferentes. Essa classificação engloba os processadores multi-core e as grades de computadores (Rauber e Rünger, 2010, p. 11).

Similar ao SIMD, mas não pertencente à taxonomia de Flynn, o SPMD (Single Program - Multiple Data $^{9}$ ) se refere a múltiplas threads executando de forma assíncrona o mesmo programa sobre dados diferentes. Esse é um dos mais populares modelos de programação paralela e o MPI ${ }^{10}$ é baseado nele (Rauber e Rünger, 2010, p. 109-110).

Apesar de ser uma classificação grosseira, a taxonomia de Flynn permite compreender o relacionamento entre a execução do programa e os dados manipulados, o que é um pré-requisito na implementação de um algoritmo para uma dada arquitetura.

\section{$2.2 \quad$ Pipeline e ILP}

O nome pipeline é utilizado em analogia com um tubo, onde podemos colocar novas entradas antes mesmo que as entradas anteriores passem pela saída do tubo (Stallings, 2003, p. 424). Ou seja, no caso do processador, podemos iniciar o tratamento de uma nova instrução antes que a anterior tenha terminado a execução.

\footnotetext{
${ }^{5}$ Fluxo de Instrução Único e Fluxo de Dados Único.

${ }^{6}$ Múltiplos Fluxos de Instruções e Fluxo de Dados Único.

${ }^{7}$ Fluxo de Instrução Único e Fluxo de Dados Múltiplo.

${ }^{8}$ Fluxo de Instrução Múltiplo e Fluxo de Dados Múltiplo.

${ }^{9}$ Programa Único e Dados Múltiplos.

${ }^{10}$ Message Passing Interface - Interface de Passagem de Mensagens. Infraestrutura para troca de mensagens entre processos paralelos utilizada para computação paralela ou distribuída. Ver http://www.mpi-forum.org e http://www.open-mpi.org (verificado em 28/11/2012).
} 
Para aplicar essa técnica é necessário que o trabalho de execução da instrução possa ser dividido em algumas fases. Como visto na figura 2.1, uma simples divisão em seis estágios poderia ser: a busca da instrução (BI), a decodificação da instrução (DI), o cálculo dos operandos (CO), a busca dos operandos (BO), a execução da instrução (EI) e por fim, a escrita do operando de resultado (EO).

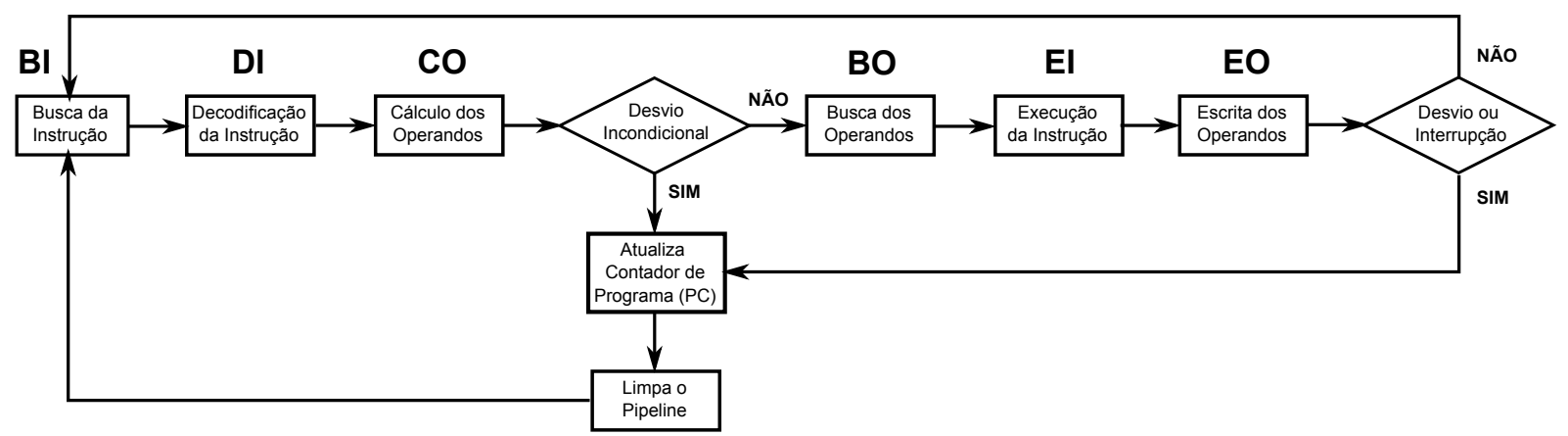

Figura 2.1: Exemplo de um pipeline com seis estágios (Stallings, 2003, p. 428).

O uso de um pipeline com 6 estágios, como mostrado no diagrama de tempo da figura 2.2, pode reduzir a execução de 9 instruções, de 54 ciclos para 14 ciclos (considerando um ciclo de relógio para cada estágio do pipeline) (Stallings, 2003, p. 426). Esse exemplo mostra uma situação onde não existe nenhum inconveniente para a execução dessa sequência de 9 instruções.

A vantagem dessa técnica está na possibilidade de sobrepor parcialmente a execução das instruções. Assim, após o tempo de execução de todos os estágios da primeira instrução, chamado de latência do pipeline, teremos uma instrução finalizada a cada novo ciclo.

Instrução 1

Figura 2.2: Diagrama de tempos da execução de instruções no pipeline de seis estágios (Stallings, 2003, p. 426).

Porém, existem casos em que a execução da sequência de instruções não pode ser feita de forma tão constante, ou seja, algum dos estágios requer que sua operação demore mais do que um ciclo de relógio (no nosso exemplo). Nessa situação, os outros estágios deverão esperar até que essa operação seja concluída. Isso pode ocorrer nos casos em que exista uma dependência de instruções ou uma dependência de dados (Abd-El-Barr e El-Rewini, 2005, p. 187-192).

A dependência de instrução ocorre quando a execução da próxima instrução depende do resultado da 
execução da instrução atual, como acontece em desvios condicionais. Por outro lado, a dependência de dados ocorre quando o operando fonte de uma instrução é do resultado da instrução anterior. Nesse caso, apesar de haver a busca da instrução, o seu operando só estará disponível após a escrita do resultado da instrução anterior. (Abd-El-Barr e El-Rewini, 2005, p. 188-189).

Um exemplo do que ocorre no pipeline devido à dependência de dados, também conhecido como dependência real ou dependência de leitura após escrita, é mostrado na figura 2.3. Nessa figura, temos o mesmo exemplo da figura 2.2, porém, com a dependência ocorrendo na instrução 2. Dessa forma, os ciclos 5 e 6 são inutilizados em função da espera pelo operando da instrução 2, que só será escrito no ciclo 6 .

Instrução 3

Figura 2.3: Diagrama de tempos da execução de instruções no pipeline de seis estágios com dependência de leitura após escrita na instrução 2.

A penalidade da dependência de leitura após escrita, que ocorre na instrução 2, impede que o pipeline continue aceitando novas instruções. Isso se reflete na entrada da instrução 5, que só acontece após a escrita da instrução 1, que elimina a contenção no pipeline. A consequência é um atraso geral na execução do fluxo de instruções enquanto a dependência não é resolvida.

\section{ILP}

Como comentado anteriormente, se o pipeline está funcionando em regime e sem nenhuma ocorrência que impeça a execução das instruções, teremos o resultado da execução de uma nova instrução a cada ciclo de relógio. Essa característica impõe um limite máximo de uma instrução executada por ciclo de relógio, que é indicado como tendo $\mathrm{CPI}^{11}=1$ (Abd-El-Barr e El-Rewini, 2005, p. 207).

Para aumentar a taxa de instruções executadas por unidade de ciclos de relógio, é necessário que haja paralelismo entre as operações de máquina individuais, como por exemplo, executar adições de inteiros e multiplicações de ponto flutuante concomitantemente. Isso é obtido através de técnicas de projeto tanto do hardware quanto do compilador (Rau e Fisher, 1992).

O resultado é a execução simultânea, ou paralela, de múltiplas operações. Isso pode ocorrer em função do envio de múltiplas operações para execução ou pelo intervalo de execução de uma dada

\footnotetext{
${ }^{11} \mathrm{CPI}$, Clock per Instruction - Ciclos de relógio por instrução.
} 
operação ser maior que o intervalo de duas instruções consecutivas (Rau e Fisher, 1992).

Conforme a técnica utilizada, tanto o compilador quanto o hardware podem verificar a dependência entre as instruções a serem executadas e reordená-las, de forma que possam utilizar da melhor maneira os recursos de execução paralela disponíveis.

O escalonamento estático resulta na utilização de instruções com palavras muito longas, conhecidas como VLIW ${ }^{12}$. Já o escalonamento dinâmico resulta na utilização de arquiteturas super-escalares (Abd-El-Barr e El-Rewini, 2005, p. 207).

Independente da técnica utilizada, o objetivo é obter, através do escalonamento das instruções e disponibilidade de múltiplas unidades funcionais no hardware, o tempo de execução médio abaixo de um ciclo de relógio, ou seja, CPI $<1$.

\subsection{Modelos}

Uma visão mais abstrata dos sistemas de computação paralela ajuda no projeto e análise dos programas paralelos. Esse distanciamento dos detalhes de hardware e software pode ser obtido com a utilização de modelos, entre os quais destacamos: os modelos de máquina, modelos de arquitetura, modelos computacionais e modelos de programação (Rauber e Rünger, 2010, p. 93).

O modelo de máquina descreve o hardware e o sistema operacional, sendo o de mais baixo nível de abstração e a base para as linguagens de montador. Um passo acima, em abstração, temos o modelo de arquitetura que descreve a organização de memória, a rede de interconexão de plataformas paralelas e o modo de execução (SIMD ou MIND) (Rauber e Rünger, 2010, p. 93).

Ainda mais abstrato é o modelo computacional, que fornece funções de custo que refletem o tempo de execução para um algoritmo em um dado computador (descrito por um modelo de arquitetura). Ele também fornece um método analítico para avaliar o desempenho teórico de algoritmos (Rauber e Rünger, 2010, p. 94).

O modelo de programação é mais abstrato que os anteriores e descreve um sistema de computação paralela em termos da semântica da linguagem de programação. Ele define como um programador pode codificar um algoritmo para obter o paralelismo. Define também a forma de sincronismo entre as unidades paralelas e o sistema de comunicação utilizado. Em resumo, ele fornece o mecanismo pelo qual o programador pode especificar os programas paralelos (Rauber e Rünger, 2010, p. 94).

Outro fator importante para modelos de programação paralela é a organização do espaço de endereçamento. Temos espaços de endereçamento compartilhados, distribuídos ou um misto de ambos. Essa organização define a forma como haverá troca de informações entre os processos paralelos sendo executados (Rauber e Rünger, 2010, p. 95).

\section{Modelos de Desempenho}

Com maior interesse para este trabalho, o modelo de desempenho faz parte dos modelos computacionais e exprime, de forma analítica, o tempo de execução de um programa.

O modelo analítico é o conjunto de relações funcionais entre os parâmetros do sistema e um critério de desempenho escolhido. Essas relações são expressas em equações que podem ser resolvidas analiticamente. Entre as ferramentas utilizadas para obter um modelo analítico podemos destacar a teoria das filas, que considera o computador como um conjunto de recursos disponíveis e que são

\footnotetext{
${ }^{12}$ Very Long Instruction Word - Instrução de palavra muito longa.
} 
demandados pelos programas. Nesse contexto, os problemas de desempenho são os atrasos de enfileiramento causados pelas contenções desses recursos (Kobayashi, 1978, p. 17).

O modelo analítico de desempenho pode auxiliar durante o desenvolvimento de programas paralelos, indicando qual versão do programa é mais promissora e qual pode levar a tempos de execução maiores (Rauber e Rünger, 2010, p. 166).

Além de um modelo que capture os principais fatores de desempenho, são necessárias algumas medidas de desempenho que forneçam dados para esse modelo. A quantidade e o tipo dessas medidas dependem do grau de abstração do modelo e, mesmo um modelo simples e abstrato pode estimar, com relativa precisão, o desempenho de sistemas computacionais (Sauer e Chandy, 1981, p. 2-3).

Entre os modelos computacionais paralelos mais conhecidos temos o $\mathrm{PRAM}^{13}$, o $\mathrm{BSP}^{14}$ e o $\log \mathrm{P}^{15}$.

\footnotetext{
${ }^{13}$ Parallel Random Access Machine - Máquina Paralela de Acesso Aleatório.

${ }^{14}$ Bulk Synchronous Parallel - Livremente traduzido para Paralelismo em Massa com Sincronismo.

${ }^{15}$ Latency, overhead, gap and Processors - Latência, sobrecarga, intervalo e Processadores.
} 


\section{Capítulo 3}

\section{Conceitos de GPU}

A função de uma placa gráfica de alto desempenho é a conversão de uma descrição de cena em uma imagem a ser exibida do ponto de vista de uma câmera de referência (Luebke e Humphreys, 2007). Essa descrição utiliza triângulos, características dos materiais, texturas e fontes de iluminação para definir a cena (Montrym e Moreton, 2005).

Para fazer essa conversão são necessárias algumas etapas, às quais, as primitivas de entrada podem ser aplicadas de forma sequencial. Isso é similar a uma linha de produção (ou montagem), onde cada estação de trabalho realiza uma transformação específica no produto e passa esse produto para a estação seguinte.

Essa linha de montagem é chamada de pipeline ${ }^{1}$ gráfico e até os anos 90 era construído com circuitos dedicados a cada uma dessas funções. Eles podiam ser configurados de acordo com as necessidades da geração da imagem, porém não eram programáveis (Kirk e mei W. Hwu, 2010, p. 22).

Basicamente, o pipeline gráfico executa três tarefas (ver figura 3.1). A primeira é o processamento dos vértices dos triângulos, onde calcula as posições e os atributos, como cor e orientação da superfície (vetor normal). A segunda é a varredura, que utilizando a posição da câmera e dos triângulos, identifica quais triângulos estão posicionados de forma a encobrir, total ou parcialmente, os outros. Os resultados são chamados de fragmentos. Por fim, é feita a aplicação da textura, cor e sombreamento. Assim, de acordo com a iluminação e a visibilidade dos fragmentos obtém-se a imagem final (Montrym e Moreton, 2005). Como o resultado final desse processo é gerar a imagem, que é dividida em pixels ${ }^{2}$, parte desse processo pode ser feita em paralelo para cada pixel.

Todas essas funções tem em comum a necessidade de cálculos, enquanto que algumas necessitam de uma maior precisão, outras demandam mais velocidade. Em cada projeto de placa gráfica há uma quantidade fixa de cada tipo de unidade funcional dessas. Conforme a imagem a ser criada, a otimização do balanço de carga de processamento entre essas unidades funcionais pode ser ruim. Para melhorar essa situação foi-se substituindo os processadores de função fixa, como as unidades de textura e transformação de vértices, por uma matriz de processadores de uso mais genérico que podiam executar essas funções (Luebke e Humphreys, 2007).

Através de sucessivas evoluções do projeto, essas unidades funcionais foram sendo substituídas por unidades processadoras com capacidade de executar cálculos como exponenciação, extração de raízes quadradas e multiplicação de matrizes por vetor (Luebke e Humphreys, 2007). Assim, em 1999, com o aparecimento da primeira Graphics Processing Unit (GPU) introduzida pela NVIDIA o processamento das imagens passou a ser feito com processadores específicos para os vértices e processadores para os pixels (Lindholm et al., 2008; NVIDIA, 2009). Em 2001 os programadores tiveram acesso

\footnotetext{
${ }^{1}$ Literalmente tubulação, mas também é um sistema através do qual se conduz algo.

${ }^{2}$ Pixel é a contração de Picture Element, ou seja, elemento de imagem.
} 


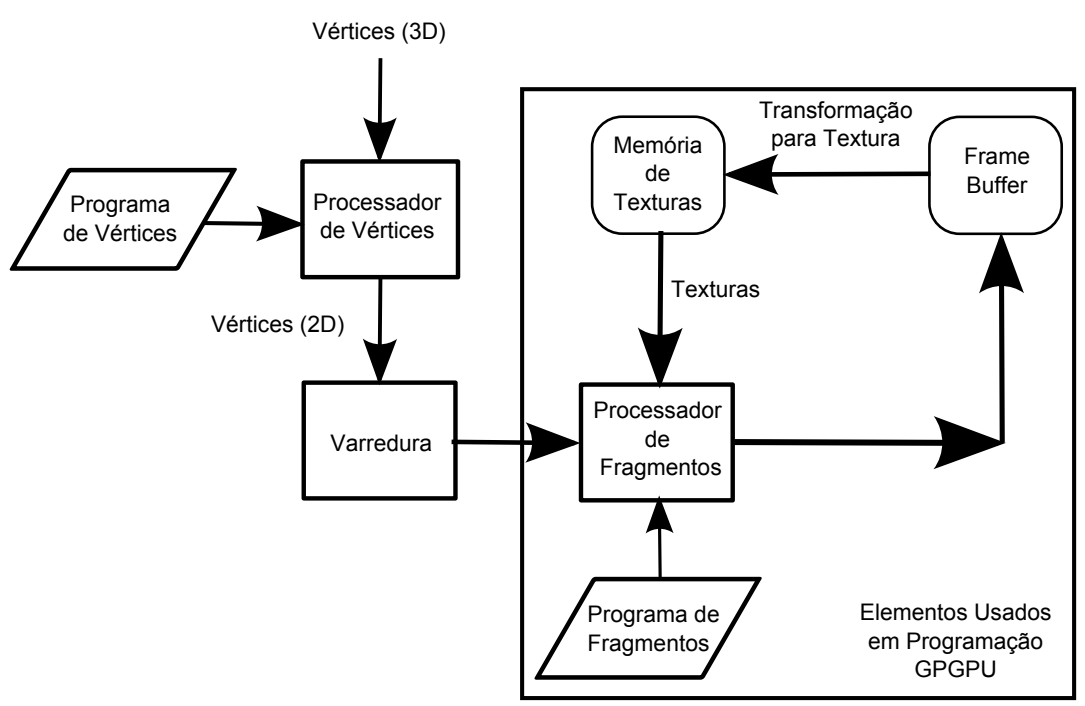

Figura 3.1: Exemplo de um pipeline gráfico (Liu et al., 2007).

ao conjunto de instruções do módulo de ponto flutuante dos vértices (Kirk e mei W. Hwu, 2010, p. 26).

Foi uma questão de tempo até perceber-se a possibilidade de utilizar esse hardware para executar processamento numérico e científico. Iniciando em 2003 e utilizando APIs $^{3}$ como o DirectX ${ }^{4}$ e o OpenGL ${ }^{5}$, alguns programadores conseguiram utilizar os recursos computacionais da placa de vídeo para outros fins que não a geração de imagens (NVIDIA, 2009).

Porém, nessa época, escrever um programa para utilizar os recursos disponíveis na placa gráfica era complicado, pois o programador precisava conhecer profundamente o hardware dessa placa e teria que definir o problema em termos de coordenadas de vértices, texturas e programas de renderização. Além disso, não havia recursos para as leituras e escritas aleatórias na memória. Também não existia a dupla precisão nos cálculos (NVIDIA, 2009). Escrito em 2006 e publicado em 2007, o artigo de Owens et al (Owens et al., 2007) mostra um panorama das técnicas que eram utilizadas para executar aplicações não gráficas nesse hardware.

Aproveitando essa tendência, a NVIDIA resolveu simplificar a utilização do seu produto para aplicações não gráficas com duas iniciativas: iniciou a compatibilidade com General Purpose Graphics Processing Unit (GPGPU) em novembro de 2006 com a introdução do CUDA (Computer Unified Device Architecture) (NVIDIA, 2011d, p. 3); e unificou e ampliou os processadores de vértices e pixels para um único processador (Lindholm et al., 2008; NVIDIA, 2009). Assim, foi introduzida a possibilidade de trabalhar com a placa gráfica no modo de computação de propósito geral. Com isso os programadores não precisavam mais utilizar a API gráfica e poderiam escrever seus programas em linguagem C. A utilização de outras linguagens de programação foi estendida e inclui Fortran e outras (NVIDIA, 2011d, p. 4).

\footnotetext{
${ }^{3}$ Application Programming Interface, ou Interface de Programação de Aplicativos

${ }^{4}$ Nome da API gráfica para Windows, criada pela Microsoft.

${ }^{5}$ Open Graphics Library ou Biblioteca Gráfica Aberta. É uma API gráfica multiplataforma.
} 


\subsection{Fundamentos}

O conceito de utilização da GPU para computação não gráfica é similar ao uso de um coprocessador. Quando o programa que roda no computador principal, ou hospedeiro, chega a um ponto onde irá utilizar a GPU ele:

1 - transfere os dados a serem utilizados da memória do computador principal para a memória da GPU;

2 - o programa a ser executado na GPU, chamado de kernel, é transferido para a GPU;

3 - o programa é executado na GPU e os resultados ficam na memória da própria GPU;

4 - o resultado é transferido da memória da GPU para a memória do computador principal;

5 - o processamento do programa principal continua normalmente.

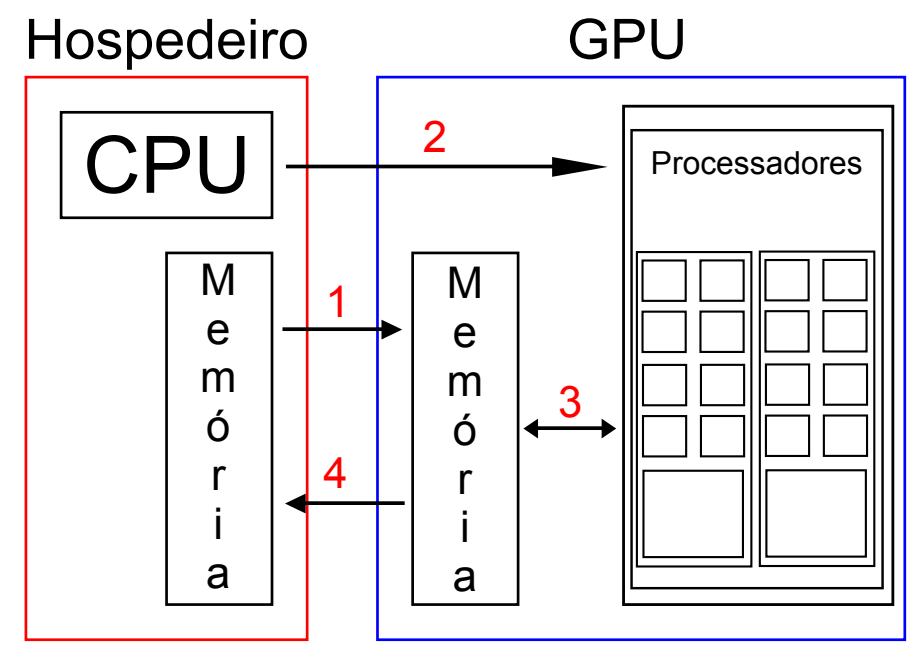

Figura 3.2: Fluxo de processamento utilizando GPU.

Dentro da GPU, os dados são processados de forma similar ao modelo paralelo SIMD, porém, em um modelo chamado SIMT (Single Instruction Multiple Threads) ${ }^{6}$. Esse modelo de execução do CUDA utiliza múltiplas threads e cada uma executa o mesmo programa sobre dados diferentes ao mesmo tempo. A diferença entre SIMD e SIMT está na exposição do tamanho do vetor de dados, que no SIMD é clara (está vinculada com o hardware), enquanto que em SIMT é definida por parâmetros na chamada do kernel (Lindholm et al., 2008; NVIDIA, 2011d, p. 86).

Dessa forma, a rotina executada na GPU é a mesma para todas as threads, porém, a execução paralela é definida pela arquitetura do hardware e pelos argumentos de chamada do kernel (ver $4.2)$.

Para que ocorram as transferências entre CPU e GPU, na tecnologia atual a GPU é conectada ao computador hospedeiro através do barramento PCI Express ${ }^{7}$ (Chen, 2009; Halfhill, 2009).

\footnotetext{
${ }^{6}$ Instrução Única Múltiplas Threads

${ }^{7}$ Peripheral Component Interconnect Express, ou seja, Interconexão Expressa de Componente Periférico
} 


\subsection{Arquitetura GPU}

Em 2011 a NVIDIA possuía duas arquiteturas distintas de GPGPU, sendo em ordem cronológica a Tesla e a Fermi. Discutiremos inicialmente a arquitetura Tesla e na seção 3.3 serão mostradas as diferenças que existem na arquitetura Fermi.

A arquitetura Tesla foi introduzida em 2006 juntamente com o CUDA (Lindholm et al., 2008) e evoluiu tecnicamente desde então. A cada passo dessa evolução foi criada uma especificação que define as diferentes características técnicas dessas gerações. Esse conjunto de especificações das gerações é chamado de compute capability ${ }^{8}$ (ver 3.2.1).

A base da escalabilidade dessa arquitetura é o Stream Multiprocessor ${ }^{9}$ ou SM (ver 3.2.2). De acordo com o modelo da GPU (e a capacidade de processamento desejada), esse bloco básico é replicado. Para dar suporte a essa matriz de SMs temos uma hierarquia de memórias e outros circuitos mostrados na figura 3.3, que usa como referência a GeForce 8800 da primeira família de GPGPU (Lindholm et al., 2008).

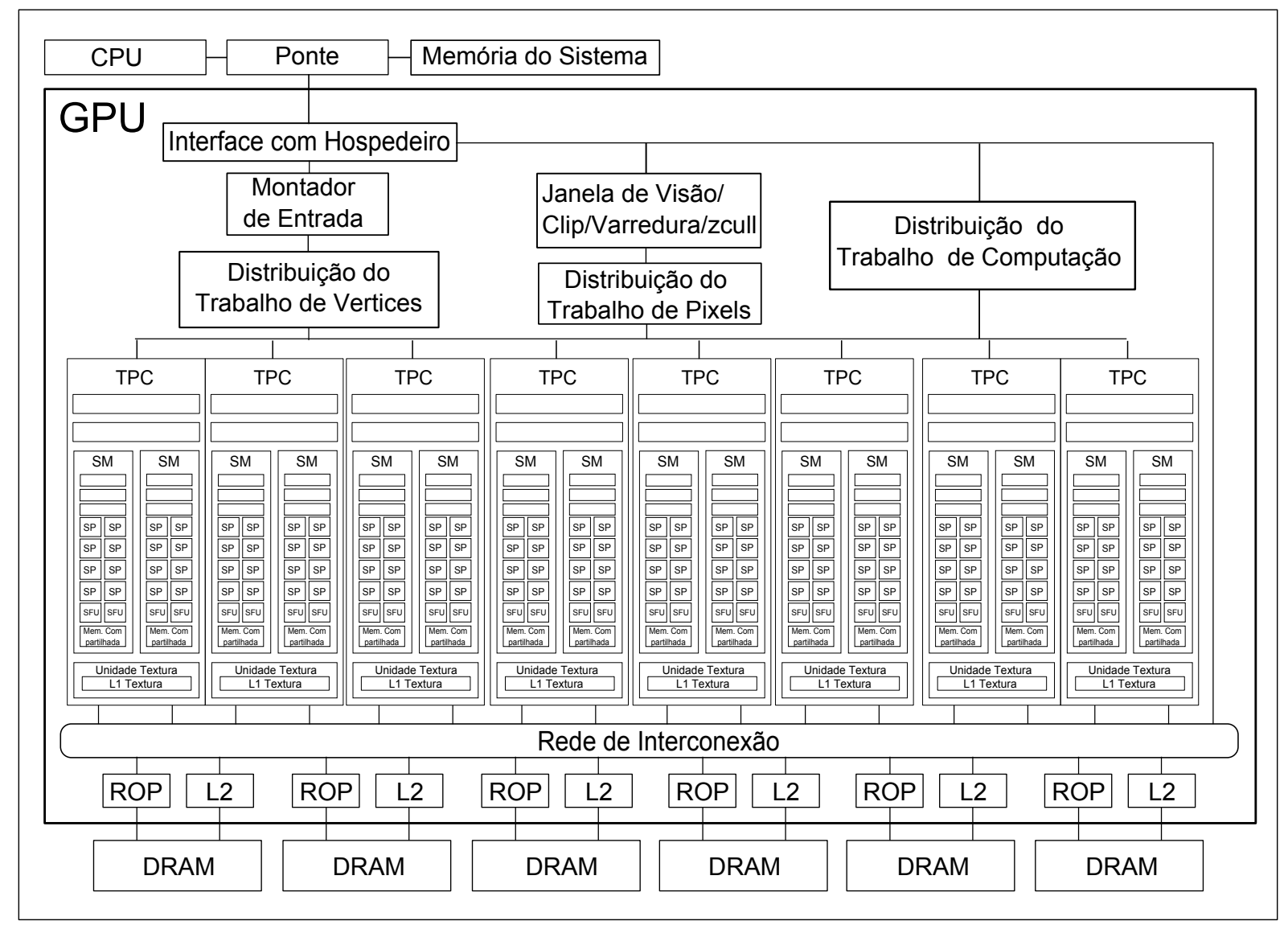

Figura 3.3: Arquitetura da GPU GeForce 8800 da NVIDIA (Lindholm et al., 2008).

Tomando como base a figura 3.3, vamos comentar a função dos principais blocos, realçando os que fazem parte da utilização em modo GPGPU (Lindholm et al., 2008):

Interface com o Hospedeiro ${ }^{10}$ : este módulo cuida da comunicação com o computador hospedeiro, incluindo verificação de consistência e resposta aos comandos enviados pelo hospedeiro.

\footnotetext{
${ }^{8}$ Capacidade computacional

${ }^{9}$ Multi Processador de Fluxo

${ }^{10}$ no original, Host Interface
} 
Distribuição do Trabalho de Computação ${ }^{11}$ : distribui o programa recebido da unidade Montador de entrada ${ }^{12}$ para a matriz de SMs na forma de múltiplas threads (Chen, 2009). Utiliza o escalonamento round-robin ${ }^{13}$ (Lindholm et al., 2008) e é o módulo que garante a escalabilidade de um mesmo programa entre modelos diferentes de GPUs.

Rede de Interconexão ${ }^{14}$ : cuida do roteamento e interconexão dos diversos módulos. Inclusive entre os blocos de memória e a matriz de SMs ou o computador hospedeiro.

TPC (Texture/Processor Clusters $^{15}$ ): é um grupo de SMs (neste caso 2 SMs) que contém o seu próprio controlador de SM e uma unidade de textura, que possui o cache de textura.

Memória Compartilhada ${ }^{16}$ : é uma memória de leitura e escrita com baixa latência (NVIDIA, 2011d, p. 10), pois está dentro da pastilha do processador e pode ser acessada à taxa de 32 bits a cada 2 ciclos de relógio (NVIDIA, 2011d, p. 163). Está dividida em bancos e dentro do domínio do SM, portanto um SM pode acessar somente a sua própria memória compartilhada e portanto, não acessa a memória compartilhada de outro SM.

Unidade de Textura ${ }^{17}$ : faz operações para criação de texturas.

L1 Textura ${ }^{18}$ : é uma memória de acesso rápido como a compartilhada, porém, somente de leitura. Em modo gráfico podem ser armazenadas as texturas e em modo GPGPU pode ser usada para o armazenamento de constantes.

SP (Processador de Fluxo ${ }^{19}$ ): é o processador básico que agrupado em 8 unidades forma o SM. As threads são executadas pelos SPs. Em alguns textos é chamado também de Scalar Processor ${ }^{20}$.

Montador de Entrada ${ }^{21}$ : trata das primitivas geométricas. Em modo GPGPU ele recebe o programa a ser executado.

ROP (Raster Operation Processor) ${ }^{22}$ : executa as operações de cor e profundidade do pixel. Também executa a leitura e escrita nos blocos de memória.

L2(Cache de Nível $2^{23}$ ): o sistema de memória global consiste em vários blocos de memória dinâmica (fora da pastilha do processador) de alta latência. Esses blocos possuem um cache de nível 2 e um controlador individual. O seu acesso é feito através do ROP e da rede de interconexão.

DRAM (Memória Dinâmica de Acesso Aleatório ${ }^{24}$ ): na GPU é a memória em maior quantidade e maior latência. É chamada de memória global, pois todos os SMs podem acessá-la. Seu acesso pode demorar de 400 a 800 ciclos de relógio (NVIDIA, 2011d, p. 91). É nessa memória que os dados de entrada e os resultado da computação são armazenados.

A GPU possui vários llocks $^{25}$ de acordo com a unidade funcional. A frequência desses sinais pode ser configurada separadamente para cada grupo funcional, como os SMs ou a unidade de memória DRAM (Aji et al., 2015; Lindholm et al., 2008).

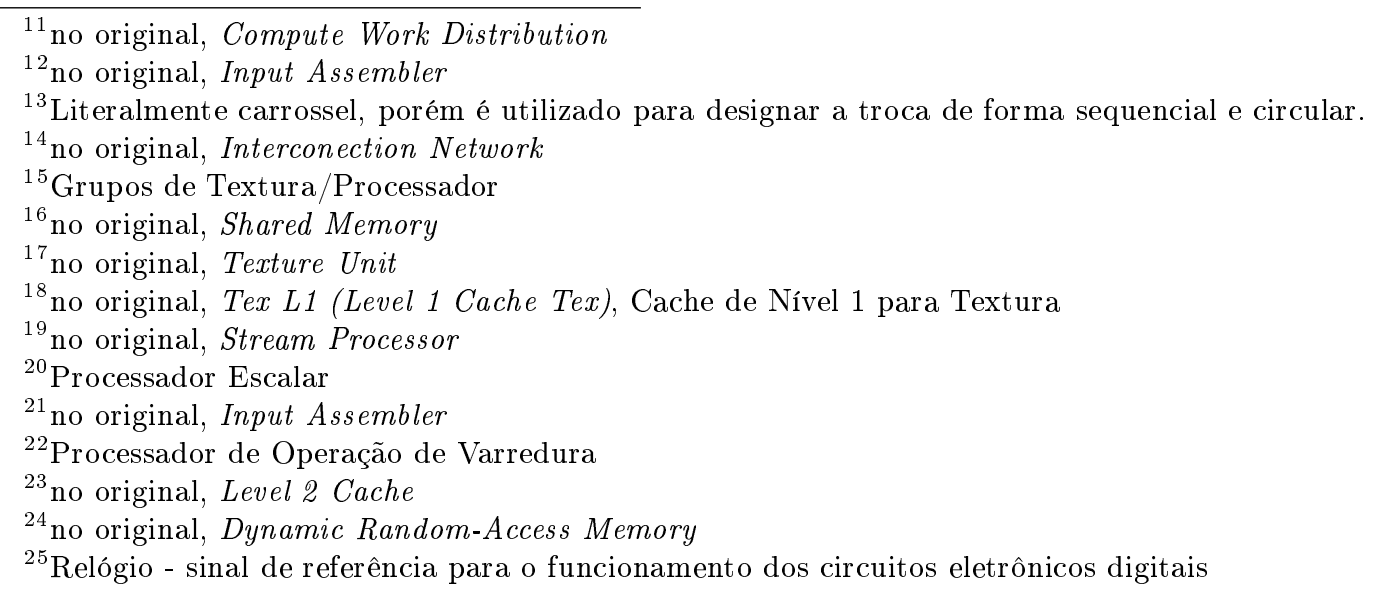


A diferença entre a arquitetura da GPU, da família Tesla, e da CPU com tecnologia atual, é que a CPU é otimizada para acesso com baixa latência a dados e instruções em caches, possui uma unidade de controle que permite execução fora de ordem e especulativa. Já a GPU executa em ordem e é otimizada para aumentar a computação paralela em dados distintos em detrimento da latência de memória (Kirk e mei W. Hwu, 2010, p. 2-5).

\subsubsection{Compute Capability}

A forma que a NVIDIA utiliza para classificar a evolução do projeto da GPU é a compute capability. Ela indica as diferenças maiores entre arquiteturas através do número de revisão de família ou tecnologia. Separado desse número por um ponto vem outro número indicando as alterações incrementais na arquitetura dos núcleos (NVIDIA, 2011d, p. 14).

Dessa forma, a tecnologia ou família Testa é conhecida como pertencendo à compute capability 1.X, enquanto que a família Fermi é a 2.X. Por outro lado, a melhoria na otimização de transações do gerenciador de memória ou a quantidade de memória compartilhada estão indicados no segundo número ou revisão secundária.

Para dar uma visão geral da abrangência das diferenças entre as diversas versões da compute capability, as principais características são apresentadas no Apêndice A.

\subsubsection{Stream Multi Processor}

Baseado no modelo SIMD, o SM é composto por 8 processadores SP. Esses processadores, conforme sua compute capability, possuem operações em ponto flutuante de 24 ou 32 bits padrão IEEE 754 , inteiros de 32 e 64 bits e possuem de $8 \mathrm{~K}$ a $16 \mathrm{~K}$ de registradores de 32 bits (ver figura 3.4 e tabela A.3 do apêndice A) (Lanfear e Ziegler, 2009).

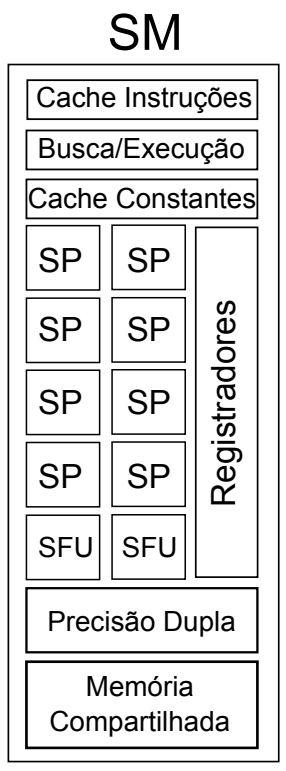

Figura 3.4: Estrutura do Stream Multi Processor CUDA com Unidade de Dupla Precisão.

Cada SP executa uma thread distinta com o mesmo código (simetria textual), porém, computando em dados diferentes. Como os 8 SPs compartilham o mesmo cache de instruções e a mesma unidade multithread de busca e execução de instruções, eles executam a mesma instrução simultaneamente em todas as threads (ver 3.2.4). Cada SM possui o seu próprio estado de execução.(Lindholm et al., 2008). 
Cada SM possui uma memória compartilhada de 16KB, acessível aos seus 8 SPs (esse valor varia conforme a compute capability e está na tabela A.3 do apêndice A). Também possui um cache de constantes e outro de texturas, ambos somente leitura (Lindholm et al., 2008).

Existem também duas unidades de funções especiais (SFU - Special Function Unit) para realizar os cálculos de funções transcendentais (como seno, cosseno, exponencial binaria, etc) e geram um resultado em ponto flutuante de 32 bits por ciclo de relógio (Lindholm et al., 2008). Temos uma unidade de precisão dupla (DP) compatível com ponto flutuante de 32 e 64 bits no IEEE 754 (dependendo da compute capability) e capaz de fazer multiplicação acumulativa em um único passo (fused multiply-add ${ }^{26}$ )(Lanfear e Ziegler, 2009).

Múltiplos SM podem ser controlados por um SMC (Stream Multiprocessor Controller ${ }^{27}$ ) formando um grupo de SMs ou TPC (ver 3.2). O SMC arbitra entre a unidade de textura, o caminho de entrada e saída e acesso a memória. Ele também faz o balanceamento de carga entre os SMs que controla (Lindholm et al., 2008).

\subsubsection{Gerenciamento de Memória}

A hierarquia de memórias da arquitetura GPU compreende os seguintes espaços de memória de leitura e escrita (Lindholm et al., 2008):

- Memória Local - implementada na DRAM externa, com alta latência, esta memória é privativa de cada thread;

- Memória Compartilhada - implementada na pastilha do circuito integrado, esta é uma memória de baixa latência e pode ser acessada por qualquer thread executando no mesmo SM;

- Memória Global - implementada na DRAM externa, com alta latência, pode ser acessada por qualquer thread executando em qualquer SM.

Nessa hierarquia existem dois tipos de memória, a compartilhada e a DRAM, sendo que nesta última os direitos de acesso são de dois tipos: o acesso permitido a todas as threads e o acesso privativo a cada thread. Essa organização exige a existência de algum tipo de unidade de controle ou gerenciamento das memórias. Não está explícito o detalhamento do sistema de memória em nenhuma bibliografia encontrada, tanto do fabricante como da comunidade científica. Apesar disso, podemos, através de algumas afirmações encontradas deduzir funcionalmente essa arquitetura.

Sobre a organização da memória compartilhada, Lindholm (Lindholm et al., 2008) nos diz que:

"A low-latency interconnect network between the SPs and the shared-memory banks provide shared-memory access.". 28

Já no manual de programação C da NVIDIA (NVIDIA, 2011d, p. 169) temos a seguinte informação sobre a organização da memória compartilhada para a compute capability 2.X:

"Shared memory has 32 banks that are organized such that successive 32-bit words are assigned to successive banks, i.e. interleaved. Each bank has a bandwidth of 32 bits per two clock cycles. ${ }^{29}$

\footnotetext{
${ }^{26}$ Multiplicação e soma fundidas

${ }^{27}$ Controlador de Multiprocessador de Fluxo

${ }^{28}$ Uma rede de interconexão de baixa latência entre os SPs e os bancos de memória compartilhada provê acesso à memória compartilhada.

${ }^{29}$ A memória compartilhada tem 32 bancos que estão organizados de tal forma que palavras de 32 bits sucessivas são atribuídas a bancos sucessivos, ou seja, intercalados. Cada banco tem uma largura de banda de 32 bits a cada dois ciclos de relógio.
} 
Para os equipamentos com compute capability 1.X, a divisão da memória compartilhada é em 16 bancos (NVIDIA, 2011d, p. 163). Isso mostra que a memória compartilhada está dividida em bancos que são intercalados para aumentar o desempenho.

Em relação a organização da memória global, novamente Lindholm et al (Lindholm et al., 2008) comenta:

"The DRAM memory data bus width is 384 pins, arranged in six independent partitions of 64 pins each. Each partition owns 1/6 of the physical address space. The memory partition units directly enqueue requests. They arbitrate among hundreds of in-flight requests from the parallel stages of the graphics and computation pipelines. The arbitration seeks to maximize total DRAM transfer efficiency, which favors grouping related requests by DRAM bank and read/write direction, while minimizing latency as far as possible. The memory controllers support a wide range of DRAM clock rates, protocols, device densities, and data bus widths." 30

Novamente vemos a divisão da memória em bancos e um controle de acesso que procura otimizar a transferência através do agrupamento de acessos ao mesmo banco ou do mesmo tipo (leitura ou escrita). Isso demonstra a existência de um controlador de memória que tem influência no desempenho da GPU.

Outro comentário de Lindholm et al (Lindholm et al., 2008) sobre o funcionamento do sistema de memória: "All processing engines generate addresses in a virtual address space. A memory management unit performs virtual to physical translation." ${ }^{31}$. Aqui fica clara a existência do gerenciamento de memória e sua dependência de um circuito complexo que foi omitido nos diagramas do fabricante.

Baseado nesses comentários, podemos criar uma arquitetura de referência para simplificar o entendimento do funcionamento do sistema de memória. Na figura 3.5 mostramos um diagrama dessa arquitetura de referência.

\section{Otimização de Acessos à Memória}

Como o modelo de execução é SIMT (ver 3.2.4), todas as threads ativas de um mesmo SM executam as instruções juntas, inclusive as de acesso à memória. Quando essas threads chegam a uma leitura ou escrita em memória a requisição de todas elas é feita concomitantemente (Hong e Kim, 2009b).

Memória Global A memória global tem um cache de nível 2 por bloco (ver 3.2) e o seu acesso é feito em blocos de bytes alinhados e com largura dependendo da compute capability da GPU. Cada acesso a um grupo de dados desses é chamado de transação do gerenciador de memória. Assim, os acessos a dados contíguos, de tamanho menor ou igual a essa leitura e alinhados, pode ser executado em uma única transação. Se os dados do acesso não estiverem dentro desse tamanho e alinhamento será necessário um número maior de transações para finalizar o acesso. O gerenciador de memória tenta otimizar os acessos para o menor número possível, porém ele possui restrições inerentes a sua compute capability. (NVIDIA, 2011d, p. 167-168).

A capacidade do gerenciador de memória global para otimizar o número de transações varia muito

\footnotetext{
${ }^{30}$ A largura do barramento de dados da memória DRAM é de 384 pinos, organizados em seis partições de 64 pinos cada. Cada partição possui $1 / 6$ do espaço de endereço físico. As unidades de cada partição de memória enfileiram diretamente os pedidos. Essas unidades arbitram entre as centenas de pedidos provenientes dos estágios paralelos dos pipelines de computação e gráficos. A arbitragem procura maximizar a eficiência de transferência total da DRAM, favorecendo o agrupamento de pedidos relacionados por banco de DRAM e direção de leitura/escrita, enquanto minimiza a latência o máximo possível. Os controladores de memória são compatíveis com uma ampla gama de frequências de relógio para a DRAM, protocolos, densidades de armazenamento e larguras de barramento de dados.

${ }^{31}$ Todos unidades de processamento geram endereços em um espaço virtual de endereçamento. Uma unidade de gerenciamento de memória executa uma tradução do virtual para o físico.
} 


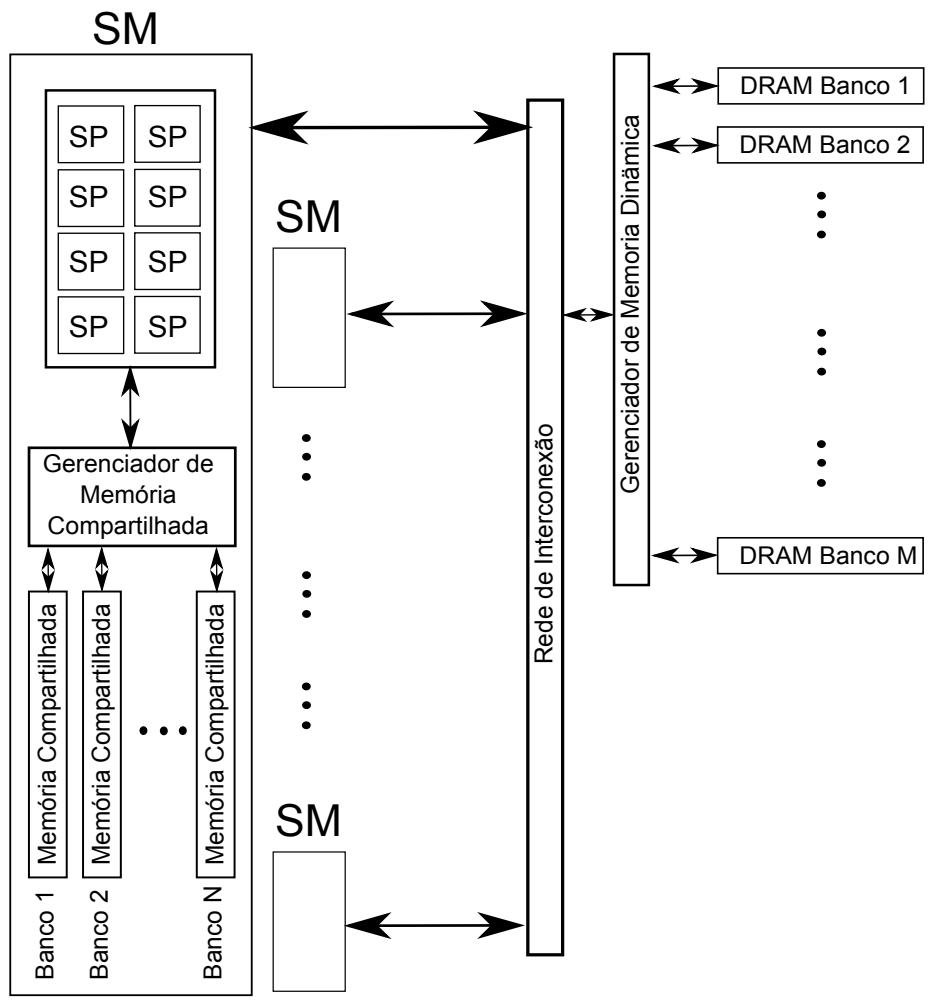

Figura 3.5: Visão Simplificada do Sistema de Memória da GPU.

entre as primeiras versões de GPGPU (compute capability 1.0) e as últimas (compute capability 2.X), porém, ele sempre usa como base para otimização um conjunto de 16 threads. Nas primeiras versões, a existência de um único dado que impedisse que o acesso fosse feito em uma transação não criava um acesso em duas transações (uma para todos dados contíguos e outra para o dado que criou a exceção). Na verdade, aconteceria uma transação por dado a ser lido (Hong e Kim, 2009b), ou seja, 16 transações (NVIDIA, 2011d, p. 163). Em versões posteriores (compute capability $1.2 \mathrm{e}$ 1.3), o acesso é otimizado para o menor número possível de transações (NVIDIA, 2011d, p. 163). $\mathrm{Na}$ compute capability 2.X, devido a existência de dois caches (ver 3.3) é considerado que sempre ocorrerá otimização e qualquer acesso ocorrerá em uma ou duas transações (NVIDIA, 2011d, p. 167-168).

Memória Compartilhada Na memória compartilhada existem os conflitos de bancos que alteram o comportamento dos acessos a essa memória. Nesta memória, o acesso é feito conjuntamente para 16 threads para equipamento com compute capability inferior a 2.0 e para 32 threads nos equipamentos com compute capability 2.X (NVIDIA, 2011d, p. 163, 169).

Segundo Kothapalli et al (Kothapalli et al., 2009):

"... if more than one thread is acessing the same bank in the shared memory at the same time, this results in a memory contention, which can increase the access cost. ${ }^{\prime \prime 2}$

A ideia básica atrás do intercalamento dos bancos é que cada thread que está executando, no mesmo SM, e participa do acesso à memória compartilhada, acesse o seu dado em um banco subsequente ao da thread anterior.

\footnotetext{
${ }^{32} \ldots$ se mais do que uma thread está acessando o mesmo banco de memória compartilhada ao mesmo tempo, isso resulta em uma disputa de memória, que pode aumentar o custo do acesso.
} 


\subsubsection{Arquitetura SIMT}

Como explica Lindholm et al (Lindholm et al., 2008) sobre as características de SIMT e SIMD:

"SIMT architecture is similar to single-instruction, multiple-data (SIMD) design, which applies one instruction to multiple data lanes. The difference is that SIMT applies one instruction to multiple independent threads in parallel, not just multiple data lanes. A SIMD instruction controls a vector of multiple data lanes together and exposes the vector width to the software, whereas a SIMT instruction controls the execution and branching behavior of one thread. ${ }^{\prime 33}$

Como o SIMT não expõe a largura do vetor de dados, ela permite a escalabilidade do programa através da distribuição e gerenciamento das threads nos SMs. Em outras palavras, essa arquitetura cuida da alocação e escalonamento das threads. Para esse fim foram criadas duas unidades, uma para escalonamento e outra para alocação das threads.

No SM são executadas 8 threads simultâneas, porém, o escalonamento é feito em grupos de 32 threads (Lindholm et al., 2008). Essa unidade de escalonamento da GPU é chamada warp. Em tecelagem, um conjunto de linhas paralelas é chamado urdidura. Da mesma forma, um conjunto de threads ${ }^{34}$ rodando em paralelo, forma um warp $^{35}$ (ver figura 3.6) (NVIDIA, 2011d, 85).

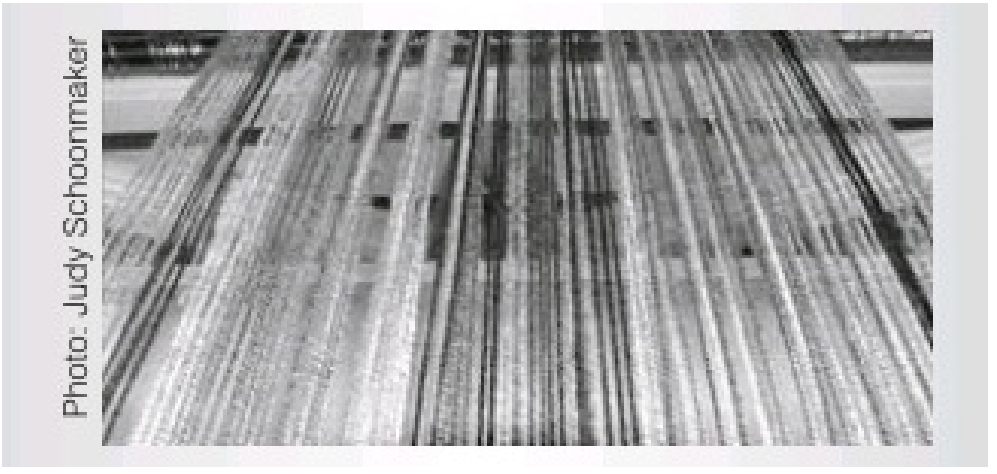

Figura 3.6: As várias linhas (threads) em um tear formando uma urdidura (warp) (Lindholm et al., 2008).

O SIMT executa a mesma instrução para todas as threads do mesmo warp antes de mover para a próxima instrução do programa (Kirk e mei W. Hwu, 2010, p. 98). Para executar a mesma instrução nas 32 threads de um warp é necessário que essa instrução seja enviada 4 vezes para execução nos 8 SP presentes no SM (Hong e Kim, 2009b). O total de warps que um SM pode gerenciar varia de acordo com a compute capability. Em consequência disso, também varia o total de threads alocadas em um SM e logo, o total de threads que uma GPGPU pode gerenciar (Lindholm et al., 2008).

\section{Alocação e Escalonamento}

O escalonamento dos warps é feito em round-robin ${ }^{36}$ por fatias fixas de tempo, porém, pode ser antecipado pelo acesso à memória global (Hong e Kim, 2009b; Lindholm et al., 2008). Similar a um computador pessoal no qual qualquer processo que fizer acesso a disco é bloqueado, indo para a fila

\footnotetext{
${ }^{33}$ A arquitetura SIMT é similar ao projeto de instrução única e múltiplos dados (SIMD), que aplica uma instrução a múltiplas vias de dados. A diferença é que o SIMT aplica uma instrução a múltiplas threads independentes em paralelo, não somente múltiplas vias de dados. Uma instrução SIMD controla um vetor de múltiplas vias de dados conjuntas e expõe a largura desse vetor ao programa, enquanto que uma instrução SIMT controla a execução e ambiente de desvio de uma thread.

${ }^{34}$ Linhas

${ }^{35}$ Urdidura

${ }^{36}$ Literalmente carrossel, porém é utilizado para designar a troca de forma sequencial e circular.
} 
de espera até seus dados estarem disponíveis, o warp que requisitar acesso à memória DRAM (que possui alta latência) também perde o direito de execução e fica na fila de espera até que os seus dados estejam todos disponíveis (Hong e Kim, 2009b).

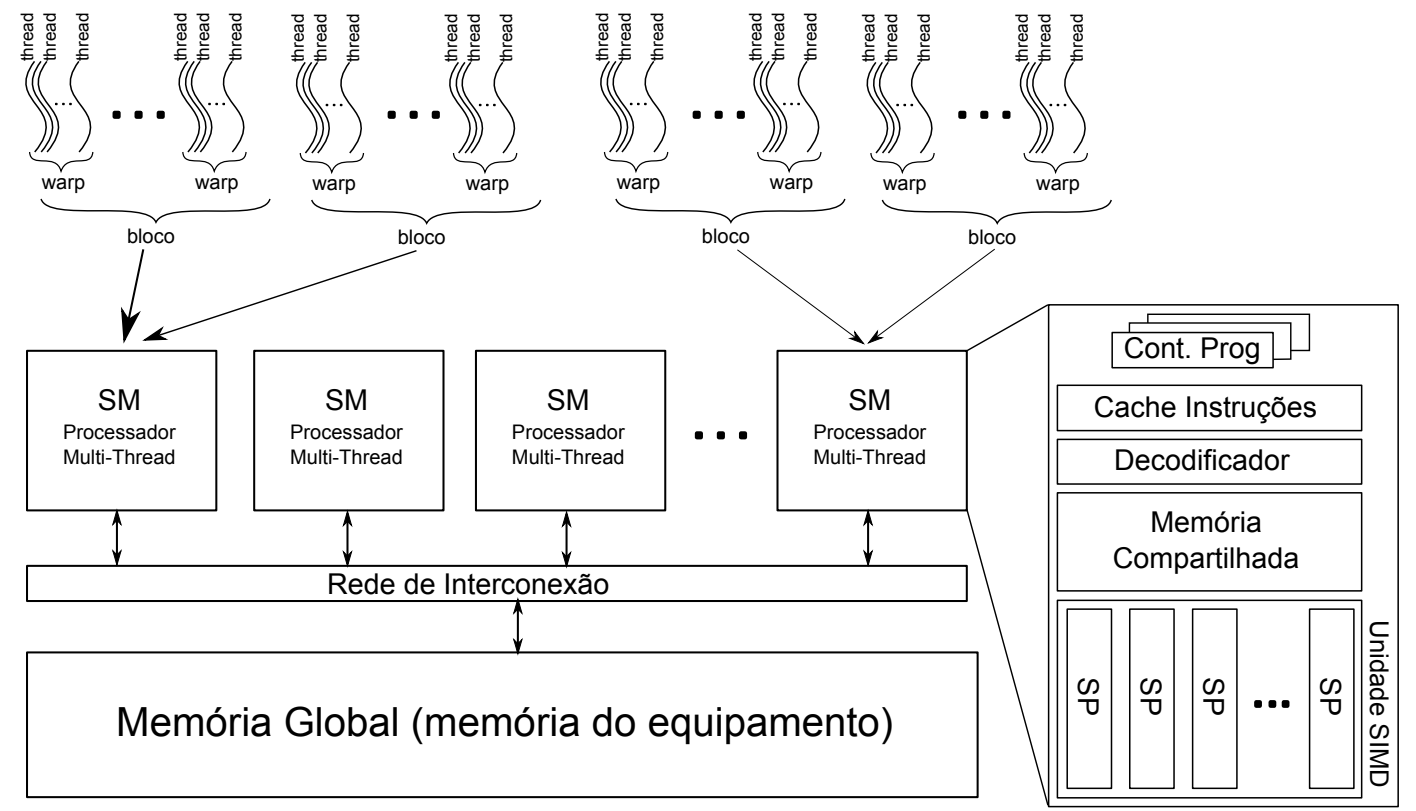

Figura 3.7: Alocação de Blocos e Warps no SM (Hong e Kim, 2009b).

Porém, a unidade warp não é exposta para o programador e sim o bloco (que é um conjunto de threads) (ver 4). Toda a programação é feita considerando-se blocos de threads. Durante a execução, um bloco é dividido em warps e alocado em um mesmo SM, ou seja, todos os warps de um mesmo bloco executam no mesmo SM (Hong e Kim, 2009b), (NVIDIA, 2011d, p. 85). Dessa forma, vê-se que a unidade de alocação é o bloco e a unidade de escalonamento é o warp.

Um SM pode receber a alocação de um ou mais blocos que serão executados concorrentemente, como pode ser visto na figura 3.7. A quantidade de blocos sendo executada em um SM dependerá do consumo de recursos (registradores e memória compartilhada) de cada bloco (Hong e Kim, 2009b) e com a limitação do máximo de warps que o SM pode gerenciar (Lindholm et al., 2008). Os blocos podem ser alocados para qualquer SM disponível, em qualquer ordem, sequencialmente ou concorrentemente (NVIDIA, 2011d, p. 5).

A cada nova execução de instrução o escalonador verifica dentre os warps ativos do SM qual possui threads prontas para executarem a próxima instrução e escolhe esse warp para executar (NVIDIA, 2011d, p. 86).

Apesar dos vários warps alocados em um SM iniciarem a execução na mesma instrução, como eles executam independentemente e devido aos efeitos da preempção durante a execução, eles poderão perder essa sincronicidade. A figura 3.8 mostra essa situação exemplificando algumas trocas de contexto da execução de 3 warps.

A troca de contexto é uma operação praticamente sem custo e pode ser feita em um ciclo de relógio (Hong e Kim, 2009b). Isso se deve ao fato de que todo o contexto de execução dos warps, como o seu contador de programa, registradores e memória compartilhada, é mantido no SM durante toda a vida desses warps. A necessidade de manter esse contexto também limita o número de blocos que podem ser alocados e processados conjuntamente em um SM. Dessa forma, quanto mais recursos um kernel consumir, menos blocos poderão ser alocados por SM. Como a quantidade desses recursos varia segundo a compute capability, se não houver recursos suficientes para executar um único bloco, o kernel não será executado e gerará um erro (NVIDIA, 2011d, p. 86). 


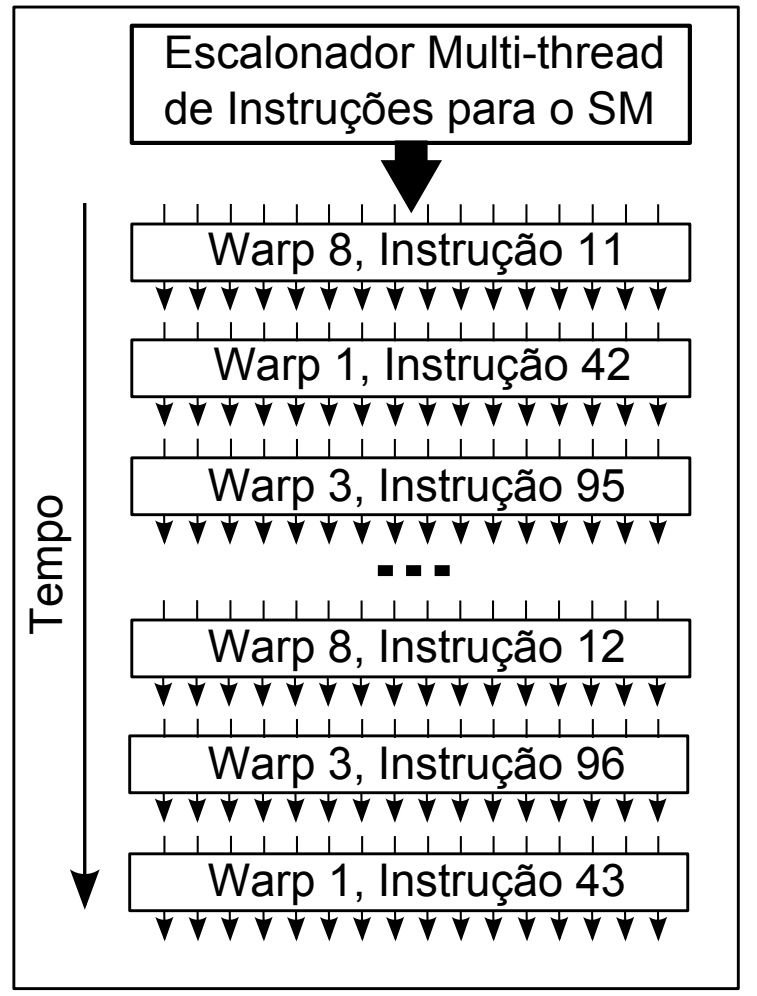

Figura 3.8: SIMT: Escalonamento e Execução dos Warps (Lindholm et al., 2008).

\section{Execução Condicional Divergente}

Se o kernel sendo executado contiver um desvio condicional, pode ocorrer de algumas threads do warp avaliarem a condição de forma contrária às restantes. Assim, algumas threads executarão um caminho, enquanto que as outras executarão o outro caminho desse desvio. Isso é chamado de execução condicional divergente do warp. Nessa situação não haverá a execução de todas as 32 threads do warp concomitantemente.

Nesse caso, será executado cada caminho divergente para as threads adequadas de forma consecutiva, ou seja, os caminhos serão serializados. Após a execução de todos os caminhos, as threads convergem novamente para a execução do mesmo código (NVIDIA, 2011d, p. 86), (Kirk e mei W. Hwu, 2010, p. 98-99).

O SM utiliza uma pilha de sincronização de desvio para gerenciar a condição das threads dentro do warp. Só existe divergência de execução dentro do mesmo warp (Lindholm et al., 2008).

Outra forma de divergência de execução ocorre quando a condição define o total de execuções de um laço. Dessa forma, algumas threads podem executar o laço com uma quantidade de vezes maior que as outras. Assim, ao fim da execução conjunta de todas as threads, teremos a execução somente para as threads que avaliaram seu total execução para um valor maior. Isso continuará ocorrendo até que a última thread chegue ao fim (Kirk e mei W. Hwu, 2010, p. 99)

\section{Sincronismo}

É possível criar barreiras de sincronismo entre threads de um mesmo bloco através da função synchthreads (). Dessa forma, quando as threads do mesmo bloco chamam essa função, elas param a execução até que todas elas cheguem até esse ponto do programa. (Kirk e mei W. Hwu, 2010, p. 68). 
Como não existe uma instrução para sincronizar threads entre blocos diferentes, os blocos podem ser executados em qualquer ordem relativa entre eles. Isso parece ser uma desvantagem, mas, permite que haja escalabilidade entre equipamentos com diferentes quantidades de SMs. Uma vez que não existe dependência entre os blocos, eles podem ser alocados de forma diferente em equipamentos diferentes sem influenciar o resultado (Kirk e mei W. Hwu, 2010, p. 69-70). Isso pode ser visto na figura 3.9 .

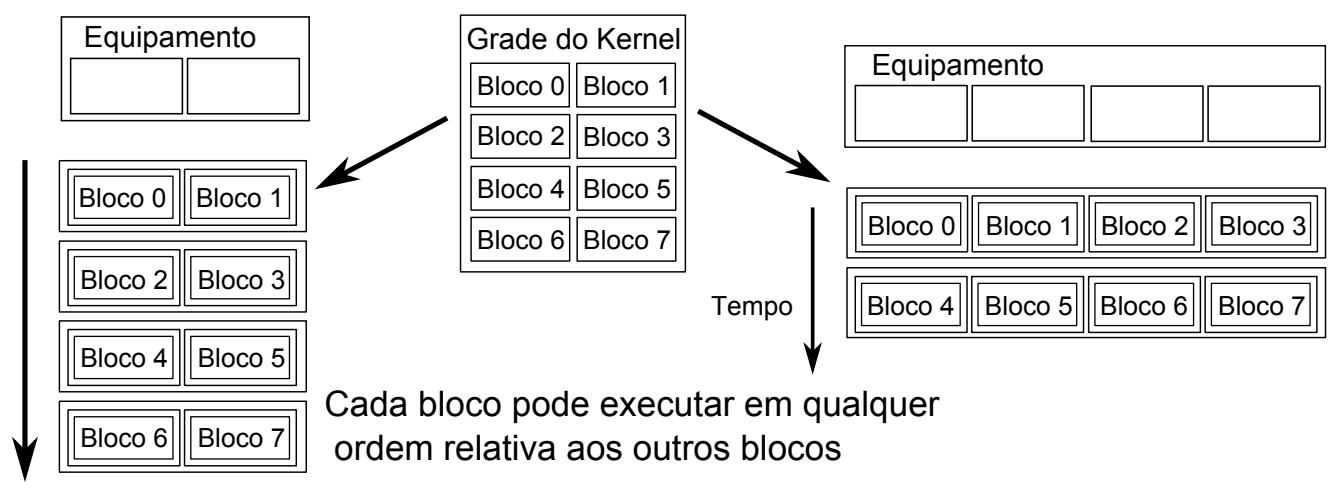

Figura 3.9: A alocação do mesmo kernel em duas GPUs, uma com 2 SMs e a outra com 4 SMs.(Kirk e mei W. Hwu, 2010, p. 68)

\subsection{Arquitetura Fermi}

Anunciada em $2009^{37}$ a arquitetura Fermi trouxe alterações estruturais na GPU, principalmente no SM. Entre elas está o aumento de processadores por placa, que na primeira versão lançada já alcançava 512 deles. Também houve alterações de nomenclatura, como por exemplo, o SP que passou a ser chamado de CUDA Core $^{38}$ (Halfhill, 2009).

Essas alterações na arquitetura envolvem, basicamente, quatro áreas: arquitetura do SM, conjunto de instruções (ISA - Instruction Set Architecture), subsistema de memória e unidade de gerenciamento de threads (NVIDIA, 2009).

\section{Arquitetura do SM}

$\mathrm{Na}$ arquitetura do SM, houve um aumento no número de processadores, que passou de 8 para 32. Como pode ser visto na figura 3.10, cada um desses 32 CUDA Cores possui duas unidades pipelineds ${ }^{39}$ de cálculos, sendo uma para cálculos em ponto flutuante e outra para inteiros. Também existe uma unidade para enviar os operandos para essas unidades de cálculo e uma fila de resultados (Halfhill, 2009). A ALU (Arithmetic Logic Unit) ${ }^{40}$, que trata dos cálculos com inteiros, trabalha com precisão de 32 bits em todas instruções. Tanto a ALU quanto a FPU (Floating Point Unit) ${ }^{41}$ podem executar uma instrução por ciclo de relógio por thread (NVIDIA, 2009).

Como se vê na figura 3.10, cada SM possui 16 unidades de carga/armazenamento, com isso, ele pode executar 16 operações por ciclo, sendo uma para cada thread. O número de SFUs também

\footnotetext{
${ }^{37} \mathrm{O}$ anuncio está em http://www.nvidia.com/object/io_1254288141829.html. Consultado em 11/12/2011

${ }^{38}$ Núcleo CUDA

${ }^{39}$ Em tradução livre, enfileiradas

${ }^{40}$ Unidade Lógica e Aritmética

${ }^{41}$ Unidade de Ponto Flutuante
} 


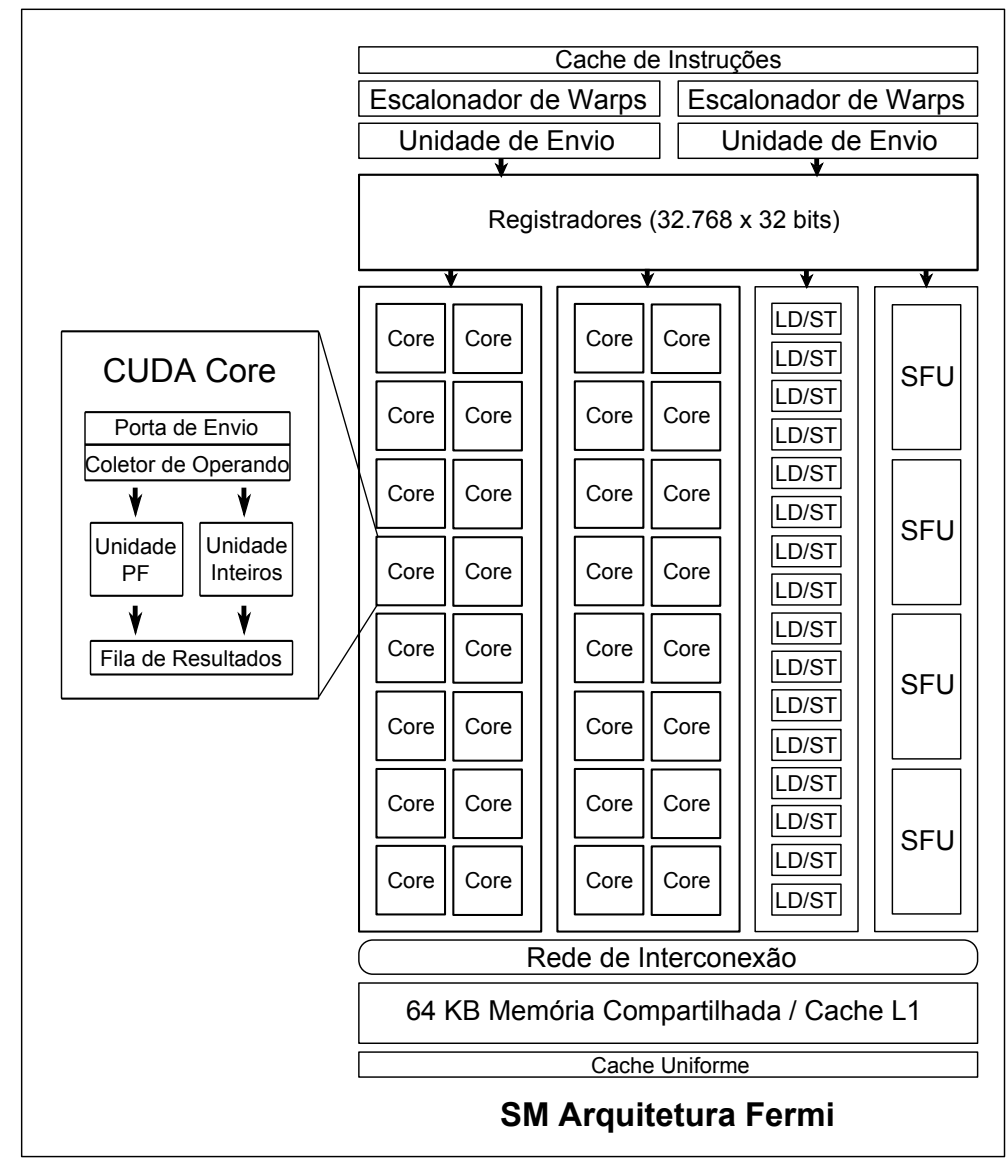

Figura 3.10: Arquitetura do SM Fermi da NVIDIA.(NVIDIA, 2009)

aumentou, passando para 4 e cada uma delas pode executar uma instrução por thread por ciclo de relógio (o que dá um warp a cada 8 ciclos). Como o pipeline das SFUs é desacoplado da unidade de envio (dispatch unit), pode haver escalonamento para outras unidades de execução enquanto a SFU está ocupada (NVIDIA, 2009).

Cada SM possui dois escalonadores e duas unidades de envio de instruções. Assim, é possível executar dois warps concorrentemente no mesmo SM. São selecionados dois warps e uma instrução de cada um deles é enviada para execução. Essa instrução é executada em 16 processadores com 16 unidades de carga/armazenamento ou 4 SFUs. Com exceção das instruções de precisão dupla, a maioria das outras instruções podem ser executadas em dupla concorrentemente. Isso pode ser visto na figura 3.11 (NVIDIA, 2009).

Uma vez que as duas unidades de envio de instruções são independentes, não pode ocorrer o envio de duas instruções da mesma thread, mas sim, de warps diferentes. Como cada SM pode gerenciar no máximo 48 warps com 32 threads, isso nos dá 1.536 threads por SM. As primeiras placas lançadas contém $16 \mathrm{SMs}$, permitindo o gerenciamento de 24.576 threads paralelas, sendo que a execução pode ser de no máximo 512 ao mesmo tempo (Halfhill, 2009).

\section{Conjunto de Instruções}

A arquitetura Fermi utiliza o novo conjunto de instruções Parallel Thread eXecution ${ }^{42}$ (PTX) 2.0. Na verdade, o PTX é uma máquina virtual e um conjunto de instruções. No momento da instalação do programa, o driver de dispositivo da GPU converte o código PTX para instruções de máquina

\footnotetext{
${ }^{42}$ Execução Paralela de Linhas - thread significa uma linha de execução de código
} 


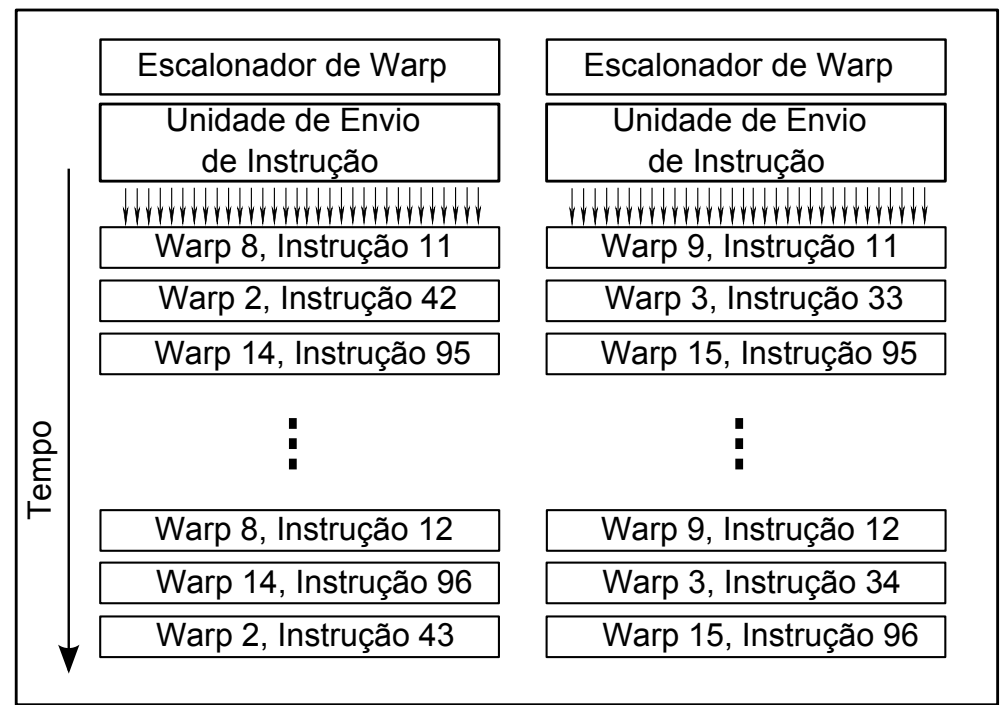

Figura 3.11: Escalonador Duplo da Arquitetura Fermi (NVIDIA, 2009).

adequadas à GPU utilizada (NVIDIA, 2009). Isso gera uma camada que é independente do hardware, abstraindo do desenvolvedor os detalhes específicos de cada arquitetura de GPU (Halfhill, 2009).

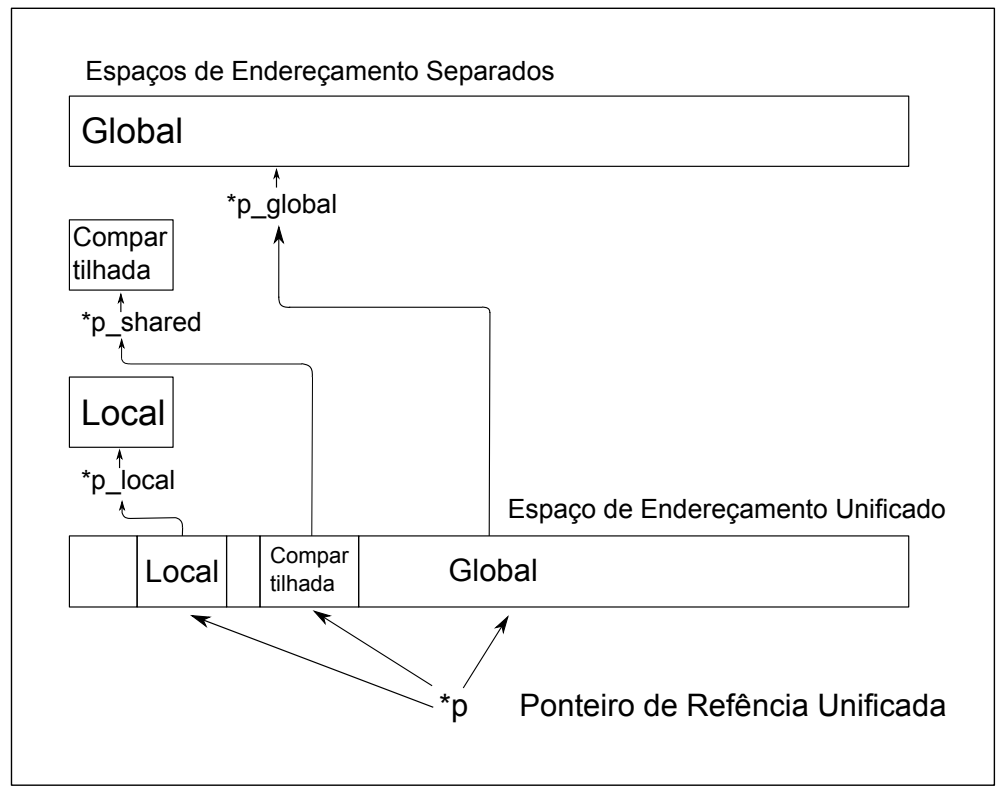

Figura 3.12: Unificação do Espaço de Endereçamento da Arquitetura Fermi (NVIDIA, 2009).

Como visto na figura 3.12, os 3 espaços de endereçamento de memória (local à thread, compartilhada dentro do SM e global) foram unificados. No PTX 1.0 o acesso a esses espaços de memória era feito por instruções específicas para cada um deles, o que dificultava a implementação de ponteiros. Na arquitetura Fermi foi introduzida uma unidade de tradução de endereços, que converte as referências de memória e os ponteiros para os endereços físicos (Halfhill, 2009).

No PTX 2.0, além da unificação houve o aumento da capacidade de endereçamento, que agora é de 1TB. Como em $\mathrm{C}++$ os objetos são passados via ponteiros e esses objetos contém as variáveis e funções; essa unificação permitiu adicionar $\mathrm{C}++$ às linguagens utilizáveis com CUDA, além de Java (através de métodos nativos) e Python (Halfhill, 2009). 


\section{Subsistema de Memória}

A grande alteração na arquitetura de memória foi a introdução de um cache L1 para cada SM e um cache L2 unificado para a memória global e de textura (ver figura 3.13). Na verdade, o cache L1 (gerenciado por hardware) e a memória compartilhada (gerenciada por software) fazem parte de uma mesma unidade de $64 \mathrm{~KB}$ que pode ser configurada de duas formas: $16 \mathrm{~KB}$ para cache L1 e $48 \mathrm{~KB}$ para memória compartilhada ou $48 \mathrm{~KB}$ para cache L1 e $16 \mathrm{~KB}$ para memória compartilhada (NVIDIA, 2009).

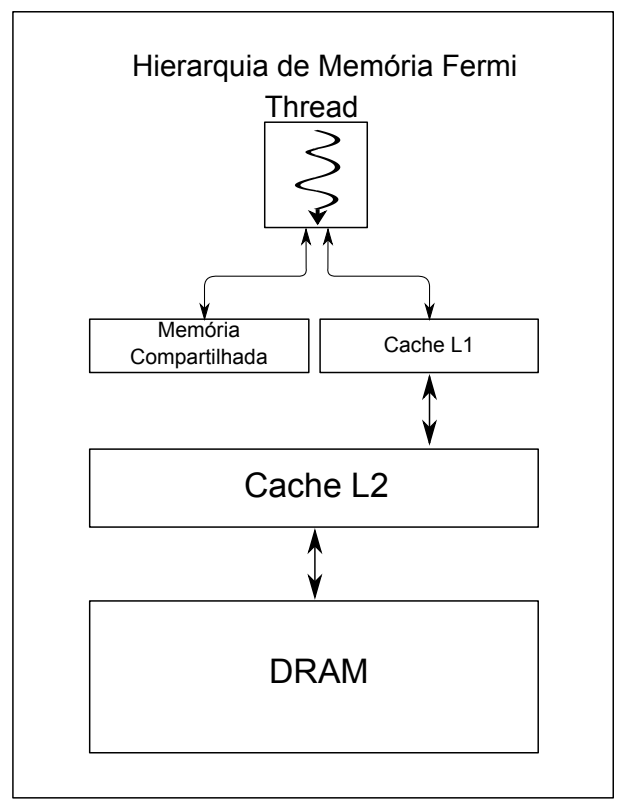

Figura 3.13: Hierarquia de Memórias da Arquitetura Fermi (NVIDIA, 2009).

Além disso, de acordo com o parâmetro de compilação utilizado, a memória global pode utilizar o cache L2 (768KB) ou ambos os caches (L1 e L2) (NVIDIA, 2011d, p. 169).

Outra novidade foi a introdução de correção de erros nas memórias DRAM (global e local), L1, L2 e nos registradores. Esse recurso de ECC (Error Correction Code ${ }^{43}$ ), apesar de ser dispensável em processamento gráfico, é de enorme importância em programas de missão crítica. O seu funcionamento é baseado em uma soma de verificação (checksum) e em caso de falha faz com que a GPU gere uma exceção que deve ser tratada pelo programa. Como esse recurso tem impacto sobre o desempenho é possível desabilitá-lo através de programação (Halfhill, 2009).

\section{Gerenciamento de Threads}

Como nas versões anteriores, o escalonador funciona em dois níveis, um para alocar os blocos aos SMs e outro para escalonar os warps dentro do SM. Porém, ao contrário das versões anteriores que podiam executar somente um kernel por vez, a arquitetura Fermi pode executar concorrentemente até 16 kernels do mesmo programa (Halfhill, 2009).

Por fim, a troca de contexto ficou mais rápida, podendo ser executada a cada instrução (NVIDIA, 2009).

\footnotetext{
${ }^{43}$ Código de Correção de Erros
} 


\section{Capítulo 4}

\section{Conceitos de Cuda}

Cuda apareceu em 2006 (NVIDIA, 2011d, p. 3) com o intuito de facilitar o uso de GPUs para aplicações não gráficas. O grande atrativo da utilização de GPUs é a sua capacidade de computação de ponto flutuante e a adequação de sua arquitetura para a execução de algoritmos massivamente paralelos (principalmente onde não houver interdependência entre os dados computados).

A programação em CUDA é considerada heterogênea, pois parte do programa executa no computador hospedeiro e parte no coprocessador (GPU) (NVIDIA, 2011d, p. 11). De uma forma resumida, quando o programa executando no computador hospedeiro chega a uma rotina que deve ser executada paralelamente na GPU, ele transfere os dados e o programa para GPU através de chamadas para procedimentos remotos (NVIDIA, 2011f, p. 1), espera o término do processamento paralelo dos cálculos e transfere de volta os resultados obtidos (ver seção 3.1).

A programação para GPGPU pode ser feita em Cuda C, Cuda Fortran, OpenCL ou Direct Compute (NVIDIA, 2011d, p. 4), porém, nos limitaremos à explicação da utilização da linguagem C.

\subsection{Modelo de Programação}

O modelo de programação CUDA foi feito considerando a escalabilidade e para tanto utiliza três abstrações chaves: uma hierarquia de grupos de threads, memória compartilhada e barreiras de sincronização. Durante a programação, a decomposição do problema deve considerar o paralelismo dos dados e threads, a cooperação entre as threads de um mesmo bloco e a independência de execução dos diversos blocos (ver seção 3.2.4) (NVIDIA, 2011d, p. 4-5).

Esse modelo ainda considera a existência de espaços separados de memória para a GPU e para a CPU (memória do hospedeiro e memória da GPU). No espaço de memória da GPU existe uma hierarquia dos tipos de memória disponíveis (ver seção 3.2.3) com suas restrições de acesso.

Por fim, cada thread executa em paralelo a mesma função (denominada kernel), sendo que cada uma dessas threads computa um conjunto diferente de dados.

\subsubsection{Kernels}

O CUDA $\mathrm{C}$ estende a linguagem $\mathrm{C}$ adicionando qualificadores, variáveis e sintaxe que permitem definir se uma função será executada no computador hospedeiro ou na GPU e no caso da GPU, em quantas threads paralelas.

O código a ser executado em cada thread é definido através do qualificador _ global__ e sua 
chamada possui uma sintaxe que define a configuração de execução em termos de número de blocos e número de threads por blocos (NVIDIA, 2011d, p. 7):

$<<<$ Total_Blocos, Total_Threads_por_Bloco $>>>$

Para definir e chamar um kernel com 5 blocos e 100 threads por bloco, seria utilizada a seguinte forma:

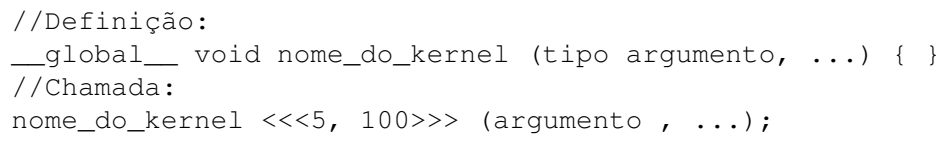

Como cada thread desse kernel executa o mesmo código, é necessária a existência de um identificador único (thread ID) para distinguir entre elas e para identificar em quais dados a computação de cada uma delas será realizada. Esse identificador é computado através das variáveis internas threadIdx e blockIdx como veremos a seguir (NVIDIA, 2011d, p. 7).

Existem outros dois qualificadores, o _ host_e o _ device_. O _ _host__ define que o código será executado no computador hospedeiro e também só pode ser chamado pelo computador hospedeiro. Esse qualificador pode ser omitido. Já o qualificador__device_ informa que a função definida é uma função a ser executada na GPU. A diferença entre __device_e__global__ está na hierarquia de chamada. Uma função __ global__ pode ser chamada do computador hospedeiro, enquanto que uma função _ device__ só pode ser chamada por uma função _ global_ ou por outra função _ device_. Ou seja, só pode ser chamada de dentro da GPU (Kirk e mei W. Hwu, 2010, p. 52) (NVIDIA, 2011d, p. 107).

\subsubsection{Hierarquia de Threads}

O conjunto de todas as threads que compõe uma chamada de kernel é chamado de grid $^{1}$. Um grid ou grade é dividido em blocos e esses blocos são compostos por threads (ver figura 4.1).

Essas threads de cada bloco, são divididas em warps e são eles que são escalonados para execução. A divisão do bloco em warps é sempre em threads consecutivas e iniciando com a thread zero (NVIDIA, 2011d, p. 85).

Por uma questão de acoplamento ao problema sendo tratado, as threads que compõe um bloco podem ser definidas em uma, duas ou três dimensões e a informação sobre essas dimensões está contida na variável interna blockDim. Da mesma forma, os blocos que compõe uma grade, podem ser definidos em até três dimensões e a informação também estará contida na variável interna chamada gridDim (NVIDIA, 2011d, p. 8, 113).

Todos os blocos dentro de uma grade possuem a mesma definição dimensional e existe um limite de threads por bloco de acordo com a especificação da compute capability do hardware sendo utilizado. Também existe uma limitação para o número máximo de threads por kernel.

No caso de kernels unidimensionais, pode-se definir as configurações de execução através de variáveis do tipo int. Em kernels com dimensões acima da unitária, a configuração de execução deve utilizar uma variável do tipo dim3, que é uma struct que possui três componentes com as coordenadas $x, y, z$ (NVIDIA, 2011d, p. 9) (Kirk e mei W. Hwu, 2010, p. 62).

$\mathrm{O}$ valor de blockIdx.x pode variar de 0 até gridDim.x - 1. O mesmo acontece para as outras coordenadas dessa variável (Kirk e mei W. Hwu, 2010, p. 62). Da mesma forma, a variável threadIdx.x pode variar de 0 até blockDim.x -1 .

Exemplificando, a chamada de um kernel com N threads separadas em blocos de 256 threads or-

\footnotetext{
${ }^{1}$ Grade.
} 


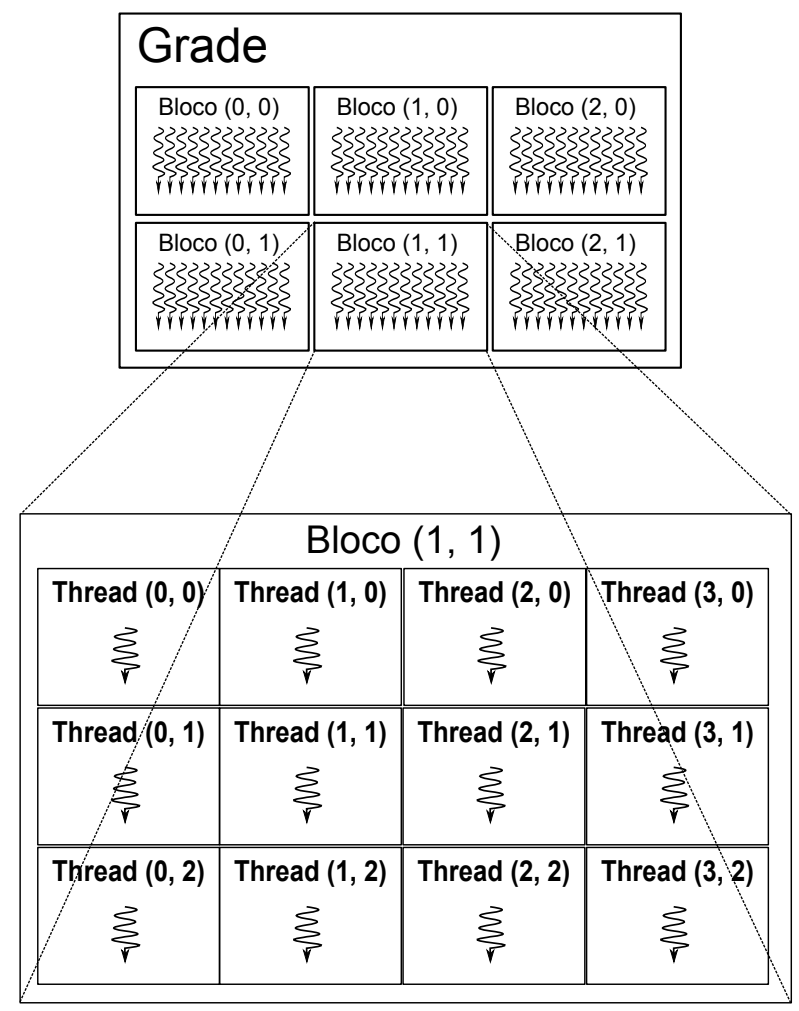

Grade de Blocos de Threads

Figura 4.1: Organização bidimensional de blocos e threads (NVIDIA, 2011d, p. 9).

ganizadas bidimensionalmente em 16 por 16 threads, poderia ser feito da seguinte forma (NVIDIA, 2011d, p. 10):

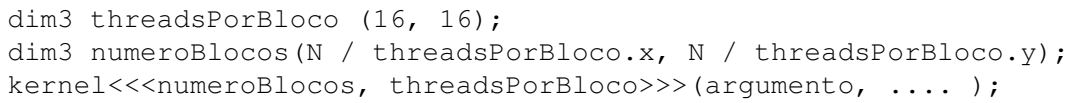

Esses blocos devem ser programados considerando-se que a sua execução poderá ocorrer em qualquer ordem. A decorrência imediata disso é que com o aumento do número de SMs, aumenta o processamento paralelo desses blocos e consequentemente o desempenho na execução.

\section{Thread ID}

Para chegar a um indicador único por thread (thread ID) é necessário converter essas variáveis internas e os índices threadIdx e blockIdx. Isso é feito de acordo com a dimensão dos blocos utilizada (NVIDIA, 2011d, p. 8):

- para um bloco unidimensional:

o thread ID é igual ao threadIdx;

- para blocos bidimensionais com dimensões $\left(D_{x}, D_{y}\right)$ :

a thread com índice $(x, y)$ terá seu thread $I D=x+y D_{x}$; 
- para blocos tridimensionais com dimensões $\left(D_{x}, D_{y}, D_{z}\right)$ :

a thread com índice $(x, y, z)$ terá seu thread $I D=x+y D_{x}+z D_{x} D_{y}$.

\section{Sincronização entre Threads}

Como será visto a seguir, as threads dentro de um bloco compartilham os dados através do acesso à memória compartilhada. Para coordenar a execução dessas threads pertencentes ao mesmo bloco, existe a função _ synchthreads(). Ela funciona como uma barreira em que as threads do mesmo bloco devem aguardar até que todas cheguem. Só após todas chegarem a esse ponto poderá prosseguir o processamento (Kirk e mei W. Hwu, 2010, p. 68).

Dentro do conjunto de instruções do CUDA, não existe recurso para sincronização entre os blocos, que como visto, permite a escalabilidade do programa (Kirk e mei W. Hwu, 2010, p. 69).

\subsubsection{Hierarquia de Memória}

Essa divisão em threads, blocos e grades também se reflete nas restrições de acesso às memórias internas da GPU. Como pode ser visto na figura 4.2, cada thread possui a sua memória local de acesso exclusivo. Cada bloco, durante a sua execução, permite o acesso pelas suas threads à memória compartilhada. Por fim, todas as threads da grade podem acessar a memória global (NVIDIA, 2011d, p. 10).

Ainda, com acesso permitido a todas threads da grade, existem outros dois espaços de memória. Eles são a memória de constantes e a memória de texturas. Ambas são somente de leitura. Juntamente com a memória global, essas duas memórias são persistentes entre chamadas de kernels da mesma aplicação (NVIDIA, 2011d, p. 10).

A utilização do qualificador __shared__ define uma variável como pertencente à memória compartilhada e o seu tempo de vida é o mesmo do bloco. Ele permite o acesso a essa variável a todas as threads do mesmo bloco. Já para a memória de constantes o qualificador é o _constant_ e a sua vida tem a mesma duração do bloco. Por sua vez, o qualificador _ device_ indica que a variável será alocada na memória global e terá o tempo de vida igual ao da aplicação. Tanto as variáveis do tipo _device_quanto _ constant_ podem ser acessadas por todas as threads da grade e também pelo computador hospedeiro (NVIDIA, 2011d, p. 109).

Caso a variável seja declarada sem um desses qualificadores, ela será alocada num registrador. Porém, o compilador pode, eventualmente, alocar na memória local (NVIDIA, 2011d, p. 108).

\subsection{Organização do Programa}

Como já visto, o modelo de programação considera um sistema composto por uma CPU e uma GPU, cada uma com a sua memória separada (NVIDIA, 2011d, p. 18).

A comunicação entre o computador hospedeiro e a GPU é feita através da transferência de dados entre os seus espaços de memória distintos. Como visto na seção 3.1 e na figura 3.2, a memória não é compartilhada entre os dois equipamentos.

Isso faz com que o programa em CUDA tenha que seguir um padrão de construção com os seguintes passos: 

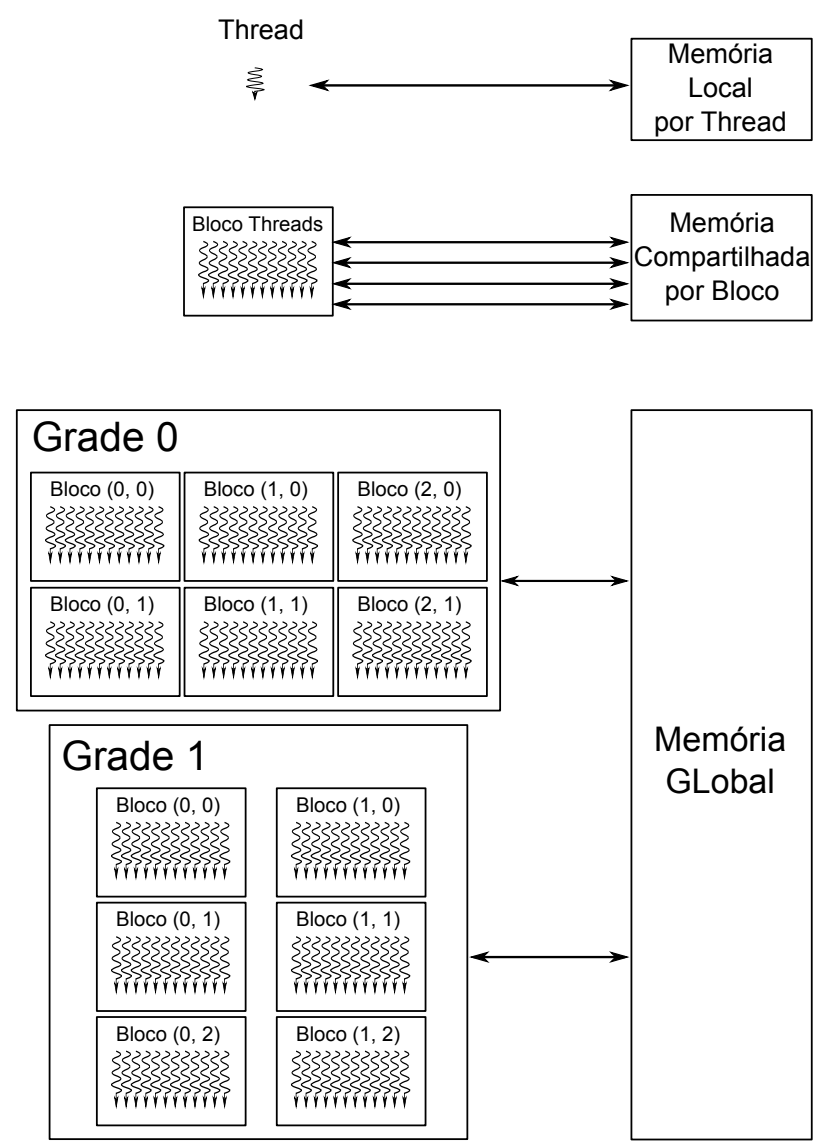

Hierarquia de Memória

Figura 4.2: Os tipos de memória e as permissões de acesso (NVIDIA, 2011d, p. 11).

1. alocação do espaço de memória na GPU;

2. transferência dos dados para a GPU;

3. execução do kernel;

4. transferência dos resultados da GPU para o computador hospedeiro;

5. liberação da memória alocada.

Um exemplo desse padrão pode ser visto a seguir:

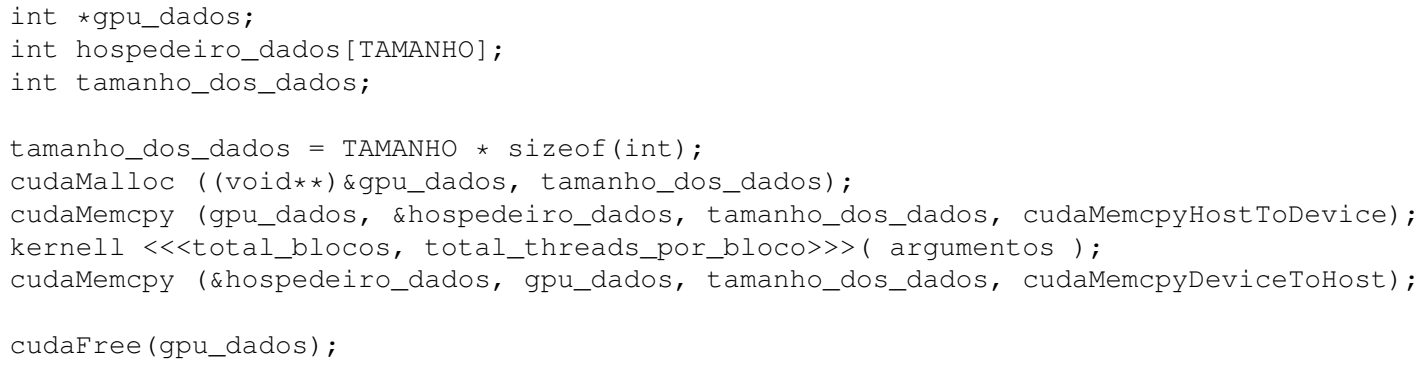

A instrução cudaMalloc() é diferente do malloc() da linguagem C, pois enquanto o malloc() retorna um ponteiro, o cudaMalloc() escreve esse ponteiro na primeira variável utilizada como parâmetro. Outra diferença é que o retorno de cudaMalloc() é o indicador de ocorrência de erros (Kirk e mei W. Hwu, 
2010, p. 48).

\subsubsection{Formas de Transferência}

Como esse processo de transferir os dados para a GPU e posteriormente transferir de volta pode ser custoso em termos de desempenho, foram criadas formas de otimizar esse processo. Uma delas é a utilização de Page Locked ${ }^{2}$ ou pinned memory ${ }^{3}$ na memória do computador hospedeiro. O uso dessa técnica permite que em GPUs com compute capability superior a 1.0, a própria memória do hospedeiro seja mapeada como memória da GPU, eliminando a transferência de dados. O inconveniente dessa técnica é a pequena disponibilidade de memória a ser travada e eventual diminuição de desempenho no hospedeiro. Essa diminuição de desempenho é devida à retirada da memória travada do total de memória disponível para paginação do sistema de memória virtual do hospedeiro (NVIDIA, 2011d, p. 28, 29).

Outra forma de melhorar o desempenho das transferências entre GPU e hospedeiro é a execução concorrente assíncrona. Ela permite que o controle retorne para o hospedeiro antes do fim da execução do kernel. E se a GPU em uso possuir o recurso de asyncEnginecount a transferência entre a memória pinada e a GPU poderá ocorrer concorrentemente com a execução do kernel (NVIDIA, 2011d, p. 30).

No caso de haver várias GPUs com compute capability 2.0 ou superior no mesmo hospedeiro, é possível a cópia de dados entre as memórias dessas GPUs (NVIDIA, 2011d, p. 36).

\subsection{Etapas de Criação do Programa}

Um programa em CUDA possui, nos seus fontes, uma mistura de código C para ser executado no computador hospedeiro e código C para ser executado na GPU. O processo de compilação de um programa CUDA consiste em (NVIDIA, 2011f, p. 1):

1. separar o código do hospedeiro das funções da GPU;

2. compilar o código das funções da GPU através do compilador/montador específico da NVIDIA;

3. compilar o código que será executado no hospedeiro através de um compilador compatível disponível;

4. incorporar as funções de GPU, como imagens carregáveis já compiladas, no arquivo objeto do programa do hospedeiro;

5. durante a fase de ligação são incorporadas as bibliotecas de tempo de execução que cuidam das chamadas de procedimentos remotos (chamadas das funções na GPU).

Para facilitar essa sequência de separação, compilação e posterior união dos objetos compilados, a NVIDIA criou o nvcc (CUDA Compiler Driver) ${ }^{4}$. O nvcc funciona similarmente ao GNU gcc ${ }^{5}$, aceitando opções de compilação e repassando o trabalho não específico de CUDA para o compilador do hospedeiro - ver figura 4.3. Em plataformas Windows, o compilador utilizado é o Microsoft Visual Studio, enquanto que em plataformas Linux, é o gcc (NVIDIA, 2011f, p. 2).

\footnotetext{
${ }^{2}$ Página travada - significa que a página de memória utilizada será impedida de ser utilizada como memória virtual

${ }^{3}$ Memória pinada.

${ }^{4}$ Controlador de Compilação CUDA

${ }^{5}$ GNU é uma sigla recursiva para "GNU's Not Unix"(GNU não é Unix) e gcc significa GNU Compiler Collection (Coleção de Compiladores GNU)
} 


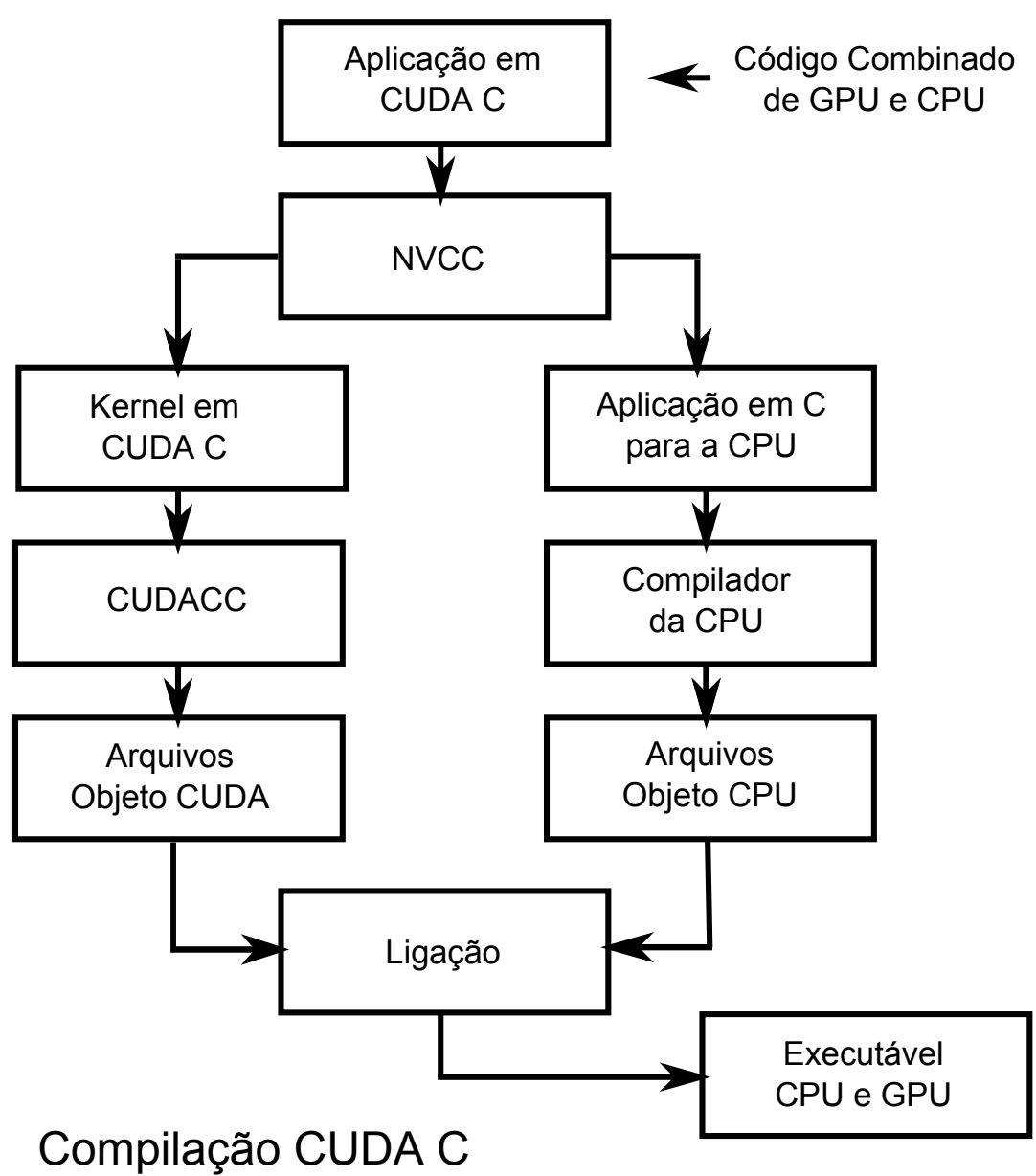

Figura 4.3: Separação de código, compilação e união final feita pelo nvcc (Lanfear e Ziegler, 2009).

\subsubsection{NVCC}

A figura 4.4 mostra a trajetória completa da compilação de um programa CUDA. O arquivo de entrada possui a extensão .cu indicando que é um arquivo fonte em CUDA. A saída pode ser tanto um arquivo ANSI $\mathrm{C}^{6}$ com extensão .cu.c (com o código objeto a ser executado na GPU inserido nele), quanto um arquivo . fatbin $^{7}$ (que contem somente o código a ser executado na GPU em várias versões otimizadas para GPUs diferentes). No caso do arquivo .cu.c, ele ainda será compilado pelo compilador local do hospedeiro (NVIDIA, 2011f, p. 22).

Ainda considerando a figura 4.4, vemos que o cudafe ${ }^{8}$ faz a separação dos códigos do hospedeiro e da GPU, criando o arquivo .c com o código do hospedeiro e .gpu com o código da GPU. De acordo com as opções utilizadas na chamada do nvcc, o código .gpu pode ser transformado em binário CUDA (com extensão .cubin) e/ou PTX (definido pela NVIDIA como: low-level Parallel Thread eXecution virtual machine and instruction set architecture(ISA) ${ }^{9}$.) com extensão .ptx. O resultado dessa etapa que trata do código GPU é identificado com um descritor e inserido no código do hospedeiro, para ser posteriormente utilizado durante a execução do programa (NVIDIA, 2011f,

\footnotetext{
${ }^{6}$ Padronização da linguagem C feita pela ANSI (American National Standards Institute - Instituto Nacional Americano de Padrões)

${ }^{7}$ Fat Binary ou arquivo binário gordo

${ }^{8}$ CUDA frontend - primeiro estágio ou preprocessador CUDA

${ }^{9}$ Arquitetura de conjunto de instruções de máquina virtual de baixo nível para execução de threads paralelas
} 


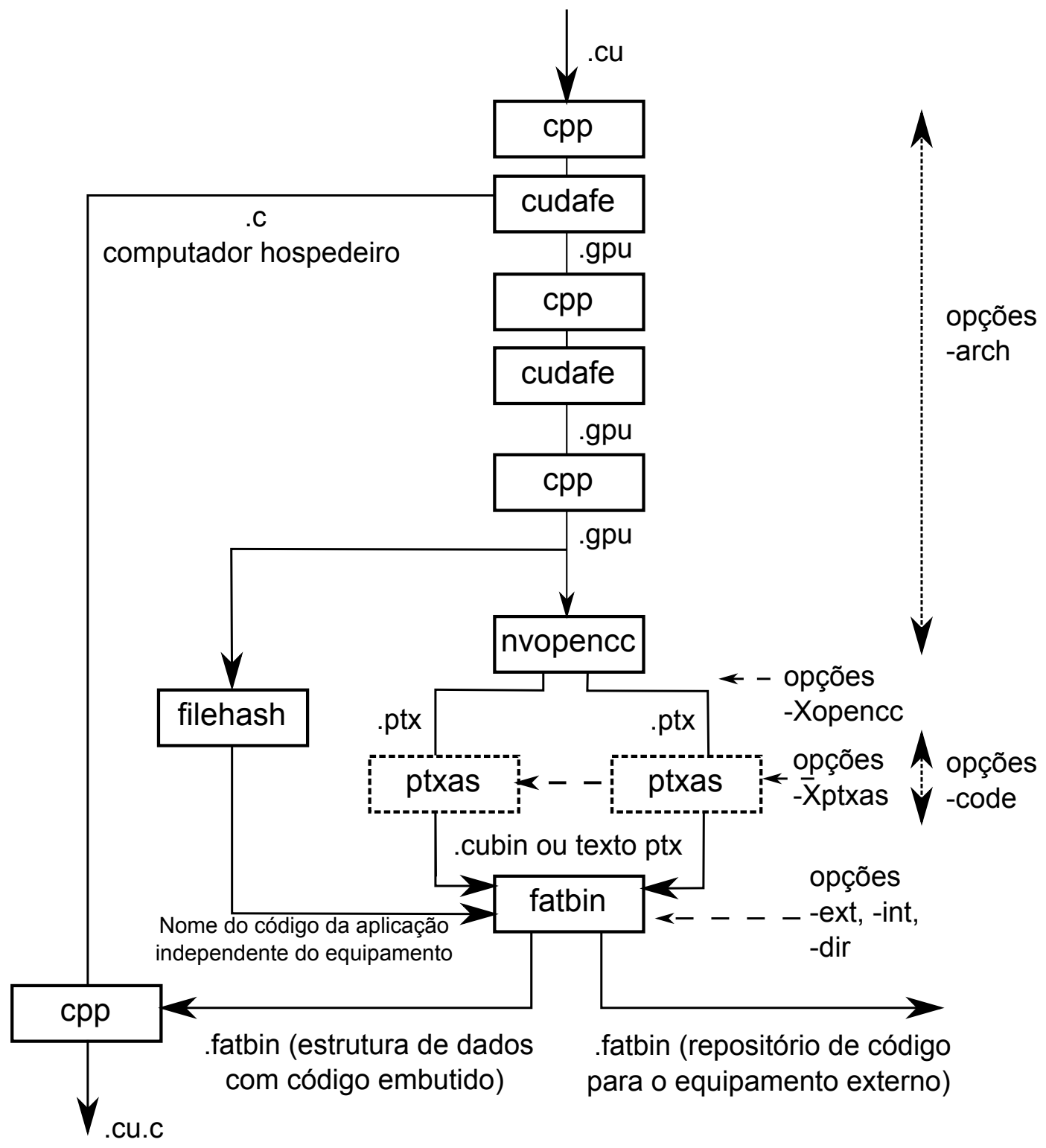

Figura 4.4: Etapas de compilação CUDA (NVIDIA, 2011f, p. 21).

p. 22).

O programa que converte o código C para PTX é o nvopencc. Ele é um compilador baseado no Open64, que é de código aberto (Murphy, 2008).

Na figura 4.4 vemos uma segunda utilização do cudafe. Ela trata somente da análise e remoção de código morto dentro do arquivo .gpu (NVIDIA, 2011f, p. 22).

O descritor que identifica o código .gpu inserido como imagem ou PTX dentro do código do hospedeiro, serve para definir a versão para a qual aquele código foi gerado.

\subsubsection{Arquitetura Virtual e Arquitetura Real}

A NVIDIA não garante compatibilidade binária do .cubin entre equipamentos com compute capability diferentes. E para garantir compatibilidade com modelos futuros, o nvcc utiliza um modelo de compilação em dois estágios, como visto na figura 4.5. A primeira etapa é a criação de uma representação intermediária, o PTX, que é um tipo de linguagem de montador para uma GPU vir- 
tual, chamada de arquitetura virtual. A segunda etapa é compilação desse PTX para código binário compatível com a arquitetura alvo, chamada de arquitetura real (NVIDIA, 2011f, p. 26, 27).

\section{X.cu (código para a GPU)}

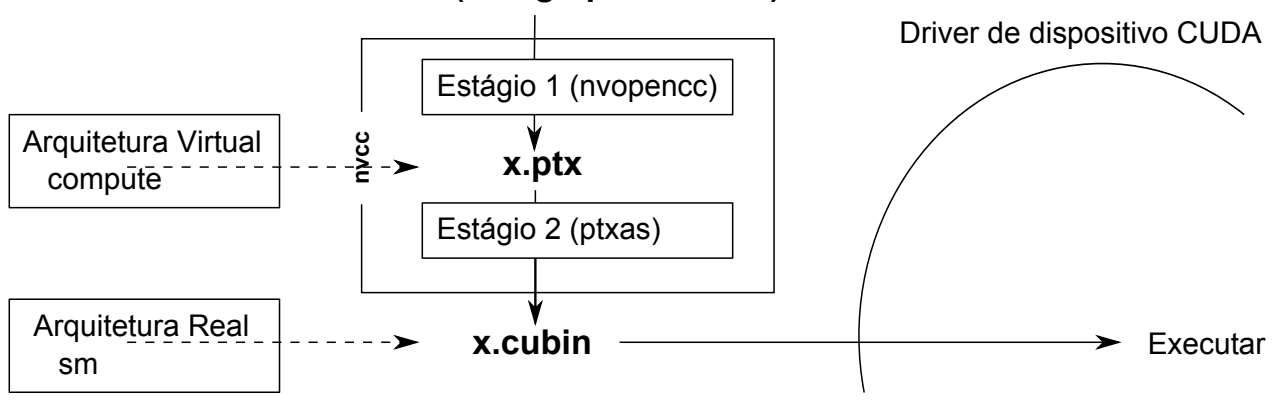

Figura 4.5: Os dois estágios de compilação, com a arquitetura virtual e a real.

A definição de qual arquitetura virtual e qual arquitetura real será utilizada é feita pelos argumentos de linha de comando:

-arch $=$ compute_10 - para definir a arquitetura virtual igual a compute capability 1.0.

- code $=s m \_13$ - para definir a arquitetura real igual a compute capability 1.3 .

O domínio dessas opções pode ser visto na lateral direita da figura 4.4. Eles indicam que o código PTX, gerado pelo nvopencc, será compatível com a a compute capability 1.0, enquanto que o código binário (.cubin) será compatível com o SM de compute capability 1.3.

Isso mostra que na verdade, temos dois conjuntos de instruções envolvidos no processo de criação do programa executável para GPU. O primeiro deles é virtual e chamado de PTX, sendo que ele possui uma grande quantidade de instruções. Até o tipo de operandos dessas instruções pode variar de acordo com a compute capability. Por exemplo, a instrução subc (subtração) só existe na compute capability 1.3 em diante, enquanto que a instrução fma (multiplicação e soma) existe na compute capability 1.4 com operando f64 (ponto flutuante de 64 bits) e na compute capability 2.0 com operando f32 (ponto flutuante de 32 bits) (NVIDIA, 2011g, p. 68, 87).

Já o segundo conjunto de instruções, que executa no dispositivo GPU, possui uma quantidade menor de instruções, como pode ser visto na nota de aplicação da NVIDIA, cuobjdump (NVIDIA, 2011e). As características das GPUs são definidas através da arquitetura real, que utiliza as seguintes opções (NVIDIA, 2011f, p. 26):

sm_10 ISA_1 - Recursos básicos;

sm_11 acrescenta operações atômicas na memória global;

sm_12 acrescenta operações atômicas na memória compartilhada e instruções para votação;

sm_13 acrescenta ponto flutuante de dupla precisão;

sm_20 acrescenta as características da arquitetura FERMI.

As características das arquiteturas virtuais, que definem o código PTX gerado, utilizam as seguintes opções (NVIDIA, 2011f, p. 27, 28):

compute_10 Recursos básicos; 
compute_11 acrescenta operações atômicas na memória global;

compute_12 acrescenta operações atômicas na memória compartilhada e instruções para votação;

compute_13 acrescenta ponto flutuante de dupla precisão;

compute_ $\mathbf{2 0}$ acrescenta as características da arquitetura FERMI.

A NVIDIA recomenda a utilização da menor arquitetura virtual possível, criando assim uma maior gama de GPUs em que o código poderá rodar. Por outro lado, ela recomenda que a arquitetura real seja a maior possível. Dessa forma, o código binário gerado será o mais compatível possível com a arquitetura alvo. Porém, isso considera que existe de antemão a informação de qual será o equipamento GPU utilizado (NVIDIA, 2011f, p. 27).

\subsubsection{Compilação por Demanda}

Para resolver os problemas de saber de antemão qual será a GPU alvo para o código gerado e de manter compatibilidade com versões futuras de GPUs (eventualmente, ainda não especificadas), a NVIDIA implementou a JIT, Just in Time Compilation ${ }^{10}$. Ele se baseia na compilação em dois estágios e funciona através do truque de definir uma arquitetura virtual na opção da arquitetura real. Isso posterga a segunda compilação para que seja executada no momento da execução do código (pelo driver CUDA), permitindo que haja a escolha exata da arquitetura alvo (NVIDIA, 2011f, p. 29).

No exemplo a seguir, a arquitetura virtual é a básica (compute_10) e como a arquitetura real também está definida como compute_10 (uma arquitetura virtual), o código binário será criado no momento da execução.

nvcc $x . c u-$ arch=compute_10 -code=compute_10

A desvantagem dessa técnica é um aumento no tempo de carregamento da aplicação, que deverá ser compilada antes de ser carregada. Por padrão, o código gerado é utilizado durante a vida da aplicação e descartado (NVIDIA, 2011f, p. 35).

Para otimizar essa situação, existe a possibilidade de se armazenar o código compilado durante a primeira execução, abreviando assim o tempo de carregamento das execuções posteriores (NVIDIA, 2011f, p. 29).

\subsubsection{Emulação}

O compilador CUDA possui recursos de emulação para características consideradas básicas, porém, inexistentes nativamente. Por exemplo, a divisão de inteiros e aritmética de inteiros com 64 bits é considerada básica e será emulada nas arquiteturas reais que não possuem essa característica nativamente (NVIDIA, 2011f, p. 28).

A figura 4.6 mostra como a implementação de recursos é feita, seja por emulação ou pela existência nativa do recurso.

Caso a arquitetura virtual seja superior à arquitetura real, como mostra a parte esquerda da figura, haverá a emulação do recurso. Caso contrário, o recurso é implementado nativamente, como mostrado no exemplo do meio e da direita da figura 4.6.

\footnotetext{
${ }^{10}$ Traduzido livremente para compilação por demanda
} 


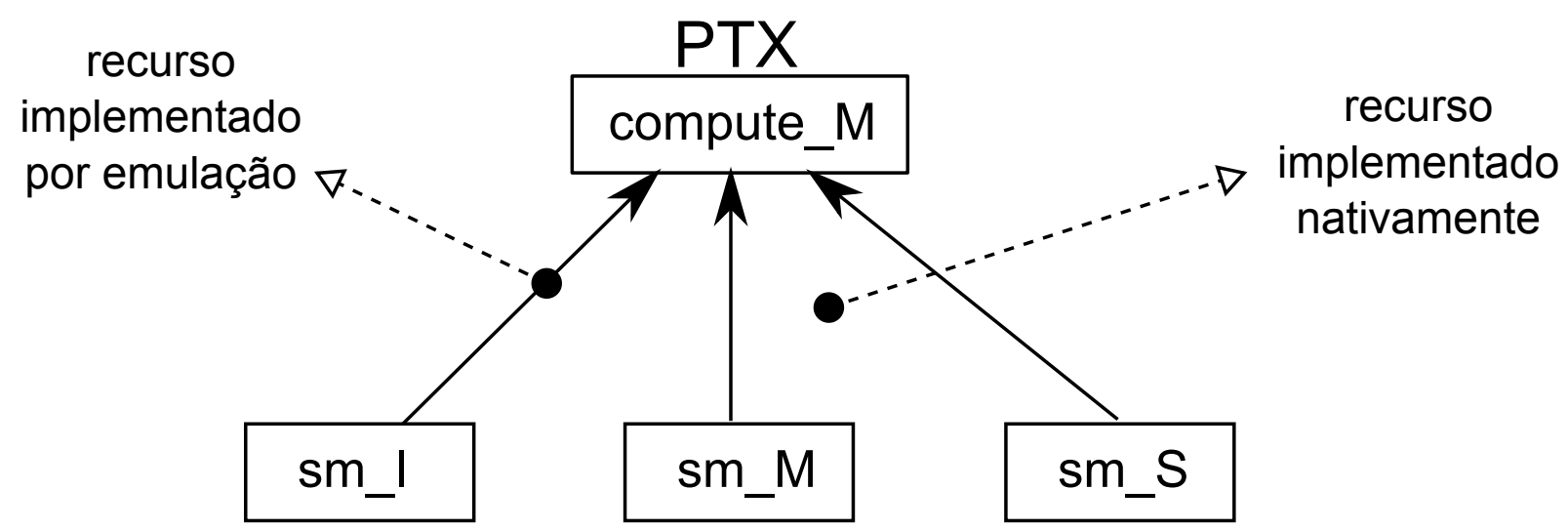

Linguagem de Máquina

\section{I: Inferior \\ M: Médio \\ S: Superior}

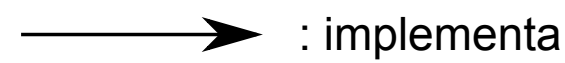

Figura 4.6: A relação entre a arquitetura virtual, a arquitetura real e a utilização de emulação de recursos (NVIDIA, 2011f, p. 29).

\subsubsection{Repositórios}

Para evitar o atraso de compilação devido a utilização do JIT, foram criados os repositórios. Eles contêm os códigos binários para cada arquitetura alvo que se deseja. Isso é feito através da múltipla definição de arquiteturas reais, como visto a seguir (NVIDIA, 2011f, p. 30):

nvcc $x . c u-a r c h=c o m p u t e \_10-$-code=compute_10,sm_10,sm_13

Esse comando cria dois códigos binários e um código PTX. No momento da execução, o driver CUDA decide se algum dos binários é adequado para a GPU em uso ou se deverá fazer a compilação por demanda do PTX (NVIDIA, 2011f, p. 30).

Para armazenar esses códigos binários é criado uma estrutura de diretórios ou um arquivo compactado. Essa criação é feita pelo sistema de execução CUDA, se for um caso de JIT, ou pelo nvcc, se for durante a compilação inicial do programa (NVIDIA, 2011f, p. 33).

Em resumo, o nvcc e o sistema de execução CUDA podem usar um dos seguintes mecanismos para tratar com código a ser executado em diferentes GPUs (NVIDIA, 2011f, p. 33):

1. Armazenar no executável uma ou mais versões do código binário;

2. Armazenar o fonte em PTX dentro do executável, para que seja compilado por demanda;

3. Manter repositórios externos ao executável, em árvores de diretórios ou arquivos compactados;

O sistema de execução CUDA possui recursos para selecionar dentro do executável, o melhor código binário para a GPU corrente ou mesmo, compilar na demanda um PTX existente, se isso for mais adequado do que os binários disponíveis. O armazenamento das compilações em demanda pode ser feito na estrutura de diretórios ou arquivo compactado sendo utilizado para o repositório (NVIDIA, 2011f, p. 33). 


\subsubsection{Informações sobre Utilização de Memória}

A utilização de registradores, memória local e memória compartilhada por um kernel é importante porque define a quantidade total de threads que poderão executar num SM e portanto a quantidade de blocos, ver seção 3.2.4.

O nvcc pode gerar um relatório do uso desses recursos através da opção enviada para o montador de PTX -Xptxas -v, como pode ser visto a seguir (NVIDIA, 2011f, p. 36):

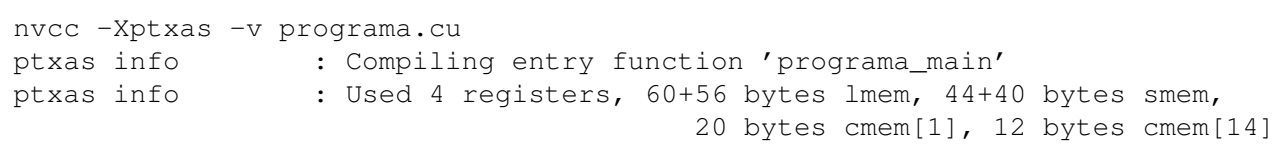

A informação sobre a utilização de memória está organizada por registradores, memória local (lmen), memória compartilhada (smem) e memória de constantes ( $\mathrm{cmem}$ ). Os totais de memória local e compartilhada são mostrados através de dois números para cada tipo de memória. O primeiro número se refere ao tamanho total de todas variáveis declaradas naquele segmento de memória, enquanto que o segundo número indica o total de dados que o sistema utiliza. Para a memória de constantes é mostrado o total alocado por banco.

Para auxiliar a escolha da melhor configuração de execução do kernel, a NVIDIA disponibiliza uma planilha para o cálculo de ocupação. Essa planilha utiliza as informações de utilização de memória para calcular o total de warps que podem ser alocados num SM. Ela retorna uma métrica que é a relação entre o número de warps residentes no SM e o número máximo de warps residentes (NVIDIA, 2011f, p. 91). A ideia por trás desse sistema é a de que quanto mais warps alocados num SM, mais provável que o trabalho de esconder as latências das memórias seja bem sucedido. 


\section{Capítulo 5}

\section{Trabalhos Relacionados}

O levantamento do tempo de execução das instruções de GPU está, em geral, envolvido com a análise de desempenho e com a criação de modelos de desempenho. Isso se deve ao fato de que esses modelos necessitam saber os tempos gastos na execução de instruções e o tempo gasto com acesso à memória.

Particularmente, o nosso trabalho foi motivado por um artigo descrevendo um modelo analítico de desempenho para GPUs da família Tesla.

A seguir apresentaremos os trabalhos que possuem relação com o levantamento do tempo de execução de um kernel de GPGPU. Eles estão organizados em ordem cronológica. Exceção feita ao último artigo, que apesar de não ser relacionado com nenhum modelo, utilizou técnicas de $m i$ crobenchmark similares às que utilizamos no nosso trabalho.

\subsection{An Analytical Model for a GPU Architecture with Memory- Level and Thread-Level Parallelism Awareness}

Esse artigo (Hong e Kim, 2009b) e o relatório técnico (Hong e Kim, 2009a) correspondente foram o ponto de partida deste trabalho. Ele descreve o que é, possivelmente, o primeiro modelo analítico para GPUs NVIDIA da família Tesla e introduz duas novas métricas, o $\mathrm{MWP}^{1}$ e o $\mathrm{CWP}^{2}$. Como descrito no artigo, a intuição básica por trás do modelo analítico, também conhecido como MWPCWP, é que a estimativa do custo das operações de memória é o componente chave para estimar o desempenho de aplicações paralelas para GPU. O modelo é todo baseado em análise estática.

Um ponto importante é a argumentação de que a ocupação ${ }^{3}$ do processador não faz uma estimativa suficientemente boa para se obter o melhor desempenho. Isso é mostrado através de um caso em que apesar de aumentar a ocupação de um kernel de teste, o desempenho não melhora.

Essa argumentação abre espaço para a utilização das duas novas métricas. Elas são os indicadores do total de warps por $\mathrm{SM}^{4}$ que podem acessar a memória simultaneamente (MWP) e do total de warps que podem ser executados durante um ciclo de acesso à memória (CWP). Isso faz com que a relação entre o CWP e MWP indique se o tempo de execução é dominado pelo tempo de computação ou pelo tempo de acesso à memória.

Quando o valor de CWP é maior do que o valor de MWP temos um kernel onde o tempo de acesso

\footnotetext{
${ }^{1}$ Memory Warp Parallelism - Paralelismo de memória do Warp.

${ }^{2}$ Computation Warp Parallelism - Paralelismo de computação do Warp.

${ }^{3}$ Occupancy - uma métrica da NVIDIA para indicar a melhor utilização dos recursos da GPU pelo kernel.

${ }^{4}$ Stream Multiprocessor, ou multiprocessador de fluxo, é a unidade básica para alocamento de blocos na GPU.
} 
à memória domina o tempo de computação. Já quando o MWP é maior do que o CWP, temos um kernel onde o tempo de computação domina o tempo de acesso à memória.

A métrica MWP está relacionada ao paralelismo de memória e é determinada pela largura de banda da memória, pelo paralelismo dos bancos de memória e pelo número de warps por SM. Um valor acima de um, indica que os custos de memória para MWP - 1 warps serão diluídos, desde que eles acessem a memória juntos. Vale lembrar que na arquitetura Tesla (compute capability 1.X), o padrão de acesso à memória global define o tempo desses acessos.

Para obter os dados necessários para o cálculo do MWP, foi feito um conjunto de microbenchmarks de memória que repetem, dentro de um laço de 1000 iterações, uma quantidade configurável de instruções de acesso à memória e instruções de computação. Esses microbenchmarks usam dois padrões de acesso à memória, o padrão com acessos fundidos ${ }^{5}$ e o padrão com acessos separados ${ }^{6}$.

Durante o cálculo do MWP é obtida a quantidade dos ciclos de memória, que é uma média ponderada entre os valores de acessos fundidos e acessos separados feitos, pelo kernel, à memória global. Os dados para esse cálculo vêm dos resultados do microbenchmark de memória e da análise do código PTX.

O CWP é parecido com a métrica de intensidade aritmética ${ }^{7}$. Ele é o menor valor entre o total de warps ativos por SM e o resultado da divisão da quantidade total de ciclos pela quantidade de ciclos de computação.

Para obter a quantidade de ciclos de computação, o modelo multiplica a quantidade de instruções PTX pela quantidade de ciclos necessários para fazer o fetch ${ }^{8}$ de uma nova instrução - que é de 4 ciclos na arquitetura Tesla. Como cada instrução PTX não é necessariamente convertida para uma única instrução de máquina, isso pode gerar um erro no cálculo do valor dos ciclos de computação. Essa é uma das explicações, dada no artigo, sobre a imprecisão do modelo.

De acordo com a relação entre CWP e MWP, o modelo possui uma fórmula diferente para o cálculo do tempo estimado para o kernel, totalizando três formas distintas de cálculo.

Todos os três casos encontram a quantidade básica de ciclos para a execução de todas as threads ativas em um único SM. O tempo total é esse valor multiplicado pela quantidade de vezes necessária para executar todos os blocos, considerando todos os SMs disponíveis (número de repetições).

A quantidade de ciclos para a execução de todas as threads ativas em um único SM é conseguida através da relação entre os tempos de computação do kernel e de acesso à memória global, além da sua capacidade de diluir a latência de memória.

Em todos os casos, o modelo utiliza a relação entre essas duas métricas para indicar a diluição das latências de memória. A partir dessa relação, para obter o resultado final, é feita a ponderação dos valores medidos pelo microbenchmark, os valores provenientes da análise estática do código e as informações de manual.

Nesse modelo os resultados são dados como a média geométrica dos erros absolutos entre as previsões do modelo e a execução das aplicações. Eles estão na faixa de 5,4\% a 13,3\%.

\footnotetext{
${ }^{5}$ Nesse caso, o controlador de memória da GPU reúne os acessos da melhor forma a obter o melhor desempenho

${ }^{6}$ Esse padrão impede que o controlador de memória da GPU consiga reunir os acessos e o desempenho é penalizado.

${ }^{7}$ Intensidade aritmética é a quantidade de operações matemáticas por operação de memória.

${ }^{8}$ Busca de uma nova instrução para execução.
} 


\section{An Integrated GPU Power and Performance Model}

Nesse artigo, o modelo MWP-CWP é utilizado conjuntamente com um modelo de consumo de potência para prever a quantidade ótima de SMs para uma dada aplicação (Hong e Kim, 2010). A base do trabalho é o fato de que, quando o kernel sendo executado atinge o pico de banda de memória, a adição de mais SMs não resulta em aumento de desempenho, mas, somente aumento de consumo.

O artigo mostra que, para kernels com limitação de desempenho pelo acesso à memória, é possível obter-se o maior desempenho sem a utilização de todos os SMs presentes na GPU (considerando GPUs com uma grande quantidade de SMs). Dessa forma, ele procura o ponto ótimo, que é a quantidade de processadores para obter o maior desempenho por watt consumido.

\section{CUDA Performance Analyser}

Essa monografia de mestrado (Dasgupta, 2011) é uma continuação do trabalho com o modelo MWPCWP. Nela é mostrado um analisador de desempenho que, além de prever o desempenho de um kernel, dá noções sobre os gargalos da implementação e ajuda o programador na otimização.

Essa ferramenta é constituída de duas partes principais, o coletor de dados e o previsor. Sendo que este último é baseado no modelo analítico.

O coletor de dados faz a análise do código PTX através do CUDA Visual Profiler ${ }^{9}$ e do GPUOcelot $^{10}$. Esse módulo obtêm estatísticas como o número de threads por bloco, o número de blocos por grade, uso de registradores, quantidade de instruções, quantidade de instruções de alta latência, a quantidade de requisições e transações de memória, quantidade de requisições de memória compartilhada, quantidade de requisições de memória compartilhada onde ocorrem conflitos de bancos, etc.

O modelo analítico foi estendido e passou a considerar instruções com alta latência (raiz quadrada, divisões de ponto flutuante, etc.). As instruções comuns ainda são consideradas como executando em quatro ciclos de relógio. Para as de alta latência são utilizados fatores de ajuste que não são explicados no texto.

\section{A performance Analysis Framework for Identifying Potential Benefits in GPGPU Ap- plications}

Nesse artigo, o modelo MWP-CWP é modificado para fazer parte de uma infraestrutura de análise de desempenho que identifica os benefícios das otimizações (Sim et al., 2012). Chamada de GPUPerf, essa infraestrutura possui métricas para prever os potenciais benefícios das otimizações.

A previsão de desempenho se baseia na obtenção do tempo de computação, tempo de acesso à memória e no tempo de sobreposição da computação com o acesso à memória. O tempo total será a soma dos dois primeiros e a subtração do tempo de sobreposição.

Como no CUDA Performance Analyser ${ }^{11}$ foi utilizado o GPUOcelot e o CUDA Visual Profiler para obter estatísticas de um determinado kernel e alimentar o modelo.

\footnotetext{
${ }^{9}$ Ferramenta visual para levantar o perfil de kernels em CUDA. Faz parte do conjunto de ferramentas do CUDA.

${ }^{10}$ Infraestrutura de compilação dinâmica para sistemas heterogêneos que permite executar programas CUDA em GPUs AMD, GPUs NVIDIA e CPUs x86. Pode ser encontrado em: http://code.google.com/p/gpuocelot/, verificado em $14 / 11 / 2012$.

${ }^{11}$ Analisador de Desempenho CUDA.
} 
Para obter o tempo total de computação é feita a soma do tempo de computação paralela com o tempo de sobrecarga de execuções em série. A computação paralela é obtida através da contabilização de quantas instruções serão executadas em paralelo nos SMs e multiplicado pelo tempo médio da instrução. Já o tempo de sobrecarga serial é obtido analisando-se o tempo gasto na sincronização (caso exista), o tempo das contenções das $\mathrm{SFUs}^{12}$, o tempo gasto em desvios condicionais divergentes e o tempo adicionado devido a conflitos de bancos da memória compartilhada.

Para o tempo médio da instrução é utilizada a análise estática, que também é feita no código binário (executado na GPU). Através de um grafo de controle de fluxo (CFG) obtêm-se os índices para ILP e MLP. O índice ILP é utilizado na modelagem do pipeline, que utiliza uma média da latência do pipeline para calcular o tempo de computação. Essa média é aproximada utilizando a latência da unidade de ponto flutuante e com o ILP são contabilizadas as instruções que podem ser executadas em paralelo.

O tempo de acesso à memória é baseado na quantidade de acessos à memória global, na latência do acesso à essa memória e no grau de paralelismo nos acessos à memória (MLP).

Por fim, o tempo de sobreposição representa o quanto do custo de acesso à memória pode ser diluído pelo sistema de múltiplas threads. Ele é calculado utilizando as métricas MWP e CWP e é o mínimo entre o tempo de acesso à memória e o tempo de computação ajustado com o fator de sobreposição. Esse fator é obtido através do total de warps executando concorrentemente e da comparação das métricas.

\subsection{A Performance Prediction Model for the CUDA GPGPU Plat- form}

Esse artigo apresenta um modelo criado a partir da combinação de outros modelos já conhecidos (Kothapalli et al., 2009), o modelo BSP (Valiant, 1990), o modelo PRAM (Fortune e Wyllie, 1978) e o modelo QRQW (Gibbons et al., 1998), que é uma extensão do PRAM.

O modelo utiliza o conceito de super passos, do modelo BSP, para modelar as diversas chamadas aos kernels que constituem o programa principal. Dessa forma, o tempo total de todos os kernels chamados é a soma do tempo individual de cada um deles, pois não há paralelismo entre kernels diferentes na tecnologia Tesla.

A modelagem do tempo de cada kernel depende dos tempos de computação e dos tempos de acesso à memória. O modelo PRAM considera as operações de computação e as de acesso à memória da mesma forma, inclusive considerando o mesmo custo para cada operação dessas, em geral, uma unidade de tempo. Como a GPU possui uma complexa hierarquia de memória, o modelo proposto no artigo, apesar de ser baseado no PRAM, trata de forma diferenciada as operações de computação e as de acesso à memória.

O custo da computação é considerado analisando a thread e ele indica três formas para estimá-lo:

- De uma maneira mais grosseira, estimando cada operação de forma uniforme e atribuindo uma unidade de tempo ou o mesmo número de ciclos para cada uma delas;

- Utilizar as informações do fabricante, como a tabela de desempenho das famílias de instruções;

- Fazer com que o número de ciclos de execução da instrução seja função do tamanho da entrada, como na análise assintótica.

Através de qualquer um desses métodos chega-se ao total de ciclos de execução, chamado de $N_{\text {comp }}$,

\footnotetext{
${ }^{12}$ Unidades de funções especiais.
} 
para um dado kernel.

Para o tempo de acesso à memória global, foi considerado o tempo médio informado na documentação do fabricante (500 ciclos). Porém, para modelar o efeito de otimização do acesso (fusão de acesso) é verificada a quantidade de threads no warp que se beneficiam da otimização - chamado de $t$. Esse valor é somado ao tempo médio e o total é divido por $t$. No caso de não haver nenhuma otimização nos acessos, é considerado o tempo médio para cada acesso.

Para a memória compartilhada foi considerado um tempo de acesso de quatro ciclos. Para os casos de conflito de acesso ao banco de memória, baseando-se no modelo QRQW, foi utilizada uma função de custo linear proporcional à quantidade de threads que estão em contenção no warp.

O tempo dos acessos de memória, $N_{\text {memory }}$, é a soma dos tempos dos acessos à memória compartilhada e à memória global de uma única thread.

Para uma thread, o efeito do escalonamento é considerado de duas formas. Caso haja total diluição das latências, o tempo total é o tempo $N_{\text {comp }}$; caso não haja diluição, o tempo total é a soma de $N_{\text {comp }}$ e $N_{\text {memory }}$.

Com esses valores é feita uma avaliação de quantos blocos executarão sequencialmente em cada SM e quantos warps e threads existirão nesses blocos. Com isso, temos a quantidade de threads que serão executadas sequencialmente. O tempo total é esse valor multiplicado pelo tempo obtido anteriormente para a thread, isso dividido pelos fatores de paralelismo. Esses fatores são a quantidade de núcleos paralelos de execução e a capacidade do pipeline executar threads em paralelo.

\subsection{An Adaptive Performance Modeling Tool for GPU Architec- tures}

Nesse artigo é apresentado um modelo analítico de desempenho que foi projetado para fornecer informações para a otimização do código pelo compilador (Baghsorkhi et al., 2010).

A ideia do trabalho foi capturar os efeitos de desempenho das maiores características da microarquitetura da GPU, ou seja, o pipeline, o sistema de memória e a forma de diluir as latências.

Para isso, foi utilizado um frontend ${ }^{13}$ de compilador que analisa o fonte do kernel e cria um grafo de dependências do programa $\left(\mathrm{PDG}^{14}\right)$. Não está claro qual o fonte que é utilizado para a análise, mas, como no trabalho anterior (Ryoo et al., 2008) foi analisado o PTX, suponho que seja utilizada a mesma técnica.

O PDG representa as dependências de dados e controle do programa. Também representa as expressões do programa de forma simbólica em termos de coordenadas de threads, variáveis de indução (para os laços) e constantes simbólicas para os parâmetros de entrada. A análise do PDG permite a criação de três índices, o WLP ${ }^{15}$, o $\operatorname{ILP}^{16}$ e o DLP ${ }^{17}$.

O WLP indica a quantidade de warps disponíveis para execução em cada trecho do grafo. Já o DLP é um indicador da quantidade de bancos paralelos de memória e do padrão de acesso (acessos fundidos ou separados). Por fim, o ILP indica a diluição das latências do pipeline. Com esses indicadores temos, no nível do warp, a eficiência de uso do pipeline SIMD, a largura de banda de memória e sua latência.

\footnotetext{
${ }^{13}$ Frontend é a primeira parte do compilador.

${ }^{14}$ Program Dependence Graph - Grafo de Dependências do Programa.

${ }^{15}$ Warp Level Parallelism ou Paralelismo ao Nível do Warp.

${ }^{16}$ Instruction Level Parallelism ou Paralelismo ao Nível da Instrução.

${ }^{17}$ Data Level Parallelism ou Paralelismo ao Nível dos Dados.
} 
Para chegar a esses indicadores é utilizada a avaliação simbólica em cada trecho do PDG. Ela determina os padrões de acesso à memória e as regras de consolidação de acessos. Também com a avaliação simbólica são identificadas divergências em desvios condicionais e é feita uma ponderação conforme a quantidade de warps que tomam cada caminho do desvio.

A próxima ferramenta do modelo é o grafo de fluxo de trabalho, $\mathrm{WFG}^{18}$, que é a combinação do exame da concorrência existente em um kernel (indicada pelo WLP, DLP e ILP) e as latências do pipeline SIMD e do sistema de memória. Ele é uma extensão do grafo de controle de fluxo, com os nodos representando operações de memória global, operações de memória compartilhada, barreiras de sincronização, blocos de $n$ instruções consecutivas, ou entradas e saídas. Além disso, existem os arcos de transição que indicam a dependência dos dados.

Esse grafo é preenchido com dados específicos da GPU para a qual o modelo está sendo aplicado. Também são criados arcos de transição com o número de ciclos necessários para executar o código do nodo.

O WFG representa um warp médio em um kernel de GPU, inclusive com pesos para os diferentes caminhos de um desvio divergente. Esse tratamento também leva em consideração os acessos à memória e os conflitos de bancos dentro das divergências.

O preenchimento do total de ciclos para execução de um trecho de código é calculado através da latência do pipeline, relação entre a largura da execução e tamanho do warp, do ILP e WLP.

Com o WFG preenchido com todos os dados, é aplicado um conjunto de regras de transformação que, recursivamente colapsam laços e desvios em pares de nodos com um único arco entre eles. Durante esse processo é obtida a quantidade de ciclos de relógio para a computação do kernel. Para isso, são ignorados os arcos que possuem informações sobre dependência de dados (acesso à memória global). Também é obtido o total de ciclos de relógio para as transferências de memória. A relação entre os ciclos de computação e os ciclos de memória é a intensidade de computação do warp.

Com os ciclos de memória e computação também é calculada a latência de memória que não é diluída, a latência exposta. Por fim, a redução do WFG permite obter o tempo de execução do kernel.

Em resumo, foi criado um modelo que considera os ganhos obtidos com a diluição da latência baseado nas métricas WLP, ILP e DLP. O modelo foi feito para a família Tesla da NVIDIA.

\subsection{A Quantitative Performance Analysis Model for GPU Archi- tectures}

Nesse artigo é descrito um modelo cujo foco é a identificação quantitativa de gargalos de desempenho e a finalidade é servir como guia para otimização (Zhang e Owens, 2011). O trabalho de doutorado (Zhang, 2012) do autor foi baseado no modelo desse artigo.

Esse modelo abrange três principais componentes da GPU, o pipeline de instruções, o acesso à memória compartilhada e o acesso à memória global. Dessa forma, pode-se estimar o tempo gasto por um kernel em cada um desses componentes e identificar qual deles é o limitante de desempenho.

Para tanto, o kernel é dividido em estágios através de instruções de sincronização. Cada estágio é analisado para encontrar em qual dos três componentes está o gargalo.

As informações sobre a execução dinâmica do kernel em análise são extraídas com o simulador

\footnotetext{
${ }^{18}$ Work Flow Graph ou Grafo de Fluxo de Trabalho.
} 
Barra $^{19}$ (DBL, 2010). Ele fornece a quantidade total de vezes que cada instrução é executada. Com essa informação é contabilizada a quantidade de transações de memória compartilhada e de transações de memória global.

O modelo do pipeline classifica as instruções em quatro grupos, segundo os custos de execução. É utilizado um microbenchmark para levantar os tempos de execução de instruções representativas de cada grupo em quantidades diferentes de warps. Dessa forma, o tempo de execução de um kernel é a combinação linear do tempo gasto em cada tipo de instrução.

Esse microbenchmark, utilizado no modelo do pipeline, é baseado no conjunto de instruções de máquina da GPU. Segundo os autores, isso é feito para evitar os problemas com as otimizações da montagem de código PTX para código de máquina.

Essa escolha, de trabalhar com as instruções de máquina, também levou à necessidade de criar uma ferramenta que evitasse as otimizações feitas pelo montador - como a eliminação de código morto. Essa ferramenta desmonta o código de máquina, faz as alterações necessárias, remonta e insere código alterado dentro do código executável. Foi utilizado o Decuda ${ }^{20}$ para implementá-la.

O microbenchmark do pipeline testa uma instrução de cada um desses quatro grupos e com quantidades diferentes de warps em execução.

Para o modelo de acesso à memória compartilhada é medida a largura de banda sustentável para diversas quantidades de paralelismo no warp. Com a informação do total de transações de memória que o kernel possui (proveniente das estatísticas do programa), juntamente com a análise de conflitos de bancos, é feita a escolha de qual resultado do microbenchmark de memória será utilizado para estimar o tempo.

O microbenchmark de acesso à memória compartilhada movimenta dados, repetidamente, de uma região para outra. Como já comentado, isso é feito com diversas quantidades de warps em execução.

A taxa de transferência da memória global é obtida através de um benchmark sintético que é executado com as mesmas configurações do kernel em análise. Ou seja, com a mesma quantidade de blocos, threads por blocos e transações de memória por thread. Para ter o mesmo padrão de acesso à memória global, foi desenvolvido um simulador de transações de memória com as mesmas regras de unificação (consolidação) de acesso da NVIDIA.

O resultado desse trabalho é uma simulação com acurácia de 5 a $15 \%$ nos três estudos de caso que foram feitos.

\subsection{Demystifying GPU Microarchitecture Through Microbenchmark- ing}

O interessante relatório técnico sobre microbenchmark na arquitetura Tesla, Micro-benchmarking the GT200 GPU ${ }^{21}$ (Misel-Myrto Papadopoulou e Wong, 2009), e o artigo posterior sobre o mesmo tema (Wong et al., 2010) utilizam um conjunto de microbenchmarks para caracterizar o hardware e confirmar as informações do fabricante.

Nesses dois trabalhos foram avaliadas as hierarquias de memória (com as $\mathrm{TLBs}^{22}$ ), as características

\footnotetext{
${ }^{19}$ Este é um simulador da arquitetura Tesla e está disponível em http://code.google.com/p/barra-sim/, verificado em $30 / 10 / 2012$.

${ }^{20}$ Ferramenta de desmontagem feita por Wladimir J. van der Laan, que pode ser encontrado em https://github.com/laanwj/decuda. Verificado em 30/10/2012.

${ }^{21}$ Encontrado em https://es100.seas.harvard.edu/download/attachments/11043272/microbenchmark_report.pdf, verificado em $06 / 11 / 2012$.

${ }^{22}$ Translation Lookaside Buffer, Buffer de Previsão da Tradução
} 
do cache de instruções, do cache de constantes, as características do pipeline aritmético, da execução de desvios condicionais divergentes, de barreiras de sincronização, de bancos de registradores e da latência de memória compartilhada, entre outras.

Segundo os autores, todos os microbenchmarks foram implementados em CUDA C e, quando necessário, o resultado em código de máquina foi verificado utilizando o desmontador Decuda ${ }^{23}$.

Para o teste do pipeline aritmético foi levantada a latência e a taxa de execução para as instruções aritméticas de acordo com o tipo de dados utilizado. Também foram indicadas as unidades funcionais que executariam cada tipo de instrução. Além disso, foi medida a latência para o pipeline do SP e das unidades funcionais, utilizando operandos em registradores.

Apesar do objetivo desses dois trabalhos não ser a análise do desempenho das instruções PTX e sim o levantamento das características do hardware, nele foram utilizadas técnicas similares às utilizadas na realização do nosso trabalho.

\subsection{Resumo das Formas de Contabilizar o Tempo de Execução}

Nos trabalhos analisados neste capítulo, encontramos oito formas diferentes para avaliar o tempo de computação de um kernel. Cada artigo indica pelo menos uma forma de avaliação, porém, temos artigos com três formas distintas. De uma forma resumida, elas são:

1 - a atribuição de tempo fixo para todas as instruções (Hong e Kim, 2009b) (Kothapalli et al., 2009);

2 - a atribuição de tempo fixo para as instruções consideradas simples e a utilização de um fator de ajuste para as instruções de alta latência (Dasgupta, 2011);

3 - a utilização dos tempos de execução das principais instruções, fornecidos pelo fabricante (Kothapalli et al., 2009);

4 - a atribuição de um número de ciclos de execução da instrução em função do tamanho da entrada, como na análise assintótica (Kothapalli et al., 2009);

5 - a modelagem do pipeline, com análise estática de trechos de código para determinação do ILP e tempo médio por trecho analisado (Sim et al., 2012);

6 - a modelagem do pipeline, com o tempo médio das instruções aproximado pela latência da unidade de ponto flutuante (Sim et al., 2012);

7 - microbenchmark de instruções de máquina, que avalia o tempo de execução de quatro instruções representativas para quatro grandes grupos de instruções (Zhang e Owens, 2011);

8 - a utilização da latência do pipeline e do ILP obtidos em trechos do kernel para calcular a duração desses trechos (Baghsorkhi et al., 2010).

\footnotetext{
${ }^{23}$ Ferramenta de desmontagem feita por Wladimir J. van der Laan, que pode ser encontrado em https://github.com/laanwj/decuda. Verificado em 30/10/2012.
} 


\section{Capítulo 6}

\section{Microbenchmark}

O objetivo do microbenchmark é medir o tempo de execução de cada instrução PTX que estiver definida no arquivo de instruções para teste. O resultado dessa medida pode ser utilizado para calcular o tempo de execução de uma rotina ou trecho de código.

Dada a necessidade de configurar quais instruções PTX serão testadas e alguns detalhes de como o teste será feito, optamos por utilizar um gerador de aplicações para criar o programa do microbenchmark. As configurações necessárias para a geração do programa são definidas em arquivos de texto que o gerador interpreta.

A figura 6.1 mostra o ciclo de criação do microbenchmark, que tem como entrada um arquivo de definição das instruções a serem testadas e outro arquivo com as opções de configuração do teste. O resultado do gerador é o fonte em CUDA C do programa do microbenchmark, que é compilado para obter-se o executável.

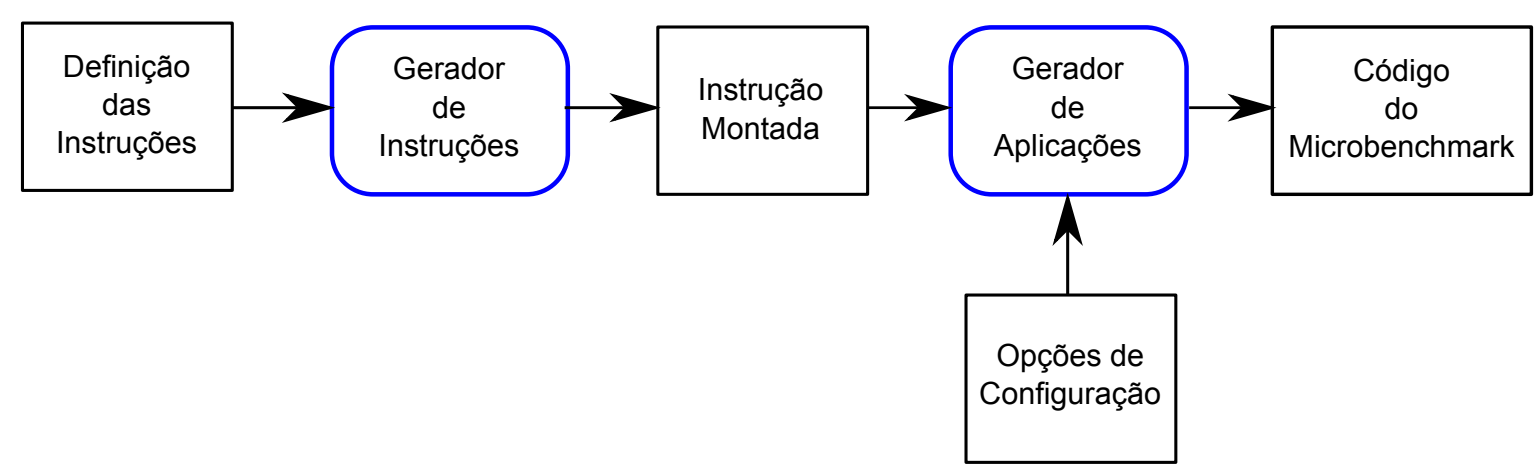

Figura 6.1: Ciclo de criação do microbenchmark

As principais opções de configuração do gerador incluem, entre outras, a forma de execução do teste; quais instruções serão testadas; a quantidade de instruções consecutivas a ser utilizada; a arquitetura real e a arquitetura virtual utilizada. Os detalhes sobre as opções de criação do microbenchmark estão na seção 6.1.4.

Para cada tipo de teste ou conjunto de instruções a ser avaliado é criado um programa de teste (microbenchmark) específico. Essa aplicação gerada também possui as suas opções de configuração, tanto por arquivo quanto por linha de comando (para detalhes das opções de execução do $m i$ crobenchmark veja a seção 6.2.1).

O processo de utilização do microbenchmark é feito em duas etapas. A primeira é a geração do microbenchmark de acordo com as características do teste desejado. Já a segunda é a execução 
do microbenchmark e depende das opções de execução. O resultado da execução é um arquivo em formato texto contendo:

- características da placa GPU onde foi executado;

- opções de execução utilizadas;

- resultados brutos de execução.

Para obter os tempos das instruções em teste é necessário um pós processamento como pode ser visto na figura 6.2 .

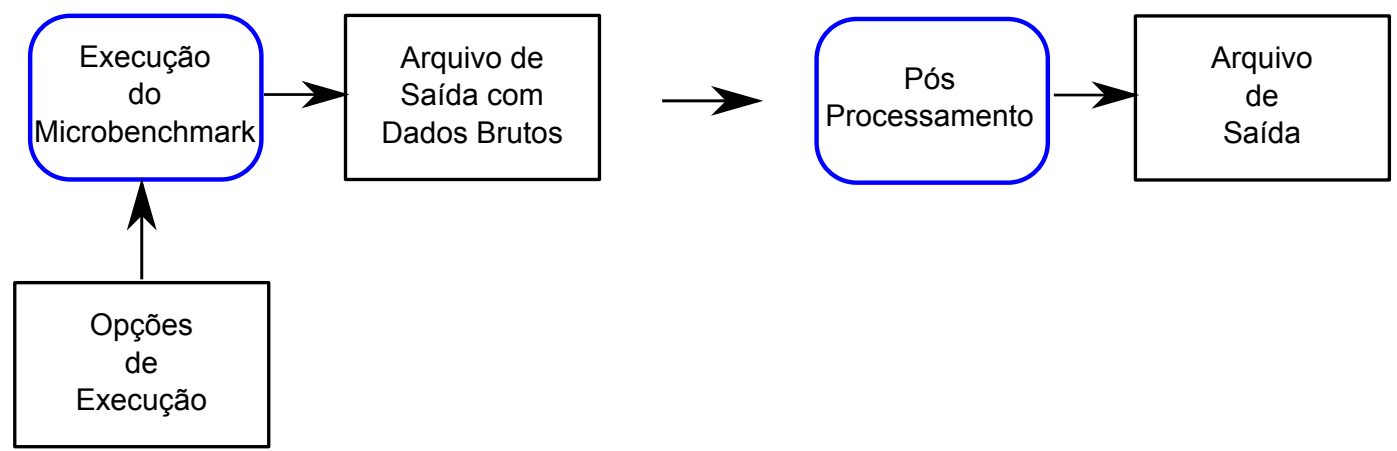

Figura 6.2: Execução e Pós Processamento do microbenchmark

No pós processamento é feita a análise de consistência dos resultados e obtida a média e variância, assim como o desconto do tempo da rotina de calibração (ver detalhes na seção 6.3).

Essa divisão em duas etapas permite uma maior flexibilidade na utilização dos resultados, inclusive com implementações de pós processamento não previstas no início do projeto.

\subsection{Gerador de Microbenchmark}

A função do gerador de aplicação é criar o programa executável com as rotinas de teste para cada instrução definida. Para tanto, ele é composto por dois módulos principais, o gerador de instruções PTX e o gerador de código de teste.

O gerador de instruções PTX cria os códigos mnemônicos das instruções juntamente com os tipos de dados utilizados e outras informações necessárias. Para isso ele se baseia no conteúdo do arquivo de definição de instruções. Esse arquivo é construído utilizando-se uma linguagem de definição de instruções que foi criada para este trabalho.

Essas informações e o código mnemônico da instrução criada é passado para a rotina de criação do código de teste. Essa etapa do gerador trata da montagem de todas as rotinas necessárias ao teste da instrução em questão e está descrita na seção 6.1.3.

\subsubsection{Gerador de Instruções em PTX}

As instruções PTX não seguem um padrão simples e homogêneo e para poder defini-las foi criada uma linguagem de descrição de instrução. Essa linguagem considera, para cada instrução separadamente, os recursos de arquitetura necessários; os tipos de operandos com que a instrução trabalha e os modificadores existentes para a instrução. 
Com o arquivo de descrição das instruções como entrada, uma rotina feita em Flex ${ }^{1}$ faz as combinações pertinentes entre os tipos e modificadores da instrução. Esse processo foi denominado de expansão da instrução e cria todas as variações definidas. O manual da NVIDIA, PTX: Parallel Thread Execution ISA Version 2.3 (NVIDIA, 2011g) contém todas as instruções PTX, com suas variações e compute capability. Ele foi utilizado como referência para este trabalho.

\section{Estrutura da Instrução PTX}

A estrutura de uma instrução em PTX é composta de um opcode ${ }^{2}$ seguido de uma lista de operandos, que é separada por virgulas e terminada em ponto e virgula. As instruções possuem, em geral, até quatro operandos e a sua estrutura é definida pela NVIDIA (NVIDIA, 2011g, p. 55) como mostrado a seguir:

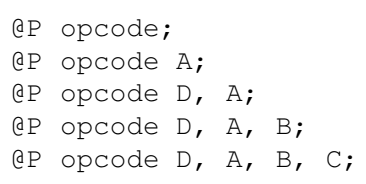

O comando e é opcional e indica a execução condicional da instrução de acordo com o valor do predicado P. Os operandos A, B e C são os operandos fonte, enquanto que o operando D é o operando de destino.

Em PTX temos cinco tipos básicos de dados e cinco tamanhos de dados. A seguir temos uma lista desses tipos de dados com seus respectivos tamanhos:

- Inteiros com sinal: .s8, .s16, .s32 e .s64

- Inteiros sem sinal: .u8, .u16, .u32 e .u64

- Ponto flutuante: .f16, .f32 e .f64

- Binário ou sem tipo: .b8, .b16, .b32 e .b64

- Predicado: .pred

Com exceção do tipo predicado (.pred), os tipos das instruções e dos dados são formados por uma letra e um ou dois dígitos, informando o tipo de dados e o total de bits utilizado. Para a letra (que define o tipo de dados) existem as opções $b^{3}, s^{4}, u^{5}$ e por fim $f^{6}$. Para os tamanhos, temos 1, 8, 16, 32 e 64 bits. O tipo .pred ocupa um registrador de um bit e é utilizado para testes lógicos. Ele segue o funcionamento da linguagem $\mathrm{C}$, ou seja, valores iguais a zero são falsos e valores não zero são verdadeiros.

As variáveis e as instruções são definidas com o tipo de dados que elas utilizarão, sendo que a compatibilidade do tamanho e do tipo dos operandos das instruções é verificado durante a compilação.

Fazendo parte do opcode, temos, além do código de definição da instrução, alguns modificadores e a definição do tipo de dado que está sendo utilizado. Um exemplo de modificador é o de arredonda-

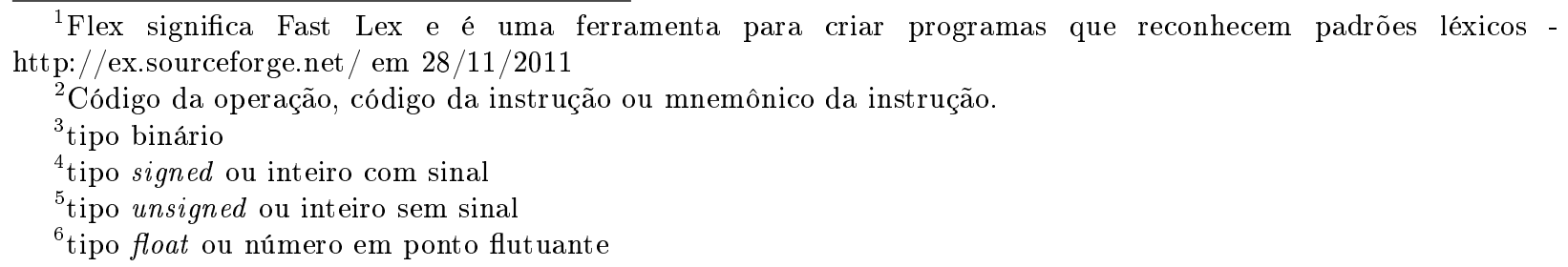


mento. Ele é utilizado nas instruções de ponto flutuante e pode ser $r n^{7}, r z^{8}, r m^{9}$ ou $r p^{10}$. Um exemplo de uma instrução de divisão de ponto flutuante com arredondamento é dado a seguir:

$$
\text { div.rn.f64 D, A, B; }
$$

Nesse caso, o mnemônico div é seguido pelo modificador $r n$ e pelo tipo da instrução f 64 (float de 64 bits) para formar o opcode da instrução. Essa instrução divide o valor do operando A pelo valor do operando B e o resultado é armazenado em D (que é do tipo float de 64 bits).

Os modificadores são específicos de cada instrução ou tipo de dados. Por exemplo, eles estão presentes nas instruções de ponto flutuante para definir a forma do arredondamento. Já na instrução de teste de ponto flutuante, ele serve para definir o tipo de teste a ser feito, como por exemplo, verificar se o operando é um número ou não, se é finito ou infinito (ver a instrução testp (NVIDIA, 2011g, p. 83)).

Apesar da estrutura mostrada no manual utilizar no máximo quatro argumentos, existe pelo menos uma instrução com 5 argumentos, que é a de manipulação de bits bfi (NVIDIA, 2011g, p. 78). A sua descrição, como encontrada no manual, é a seguinte:

bfi.type f, a, b, c, d;

.type $=\{. b 32, . b 64\}$

Nessa instrução temos um destino e 4 operandos fonte. Além disso, podemos utilizá-la com dois tipos de operando, ambos binários, um com 32 bits e a outro com 64 bits.

\subsubsection{Linguagem de Definição de Instruções}

Para representar as características das instruções PTX foi criada uma linguagem de descrição. Sua sintaxe é muito simples e foi baseada na descrição das instruções encontradas no manual da NVIDIA (NVIDIA, 2011g).

Ela define um alvo de montagem ou instrução por linha, onde temos a especificação da arquitetura real e virtual da instrução, seu mnemônico, os modificadores existentes na instrução (dispostos em ordem e com a possibilidade de omissão) e os tipos que serão usados para cada argumento.

Para representar essas informações a linguagem utiliza os seguintes comandos:

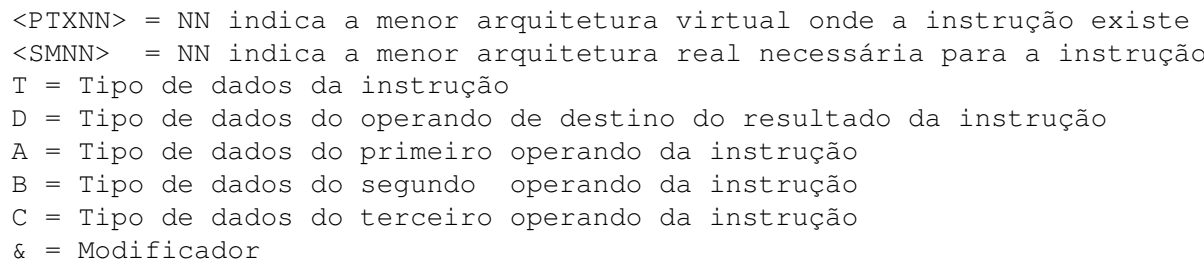

Para cada linha do arquivo de definição de instruções teremos no mínimo os seguintes comandos:

<PTXNN $><$ SMNN $>$ mnemônico $\mathrm{T}\{$ tipos da instrução\} $\mathrm{D}\{$ tipos do destino\} A tipos do operando\}

Esse seria o caso de uma instrução que não possui modificadores e utiliza um único operando, como o absoluto de um dado ou uma instrução de inversão de sinal do dado.

Uma instrução que utiliza dois operandos, como a soma, subtração, multiplicação e divisão, teria a seguinte sintaxe mínima:

<PTXNN $><$ SMNN $>$ mnemônico $\mathrm{T}\{$ tipos da instrução\} $\mathrm{D}\{$ tipos do destino\} A tipos $\}$ B $\{$ tipos $\}$

\footnotetext{
${ }^{7}$ Arredonda para o par mais próximo.

${ }^{8}$ Arredonda para zero.

${ }^{9}$ Arredonda para infinito negativo.

${ }^{10}$ Arredonda para infinito positivo.
} 
Os tipos de instrução e de dados são conjuntos representados entre chaves e com seus componentes separados por vírgulas. Dessa forma, no caso de um conjunto de tipos que incluísse $u 16, u 32, u 64, s 16, s 32, s 64$, teríamos:

$\mathrm{T}\{. \mathrm{u} 16, . \mathrm{u} 32, . \mathrm{u} 64, . \mathrm{s} 16, . \mathrm{s} 32, . \mathrm{s} 64\}$

$\mathrm{ou}$

$D\{.416, .432, .464, . s 16, .532, .564\}$

$\mathrm{ou}$

A $\{.416, .432, .464, . s 16, .532, .564\}$

Por outro lado, um conjunto de modificadores contendo $r n$, $r z$, rm e rp seria definido da seguinte maneira:

$\&\{. r n, . r z, . r m, . r p\}$

Caso essa instrução, além de possuir todos esses modificadores, também pudesse ser executada sem modificador nenhum, a sua definição incluiria o indicador de omissão. Ele é definido através do caractere asterisco $(*)$. Nesse caso, a sintaxe ficaria como segue:

$\&\{\star, . r n, . r z, . r m, . r p\}$

De acordo com o total de argumentos e/ou modificadores da instrução, alguns comandos da descrição podem ser desnecessários.

No caso de haver dois ou mais modificadores, basta colocá-los na sequência adequada, como é mostrado na instrução hipotética vista abaixo. Nela temos um modificador sat ${ }^{11}$ e outro ftz ${ }^{12}$ e ambos podem ser omitidos.

instrução $\&\{*,$. sat $\} \&\{*, . f t z\} \quad T\{. s 32\} \quad D\{. s 32\} \quad A\{. s 32\} \quad B\{. s 32\}$

Essa construção seria expandida para as seguintes instruções:

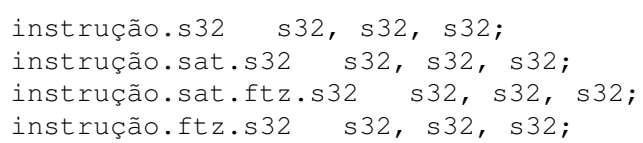

Uma vez definidas todas as instruções, o resultado da sua expansão é transferido para o gerador de aplicação. Ele tem por função montar todos os kernels e o código em CUDA para avaliar os tempos dessas instruções. Também é gerado o código que será executado no computador hospedeiro.

Utilizando o exemplo de expansão anterior, a informação passada para o gerador de código de teste seria o mnemônico instrução.s32, que possui três operandos (incluindo o destino) e tanto o destino como os dois operandos são do tipo s32.

\section{Etiquetas de Definição da Arquitetura}

As etiquetas $<$ PTXNN $>$ e $<$ SMNN $>$ servem como indicadores dos recursos necessários para executar a instrução definida na mesma linha. Essas etiquetas estão vinculadas com a arquitetura real e virtual da instrução. Por exemplo, $<$ PTX20 > indica que a versão mínima da arquitetura virtual que contém essa instrução é a 2.0. Por outro lado, <SM21> informa que a versão mínima da compute capability da GPU necessária para executar essa instrução é a 2.1.

Durante o processo de expansão da instrução essas etiquetas são verificadas para decidir se a linha será utilizada ou não. Elas funcionam como um filtro que só permite que sejam expandidas as

\footnotetext{
${ }^{11}$ Modificador de saturação, que limita o resultado entre MININT e MAXINT.

${ }^{12}$ Limpa entradas sub normais (abaixo do menor número representável), e preserva o sinal do zero
} 
instruções cujas definições são compatíveis com as opções de geração do microbenchmark (ver seção 6.1.4 ). Isso permite ter um arquivo com todas as definições de instruções e automaticamente só utilizar as instruções suportadas pela configuração utilizada na geração do microbenchmark.

Por exemplo, a linha a seguir seria expandida numa configuração que define arquitetura virtual 1.0 ou superior com arquitetura real 1.3 ou superior. Porém, não seria expandida caso a configuração utilizasse arquitetura real 1.2 .

$\langle\operatorname{PTX} 10\rangle\langle\operatorname{SM} 13>\operatorname{mul} \&\{*, . \mathrm{rn}, . \mathrm{rz}\} \mathrm{T}\{. \mathrm{f} 64\} \quad \mathrm{D}\{. \mathrm{f} 64\} \quad \mathrm{A}\{. \mathrm{f} 64\} \quad \mathrm{B}\{. \mathrm{f} 64\}$

Por fim, as instruções que não podem ser executadas isoladamente ou repetidamente, como o call ou o ret, e as instruções que são específicas do processamento gráfico não foram tratadas neste trabalho. Foi dado ênfase às instruções utilizadas em processamento científico em geral.

\subsubsection{Gerador de Código de Teste}

O gerador de código de teste tem como entrada a expansão das instruções a serem testadas e como saída os arquivos com os fontes do microbenchmark a serem compilados.

Ele utiliza uma estrutura básica de rotina de teste que é adaptada para cada tipo de instrução sendo testada. Essa estrutura consta de uma rotina em C, que é executada no computador hospedeiro e chama um kernel escrito em CUDA C. Esse kernel possui o trecho específico do teste codificado em PTX. O recurso de programação assembly dentro da linguagem $\mathrm{C}$ do kernel é apresentado na nota de aplicação da NVIDIA, Using Inline PTX Assembly in CUDA (NVIDIA, 2011b).

Como pode ser visto na figura 6.3, a rotina que é executada no computador hospedeiro tem duas funções, que são a chamada do kernel de teste adequado e a escrita dos resultados de tempos no arquivo de saída.

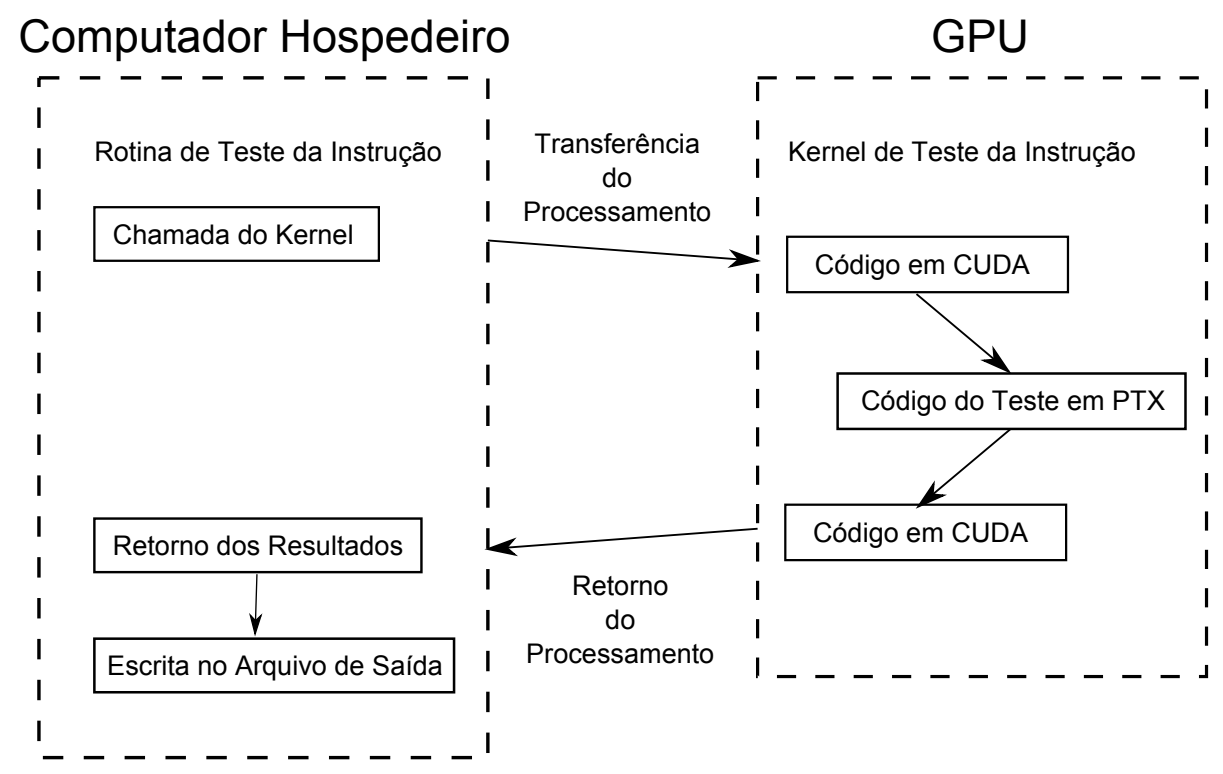

Figura 6.3: Fluxo do teste entre o computador hospedeiro e a GPU.

Por sua vez, o kernel de teste faz o trabalho de medição de tempo e retorna os valores obtidos para a rotina do computador hospedeiro. A estratégia de teste é a mais comum, ou seja, uma medição 
do tempo antes do inicio do teste e outra logo após o término.

\section{Estrutura Básica da Rotina de Teste Executada na GPU}

O teste propriamente dito está todo no código em CUDA e pode ser visto por completo na listagem do apêndice C. No algoritmo 1 (logo a seguir) temos a estrutura completa da rotina de teste.

Para contabilizar o tempo gasto pela execução da instrução foi utilizado o recurso de contagem de ciclos de relógio entre dois, ou mais, momentos distintos. Isso é feito através da leitura do registrador especial \%clock (NVIDIA, 2011g, p. 162). Esse registrador é um contador circular de 32 bits que armazena o número de pulsos de relógio ocorridos. Na compute capability 2.X existe um contador de 64 bits, o \%clock64.

Na versão mostrada no algoritmo 1, temos a leitura do inicio e fim da thread, que é opcional. Essa leitura é útil para verificar como ocorre o escalonamento das threads e não deve ser utilizada na obtenção dos resultados finais, pois as duas leituras extras alteram o resultado do teste.

Essa rotina de teste é configurável de acordo com as opções de geração do microbenchmark (ver seção 6.1.4 para detalhes das opções). A mudança mais significativa é a leitura ou não dos valores do inicio e fim da thread e a forma de fazer as leituras do registrador \%clock.

A codificação é feita através do comando para inserção de linguagem de montador, asm ( ) . É possível passar argumentos para a função em PTX e receber parâmetros de retorno (NVIDIA, 2011b, p. 4, 5). Para evitar que o compilador otimize as rotinas de teste em PTX é necessário entrar com dados na rotina PTX e fazer a saída de alguma manipulação desses dados, mesmo que esse resultado seja descartado posteriormente. Mais detalhes sobre a otimização do compilador e os problemas encontrados no microbenchmark estão na seção 6.4.

Como o contador de ciclos de relógio é circular, é necessário verificar a consistência dos valores inicial e final. Isso é feito no pós processamento. Como o tempo de $2^{32}$ ciclos de relógio é muito superior ao tempo de execução de 10 instruções seguidas (maior quantidade possível no teste), não existe a possibilidade de o contador passar por zero mais do que uma vez.

Nos testes iniciais utilizando uma única thread, os maiores valores obtidos foram inferiores a 5.000 ciclos de relógio. Esses casos ocorreram com instruções emuladas, ou seja, uma instrução PTX é expandida para várias instruções de máquina. Mesmo nesse caso, teríamos uma cota superior de 50.000 ciclos para 10 instruções, o que é muito inferior aos $2^{32}$ ciclos do contador.

Outro fator importante é a existência das conversões de tipo de dados na entrada do teste e a sequência de somas existente após a leitura final do tempo do trecho de teste. Esses trechos de código tem a função secundária de evitar a execução concomitante do trecho de teste em um warp e do acesso à memória global em outro. Isso criaria distorções no valor obtido pelo microbenchmark como pode ser visto na seção 6.4.

Por fim, para evitar que haja problemas com a execução do código do microbenchmark se o mesmo for chamado mais do que uma vez, ele foi criado dentro de chaves, o que indica que as variáveis terão um escopo separado para cada vez que for invocado (NVIDIA, 2011b, p. 7).

Além da rotina de teste de cada instrução definida, também é gerada uma rotina especial chamada de calibragem. Ela possui a mesma estrutura, porém sem nenhuma instrução dentro do trecho de teste. A sua função é obter o tempo de leitura do contador de ciclos de relógio. Como esse tempo está embutido em todas leituras dos testes do microbenchmark, é necessário descontar esse valor do resultado final. Isso é feito na etapa de pós processamento e temos mais detalhes na seção 6.3. 


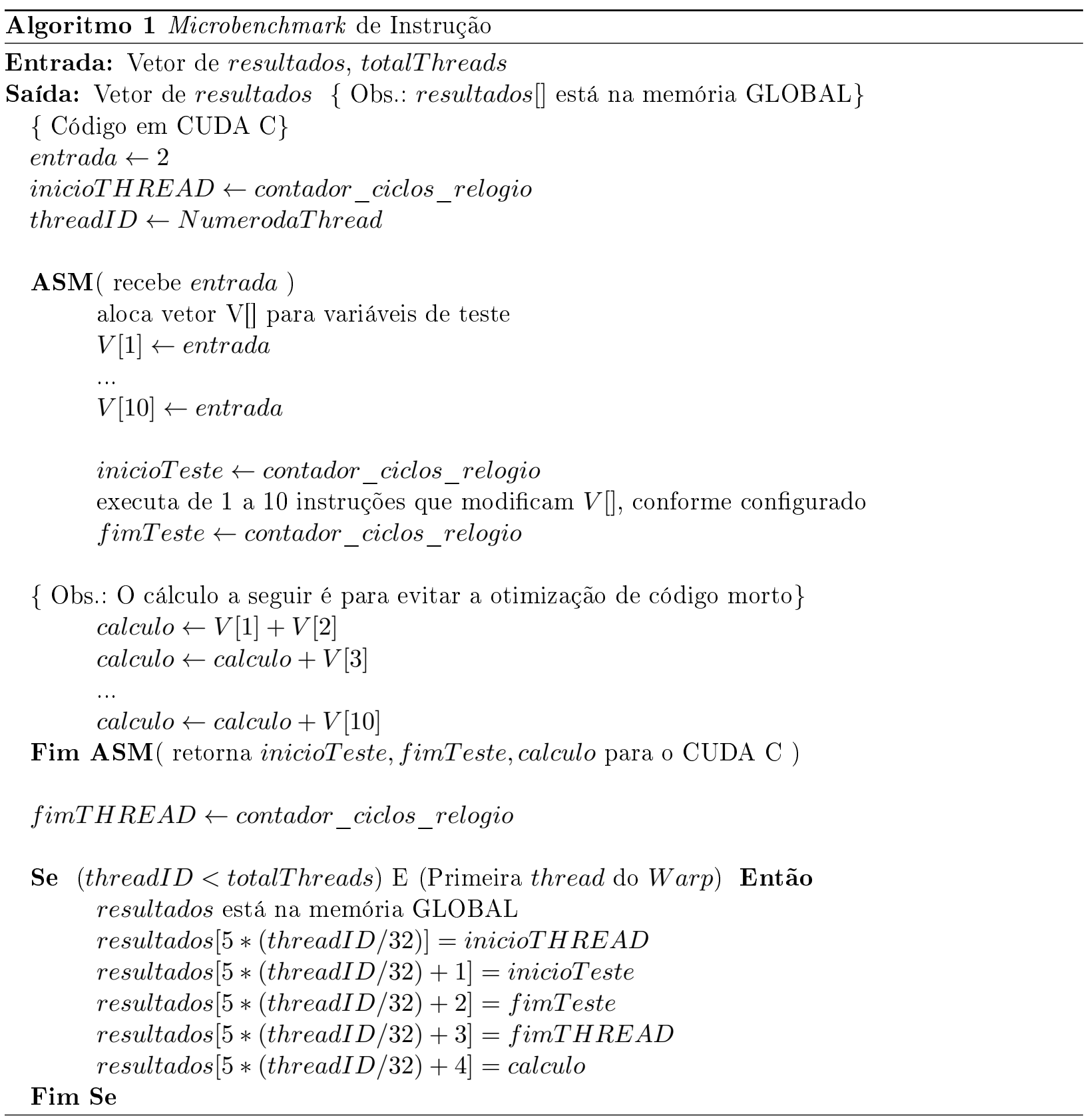




\section{Estrutura Básica da Rotina de Teste Executada no Hospedeiro}

Como vimos, a função do código que é executado no computador hospedeiro é a chamada da rotina de teste na GPU e o controle e formatação da escrita dos resultados no arquivo de saída. Porém, para obter resultados com relevância estatística, a chamada da rotina de teste pode ser feita uma quantidade definida de vezes. Dessa forma, os resultados serão escritos no arquivo de saída com a identificação da sequência de chamada e posteriormente, no pós processamento, utilizados para calcular a média e o desvio padrão dos tempos de execução.

Existem duas possibilidades de chamar múltiplas vezes a rotina de teste de instrução. Podemos optar por chamar o teste da mesma instrução várias vezes consecutivas, ou seja, em rajada ou podemos chamá-lo intercalado com o teste de outras instruções (denominamos essa forma de intercalada). Para exemplificar melhor, temos no algoritmo 3 a forma intercalada e no algoritmo 2 a chamada em rajada.
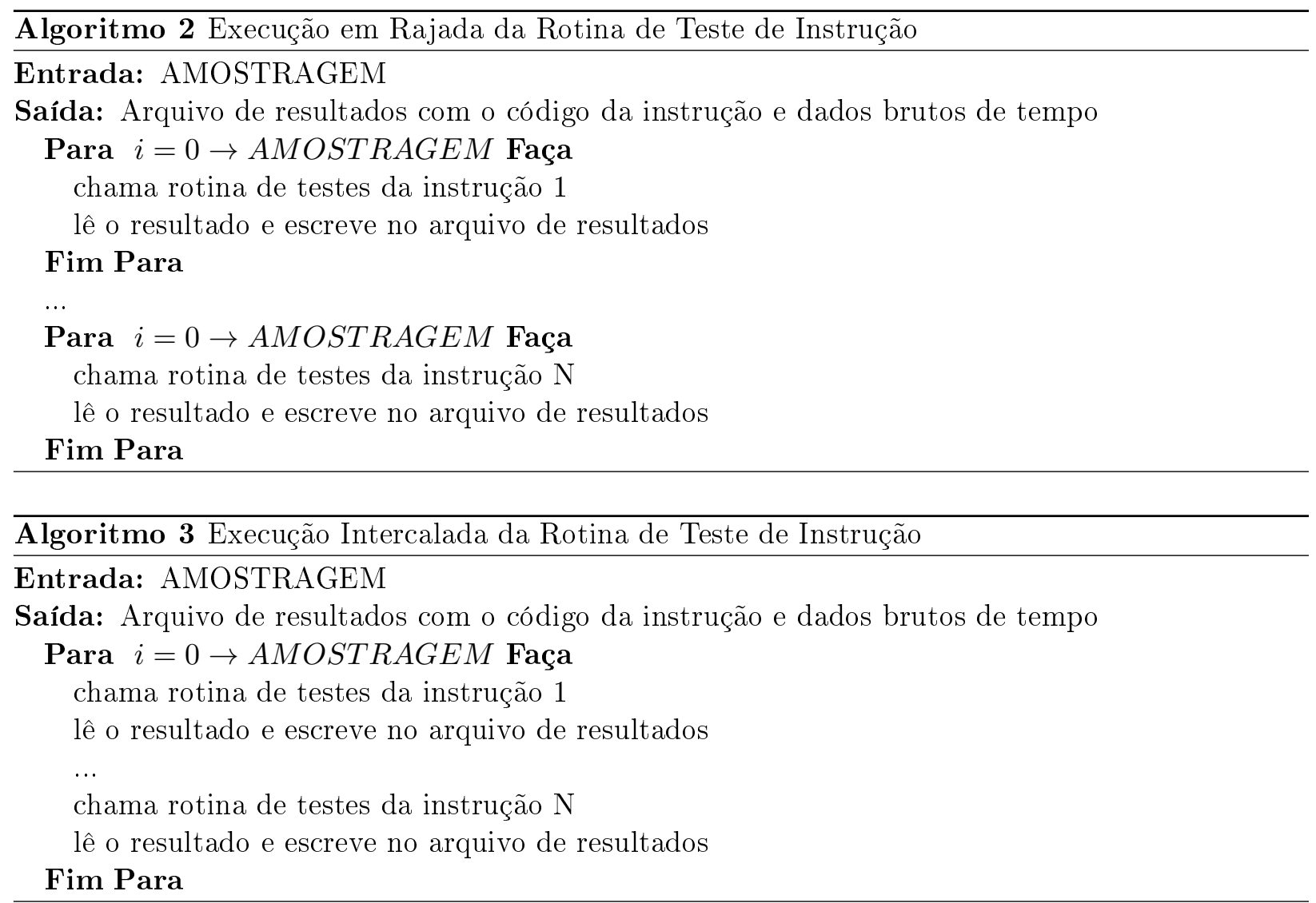

A definição de como fazer a chamada dos testes é feita na linha de comando através de opções distintas (detalhes sobre as opções de execução na seção 6.2.1). A chamada de forma intercalada permite minimizar o efeito do cache de memória, existente na arquitetura FERMI. Independente de qual a forma de executar o teste, os resultados terão um identificador sequencial da execução e aparecerão no arquivo de saída na ordem de execução do teste.

\subsubsection{Opções de Configuração do Gerador de Microbenchmark}

Para controlar o processo de criação do executável do microbenchmark foram criadas algumas opções que podem tanto ser definidas na linha de comando como em um arquivo de configuração.

O formato do arquivo de configuração será explicado em seguida e as opções de configuração estão listadas abaixo, juntamente com a sua chave de linha de comando: 
- a - definir o arquivo de entrada com as instruções PTX a serem testadas.

- f - definir o arquivo de configuração da criação do microbenchmark.

- $\mathbf{l}$ - definir o arquivo para a listagem das instruções PTX geradas.

- $\mathbf{k}$ - definir o total de instruções consecutivas no trecho de teste.

- c - definir o tipo de leitura de clock a ser usado na criação do microbenchmark.

- $\mathbf{m}$ - definir o tipo de teste para a instrução mov.

- p - definir a Compute Capability da Arquitetura Virtual (PTX) usada na criação do microbenchmark.

- s - definir a Compute Capability da Arquitetura Real, SM, usada na criação do microbenchmark.

- d - definir o nível das mensagens de debug durante a criação do microbenchmark.

A opção -a indica o nome do arquivo com as definições das instruções a serem testadas. Esse arquivo é definido como explicado na seção 6.1.2.

Já a opção -f indica o arquivo com as configurações para a criação do microbenchmark. O formato desse arquivo é mostrado na seção 6.1.4.

Com a opção -l é definido o nome do arquivo que irá conter uma listagem de controle das instruções que foram expandidas. Para cada instrução gerada teremos duas linhas nesse arquivo. A primeira linha contém o número sequencial da expansão (iniciando em zero) e a indicação da sua arquitetura virtual e real. $\mathrm{Na}$ segunda linha temos a listagem da expansão dessa instrução, com o seu opcode e os tipos de dados utilizados. A seguir temos um exemplo da listagem de duas instruções desse arquivo:

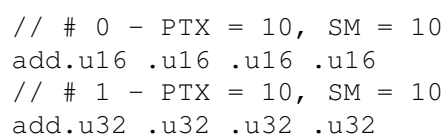

Para poder controlar a quantidade de instruções consecutivas no trecho de teste, a opção -k é definida com um número de 1 a 10 . Esse será o total de instruções avaliadas no teste e deverá ser considerado no momento de calcular o tempo médio. Essa opção também é interessante para verificar como o pipeline reage à repetição de uma dada instrução.

A chave de linha de comando -c permite escolher entre as seguintes formas de leitura do registrador \%clock:

- valor 1 - faz duas leituras, uma antes do trecho de teste e uma depois. Essa leitura é feita uma vez por warp na thread número 0.

- valor 2 - faz duas leituras, uma antes do trecho de teste e uma depois. Essa leitura é feita em todas threads do warp.

- valor 4 - faz quatro leituras, uma no inicio da thread, uma antes do início do trecho de teste, outra no fim desse trecho e a última no fim da thread. Essa leitura é feita em todas threads do warp.

- valor 5 - o mesmo que a opção 2, porém, adiciona duas instruções mov para equalizar o pipeline.

A forma de leitura da opção 1 da chave -c é a mesma utilizada no exemplo clock (programa 
clock_kernel.cu) do SDK 4.1 do Toolkit da NVIDIA. O código para verificar qual a thread que irá fazer a leitura adiciona algumas instruções no kernel.

A opção -c 2 é praticamente o mesmo código, porém, sem o teste de qual thread irá fazer a leitura do registrador.

Como já comentado, a opção -c 4, é útil para entender o escalonamento dos warps e foi muito utilizada durante os trabalhos de teste. Para os resultados finais ela não deve ser utilizada porque as duas leituras extras do registrador $\circ \mathrm{clock}$ alteram os resultados obtidos no teste.

A opção -c 5 foi criada para resolver alguns problemas de execuções, com uma instrução no trecho de teste e grandes quantidades de threads, que geravam resultados negativos. Essa opção adiciona duas instruções mov após a leitura do registrador de ․clock (da mesma forma que o compilador da NVIDIA) e aparentemente se adequa melhor ao funcionamento do pipeline. Essa foi a opção mais utilizada nos testes e seu código está mostrado no apêndice C.

Trabalhando somente com a instrução mov, a opção -m, altera a forma como são utilizados os dados no trecho de teste. Essa necessidade apareceu durante a validação e o seu objetivo foi obter valores mais coerentes com a forma como o compilador utiliza a instrução mov. Mais detalhes podem ser vistos na seção 7.2.3.

Essa opção, com o valor igual a zero, faz com que a origem dos dados e o destino estejam em vetores diferentes e que não haja dependência entre os dados de duas instruções consecutivas. Essa é a mesma forma que todas as instruções são testadas. Por outro lado, com o valor 1 para essa opção, a montagem do trecho de teste segue o exemplo a seguir (mostrado para o caso de dez instruções no trecho), onde é usado o mesmo vetor e existe dependência entre os dados de testes consecutivos:

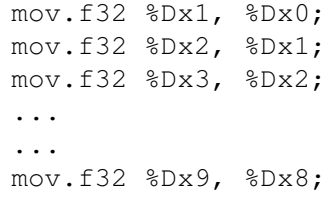

Por fim, as opções -p -s -d são auto explicativas.

\section{Formato do Arquivo de Configuração do Gerador de Microbenchmark}

O arquivo de configuração é definido através da opção de linha de comando -f e contém um comando por linha. As linhas iniciadas com o caractere \# são tratadas como comentários.

Os comandos aceitos no arquivo de configuração estão listados abaixo, juntamente com a equivalência da opção de linha de comando:

- ArquivoListagem [-1] - nome do arquivo no qual será feita a listagem das instruções criadas.

- DefinicaoInstrucoes [-a] - nome do arquivo que contém a listagem das instruções a serem testadas.

- ptx [-p] - valor com dois dígitos que indica a compute capability da arquitetura virtual.

- sm [-s] - valor com dois dígitos que indica a compute capability da arquitetura real.

- debug [-d] - um dígito que define o nível de detalhes das mensagens de debug.

- unroll [-k] - valor entre 1 e 10 que define o total de instruções no trecho de teste.

- clock [-c] - valor 1, 2, 4 ou 5 que define a forma de leitura do registrador oclock. 
- $\operatorname{mov}[-\mathbf{m}]$ - valor 0 ou 1 que define a forma do teste da instrução mov.

Os nomes dos comandos podem ser em letras maiúsculas, minúsculas ou uma combinação delas. Deve haver um comando por linha e ser seguido por um ou mais espaços (ou tabulações) e pelo argumento. Os argumentos utilizados no arquivo de configuração são exatamente os mesmos das opções de linha de comando que estão descritos no início desta seção.

\subsubsection{Compilação do Microbenchmark}

Como vimos anteriormente, temos duas etapas para a criação do executável do microbenchmark, sendo a primeira a execução do gerador de aplicativos baseada no arquivo de definição de instruções desejado e a segunda a compilação do resultado dessa geração. O resultado do gerador é constituído basicamente por quatro arquivos fonte:

- arquivo com o código das rotinas que executam na CPU.

- arquivo com o código das rotinas que executam na GPU.

- arquivo com o código das rotinas de leitura das propriedades da GPU.

- arquivo de header ${ }^{13}$.

Os dois primeiros arquivos, levam em seu nome a caracterização da arquitetura virtual e real com que foram criados. Isso é feito com a sequência PTXNN-SMNN, onde NN indica a compute capability utilizada para a arquitetura virtual (PTX) e real (SM). Por exemplo, o resultado de uma geração de aplicativo para arquitetura virtual 1.0 e arquitetura real 1.2 seriam os seguintes quatro arquivos:

1. microbench-instrucoes-PTX10-SM12.cu

2. codigo-PTX10-SM12.cu

3. rotinasPropriedadesCUDA.cu

4. microbench.h

O processo de compilação desses arquivos respeita as definições de arquitetura virtual e real selecionadas durante a geração dos fontes. Ou seja, é passado explicitamente para o compilador da NVIDIA, o nvcc, a arquitetura real e virtual que ele deve usar na compilação.

O processo de compilação também possui uma etapa que tem por finalidade obter informações das rotinas executadas na GPU e a partir delas modificar o próprio código fonte (mais especificamente, o arquivo de header microbench.h). A sequência de compilação do microbenchmark está na figura 6.4 mostrada a seguir.

Isso é feito para poder disponibilizar, em tempo de execução, informações que são geradas durante o processo de compilação. Esse é o caso da informação sobre utilização de memória compartilhada e registradores pelas rotinas CUDA. Essa informação é útil no momento da execução para orientar sobre os limites (em total de threads) de execução dos testes.

Para obter esses valores é feita a compilação do arquivo codigo-PTXNN-SMNN. cu com a opção -Xptxas -v, que mostra as estatísticas de geração do código na tela. Essas estatísticas incluem o total utilizado com registradores e memória compartilhada para cada rotina em CUDA $\mathrm{C}$ do fonte compilado. A seguir temos um exemplo do tipo de saída gerado por essa opção:

ptxas info: Compiling entry function '_z13executaAddu32Pli' for 'sm_12'

ptxas info: Used 13 registers, 12+16 bytes smem, 20 bytes cmem[1]

\footnotetext{
${ }^{13}$ cabeçalho - arquivo com definições necessárias à compilação do programa em $\mathrm{C}$ ou CUDA C
} 


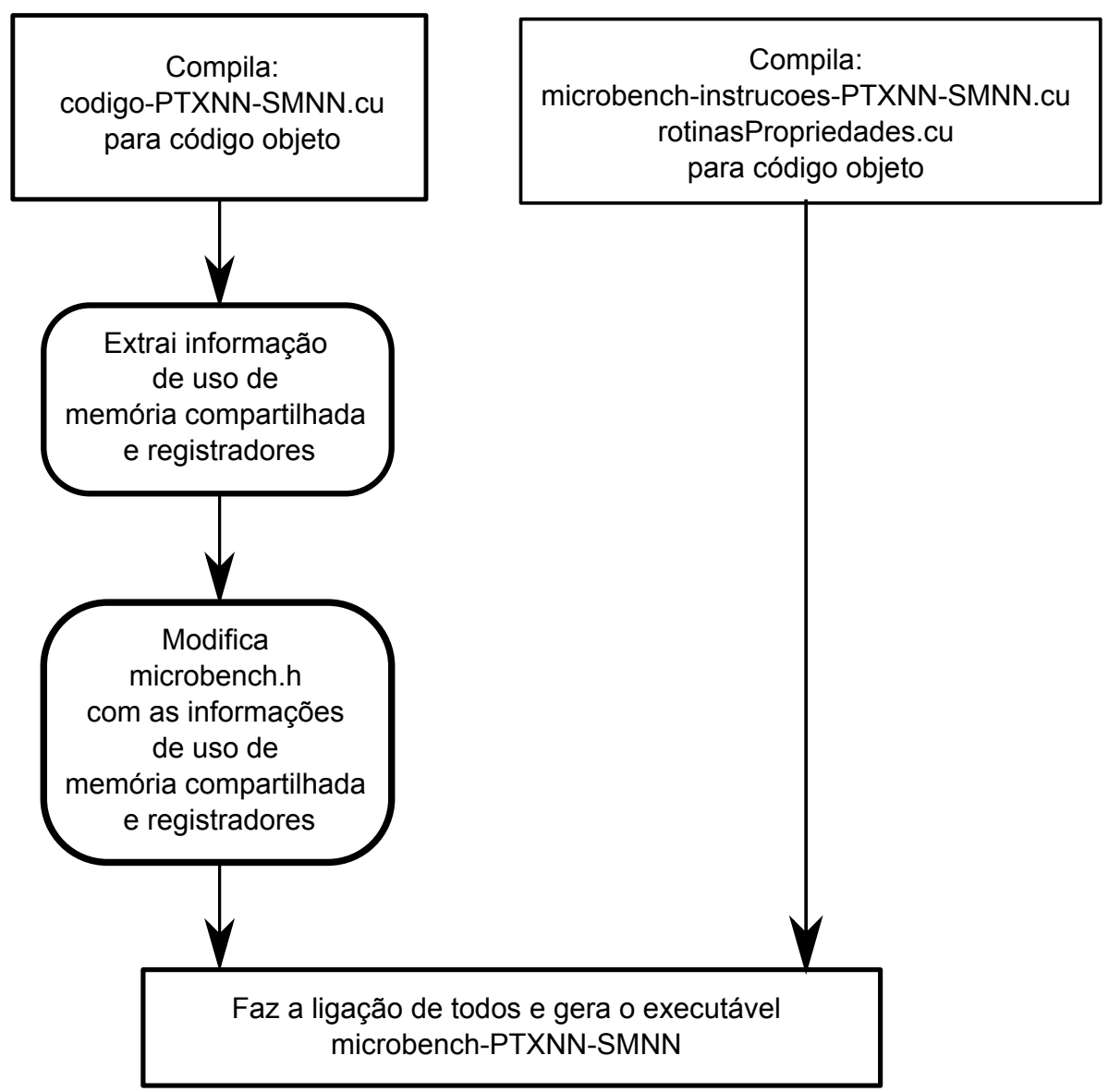

Figura 6.4: Sequência de etapas da compilação do microbenchmark.

Para fazer uso futuro desses dados, a informação da tela é redirecionada para um arquivo que será analisado na etapa seguinte. Essa análise compreende a varredura do arquivo para obter os maiores valores tanto de uso de memória compartilhada quanto de registradores. Esses valores são inseridos no microbench.h e assim podem ser utilizados durante a execução do microbenchmark.

Esses valores são inseridos como comandos \# define da linguagem $\mathrm{C}$ como mostrado a seguir:

\#define MAXREG 21

\#define MAXSHARED 28

O cálculo do maior número de threads executáveis é feito em tempo de execução e compreende três etapas. A primeira é a divisão do total de memória disponível na GPU (em que será executado o teste) pelo total de memória utilizada pela rotina; a seguir a divisão do total de registradores disponíveis na GPU pelo total de registradores utilizados pela rotina; e por fim utiliza-se o menor número de threads que se obteve nessas duas divisões. No caso do microbenchmark, esses cálculos não são feitos rotina a rotina e sim com os maiores usos de recursos. Dessa forma, consegue-se um limite onde todas as rotinas serão executadas sem problemas com falta de recursos.

Esse recurso é utilizado para uma comparação da resposta das instruções em condições iguais. Porém, se o intuito é saber o máximo possível sobre o perfil da execução dessas instruções, de acordo com a quantidade de threads executada, basta chamar o microbenchmark com o valor de threads desejado. Se alguma rotina não puder ser executada devido a falta de recursos, somente os seus valores serão omitidos do arquivo de saída.

Outro detalhe importante, utilizado durante a compilação, envolve as opções de otimização do código. Durante todo este trabalho desabilitamos as otimizações o máximo possível, apesar de que, mesmo assim, o compilador continua otimizando o uso de recursos. No arquivo Makefile usamos 
a opção de não otimizar tanto o código da CPU quanto o código da GPU. No caso da GPU, isso é feito através da chave de debug - $\mathrm{g}$ com visto a seguir:

OPTIONS $=-g-G-O 0-$ arch=compute_10 -code=sm_20

\subsection{Executável do Microbenchmark}

Uma vez gerado o executável do microbenchmark, a próxima etapa é a sua execução para obter os valores de tempo das instruções desejadas. Para tanto, ele possui algumas opções de linha de comando que controlam a forma de realizar os testes. Essas opções são mostradas a seguir, juntamente com o formato do arquivo de saída que será utilizado durante o pós processamento.

\subsubsection{Opções de Configuração do Executável do Microbenchmark}

O microbenchmark possui as seguintes opções de linha de comando:

- -a total de amostragens (execução em rajada) dos testes a serem executados.

- -d define as mensagens de debug a serem apresentadas.

- -g define a GPU na qual o teste será executado.

- -h mostra o texto de ajuda.

- -i lista as características de todas GPUs instaladas.

- -r executa cudaDeviceReset () após cada teste de instrução.

- -t total de threads que será utilizado na execução de cada teste.

- -x total de iterações (execução intercalada) dos testes a serem executados.

Como foi explicado na seção 6.1.3, a execução dos testes das instruções pode ser feita de forma sequenciada (em rajada) ou de forma intercalada. Isso é feito através das opções auto excludentes -a ou $-\mathrm{x}$.

A opção de mensagens de debug pode ser omitida e consequentemente não haverá mensagem além dos erros graves. Conforme o valor atribuído (de 1 a 9 ) teremos mensagens cada vez mais detalhadas, indicando os processos executados.

Para máquinas que possuem mais do que uma GPU instalada, a opção -g permite escolher em qual delas o teste será executado. Na omissão dessa opção, a escolha vai para a GPU de número zero. A opção é feita com o número da GPU que pode ser obtido através da opção -i.

Além de mostrar as características de todas as placas GPUs instaladas, a opção -i também exibe informações sobre os recursos de registradores e memória compartilhada, juntamente com o valor máximo de threads em que haverá execução de todas as instruções testadas.

Devido a um teste específico, durante este trabalho, foi necessário fazer a limpeza de contexto ${ }^{14}$ da placa GPU a cada teste de instrução. Para atender a essa necessidade foi criada a opção -r, que executa uma chamada de API para a função cudaDeviceReset () a cada teste de instrução. A função cudaDeviceReset () destrói o contexto primário da GPU em uso e desaloca toda a memória previamente alocada (NVIDIA, 2011d, p. 20 e 124).

\footnotetext{
${ }^{14} \mathrm{O}$ contexto em CUDA é análogo ao processo na CPU - ver (NVIDIA, 2011d, p. 59).
} 
Com o intuito de traçar um perfil da execução da instrução, foi criada a opção -t, que define o total de threads com que o teste será executado. Em geral, os testes são feitos com múltiplos de 32 threads, ou seja, com warps inteiros. Porém, nada impede a execução de um teste com uma única thread ou com frações de warps. Esses testes são interessantes para intuir os ganhos de escala na execução da GPU.

Na opção -h, além de mostrar o texto de ajuda, explicando as opções existentes, também informa a arquitetura real e virtual utilizada na geração do microbenchmark.

O mínimo de opções de execução do teste são a quantidade de threads a utilizar e o total de iterações ou amostragens executadas. Para a grande maioria dos testes essas duas opções bastam.

\subsubsection{Arquivo de Saída do Microbenchmark}

Ao término da execução do microbenchmark, temos um arquivo de resultados que pode ser dividido em duas partes, o cabeçalho e os resultados. O cabeçalho é constituído por uma listagem de algumas informações sobre o teste e sobre a placa GPU onde ele ocorreu. Já nos resultados temos, para cada amostragem ou iteração, uma listagem dos tempos da primeira thread de cada warp executado.

\section{Cabeçalho do Arquivo de Saída}

Para ajudar a identificar o teste que foi realizado, temos no cabeçalho algumas informações sobre o número de threads usado na execução; sobre o total de instruções dentro do trecho de teste; sobre o total de amostragens executadas; sobre a arquitetura real e virtual utilizadas. Além desses, temos o tipo de leitura do registrador oclock utilizado e o total de instruções avaliadas. Essas informações estão contidas nas 5 linhas iniciais do cabeçalho e podem ser vistas na listagem a seguir:

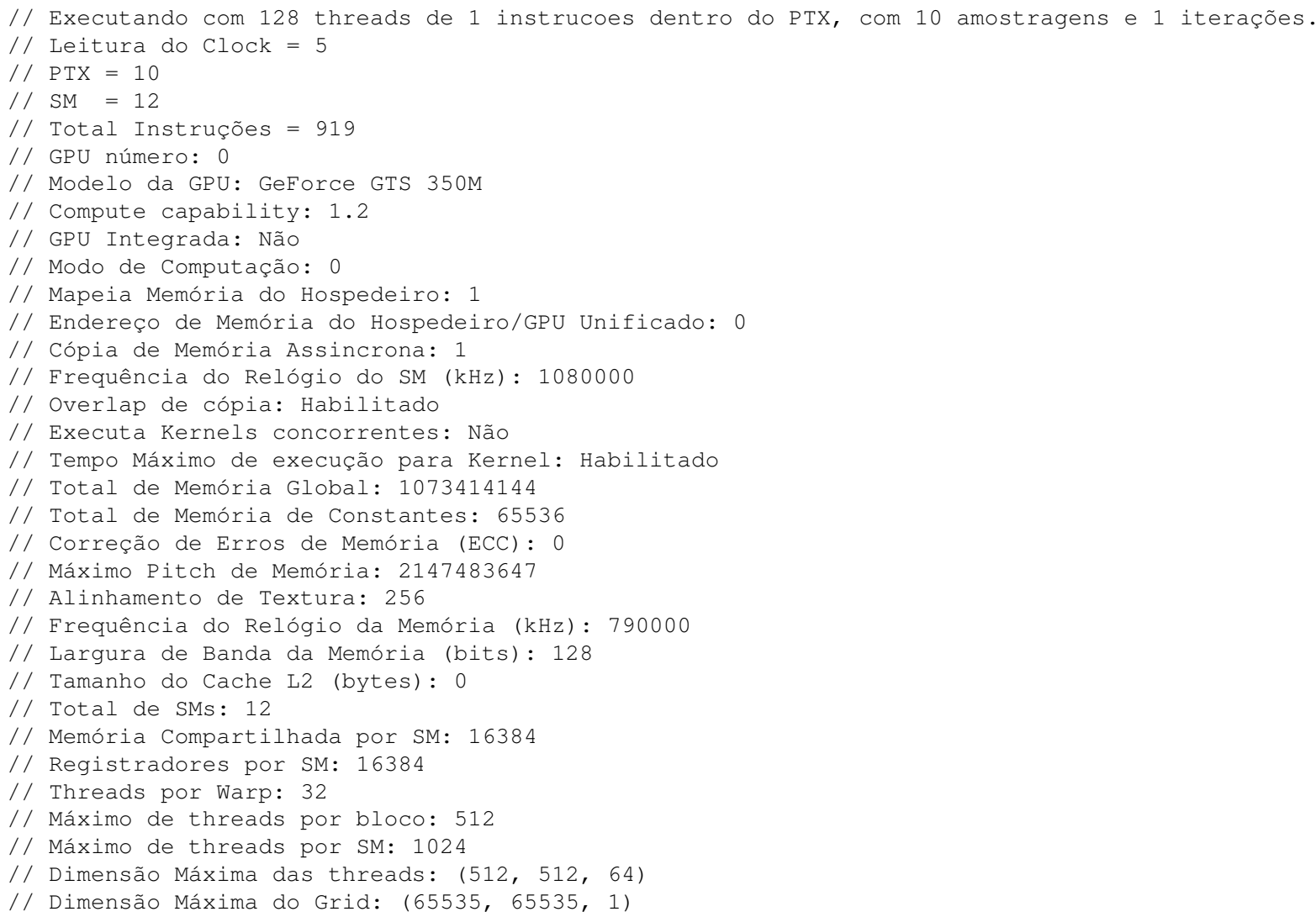


As informações sobre a placa GPU, na qual o teste foi executado, se iniciam na sexta linha e vão até o fim do cabeçalho. Elas são obtidas pela chamada de API cudaGetDeviceProperties, que retorna uma estrutura de dados com as características da placa. Essa estrutura de dados está documentada no manual de referência da API do CUDA ((NVIDIA, 2011c, p. 18)).

Apesar de não utilizar todas as informações listadas, elas foram mantidas para auxiliar na identificação da estrutura da placa em uso e para um eventual uso futuro. Das informações utilizadas, vale mencionar o total de memória e registradores; o modelo da placa utilizada; o número dessa placa dentro do computador hospedeiro (que inicia em zero) e sua compute capability.

Uma informação importante que está no cabeçalho e não foi utilizada neste trabalho é a frequência do relógio dos SMs. Ela pode ser utilizada para transformar os valores lidos pelo microbenchmark (dados em unidades de transição do relógio) para uma unidade de tempo.

\section{Listagem dos Tempos de Execução}

Os resultados das leituras do microbenchmark aparecem no arquivo de saída na mesma ordem em que os testes foram realizados. Esses resultados ocupam várias linhas e o total depende da quantidade de threads com que o teste foi executado.

A primeira linha informa a instrução testada (através de seu mnemônico) e o número da amostragem (teste em rajada) ou iteração (teste intercalado).

Nas linhas seguintes estão as leituras para a primeira thread de cada warp. Esses valores estão representados em seis colunas, com o seguinte significado para cada coluna:

- Coluna 1: número da thread (sempre a primeira do warp)

- Coluna 2: leitura do início da thread

- Coluna 3: leitura do início do trecho de teste

- Coluna 4: leitura do fim do trecho de teste

- Coluna 5: leitura do fim da thread

- Coluna 6: diferença entre o fim e início do trecho de teste.

Conforme o tipo de teste executado, os valores das colunas dois e cinco podem aparecer com resultado zero. Isso significa que houve somente duas leituras do registrador de $\circ$ clock, uma antes e uma depois do trecho de teste. Para ter um único formato de arquivo de saída, optou-se por manter a coluna com valor zero. Para verificar se houve um erro de leitura ou se o teste não executou a leitura, basta comparar esses resultados com a informação do cabeçalho sobre o tipo da leitura do ○clock utilizada.

A seguir é mostrado um exemplo de arquivo de saída de resultados, executado com opção de teste em rajada (amostragens):

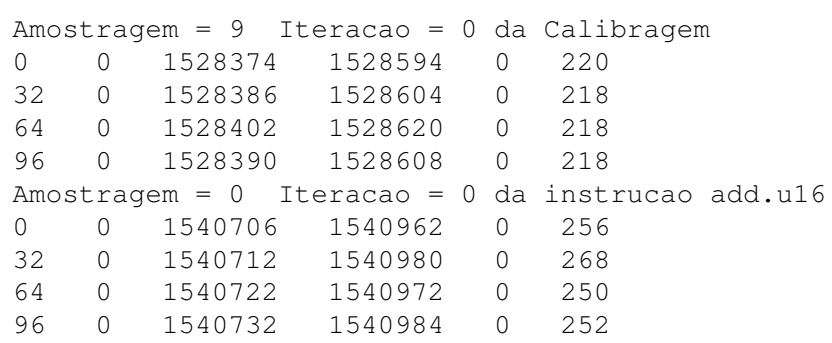

Apesar da informação sobre o tipo de teste (amostrado ou iterado) estar presente no cabeçalho, ela 
foi repetida na identificação da instrução para evitar que fosse perdida durante algum pós processamento que removesse o cabeçalho. Neste exemplo, que é um teste em rajada (amostrado), pode-se ver que a indicação da amostragem é alterada, enquanto que o número da iteração permanece fixo em zero.

No exemplo a seguir temos um este iterado, onde o valor da amostragem permanece zero e o da iteração é alterado.

\begin{tabular}{|c|c|c|c|c|c|}
\hline & & $m=0$ & $\operatorname{acao}=$ & $d \bar{c}$ & $\mathrm{Ca}$ \\
\hline 0 & 0 & 5966288 & 5966508 & 0 & 220 \\
\hline 32 & 0 & 5966300 & 5966518 & 0 & 218 \\
\hline 64 & 0 & 5966316 & 5966534 & 0 & 218 \\
\hline 96 & 0 & 5966304 & 5966522 & 0 & 218 \\
\hline Amc & $\operatorname{tra}$ & $\mathrm{em}=0$ & eracao $=$ & $\mathrm{da}$ & instrucao add.u16 \\
\hline 0 & 0 & 5943108 & 5943362 & 0 & 254 \\
\hline 32 & 0 & 5943116 & 5943380 & 0 & 264 \\
\hline 64 & 0 & 5943134 & 5943386 & 0 & 252 \\
\hline 96 & 0 & 5943126 & 5943372 & 0 & 246 \\
\hline
\end{tabular}

\subsection{Pós Processamento do Microbenchmark}

Como o arquivo de saída do microbenchmark é um arquivo de texto, o pós processamento foi feito em linguagem $\mathrm{AWK}^{15}$. Isso permitiu uma grande flexibilidade e agilidade na implementação de testes.

O principal resultado do pós processamento é a obtenção do tempo médio e variância de cada instrução testada, porém, também foram levantados dados do perfil de desempenho para cada instrução, considerando-se a quantidade de threads executadas e o total de instruções no trecho de teste.

\subsubsection{Obtenção do Tempo Médio}

Como visto na seção 6.1.3, o trecho de teste é executado entre duas leituras do registrador de ○clock e portanto, o tempo gasto na leitura desse registrador está embutido no resultado obtido. Isso pode ser visto na expressão abaixo:

$\mathrm{T}_{\text {lido }}=\mathrm{T}_{\text {execucao_instrucoes }}+\mathrm{T}_{\text {execucao_leitura }}$

Para conseguir um resultado mais preciso é necessário descontar o valor de tempo gasto com o processo de leitura do resultado total lido. O tempo gasto no processo de leitura é obtido através de uma rotina de teste especial, chamada de calibragem. Ela não possui nenhum código dentro do trecho de teste e reflete o tempo gasto com a leitura do registrador de \%clock.

O tempo líquido de todas as instruções do trecho de teste é dado por:

$\mathrm{T}_{\text {execucao_instrucoes }}=\mathrm{T}_{\text {lido }}-\mathrm{T}_{\text {execucao_leitura }}$

Como o tempo de execução da leitura é o tempo obtido pela rotina de calibragem, ficaríamos com :

$\mathrm{T}_{\text {execucao_instrucoes }}=\mathrm{T}_{\text {lido }}-\mathrm{T}_{\text {calibragem }}$

Assim, para cada amostragem ou iteração de teste, é executada uma calibragem, que é utilizada

\footnotetext{
${ }^{15}$ Linguagem de programação criada por Alfred V. Aho, Peter J. Weinberger e Brian W. Kernighan para processamento de dados baseado em texto. A ideia básica dessa linguagem é a busca de padrões, definidos como expressões regulares, no arquivo de entrada e para cada padrão encontrado, é executada a ação programada. Para detalhes, veja http://www.gnu.org/software/gawk/manual/gawk.html
} 
para ajustar os valores lidos.

Como o interesse está no tempo de execução de uma única instrução, ainda devemos dividir o tempo obtido pelo total de instruções no trecho de teste:

$\mathrm{T}_{\text {execucao_uma_instrucao }}=\frac{T_{\text {lido }}-T_{\text {calibragem }}}{\text { numero_instrucoes_trecho }}$

Esse cálculo é feito para cada amostragem, de cada instrução. Também é calculada a média e variância por instrução.

Todo esse procedimento descrito considera a execução de um único warp. A diferença para a execução com vários warps é que o tempo inicial e final precisam ser considerados de forma distinta. Para o valor de início é necessário verificar qual o menor valor inicial entre todos os warps. E da mesma maneira, para o valor final é necessário verificar qual o maior valor final entre todos os warps. Isso é mostrado na figura 6.5.

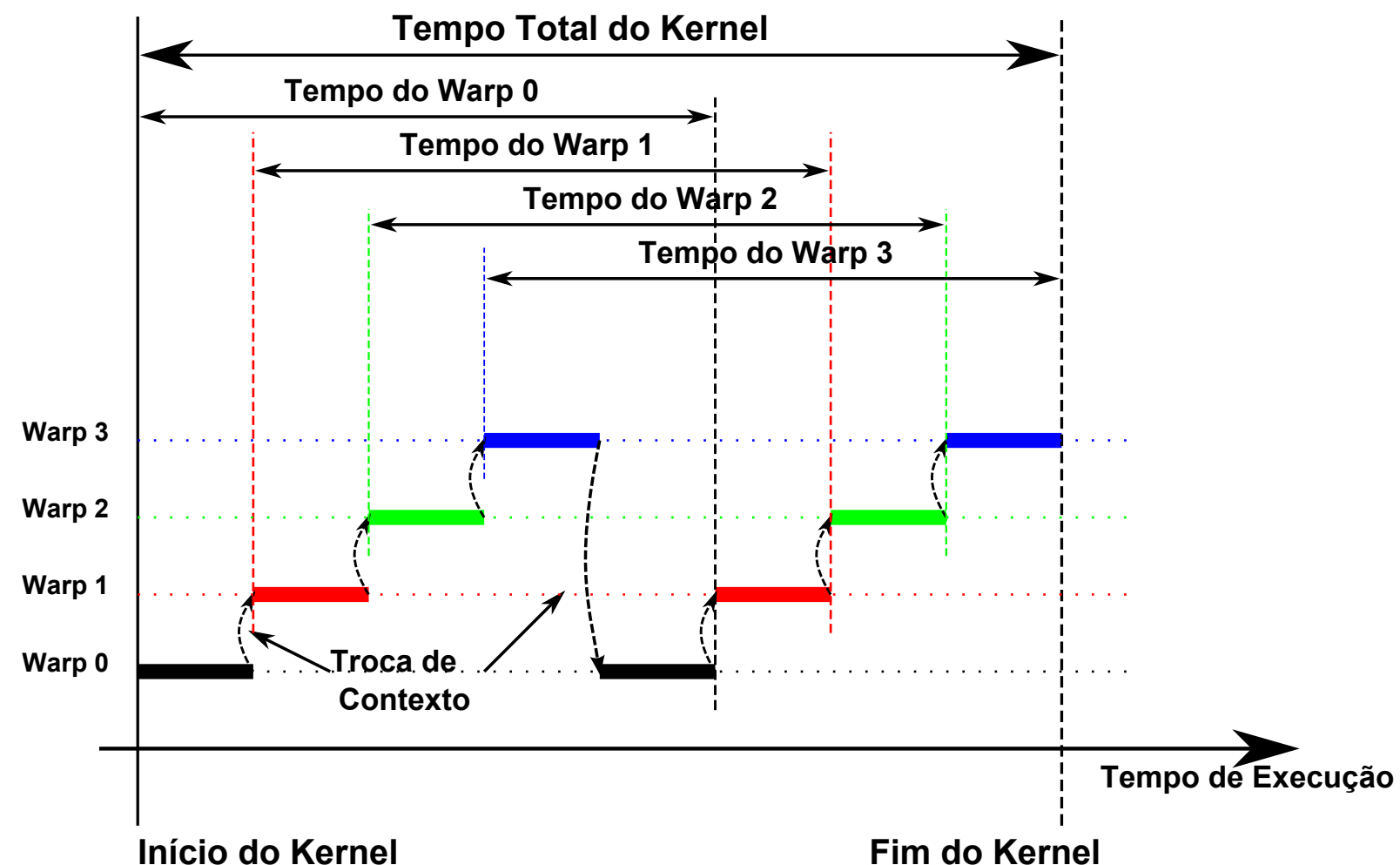

Figura 6.5: Contabilização do tempo inicial e final com a execução de quatro warps.

\section{Consistência das Leituras}

É necessário verificar a consistência dos valores obtidos pelo microbenchmark, principalmente em função do sistema de leitura do registrador ${ }^{\circ} \mathrm{clock}$. Como esse registrador é um contador circular, podemos ter o valor da leitura inicial maior do que o valor da leitura final. Isso significa que entre as duas leituras o contador passou por zero. Nesse caso, antes de fazer a diferença dos valores final e inicial, deve-se adicionar ao valor final um total de $2^{32}$, que é o valor máximo de contagem.

Como o tempo equivalente a $2^{32}$ ciclos de relógio é muito superior ao tempo de execução de 10 instruções seguidas (caso máximo), não existe a possibilidade do contador passar por zero mais do que uma vez e portanto, essa solução é adequada.

Outro problema que é verificado no pós processamento é a concomitância entre a execução do trecho de teste e o acesso à memória global. Essa ocorrência invalida o teste, uma vez que os warps que 
acessam a memória são retirados do conjunto em execução e, consequentemente, o escalonamento é afetado. Isso altera o resultado do teste pois teremos um total de threads executando diferente do qual foi especificado na chamada do microbenchmark.

\subsubsection{Perfil de Desempenho das Instruções}

Para levantar o perfil de desempenho das instruções é feita uma bateria de testes. Ela obtém os resultados de tempo para cada instrução em função do total de instruções no trecho de teste, do total de warps executados no teste e do total de amostragens.

Esse levantamento permite observar a forma como o pipeline reage à repetição das instruções em sequência (definido pelo total de instruções no trecho de teste) e como reage ao aumento de threads em execução.

A estrutura básica desse teste é mostrada no algoritmo 4 apresentado a seguir.

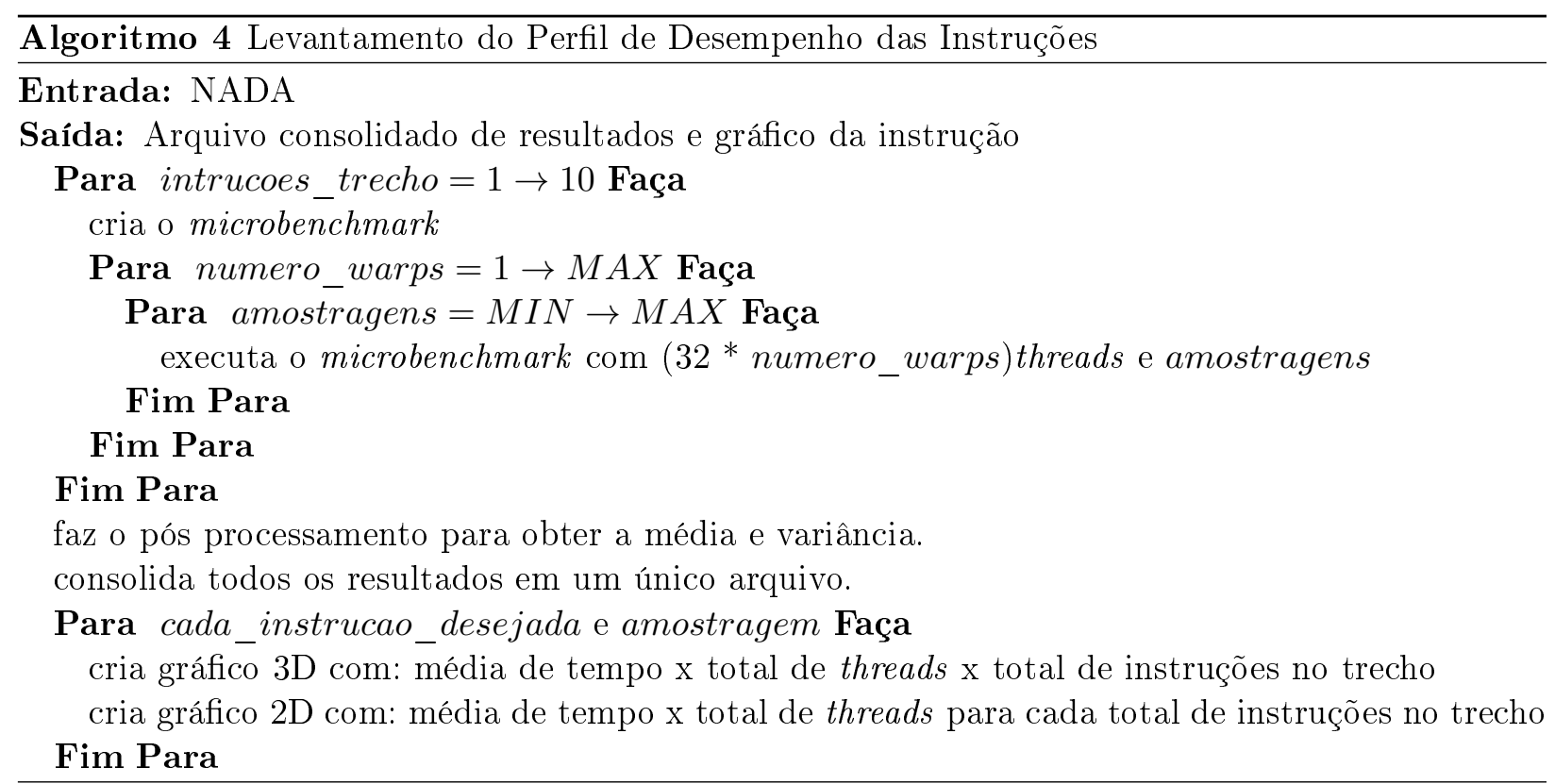

\subsubsection{Arquivo de Saída do Pós Processamento}

Para os testes realizados neste trabalho tivemos dois tipos de arquivos de saída. O primeiro contém os resultados de média e variância para um conjunto de instruções (um único teste). O segundo tipo é o resultado consolidado de uma quantidade maior de testes, que se refere ao levantamento do perfil de desempenho.

\section{Saída de um Teste Individual}

No arquivo de saída de um único teste a organização é similar a do aquivo de saída do microbenchmark, inclusive com a presença do mesmo cabeçalho. Porém, a diferença está na apresentação dos resultados por instrução, que segue o formato mostrado a seguir:

$\begin{array}{lcccccc}\text { \# Instrução } & \text { Média } & \text { Variância } & \text { Desvio Padrão } & \text { CV } & \text { Menor } & \text { Maior } \\ \text { abs.f32 } & 20 & 0 & 0 & 0 & 266 & 266 \\ \text { abs.ftz.f32 } & 20 & 0 & 0 & 0 & 266 & 266 \\ \text {. . } & 246 & 0 & 0 & 0 & 246 & 246\end{array}$


Para identificar cada instrução é utilizado o seu mnemônico, que é seguido pelos valores da média, variância e desvio padrão obtidos. Também temos o coeficiente de variação ${ }^{16}$ e o maior e menor valores brutos ${ }^{17}$ obtidos.

\section{Saída do Perfil de Desempenho}

Como no arquivo individual, no resultado consolidado temos o mesmo cabeçalho dos testes do microbenchmark. Ele é seguido pelas informações sobre as instruções (identificada pelo seu mnemônico), que estão organizadas pelo total de instruções no trecho de teste (em ordem decrescente); pelo total de threads (em ordem crescente) e pelo total de amostragens (em ordem decrescente). As colunas seguintes são as mesmas do arquivo de teste individual, ou seja, a média, a variância, o desvio padrão, o coeficiente de variação e o menor e maior valores brutos obtidos.

Na listagem a seguir temos a forma de apresentação do arquivo consolidado:

\begin{tabular}{|c|c|c|c|c|c|c|c|c|c|}
\hline $\begin{array}{l}\text { \# Instrução } \\
\text { calibragem } \\
\text { shr.b64 }\end{array}$ & $\begin{array}{c}\text { TRECHO } \\
10 \\
10\end{array}$ & $\begin{array}{l}\text { Threads } \\
32 \\
128\end{array}$ & $\begin{array}{c}\text { Amostragem } \\
100 \\
100\end{array}$ & $\begin{array}{r}\text { Média } \\
78 \\
200.904\end{array}$ & $\begin{array}{r}\text { Variância } \\
0 \\
5.22278\end{array}$ & $\begin{array}{c}\text { Desvio Padrão } \\
0 \\
2.28534\end{array}$ & $\begin{array}{r}C V \\
0 \\
1.13753\end{array}$ & $\begin{array}{r}\text { Menor } \\
78 \\
2082\end{array}$ & $\begin{array}{r}\text { Maior } \\
78 \\
2256\end{array}$ \\
\hline$\cdots$ & & & & & & & & & 204 \\
\hline $\begin{array}{c}\text { mov.u64 } \\
\text {... } \\
\text { sub.u32 }\end{array}$ & 10 & $\begin{array}{l}128 \\
128\end{array}$ & 100 & 12 & 0 & 0 & 0 & 144 & 144 \\
\hline $\begin{array}{l}\cdots \\
\ldots\end{array}$ & & & & & & & & & \\
\hline min.ftz.f 32 & 4 & 96 & 10 & 6.75 & 0.5625 & 0.75 & 11.1111 & 106 & 112 \\
\hline $\begin{array}{c}\cdots \\
\text { calibragem }\end{array}$ & 2 & 448 & 100 & 138.46 & 34.0684 & 5.83681 & 4.21552 & 124 & 148 \\
\hline $\begin{array}{c}\cdots \\
\min . s 64\end{array}$ & 1 & 448 & 3 & 64 & 0 & 0 & 0 & 188 & 188 \\
\hline $\begin{array}{l}\text { alibragem } \\
\text { albra }\end{array}$ & 1 & 384 & 1 & 104 & 0 & 0 & 0 & 104 & 104 \\
\hline
\end{tabular}

\subsection{Problemas Encontrados}

Entre os problemas encontrados, alguns se destacaram tanto por definirem uma mudança na estratégia de teste como por serem um limitante na precisão dos resultados obtidos.

Durante o processo de criação da estrutura do microbenchmark, as otimizações executadas pelo compilador foram o maior fator a ser contornado. Porém, isso levou a uma análise comparativa entre o código executável da GPU e o código PTX, o que se revelou de grande auxílio posteriormente.

Um dos primeiros problemas de execução foi a utilização de uma placa GPU não dedicada ao cálculo, mas, também utilizada para gerar o vídeo do computador hospedeiro. A interferência entre essas funções gerou diferenças nos resultados.

Numa etapa posterior, a análise dos resultados levou à análise do escalonamento dos warps e sua influência nos tempos obtidos. A seguir veremos cada um desses problemas.

\footnotetext{
${ }^{16}$ Medida de dispersão formada pela divisão do desvio padrão pela média. É utilizado para comparar os resultados de distribuições diferentes.

${ }^{17}$ Valor sem o desconto da calibragem.
} 


\subsubsection{Interferência da Geração de Vídeo}

O início do desenvolvimento foi feito em um computador portátil ${ }^{18}$ com uma placa GPU interna. A ideia inicial era executar cada teste e fazer a saída dos resultados diretamente na tela. Assim, quando fosse necessário, seria possível desviar os resultados para um arquivo através de um simples comando de redirecionamento da saída padrão.

Porém, durante uma verificação dos resultados, foi notada uma diferença entre os resultados criados em arquivo para os resultados impressos na tela. Os resultados em arquivo tinham um desempenho melhor que os resultados impressos na tela. Como essa diferença era consistente entre vários testes, começamos a levantar a possibilidade da geração de vídeo do sistema operacional influenciar a execução dos testes.

Um teste que demonstrou essa influência foi a execução do microbenchmark com várias amostragens da mesma instrução e exibindo os resultados na tela. Enquanto esse teste era executado sem nenhuma interferência externa, havia uma variação pequena entre os resultados de execuções consecutivas. Porém, se durante a execução do teste fossem abertas outras janelas, os resultados variavam de forma muito mais significativa.

Apesar de não terem sido levantados os valores ou a diferença de variação, o resultado apontou uma influência da geração de vídeo na execução do microbenchmark. Assim, os testes seguintes foram feitos em outro computador com GPU dedicada ao cálculo e sem funções de geração de vídeo.

\subsubsection{Análise de Código Morto}

Como visto na seção 4.3.1, o processo de compilação faz a remoção do código morto. Essa otimização ajuda na diminuição do uso de registradores, o que é importante para aumentar a quantidade de warps que podem executar num mesmo SM e, consequentemente, aumentar o índice de ocupação.

Segundo o manual de montagem inline da NVIDIA, uma rotina asm ( ) é considerada como somente alterando os seus parâmetros de saída, sem nenhum outro efeito colateral (NVIDIA, 2011b, p. 7, 8). Dessa forma, o compilador pode eliminar todo código que não esteja ligado com a alteração das variáveis de saída. Como uma parte principal do código do microbenchmark é programada em montagem inline, ela sofre com essa otimização.

Apesar de utilizar as opções de compilação sem otimização (-g -G -O0), o compilador continua otimizando o código morto. Para verificar se o resultado da compilação das rotinas de teste era compatível como o desejado, foi feito o disassembly ${ }^{19}$ do código compilado através do programa ob jdump. Esse programa faz a desmontagem do resultado da compilação do código PTX, ou seja, as instruções pertencentes à arquitetura real e que serão executas pelo hardware (NVIDIA, 2011e).

Para contornar essa otimização, a rotina de teste retorna uma variável que é resultado de todo o processo de teste. Assim, mesmo que o teste não utilize esse valor posteriormente, o compilador, que não faz um controle após a saída da rotina asm(), deixa de otimizar as instruções em teste dentro do código inline PTX.

Outro problema encontrado foi a otimização do uso de registradores dentro do código compilado. Ou seja, um mesmo registrador é reutilizado para diminuir o uso desse recurso escasso. Essa reutilização pode gerar uma dependência entre escrita e leitura de um mesmo registrador, o que afeta o tempo de resposta como pode ser visto no capítulo sobre diretivas de desempenho do (NVIDIA, 2011d, p. 91). Como esse processo está fora do controle do programador, não há nada que possa ser feito para

\footnotetext{
${ }^{18}$ Toshiba Satellite modelo A665 com processador Intel I5 M460 a 2,53GHz, 4GB de RAM, com GPU NVIDIA GeForce GTS350M, rodando Linux Ubuntu 10.10

${ }^{19}$ Desmontagem.
} 
evitar esse reuso e eventuais dependências que influenciam o processo de execução no pipeline. Esse fato pode gerar diferenças entre os tempos obtidos com o microbenchmark e em outras execuções da mesma instrução, desde que haja dependência em uma das avaliações e na outra não.

\subsubsection{Código PTX e Código de Máquina}

De acordo com as arquiteturas real e virtual utilizadas, a tradução do código PTX para código de máquina não é necessariamente a conversão de uma instrução PTX para uma instrução de máquina (correspondência direta de instruções). Como foi visto na seção 4.3.4, as características consideradas básicas podem ser emuladas em equipamentos que não possuem esse recurso nativamente (por exemplo, a divisão de 64 bits). Dessa forma, teremos resultados de compilação diferentes conforme as arquiteturas escolhidas. Isso faz com que a geração do microbenchmark tenha que considerar as arquiteturas utilizadas. Assim, não podemos utilizar um resultado de teste de uma dada GPU para qualquer análise indistintamente, mas sim, possuir um repositório com resultados diversos a serem utilizados de acordo com os requisitos da análise a ser feita.

Para exemplificar isso, veremos o resultado da desmontagem da linha de leitura de ciclos de relógio. A seguir temos o código em PTX para a leitura o registrador especial de ciclos de relógio :

mov.u32 \%0, %clock;

Essa única linha, se compilada para arquitetura real e virtual 1.0 com a otimização totalmente desligada, gera o seguinte código de máquina, obtido pelo objdump:

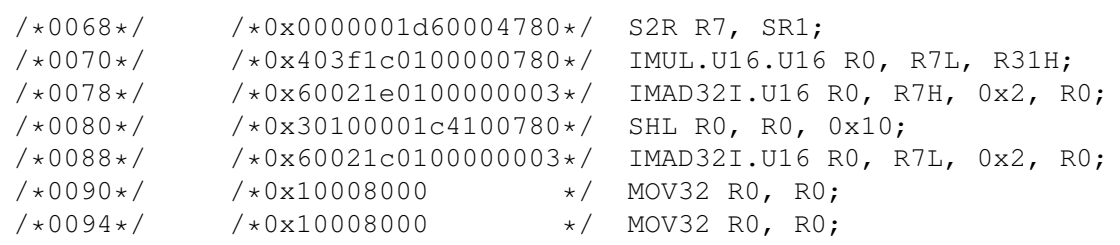

Apesar de ser escassa a documentação sobre essas instruções de máquina, elas estão especificadas resumidamente na nota de aplicação do objdump. Com essa informação foi possível verificar a funcionalidade do código gerado (NVIDIA, 2011e, p. 6-12).

Um caso mais extremo são as instruções complexas, como as divisões de 64 bits com emulação, que são compiladas para rotinas com desvios condicionais. No apêndice D.1 temos um exemplo de uma divisão de inteiros com 64 bits, mostrando o código do microbenchmark em PTX e a desmontagem do código de máquina obtido. A presença desses desvios condicionais faz com que o tempo de execução tenha uma variação dependente dos argumentos da instrução. Dessa forma, a utilização de um benchmark sintético não obtêm resultados precisos para essa classe de instruções.

\subsubsection{Variações no Tempo de Execução}

Ao contrário do que era inicialmente esperado, as tempos das instruções obtidos não estão totalmente livres de variância. Isso pode ser explicado por algumas características da GPU e aparece com mais frequência nas instruções mais complexas.

Como a GPU utiliza o escalonamento para diluir as latências, tanto de memória quanto de pipeline, o tempo de execução de uma instrução dependerá do seu contexto de execução. Isso pode ser visto na observação abaixo, que foi retirada do manual de melhores práticas do CUDAC (NVIDIA, 2011a, p. 42).

Generally, accessing a register consumes zero extra clock cycles per instruction, but delays may occur due to register read-after-write dependencies and register memory 
bank conflicts.

The latency of read-after-write dependencies is approximately 24 cycles, but this latency is completely hidden on multiprocessors that have at least 192 active threads (that is, 6 warps) for devices of compute capability 1.x (8 CUDA cores per multiprocessor $* 24$ cycles of latency $=192$ active threads to cover that latency). For devices of compute capability 2.0, which have 32 CUDA cores per multiprocessor, as many as 768 threads might be required to completely hide latency.

The compiler and hardware thread scheduler will schedule instructions as optimally as possible to avoid register memory bank conflicts. They achieve the best results when the number of threads per block is a multiple of 64 . Other than following this rule, an application has no direct control over these bank conflicts. In particular, there is no register-related reason to pack data into float 4 or int 4 types. ${ }^{20}$

Pelas análises em código que fizemos, o compilador favorece a geração de dependências de leitura após escrita ${ }^{21}$ ao invés de usar mais registradores. Isso, provavelmente, se deve à suposição de que haverá warps suficientes para esconder essas latências, uma vez que todas diretivas de uso da GPU incentivam o uso de grandes quantidades de threads. Assim, pode-se concluir que as latências de pipeline (como visto, são 24 ciclos) são significativas em relação ao resultado de tempo das instruções e podem, eventualmente, não ser escondidas pelo escalonamento.

Pelo que foi visto acima, na execução com menos de 192 ou 768 threads, para compute capability 1.x e 2.x respectivamente, o peso das dependências de leitura após escrita aparece e influencia os resultados do microbenchmark.

À primeira vista, a solução parece ser simples, bastaria executar os testes com uma grande quantidade de threads. Porém, como será explicado no capítulo 7, o sistema de leitura do registrador oclock influencia os resultados obtidos com um grande número de threads. Isso mantém a acurácia dos resultados em função da quantidade de threads entre dois limitantes. Pelo lado inferior, temos os problemas com a falta de warps para esconder as latências. Pelo lado superior, temos a influência do sistema de leitura do registrador oclock.

$\mathrm{Na}$ arquitetura FERMI, a existência do cache afeta os resultados obtidos em amostragens consecutivas da mesma instrução. Nos testes iniciais, as duas primeiras amostragens de algumas instruções obtinham valores de tempo de execução maiores, enquanto que as execuções posteriores, porém em seguida, obtinham tempos menores. Essa situação introduz uma distorção no valor médio obtido e para contorná-la foi criada a opção de execução -x (as opções estão explicadas na seção 6.2.1). Com essa opção, as instruções não são executadas em sequência, mas, de forma intercalada e os resultados ficam mais homogêneos.

\footnotetext{
${ }^{20}$ Geralmente, o acesso a um registro consome zero ciclos de clock extras por instrução, mas atrasos podem ocorrer devido a dependências do tipo leitura após gravação e a conflitos de bancos de memória de registradores.

A latência de dependências de leitura após escrita é de aproximadamente 24 ciclos, mas esta latência é completamente escondida em multiprocessadores que têm pelo menos 192 threads ativas (isto é, 6 warps) para dispositivos de compute capability 1.x (8 núcleos CUDA por multiprocessador * 24 ciclos de latência $=192$ threads ativas para cobrir a latência). Para dispositivos de compute capability 2.0, que possuem 32 núcleos CUDA por multiprocessador, podem ser necessárias 768 threads para esconder completamente a latência.

O compilador e o escalonador de threads do hardware irão agendar instruções da melhor forma possível para evitar conflitos de bancos de memória de registradores. Eles alcançam os melhores resultados quando o número de threads por bloco é um múltiplo de 64. Além de seguir esta regra, uma aplicação não tem controle direto sobre esses conflitos de bancos. Em particular, não há razão relacionada a registradores para empacotar dados em tipos float 4 ou int 4.

${ }^{21}$ Uma dada instrução precisa ler um registrador que foi escrito por uma instrução anterior, porém, essa instrução anterior ainda não chegou ao ponto do pipeline em que ocorre a escrita. Essa situação faz com que a execução da primeira instrução seja congelada até que o registrador seja escrito pela instrução anterior a ela.
} 


\subsection{Escolhas do Projeto}

No inicio, e durante o trabalho, foram feitas algumas escolhas de como implementar o microbenchmark. Nesta seção, vamos comentar algumas dessas escolhas, com as suas motivações e as suas consequências.

As duas escolhas iniciais foram: criar um benchmark sintético e utilizar a linguagem PTX para implementar as rotinas de teste. A escolha do microbenchmark sintético é consequência imediata da intenção de avaliar o desempenho das instruções individualmente.

Basear o microbenchmark na linguagem de montagem PTX, da NVIDIA, e não no código binário, que será executado na GPU, foi um compromisso entre a precisão obtida e a garantia de vida dessa definição. Outro fator que influenciou a decisão foi a disponibilidade de documentação para PTX.

As instruções executadas pela GPU, não são bem documentadas pela NVIDIA e não possuem garantia de tempo de vida. Por outro lado, a NVIDIA se compromete com a compatibilidade através do uso do PTX. A consequência dessa escolha foi a diminuição da precisão dos resultados, como foi visto na seção 6.4.4.

Outro ponto importante foi a forma como executar a leitura do registrador ㄷ lock. A NVIDIA, no exemplo de aplicação clock, existente no SDK 4.1, indica a forma mais precisa de obter o tempo total de execução de uma aplicação. Isso seria através da leitura do registrador o clock somente no início e fim da thread zero de cada bloco.

Nos testes, percebemos que o código extra necessário para verificar o número da thread alterava o escalonamento. Provavelmente porque ele cria um desvio condicional divergente, que faz com que as threads do warp sejam executadas em duas sequências consecutivas. Além disso, pelos testes que fizemos, o escalonamento não é o mesmo entre chamadas consecutivas do mesmo teste. Ou seja, o primeiro warp a ser executado em uma chamada não é necessariamente o mesmo que será executado primeiro em outra chamada posterior. Outro detalhe é que o primeiro warp a ser executado também não é, necessariamente, o warp que contém a thread zero. E o último warp a ser executado não é, necessariamente, o mesmo que iniciou as execuções. Dessa forma, se considerarmos somente a leitura da thread zero, não estaremos medindo o momento exato do início ou do final da execução (ou ambos).

Essa diferença, que podemos obter medindo somente a thread zero, pode não ser significativa no caso de kernels grandes (com muitas instruções) e executando vários blocos. Porém, elas ganham relevância no contexto da rotina de teste (que possui no máximo dez instruções consecutivas) e é executada num único bloco.

A escolha de fazer um gerador de aplicação e ter sua configuração baseada em arquivos facilitou a automatização dos testes finais, que chegaram a demorar 4 horas para um levantamento de perfil de execução de todas instruções.

As saídas em modo texto foram preferidas por facilitarem a verificação dos resultados e auxiliaram na execução do pós processamento. E foi justamente no pós processamento que tivemos a escolha que mais impacto teve na produtividade: utilizar a linguagem AWK no tratamento dos arquivos de saída do microbenchmark. Nas primeiras versões, todo o trabalho do pós processamento era executado dentro do próprio programa do microbenchmark e o tempo necessário para qualquer alteração na forma de interpretar os dados era grande, quando comparado com o necessário para fazer em AWK. 


\section{Capítulo 7}

\section{Experimentos e Resultados}

Os experimentos para verificar e validar o microbenchmark se dividiram em duas etapas: as análises preliminares e a validação dos resultados.

As análises preliminares englobaram testes funcionais e verificação de estabilidade dos resultados. Basicamente, foi avaliado o comportamento do microbenchmark nas diversas opções de execução. Como resultado, além da verificação funcional do programa, obtivemos alguns dados indicativos de um limitante de precisão nos resultados obtidos. Essa não era a intuição inicial para este trabalho.

A validação tratou da confirmação dos resultados obtidos com o microbenchmark. Isso foi feito utilizando-se um modelo que, com os resultados do microbenchmark, poderia prever o tempo de execução de alguns kernels de teste escritos em CUDA C.

Os testes foram realizados em três placas GPUs, duas de tecnologia Tesla e uma Fermi. O início dos testes foi executado em um computador portátil Toshiba Satellite modelo A665 com processador Intel I5 M460 a 2,53GHz, 4GB de RAM, com GPU NVIDIA GeForce GTS 350M (compute capability 1.2), rodando Linux Ubuntu 10.10 (posteriormente atualizado para 11.10) com o SDK e driver CUDA 4.0 (e posteriormente atualizado para 4.1). Como visto na seção 6.4.1 a utilização de uma GPU compartilhada para geração de vídeo influencia os resultados, portanto, mantivemos essa plataforma somente os testes funcionais.

Os testes de estabilidade foram executados em um mesmo computador com duas placas GPUs utilizadas como GPGPU (sem compartilhar a geração de vídeo). Essa máquina era equipada com uma placa mãe Intel DX58SO com processador Intel Core i7 920 de 2,67GHz (4 cores e 8 threads), 6GB de RAM e duas GPUs, uma GeForce GTX 470 (compute capability 2.0) e outra GeForce GTX 275 (compute capability 1.3). Foi utilizado o Ubuntu 11.04 e o CUDA driver e SDK 4.1.

Dada a diretiva de compilação da NVIDIA, de usar a menor arquitetura virtual (PTX) com a maior arquitetura real (SM), utilizamos o PTX 1.0 e a arquitetura real da GPU em que o teste fosse ser executado.

O processo de teste e redefinição do projeto esteve muito presente neste trabalho. Algumas opções do microbenchmark apareceram como respostas a necessidades de teste e acabaram virando definitivas, em função da sua utilidade.

\subsection{Análises Preliminares}

As análises preliminares iniciaram com a confecção do histograma dos resultados das instruções. Para ajudar na explicação dos resultados obtidos, com os gráficos de dispersão, foi analisada a 
sequência de escalonamento das instruções.

Em seguida, foi analisada a influência da quantidade de instruções no trecho de teste. Isso levou a algumas alterações no microbenchmark ${ }^{1}$, após as quais, analisamos novamente o histograma dos tempos de execução das instruções, para verificar as melhorias obtidas.

Também foi analisado o sistema de medição, com algumas opções de como fazer a medida e seu impacto nos resultados. E finalmente fizemos uma análise do perfil da instrução, que envolveu o levantamento dos tempos de cada instrução em função do total de threads executadas e do total de instruções dentro do trecho de teste.

Todos os gráficos da análise preliminar mostrados neste capítulo utilizam valores brutos de tempo de execução, ou seja, antes da subtração do tempo de calibragem ${ }^{2}$. As análises foram feitas dessa forma para evitar que variações no processo de medição pudessem interferir nas variações dos tempos obtidos. Em casos de exceção há a indicação de como foram considerados os tempos.

\subsubsection{Análise de Dispersão}

Durante essas primeiras análises, o microbenchmark só executava testes com dez instruções dentro do trecho. A opção de trecho configurável (ver seção 6.1.4) ainda não tinha sido implementada, pois, foi uma necessidade que apareceu durante a realização das análises preliminares. Além disso, no início dos testes era computado o tempo de cada warp para se obter uma média do tempo de execução por warp. Essa forma de considerar o tempo de execução também foi alterada em função dos resultados obtidos.

A primeira análise feita com o microbenchmark foi a verificação do resultado de cada instrução e a sua variância. E, ao contrário do esperado, todas as instruções possuíam alguma variância. Para ter um panorama melhor desses resultados, fizemos o histograma de cada instrução e a análise da dispersão.

Era de se esperar que as instruções mais simples possuíssem resultados estáveis, enquanto que as mais complexas pudessem ter alguma variação no tempo de execução. Porém, como visto no gráfico da figura 7.1, até uma instrução simples, como um ADD de 32 bits, obteve uma dispersão significativa, com um coeficiente de variação de $14,78 \%^{3}$.

Instruções mais complexas, como mad.hi.u32, div.rn.f64 ou rsqrt.approx.ftz.f32, quando não apresentaram uma dispersão ainda maior, apresentavam mais de uma tendência central para o tempo de execução. Um exemplo desse resultado pode ser visto nas figuras 7.2, 7.3 e 7.4. Esses comportamentos nos levaram ao questionamento sobre os resultados obtidos.

Para tentar entender o motivo dessas variações, iniciamos pela análise do escalonamento dos warps durante a execução dos testes.

\subsubsection{Análise do Escalonamento}

Em função da presença constante de variação nos resultados, a segunda análise executada foi o levantamento do escalonamento. Para isso, utilizamos o microbenchmark com a opção de quatro leituras de tempo por thread. Um exemplo de resultado obtido, para a instrução add.u16, executando com 128 threads (quatro warps), está mostrado na tabela 7.1.

\footnotetext{
${ }^{1}$ Essas alterações foram: a configuração do total de instruções no trecho de teste e a inicialização das variáveis utilizadas. Esta última aumentou o distanciamento entre o início da rotina em PTX e o início do trecho de teste.

${ }^{2}$ Detalhes sobre o cálculo do tempo médio das instruções estão na seção 6.3 .1

${ }^{3} \mathrm{O}$ coeficiente de variação é razão entre o desvio padrão e a média.
} 


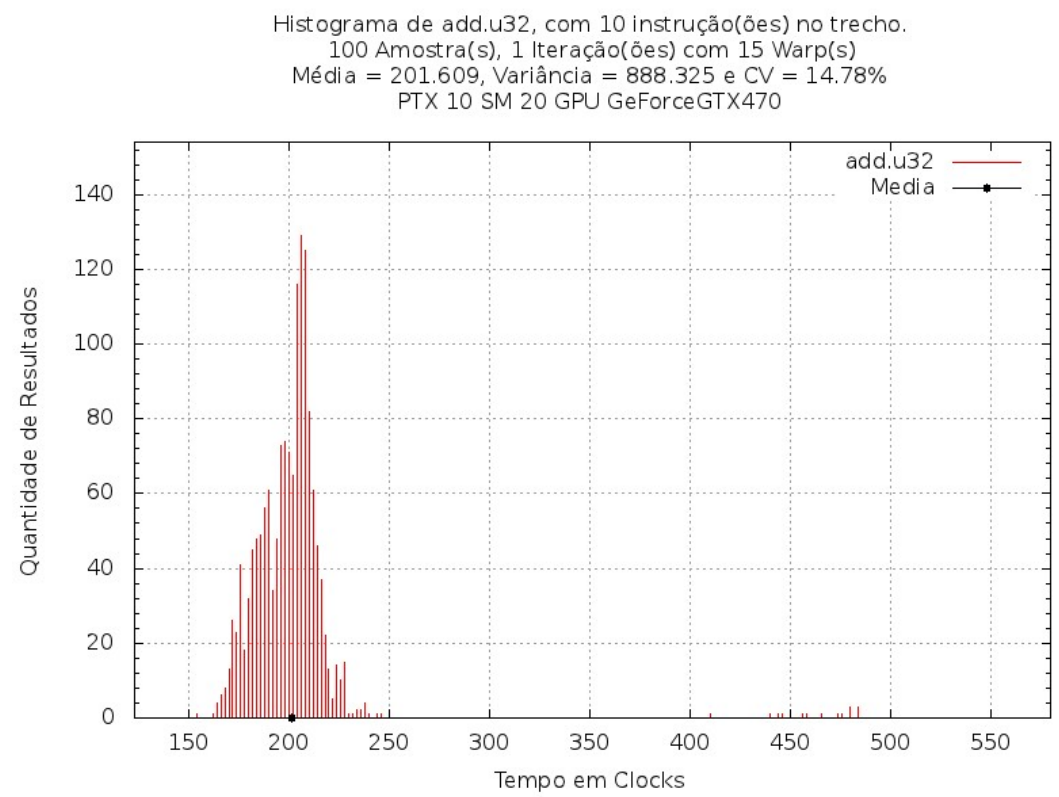

Figura 7.1: Histograma da instrução add.u32 com 10 instruções no trecho, 480 threads (15 warps) e 100 amostragens.

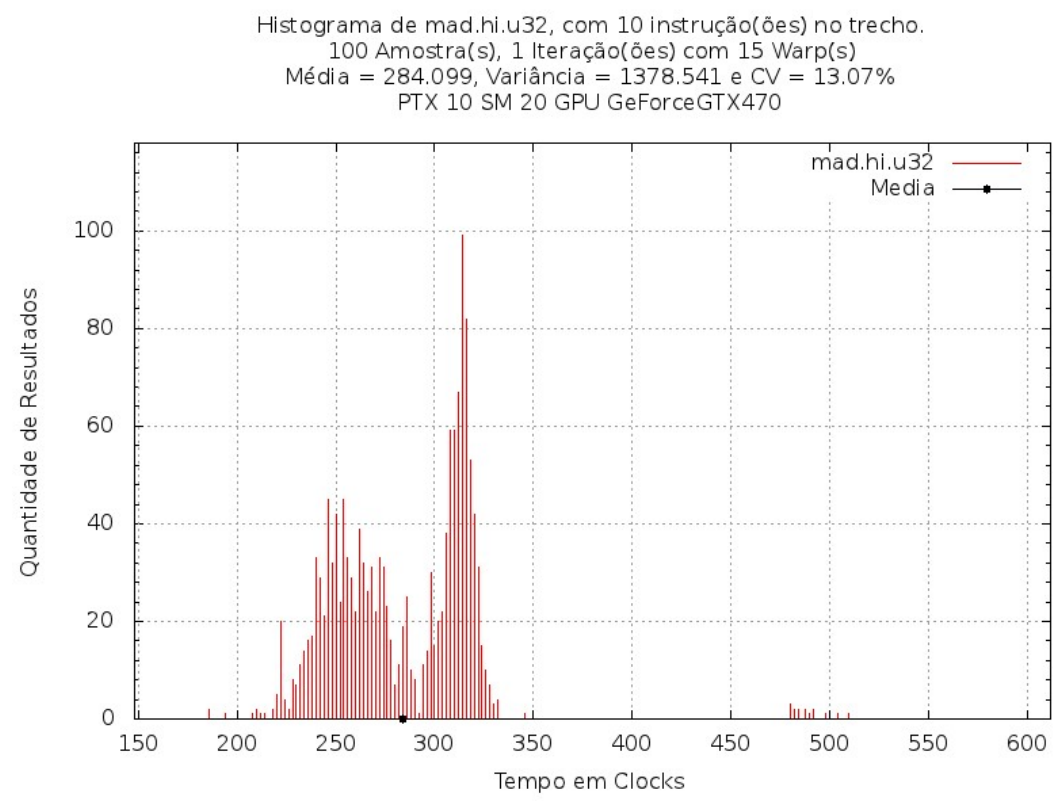

Figura 7.2: Histograma da instrução mad.hi.u32 com 10 instruções no trecho, 480 threads (15 warps) $e$ 100 amostragens.

Esse resultado mostrou que havia uma inversão na sequência de execução dos warps, explicando assim as diferenças no tempo de execução entre os warps. Como o tempo considerado, até então, era o tempo de cada warp, só isso já justificaria a variação. Porém, para verificar se o problema também estava vinculado com a quantidade de instruções executadas, criamos a opção de configuração da quantidade de instruções no trecho e refizemos os testes.

Para facilitar esse trabalho foi feito um programa de pós processamento em AWK. Ele lista a sequência de escalonamento baseado nos tempos de início da thread, início do trecho de teste, fim do trecho de teste e fim da thread.

Os resultados obtidos mostraram que o escalonamento também estava relacionado com a quantidade 


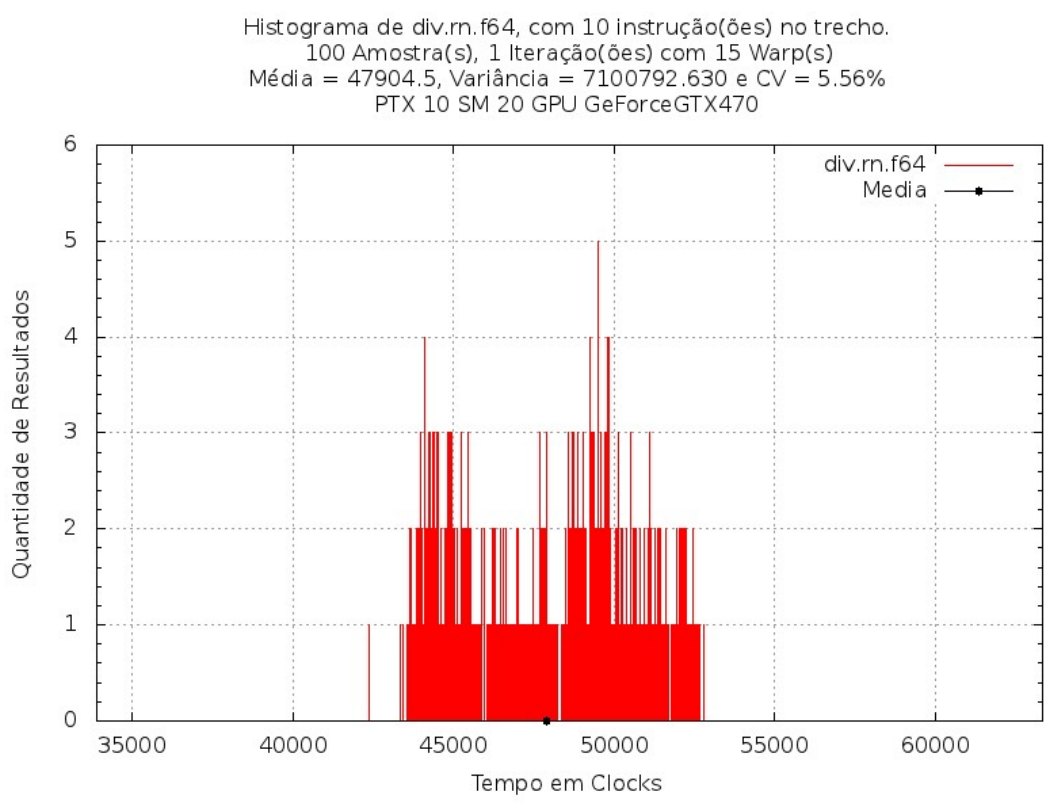

Figura 7.3: Histograma da instrução div.rn.f64 com 10 instruções no trecho, 480 threads (15 warps) e 100 amostragens.

\section{Análise dos tempos do Kernel addU16:}

Amostragem $=0$ da instrucao Addu16

\begin{tabular}{|c|c|c|c|c|c|}
\hline \#Thread & InicioThread & InicioInstrucao & FimInstrucao & FimThread & Warp \\
\hline 0 & 21677146 & 21677430 & 21677542 & 21677722 & W0 \\
\hline 32 & 21677144 & 21677422 & 21677536 & 21677716 & W1 \\
\hline 64 & 21677150 & 21677432 & 21677544 & 21677724 & W2 \\
\hline 96 & 21677148 & 21677426 & 21677540 & 21677720 & W3 \\
\hline
\end{tabular}

Análise da sequência de execução do Warps:

\begin{tabular}{|l|c|c|c|c|}
\hline InicioThread & W1 & W0 & W3 & W2 \\
\hline InicioInstrucao & W1 & W3 & W0 & W2 \\
\hline FimInstrucao & W1 & W3 & W0 & W2 \\
\hline FimThread & W1 & W3 & W0 & W2 \\
\hline
\end{tabular}

Tabela 7.1: Escalonamento da instrução add.u16 com 4 warps

de instruções no trecho. Para testes com a instrução div.s32, executando com 96 threads (três warps), o escalonamento mostrou um padrão constante para até 4 instruções no trecho, como exemplificado nas tabelas 7.2 e 7.3.

\section{Instrução div.s32 com 96 threads (3 warps) e 2 instruções no trecho:}

Amostragem 9:

\begin{tabular}{|l|c|c|c|}
\hline Inicio da Thread & W2 & W1 & W0 \\
\hline Inicio do Trecho & W2 & W1 & W0 \\
\hline Fim do Trecho & W2 & W1 & W0 \\
\hline Inicio da Memoria & W2 & W1 & W0 \\
\hline
\end{tabular}

Este padrão é estável para todas amostragens, independentemente se ela é par ou ímpar.

Tabela 7.2: Escalonamento da instrução div.s32 com 3 warps e 2 instruções no trecho de teste.

Essas tabelas nos mostram que para a amostragem de número 9, a sequência de execução iniciou com o warp que tem como primeira thread a de número 64 (W2 - compreende as threads 64 a 95), 
Instrução div.s32 com 96 threads (3 warps) e 4 instruções no trecho: Amostragem 9:

\begin{tabular}{|l|l|c|c|c|}
\hline Inicio da Thread & W2 & W1 & W0 \\
\hline Inicio do Trecho & W2 & W1 & W0 \\
\hline Fim do Trecho & W2 & W1 & W0 \\
\hline Inicio da Memoria & W2 & W1 & W0 \\
\hline Este padrão é estável para todas amostragens, independentemente se ela é par ou ímpar.
\end{tabular}

Tabela 7.3: Escalonamento da instrução div.s32 com 3 warps e 4 instruções no trecho de teste.

seguido pelo warp iniciado pela thread 32 (W1 - compreende as threads 32 a 63) e por fim o warp da thread 0 (W0 - compreende as threads 0 a 31). Essa sequência ficou estável em todos os trechos de leitura do registrador oclock. Ou seja, a sequência de escalonamento foi estável durante toda a execução e esse padrão de escalonamento foi estável entre chamadas consecutivas do mesmo teste.

Porém, alterando somente a quantidade de instruções no trecho para 5, o padrão do escalonamento alterou, entre duas chamadas consecutivas, como mostrado nos resultados da tabela 7.4. Podemos ver que, na nona amostragem houve a inversão da sequência de execução dentro do trecho de teste. Novamente, essa inversão leva a uma variação no tempo de execução dos warps entre as chamadas, aumentando assim a variação dos tempos das amostras.

Amostragem 8:

Instrução div.s32 com 96 threads (3 warps) e 5 instruções no trecho:

Amostragem 9:

\begin{tabular}{|l|c|c|c|}
\hline Inicio da Thread & W2 & W1 & W0 \\
\hline Inicio do Trecho & W2 & W1 & W0 \\
\hline Fim do Trecho & W2 & W1 & W0 \\
\hline Inicio da Memoria & W2 & W1 & W0 \\
\hline
\end{tabular}

\begin{tabular}{|l|c|c|c|}
\hline Inicio da Thread & W2 & W1 & W0 \\
\hline Inicio do Trecho & W2 & W1 & W0 \\
\hline Fim do Trecho & W1 & W2 & W0 \\
\hline Inicio da Memoria & W1 & W2 & W0 \\
\hline
\end{tabular}

Este padrão é estável, com ciclo de duas amostragens, diferenciando as amostragens pares das ímpares.

Tabela 7.4: Escalonamento da instrução div.s32 com 3 warps, 5 instruções no trecho de teste e inversão no escalonamento.

Nestes testes, o tempo mensurado foi o tempo de cada warp separado, sendo executado em paralelo. Porém, considerando a medição dessa forma, com o aumento do número de threads em execução, o tempo de cada warp também aumentava ${ }^{4}$ (juntamente com a variância). Para evitar esse efeito e chegar a um valor que representasse melhor o tempo de execução, decidimos considerar o tempo total de execução do kernel e dividí-lo pelo número de warps e instruções sendo executado. Essa estratégia mostrou-se mais coerente com o funcionamento da GPU e alguns resultados passaram a ter variação muito menor. Além disso, para as instruções mais simples ou para as que fossem testadas com poucos warps, a variância passou a tender a zero. Essa modificação teve um resultado significativo na análise do sistema de medição (ver seção 7.1.5).

Para termos uma noção do impacto dessa alteração, na forma de considerar o tempo medido, podemos ver o caso da instrução rsqrt.approx.ftz. f32. Ela tem o histograma do tempo de cada warp na figura 7.4 e do tempo total de execução do kernel, conforme a alteração, na figura 7.5. A variância caiu de $15.905,8$ para 0,3136 e o coeficiente de variação, de $11,42 \%$ para $0,042 \%$.

Apesar dessa melhoria, a variância não diminuiu ou desapareceu em todas as instruções. E isso nos

\footnotetext{
${ }^{4}$ Como vimos na seção 6.3.1 os warps executam de forma entrelaçada e por isso, adicionar mais um warp, aumenta o tempo total de execução de cada warp.
} 
levou a questionar a relação entre a variância e a quantidade de instruções no trecho de teste.

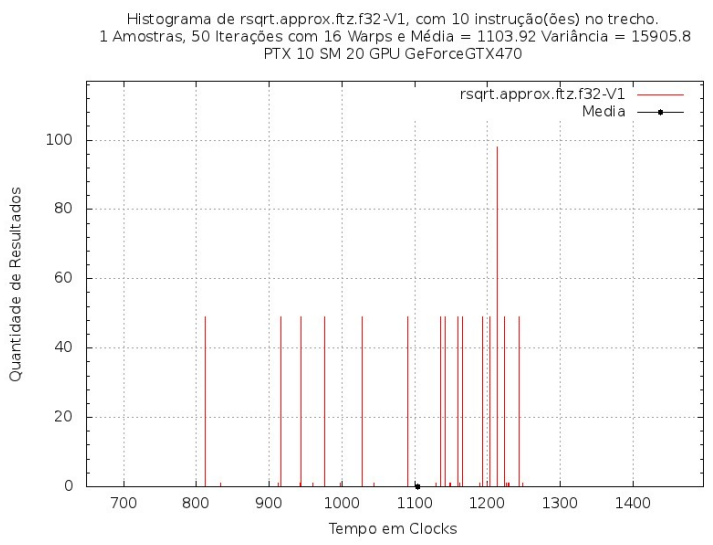

Figura 7.4: Histograma da instrução rsqrt.approx.ftz.f32 com 10 instruções no trecho, 512 threads (16 warps), 50 amostragens e considerando o tempo de cada warp.

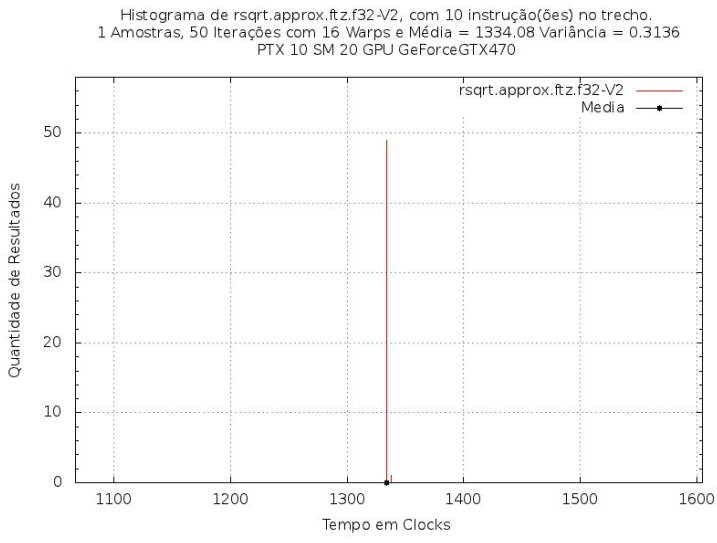

Figura 7.5: Histograma da instrução rsqrt.approx.ftz.f32 com 10 instruções no trecho, 512 threads (16 warps), 50 amostragens e considerando o tempo total do kernel.

\subsubsection{Análise do Trecho de Teste}

Uma característica da dispersão dos tempos das instruções, que se evidenciou, foi a existência de distribuições com duas tendências centrais, ou seja, bimodal ${ }^{5}$. Um bom exemplo está na figura 7.6, que mostra o resultado da instrução mov.s64 e considera os tempos de cada warp em execução.

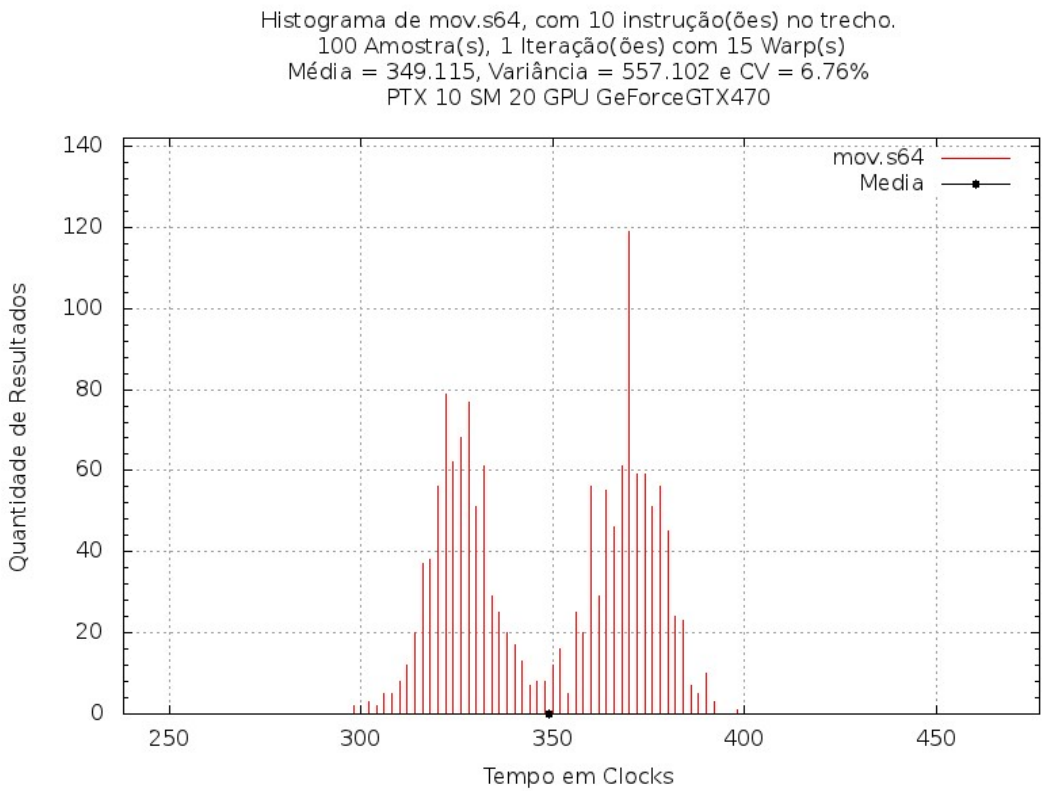

Figura 7.6: Histograma da instrução mov.s64 com 10 instruções no trecho, 480 threads (15 warps) e 100 amostragens. Os tempos se referem a cada warp sendo executado.

Pela análise desse gráfico, podemos dizer que existem dois resultados principais para essa instrução. Ou seja, temos, pelo menos, duas situações de execução da instrução e com tempos diferentes.

A primeira tentativa de entender a razão dessa distribuição nos levou a modificar o microbenchmark. Essa modificação permitiu que a quantidade de instruções dentro do trecho de teste fosse

\footnotetext{
${ }^{5}$ Presença de duas modas. O gráfico aparenta um duplo sino ou duas curvas gaussianas próximas.
} 
configurável (ver seção 6.1.4).

Com esse recurso, foram executados testes incrementando a quantidade de instruções no trecho. Os resultados serviram para duas análises distintas. Uma delas, procurando o momento em que a distribuição bimodal aparece e a outra, para verificar como a variância se comporta em função da quantidade de instruções no trecho.

\section{Quantidade de Instruções no Trecho e Distribuição Bimodal}

Para verificar a formação da distribuição bimodal, utilizamos a instrução mov.s 64 em testes com uma, duas, três, quatro, cinco e dez instruções dentro do trecho. Os histogramas desses testes podem ser vistos nas figuras 7.7, 7.8, 7.9, 7.10, 7.11 e 7.12 .

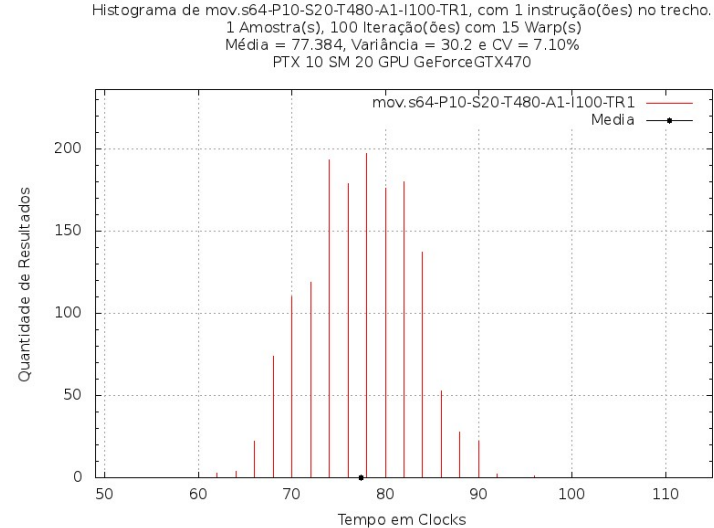

Figura 7.7: Histograma da instrução mov.s64 com 1 instrução no trecho, 480 threads (15 warps), 100 amostragens e considerando o tempo de cada warp.

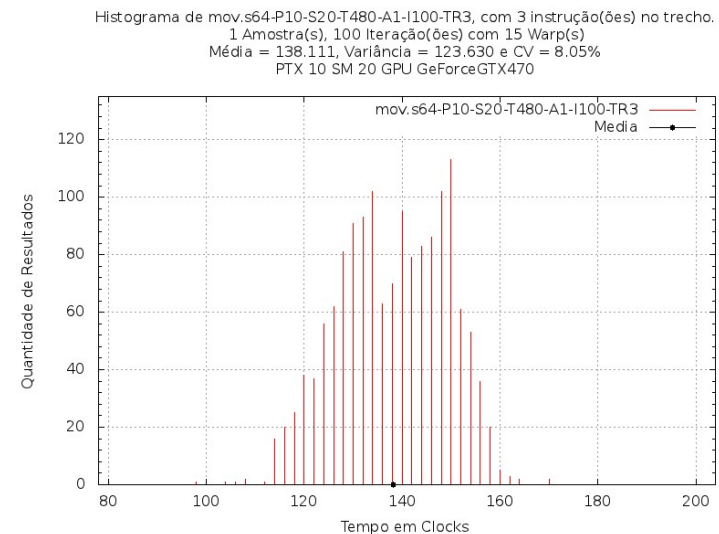

Figura 7.9: Histograma da instrução mov.s64 com 3 instruções no trecho, 480 threads (15 warps), 100 amostragens e considerando o tempo de cada warp.

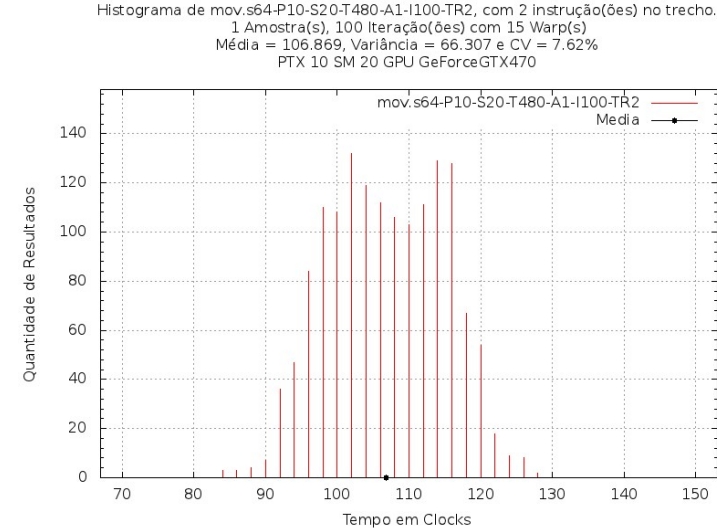

Figura 7.8: Histograma da instrução mov.s64 com 2 instruções no trecho, 480 threads $(15$ warps), 100 amostragens e considerando o tempo de cada warp.

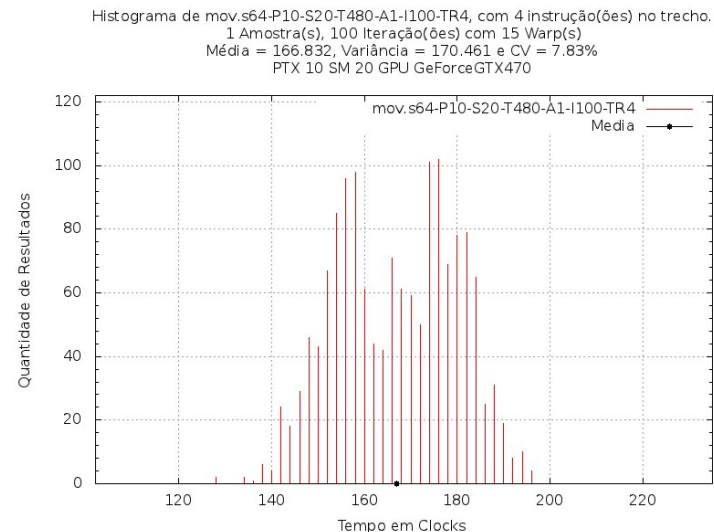

Figura 7.10: Histograma da instrução mov.s64 com 4 instruções no trecho, 480 threads (15 warps), 100 amostragens e considerando o tempo de cada warp.

Pela evolução mostrada, podemos concluir que a distribuição bimodal aparece em função da quantidade de instruções no trecho. Esse resultado nos levou a verificar como se comporta a distribuição em função da quantidade de warps sendo executada.

Para essa análise comparamos os histogramas da mesma instrução, mov •s64, para a execução com dez instruções no trecho de teste e com a sequência de 1 a 15 warps em execução. Os histogramas 


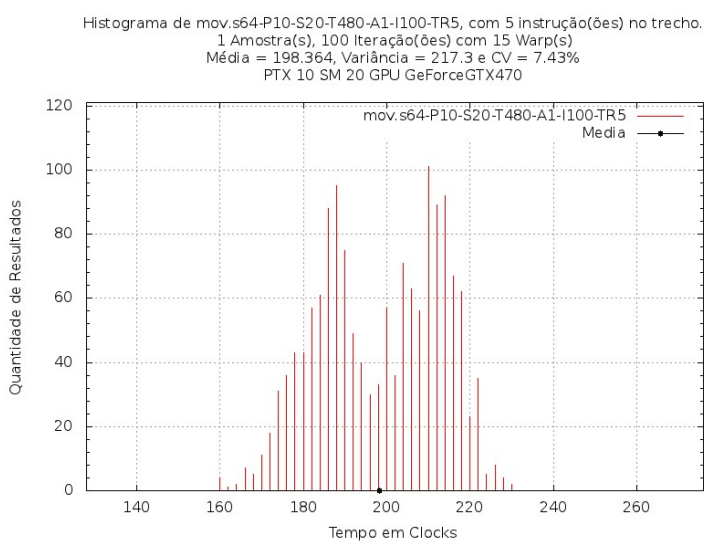

Figura 7.11: Histograma da instrução mov.s64 com 5 instruções no trecho, 480 threads (15 warps), 100 amostragens e considerando o tempo de cada warp.

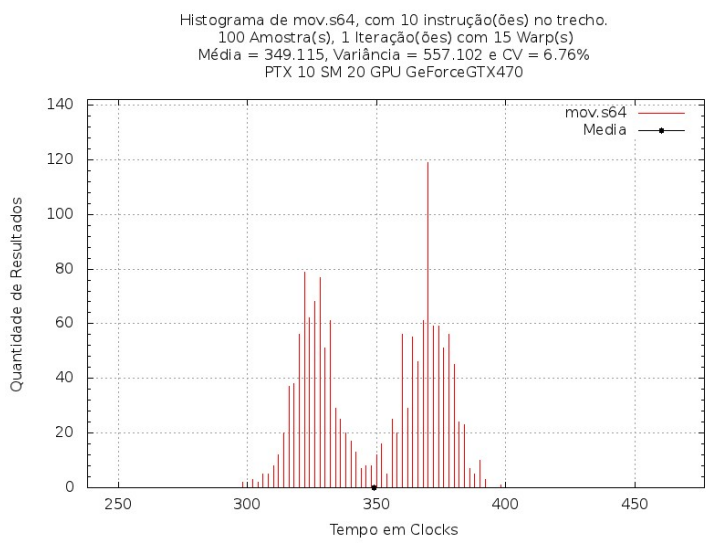

Figura 7.12: Histograma da instrução mov.s64 com 10 instruções no trecho, 480 threads (15 warps), 100 amostragens e considerando o tempo de cada warp.

desses resultados estão mostrados nas figuras 7.13 até 7.26.

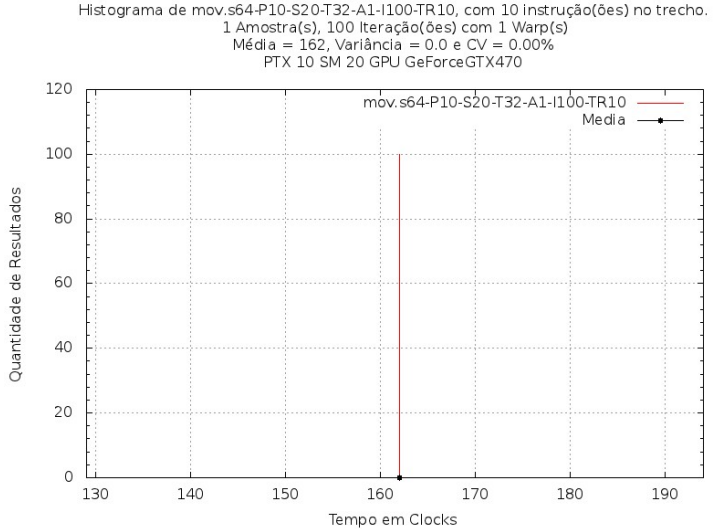

Figura 7.13: Histograma da instrução mov.s64 com 10 instruções no trecho, 32 threads (1 warp), 100 amostragens e considerando o tempo de cada warp.

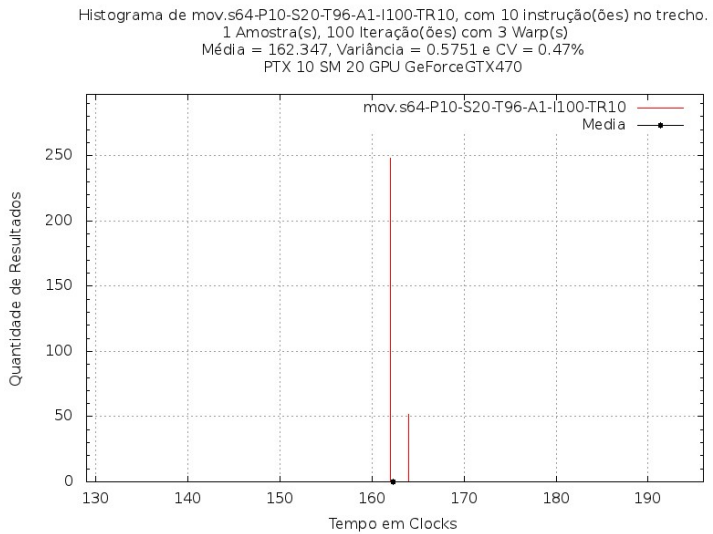

Figura 7.15: Histograma da instrução mov.s64 com 10 instruçôes no trecho, 96 threads (3 warps), 100 amostragens e considerando o tempo de cada warp.

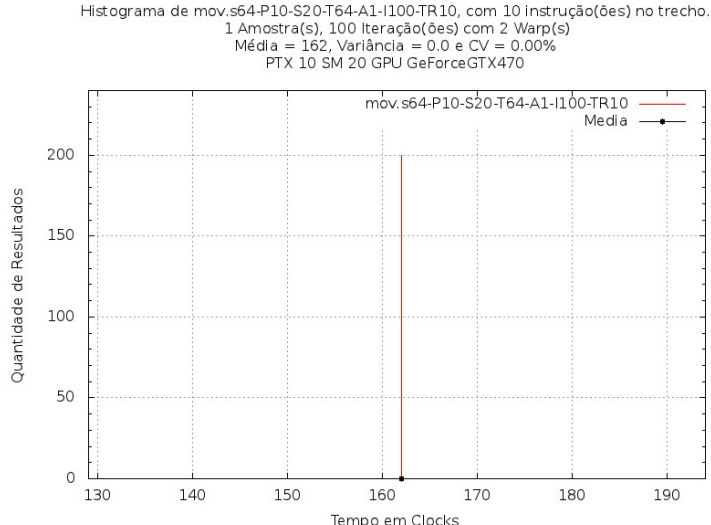

Figura 7.14: Histograma da instrução mov.s64 com 10 instruções no trecho, 64 threads (2 warps), 100 amostragens e considerando o tempo de cada warp.

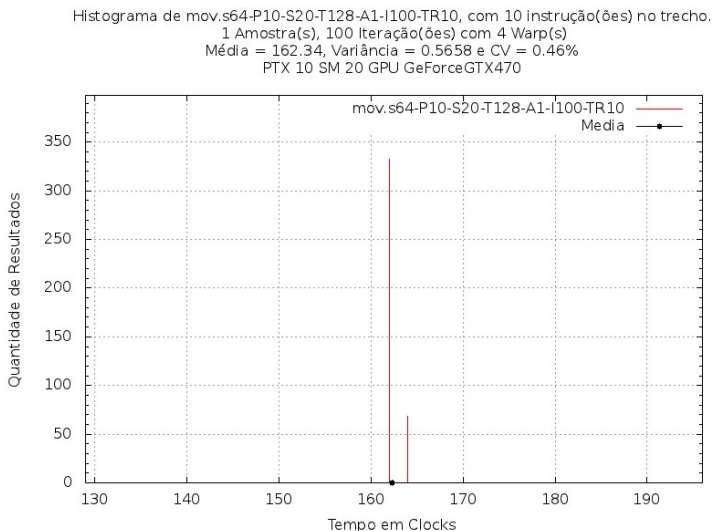

Figura 7.16: Histograma da instrução mov.s64 com 10 instruções no trecho, 128 threads (4 warps), 100 amostragens e considerando o tempo de cada warp. 
Histograma de mov.S54-P10-S20-T160-Al-I100-TR10, com 10 instrusāolöoes) no trecho. 1 Amostra(s), 100 Iteração(ôes) com 5 Warp(s)
Média 164.4 , Variância $=3.8477 \mathrm{e} C \mathrm{CV}=1.19 \%$
PTX 10 SM 20 GPU GeForceGTX470

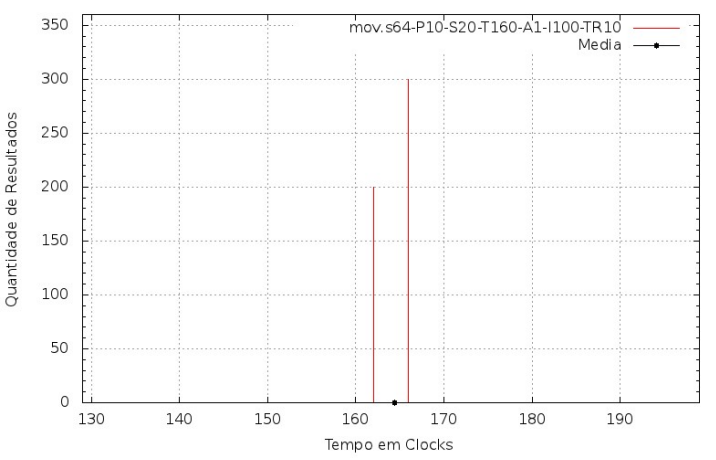

Figura 7.17: Histograma da instrução mov.s64 com 10 instruções no trecho, 160 threads (5 warps), 100 amostragens e considerando o tempo de cada warp.

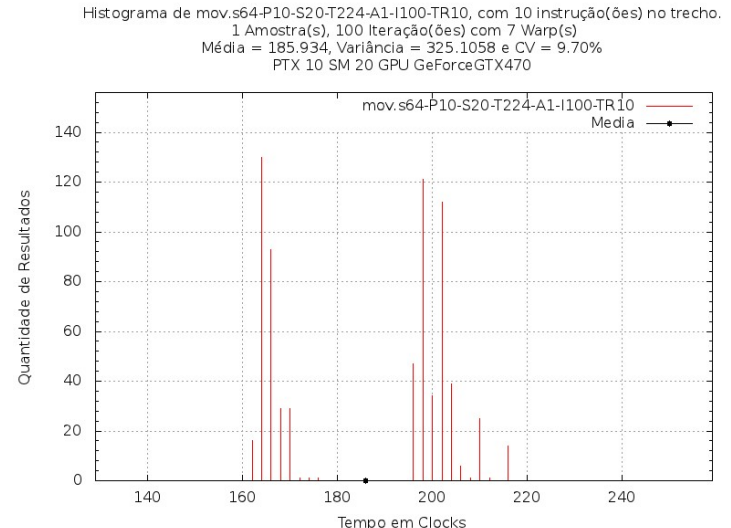

Figura 7.19: Histograma da instrução mov.s64 com 10 instruçôes no trecho, 224 threads (7 warps), 100 amostragens e considerando o tempo de cada warp.

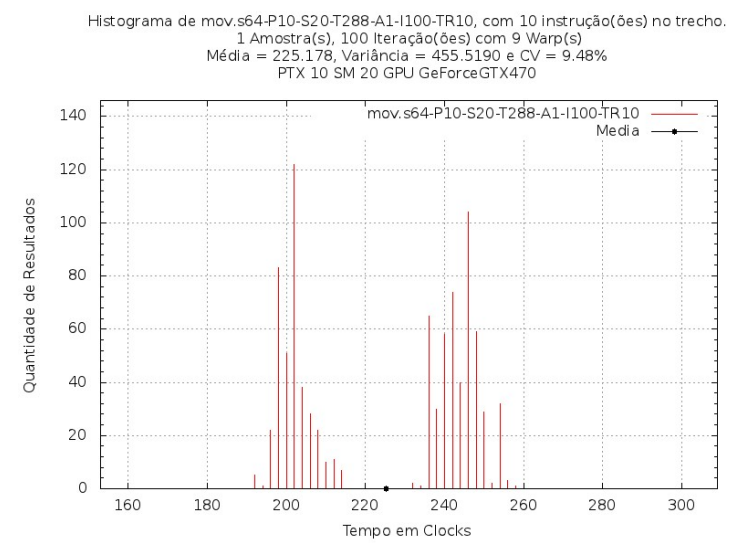

Figura 7.21: Histograma da instrução mov.s64 com 10 instruçôes no trecho, 288 threads (9 warps), 100 amostragens e considerando o tempo de cada warp.

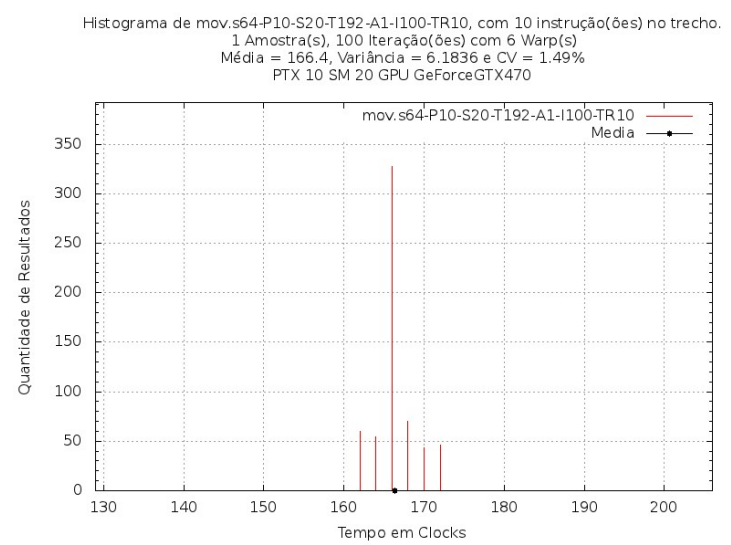

Figura 7.18: Histograma da instrução mov.s64 com 10 instruções no trecho, 192 threads (6 warps), 100 amostragens e considerando o tempo de cada warp.

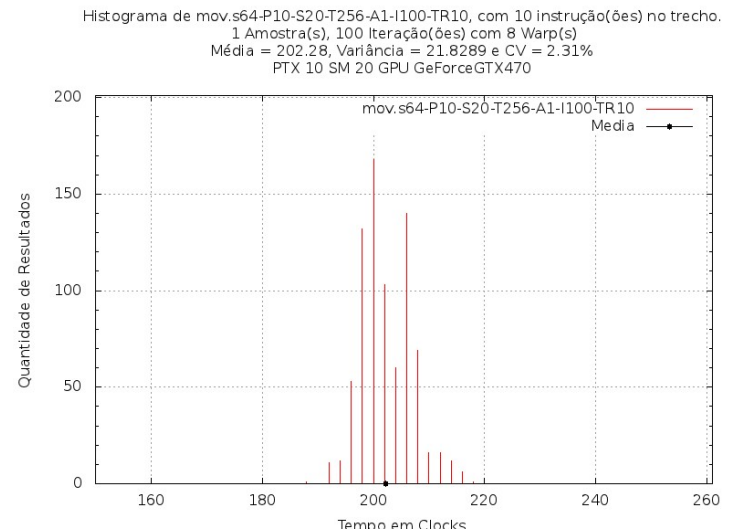

Figura 7.20: Histograma da instrução mov.s64 com 10 instruções no trecho, 256 threads (8 warps), 100 amostragens e considerando o tempo de cada warp.

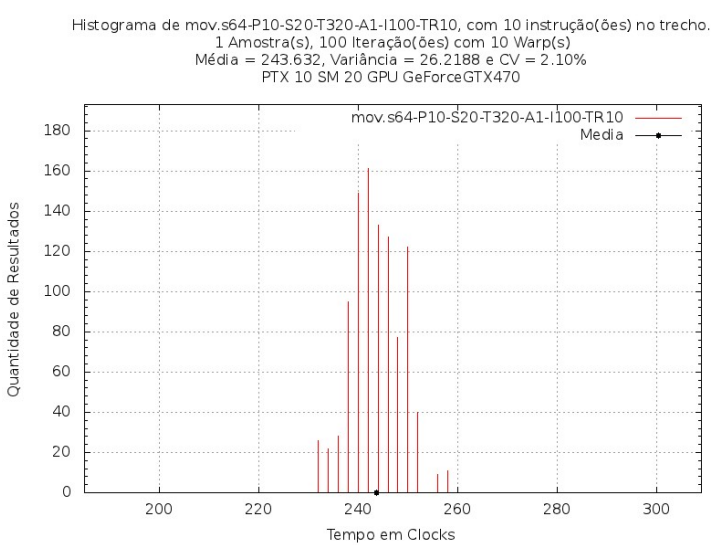

Figura 7.22: Histograma da instrução mov.s64 com 10 instruções no trecho, 320 threads (10 warps), 100 amostragens e considerando o tempo de cada warp.

Pelos gráficos pode-se notar que, de 32 a 192 threads, temos uma moda somente. A partir de 224 


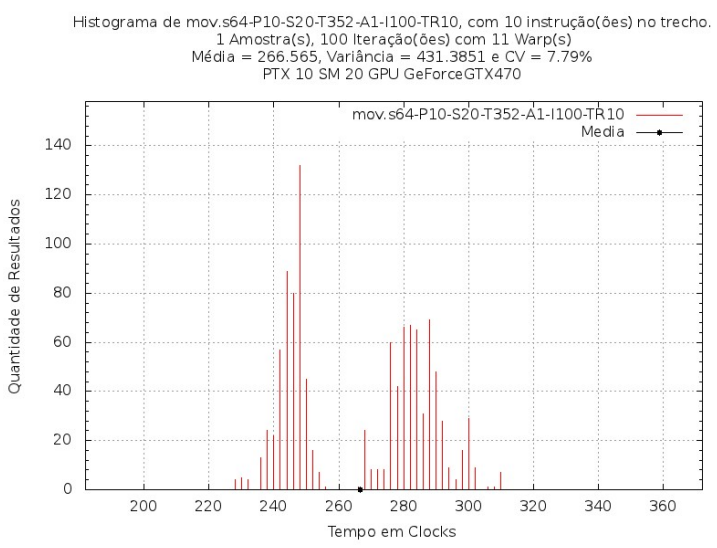

Figura 7.23: Histograma da instrução mov.s64 com 10 instruções no trecho, 352 threads (11 warps), 100 amostragens e considerando o tempo de cada warp.

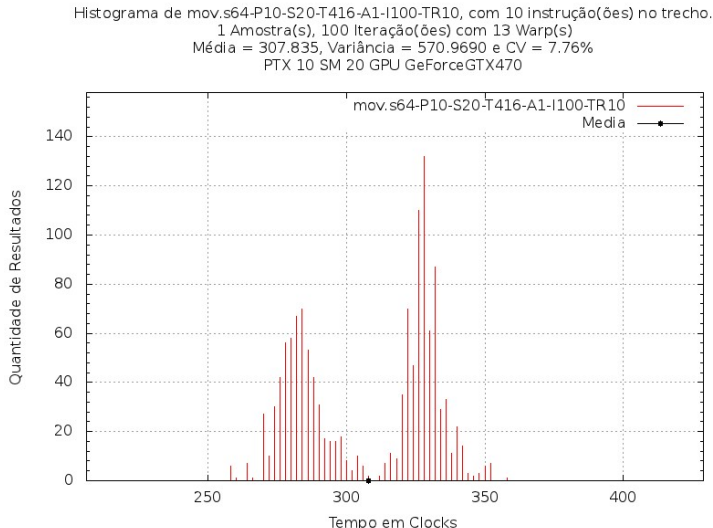

Figura 7.25: Histograma da instrução mov.s64 com 10 instruções no trecho, 416 threads (13 warps), 100 amostragens e considerando o tempo de cada warp.

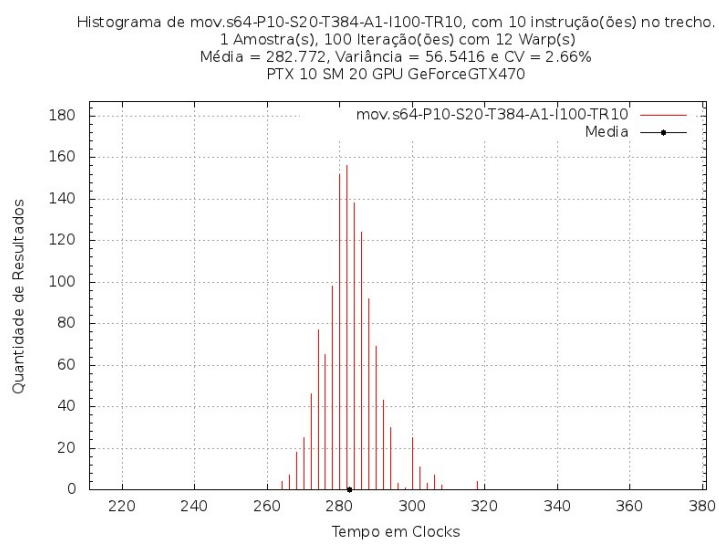

Figura 7.24: Histograma da instrução mov.s64 com 10 instruções no trecho, 384 threads (12 warps), 100 amostragens e considerando o tempo de cada warp.

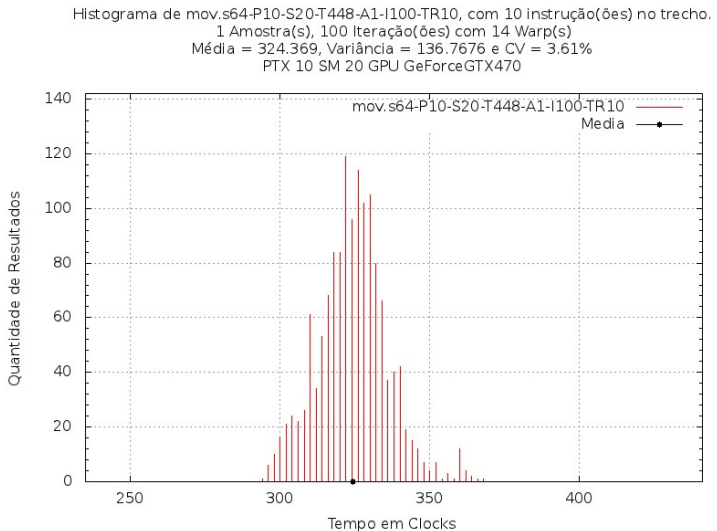

Figura 7.26: Histograma da instrução mov.s64 com 10 instruções no trecho, 448 threads (14 warps), 100 amostragens e considerando o tempo de cada warp.

threads se inicia o processo de separação em duas modas, o qual se acentua com o aumento na quantidade de threads em execução e ocorre principalmente em quantidades ímpares de warps em execução.

Para verificar se esse comportamento era derivado do código de teste ou da forma de funcionamento da GPU, foi feita uma análise de possíveis dependências de leitura após escrita ${ }^{6}$ dentro do código PTX. Inclusive, foi feita a verificação do resultado da compilação diretamente no código de máquina.

Após essa verificação e algumas alterações no código $^{7}$, a distribuição bimodal desapareceu nas instruções mais simples. Porém, em algumas instruções, a distribuição bimodal era dependente tanto da quantidade de threads, quanto da quantidade de instruções no trecho. Isso nos levou a considerar a possibilidade de o pipeline, a partir de certa demanda na execução da mesma instrução, atingisse a sua máxima capacidade de execução. Provavelmente em função da disputa pelas unidades funcionais ou recursos de execução.

Para fazer uma verificação simples, analisamos a mesma instrução, mov.s64, repetida uma única

\footnotetext{
${ }^{6}$ Essa é a dependência mais comum e temos mais detalhes na seção 2.2 .

${ }^{7}$ Como comentado anteriormente, as alterações foram a inicialização das variáveis utilizadas, o que distanciou o início da rotina PTX do trecho de teste. Também foram corrigidas eventuais dependências de leitura após escrita.
} 
vez no trecho de teste e com a sequência de um até 15 warps em execução. Os resultados para 12, 13, 14 e 15 warps em execução estão nas figuras 7.27, 7.28, 7.29 e 7.30. Podemos notar que houve o desaparecimento da distribuição bimodal, da mesma forma que ocorreu no teste anterior, quando utilizou-se quantidades menores de warps em execução. Esse é um indicador de que a distribuição bimodal é função da quantidade da mesma instrução sendo executada.

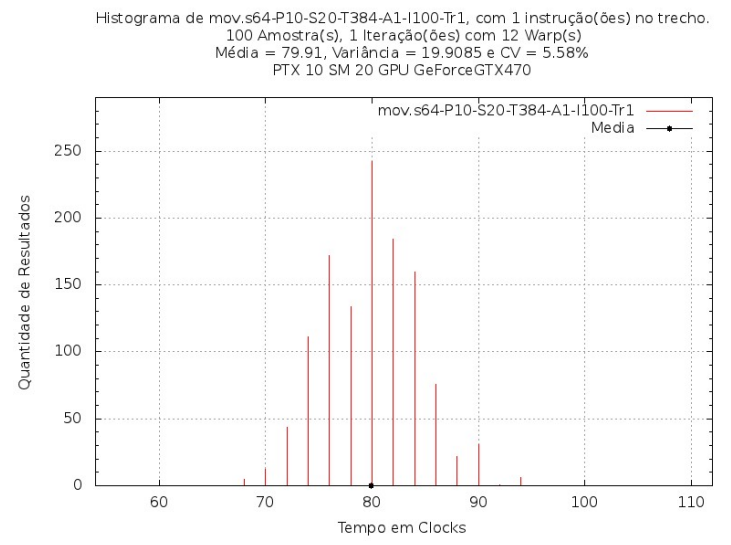

Figura 7.27: Histograma da instrução mov.s64 com 1 instrução no trecho, 384 threads (12 warps), 100 amostragens e considerando o tempo de cada warp.

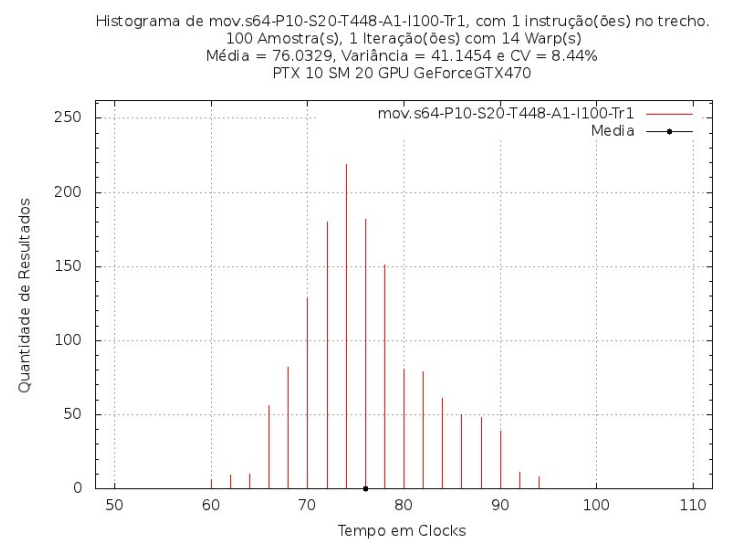

Figura 7.29: Histograma da instrução mov.s64 com 1 instrução no trecho, 448 threads (14 warps), 100 amostragens e considerando o tempo de cada warp.

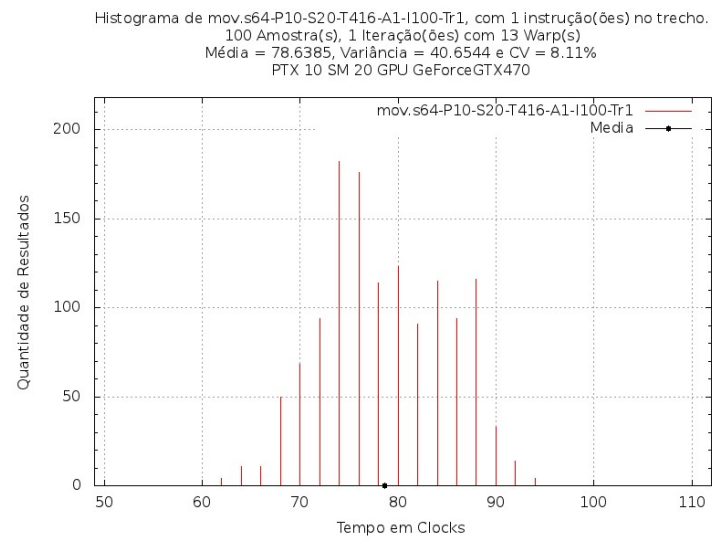

Figura 7.28: Histograma da instrução mov.s64 com 1 instrução no trecho, 416 threads (13 warps), 100 amostragens e considerando o tempo de cada warp.

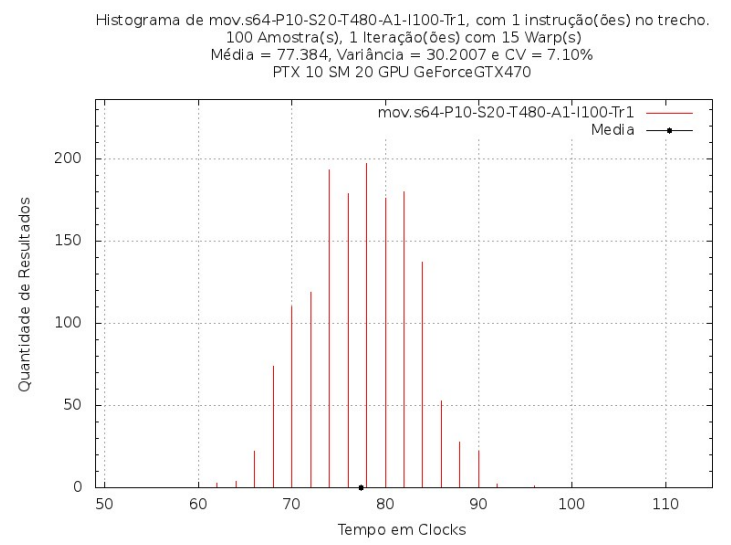

Figura 7.30: Histograma da instrução mov.s64 com 1 instrução no trecho, 480 threads (15 warps), 100 amostragens e considerando o tempo de cada warp.

\section{Quantidade de Instruções no Trecho e Variância}

Esta análise teve como objetivo verificar se havia relação entre a variância e a quantidade de instruções no trecho de teste.

Dos resultados obtidos ${ }^{8}$ foi criada uma tabela por instrução que contém o total de instruções repetidas no trecho e a última quantidade de warps onde a variância era zero. Dessa forma, a tabela indica, para cada quantidade de instruções no trecho, em qual momento (dado em quantidade de warps), os resultados começaram a apresentar variância diferente de zero.

\footnotetext{
${ }^{8}$ Os tempos utilizados foram os tempos brutos, ou seja, sem a subtração do valor de calibração. Ver seção 6.3 .1 para detalhes sobre o cálculo dos tempos. Esses resultados foram obtidos com a versão do microbenchmark que já possuía as alterações efetuadas na subseção anterior (Quantidade de Instruções no Trecho e Distribuição Bimodal).
} 
De uma forma geral, a variação nos resultados é função tanto da quantidade de instruções no trecho de teste, quanto do total de warps em execução no teste. Assim, quanto maior a quantidade de instruções no trecho de teste, menor é a necessidade de warps para iniciar a ocorrência de variação nos resultados. Por outro lado, quanto menos instruções no trecho de teste, mais warps são necessários para iniciar a ocorrência de variação nos resultados. Isso, apesar de a variância não ter seu valor necessariamente proporcional à quantidade de warps ou instruções no trecho.

Como exemplo dos resultados, mostramos a instrução add.s32, que está representada tanto na tabela 7.5, como no gráfico 7.31, dados a seguir.

\begin{tabular}{|c|c|}
\hline Trecho & Warps \\
\hline 1 & 8 \\
\hline 2 & 6 \\
\hline 3 & 6 \\
\hline 4 & 6 \\
\hline 5 & 5 \\
\hline 6 & 4 \\
\hline 7 & 5 \\
\hline 8 & 2 \\
\hline 9 & 2 \\
\hline 10 & 1 \\
\hline
\end{tabular}

Tabela 7.5: Tabela da quantidade de instruções no trecho versus a quantidade de warps onde inicia a variância diferente de zero, para a instrução add.s32. Executado na GPU GeForceGTX470 com 50 iterações, arquitetura virtual PTX 10 e arquitetura real SM 20.

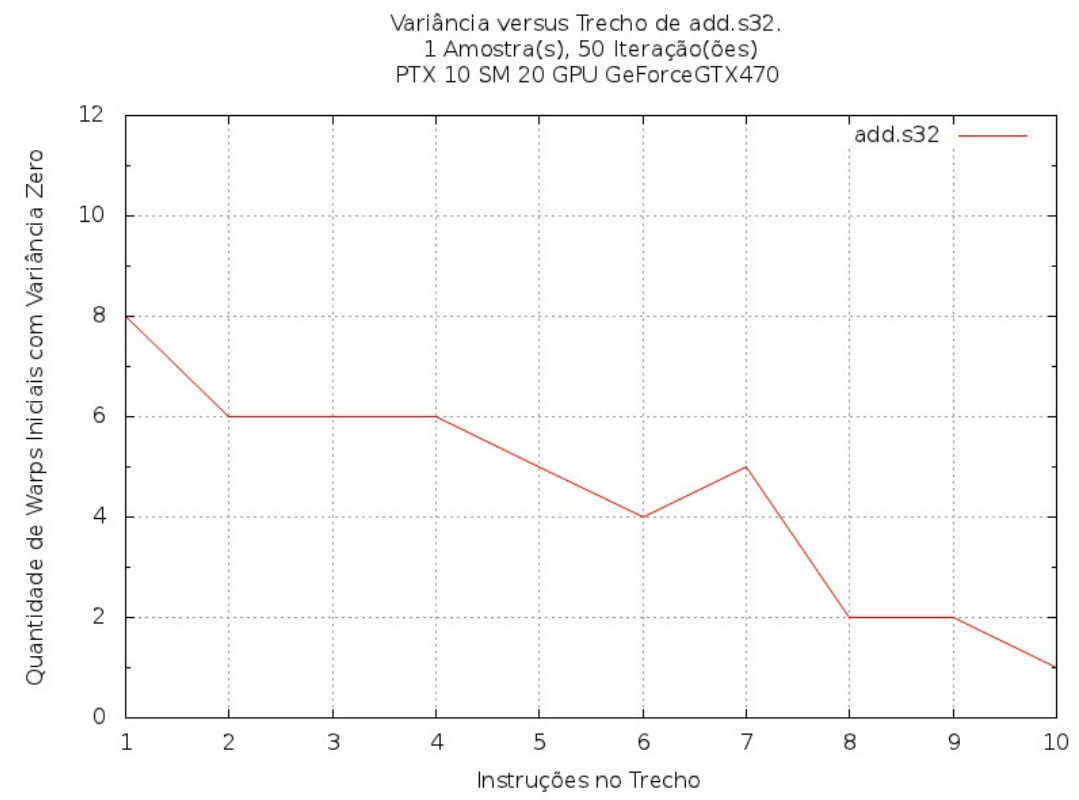

Figura 7.31: Instrução add.s32, gráfico da quantidade de instruções no trecho versus a quantidade de warps onde inicia a variância diferente de zero. Executado na GPU GeForceGTX470 com 50 iterações, arquitetura virtual PTX 10 e arquitetura real SM 20.

Como podemos ver, executando o teste com uma instrução no trecho, os resultados com até oito warps obtiveram variância zero. Já com duas, três e quatro instruções no trecho, só obtivemos variância zero até seis warps. No outro extremo, com dez instruções no trecho de teste, obtivemos variância zero apenas para o teste com um warp.

Apesar de ser uma característica geral dos resultados obtidos, houve casos de instruções que não se 
comportaram dessa maneira, como por exemplo, algumas instruções de 64 bits. Os gráficos 7.32 e 7.33 mostram os resultados para as instruções mad.lo.u64 e mul.f64.

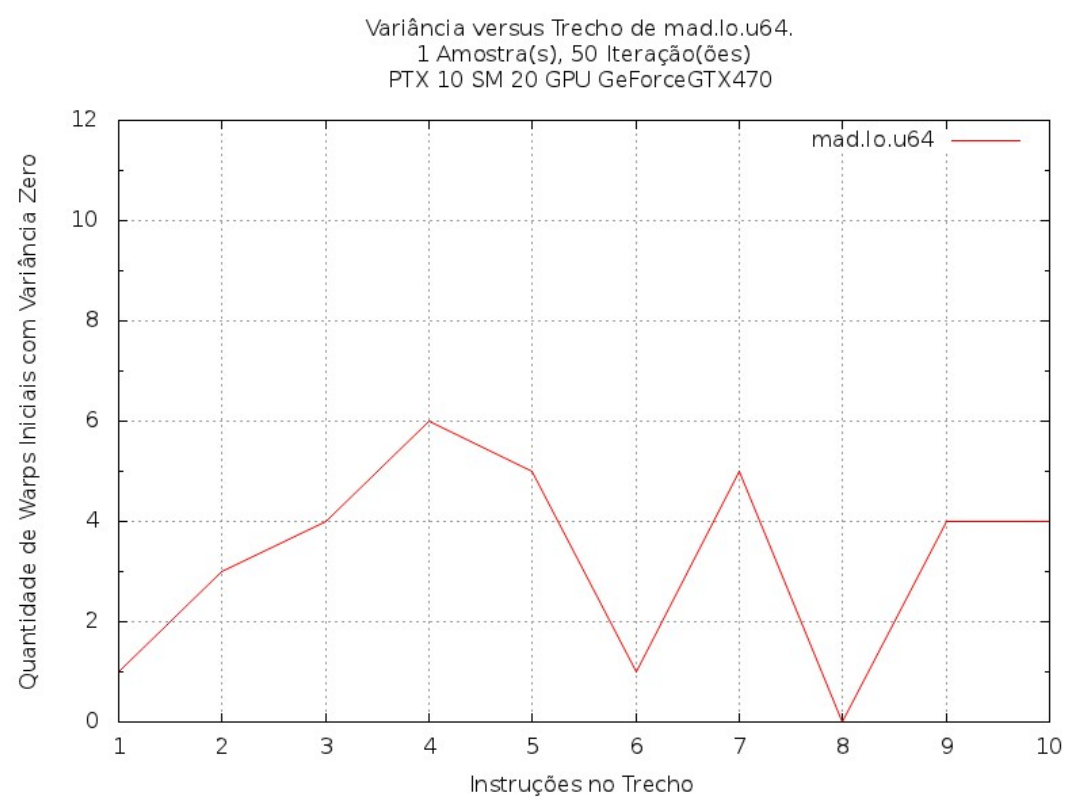

Figura 7.32: Instrução mad.lo.u64, gráfico da quantidade de instruções no trecho versus a quantidade de warps onde inicia a variância diferente de zero. Executado na GPU GeForceGTX470 com 50 iterações, arquitetura virtual PTX 10 e arquitetura real SM 20.

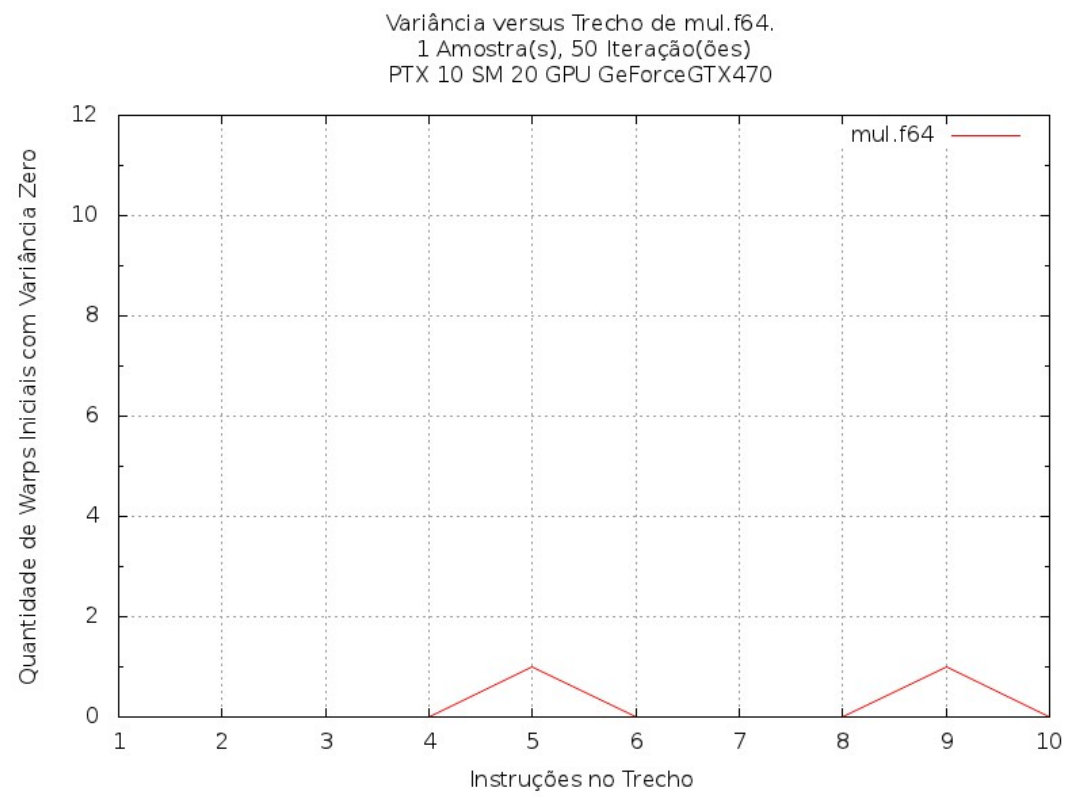

Figura 7.33: Instrução mul.f64, gráfico da quantidade de instruções no trecho versus a quantidade de warps onde inicia a variância diferente de zero. Executado na GPU GeForceGTX470 com 50 iterações, arquitetura virtual PTX 10 e arquitetura real SM 20.

Com estes testes, concluímos que a variância aparece em função da quantidade de instruções no trecho e dos warps em execução. Porém, uma visão melhor dessa dependência foi obtida com os gráficos da próxima análise. 


\section{Variância em Função do Trecho de Teste e dos Warps}

Para ter uma visão geral de como a dispersão dos resultados se comportava com o aumento dos warps e das instruções dentro do trecho, foi feito um gráfico relacionando o desvio padrão com a quantidade de instruções e de warps.

O resultado para a instrução add. $\$ 32^{9}$, analisada anteriormente, está mostrado na figura 7.34.

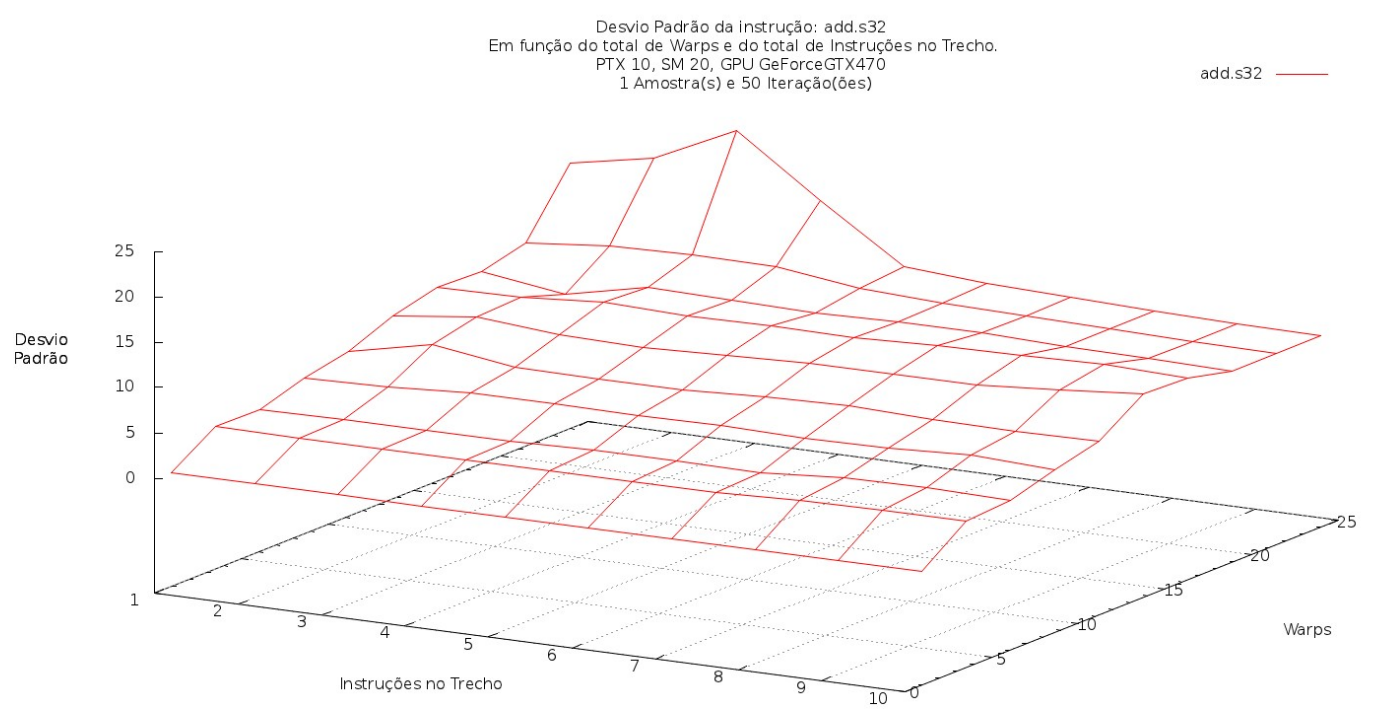

Figura 7.34: Instrução add.s32, gráfico do desvio padrão versus a quantidade de instruções no trecho versus a quantidade de warps. Executado na GPU GeForceGTX470 com 50 iterações, arquitetura virtual PTX 10 e arquitetura real SM 20.

A característica desse gráfico, de aumentar a dispersão com o aumento de warps, é representativa do comportamento das outras instruções testadas.

\subsubsection{Análise da Distribuição Após Alteração na Forma de Contabilizar o Tempo}

Nesta análise, além da variância, o foco foi a distribuição dos resultados de tempo obtidos. Para isso, foram gerados os histogramas das instruções com todas as alterações criadas anteriormente, ou seja, a forma de contabilizar o tempo, a quantidade configurável de instruções no trecho de teste e as otimizações de código.

Ao contrário das análises anteriores que consideravam o tempo bruto da instrução ${ }^{10}$, neste teste utilizamos os tempos líquidos, ou seja, o tempo do teste descontado o tempo do sistema de medição, porém, ainda não dividido pela quantidade de warps em execução e pela quantidade de instruções no trecho. Além disso, esses histogramas representam a distribuição dos tempos de execução completa do kernel em teste e não os tempos de cada warp sendo executado.

Como veremos nos exemplos a seguir, o comportamento básico dos tempos de execução seguiram o seguinte padrão:

- Em baixas quantidades de warps (abaixo de oito), poucas instruções no trecho de teste (abaixo de quatro) e instruções simples, os resultados possuem variância zero ou perto de zero;

\footnotetext{
${ }^{9}$ Os tempos utilizados foram os tempos brutos, ou seja, sem a subtração do valor de calibração. Ver seção 6.3 .1 para detalhes sobre o cálculo dos tempos.

${ }^{10}$ Sem a subtração do valor de calibração. Ver seção 6.3.1 para detalhes sobre o cálculo dos tempos.
} 
- Para instruções mais complexas, o aparecimento das variações nos resultados ocorre com uma quantidade menor de warps e instruções no trecho;

- Aumentando tanto a quantidade de warps quanto a quantidade instruções no trecho de teste, a distribuição se espalha, criando uma distribuição bimodal, principalmente em execuções com quantidades ímpares de warps. Em quantidades pares de warps, a bimodal nem sempre aparece;

- Ocorreu um limite de 10 warps para o início do aparecimento da variação nos resultados, ou seja, nenhuma instrução obteve variância zero com 11 warps;

- Apesar do limite comentado acima, algumas instruções obtiveram variância zero com 12 warps e voltaram a apresentar variação nos resultados com mais warps.

- Algumas instruções, executadas com muitos warps e muitas instruções no trecho, apresentaram distribuições divididas em bandas, de tal forma que a média não seria um bom indicador de tendência.

Para exemplificar os dois primeiros itens comentados acima, temos na figura 7.35 o histograma da instrução add.s32, que foi testada com quatro instruções no trecho e seis warps. Esse caso mostra a maior execução dessa instrução com variância zero. Já a figura 7.36 mostra a instrução lg2 approx.ftz.f32 sendo executada com três instruções no trecho de teste e três warps. O limite para a ocorrência de variações nos resultados foi menor nessa instrução do que na instrução add.s32.

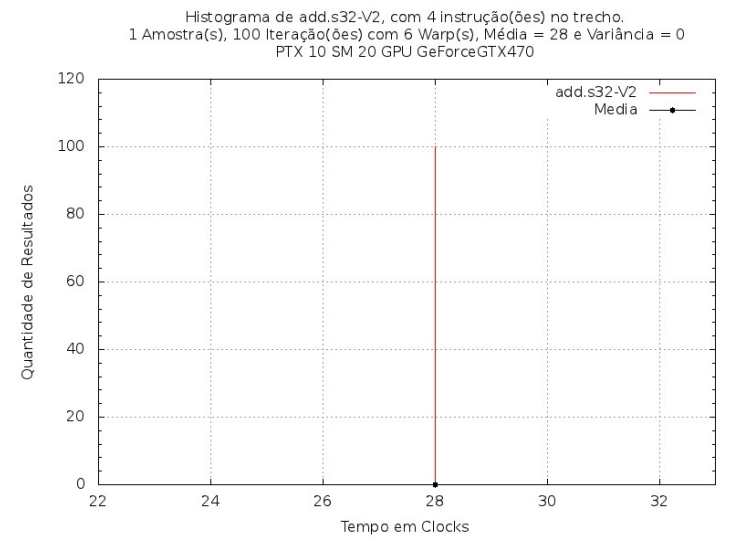

Figura 7.35: Histograma da instrução add.s32 com 4 instruções no trecho, 192 threads (6 warps), 100 amostragens e considerando o tempo total do kernel. Os tempos indicados possuem a calibragem descontada.

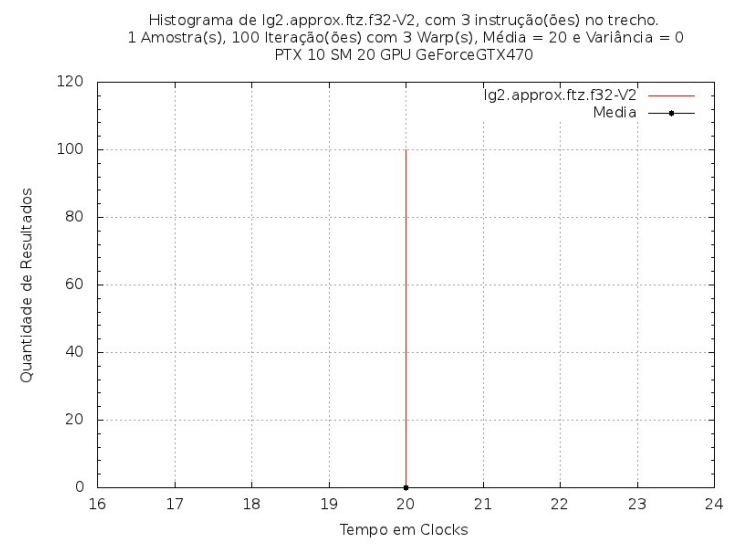

Figura 7.36: Histograma da instrução lg2.approx.ftz.f32 com 3 instruções no trecho, 96 threads (3 warps), 100 amostragens $e$ considerando o tempo total do kernel. Os tempos indicados possuem a calibragem descontada.

O terceiro item dos padrões está exemplificado nos histogramas das figuras 7.37 e 7.38 , onde temos a instrução mul.hi.u32 em execuções com 15 e 16 warps, ambas com 10 instruções no trecho. Nessas figuras fica evidenciada a dependência da distribuição bimodal e da paridade da quantidade de warps sendo executada. Ou seja, para a mesma instrução, com uma grande quantidade de instruções no trecho (dez) e executada com 15 warps a distribuição é mais espalhada e a variância maior do que se executarmos com 16 warps.

O quarto e o quinto itens dos padrões está exemplificado nas figuras 7.39 e 7.40. Elas mostram a execução da instrução mul.sat.f32 com dez instruções no trecho de teste e com 11 e 12 warps respectivamente. Como todas as outras instruções, na execução com 11 warps, sempre existe variação nos resultados, apesar dela sumir em algumas instruções quando executado com 12 warps.

Por fim, o sexto item dos padrões está exemplificado nas figuras 7.41 e 7.42. Nelas temos as instruções 


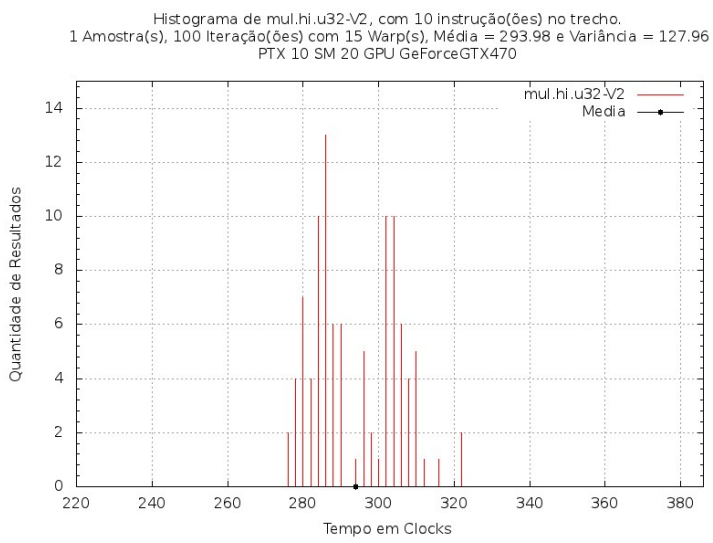

Figura 7.37: Histograma da instrução mul.hi.u32 com 10 instruções no trecho, 480 threads (15 warps), 100 amostragens e considerando o tempo total do kernel. Os tempos indicados possuem a calibragem descontada.

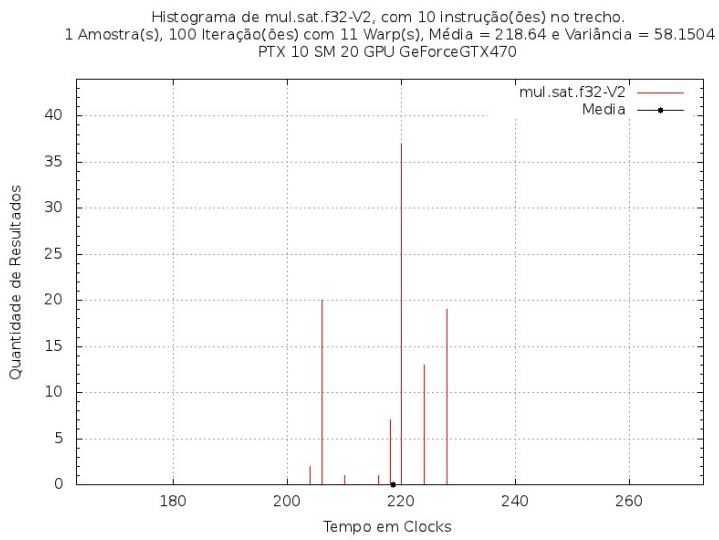

Figura 7.39: Histograma da instrução mul.sat.f32 com 10 instruções no trecho, 352 threads (11 warps), 100 amostragens e considerando o tempo total do kernel. Os tempos indicados possuem a calibragem descontada.

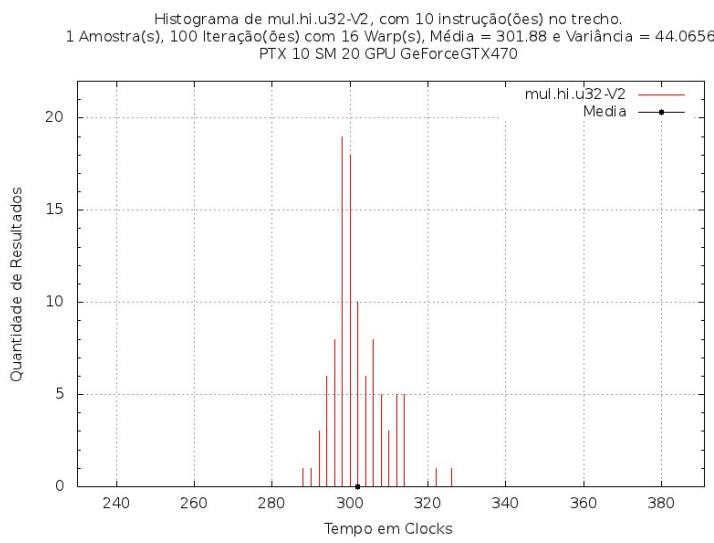

Figura 7.38: Histograma da instrução mul.hi.u32 com 10 instruções no trecho, 512 threads (16 warps), 100 amostragens e considerando o tempo total do kernel. Os tempos indicados possuem a calibragem descontada.

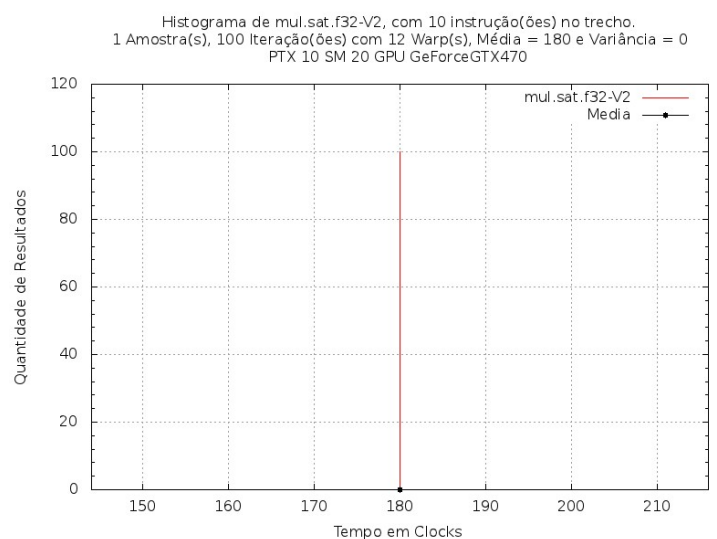

Figura 7.40: Histograma da instrução mul.sat.f32 com 10 instruções no trecho, 384 threads (12 warps), 100 amostragens e considerando o tempo total do kernel. Os tempos indicados possuem a calibragem descontada.

mov.f64 e selp.f64 executadas com dez instruções no trecho de teste e 15 warps. Podemos ver que as distribuições possuem alta variabilidade e tendências laterais. Como comenta Raj Jain (Jain, 1991, p. 179-219), nesse tipo de distribuição a média não é o valor mais indicado para representar a tendência.

\subsubsection{Análise do Sistema de Medição}

Durante os testes de verificação da variância em função do número de warps em execução, notamos que o sistema de calibragem também possui variação nos resultados e que ela depende do total de warps em execução.

Como o valor da calibragem (ou calibração) entra no cálculo do tempo líquido da instrução, sua variância influencia a variância final de todas as instruções testadas (ver a seção 6.3.1 para detalhes sobre o cálculo do tempo da instrução). Essa característica, por si só, já limita a acurácia dos resultados obtidos com mais de dez warps. 


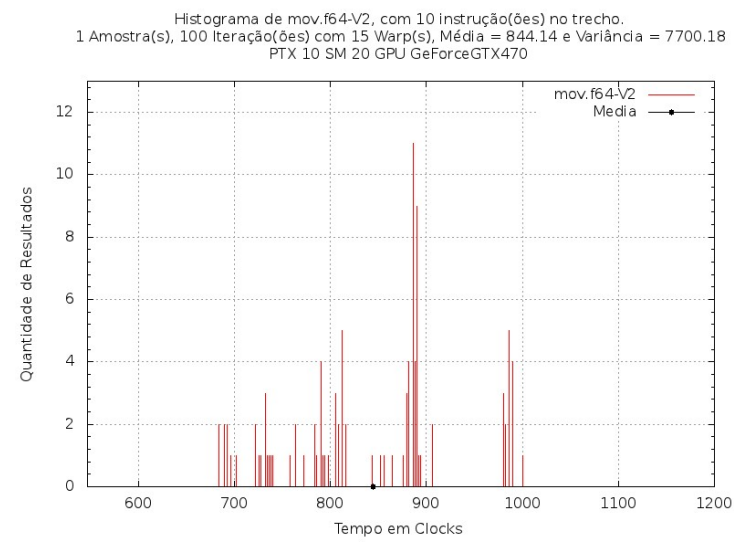

Figura 7.41: Histograma da instrução mov.f64 com 10 instruções no trecho, 480 threads (15 warps), 100 amostragens e considerando o tempo total do kernel. Os tempos indicados possuem a calibragem descontada.

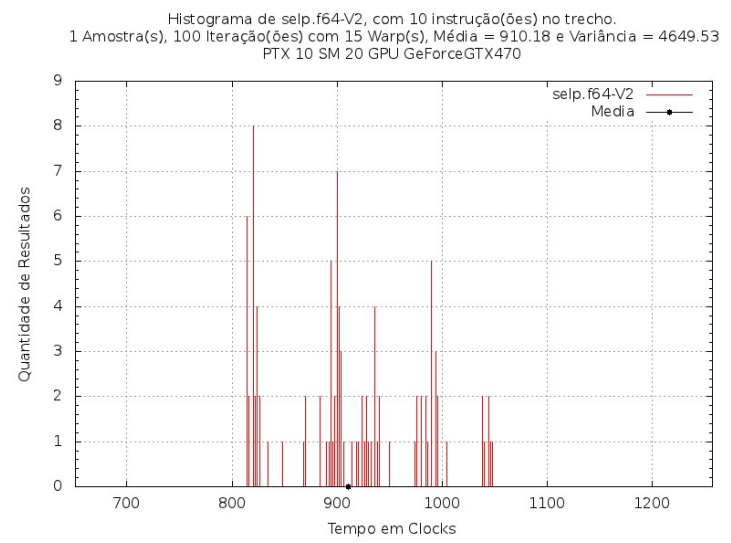

Figura 7.42: Histograma da instrução selp.f64 com 10 instruções no trecho, 480 threads (15 warps), 100 amostragens e considerando o tempo total do kernel. Os tempos indicados possuem a calibragem descontada.

A variação nos resultados da calibragem aparece a partir da execução com 11 warps ${ }^{11}$. Ou seja, nas execuções com um warp até dez warps, a variância dos resultados do sistema de medição é zero, como pode ser visto na figura 7.43.

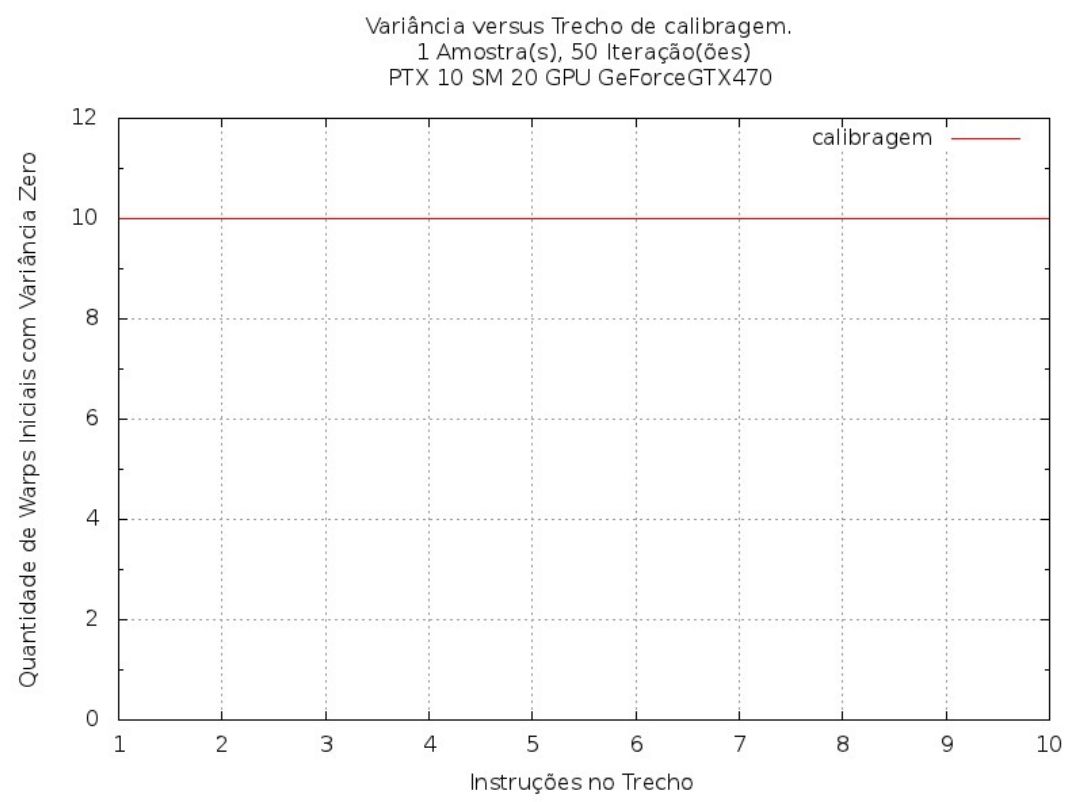

Figura 7.43: Calibragem, gráfico da quantidade de instruções no trecho versus a quantidade de warps onde inicia a variância diferente de zero. Executado na GPU GeForceGTX470 com 50 iterações, arquitetura virtual PTX 10 e arquitetura real SM 20.

As distribuições das execuções acima de dez warps, com exceção da execução com 12 warps, sempre possuem dispersão, independentemente se o número de warps sendo executado é par ou ímpar. Alguns exemplos são mostrados nas figuras 7.44, 7.45, 7.46 e 7.47. Neles estão os histogramas dos resultados da calibragem para 13, 14, 23 e 24 warps respectivamente. Esses histogramas são representativos do que acontece acima de 12 warps e podemos notar o espalhamento dos resultados.

Esses gráficos nos mostram que o sistema de leitura do registrador ${ }^{\circ} \mathrm{clock}$, utilizado para contabilizar o tempo de execução, responde de forma diferente conforme a quantidade de warps em

\footnotetext{
${ }^{11}$ Como a calibragem é um trecho vazio, o resultado é independente da quantidade de instruções no trecho.
} 


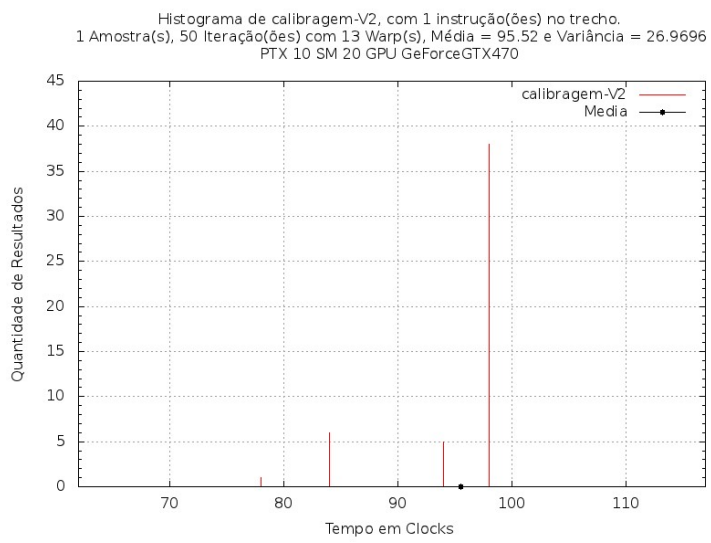

Figura 7.44: Histograma da calibragem com 416 threads (13 warps), 50 amostragens e considerando o tempo total do kernel.

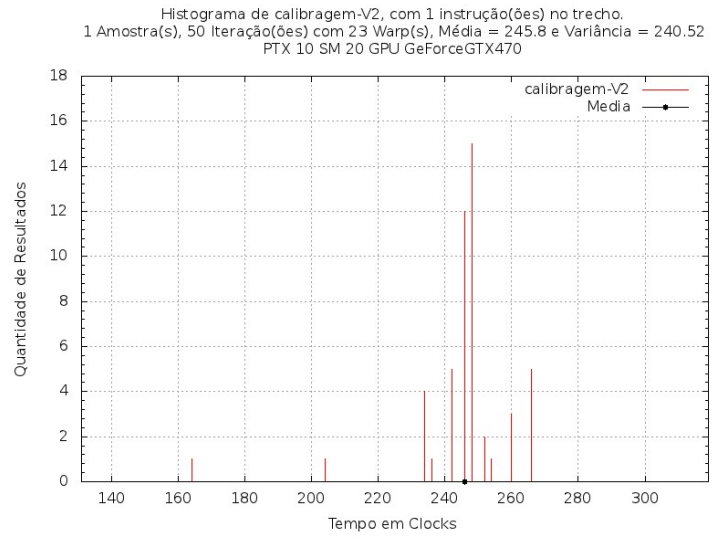

Figura 7.46: Histograma da calibragem com 736 threads (23 warps), 50 amostragens e considerando o tempo total do kernel.

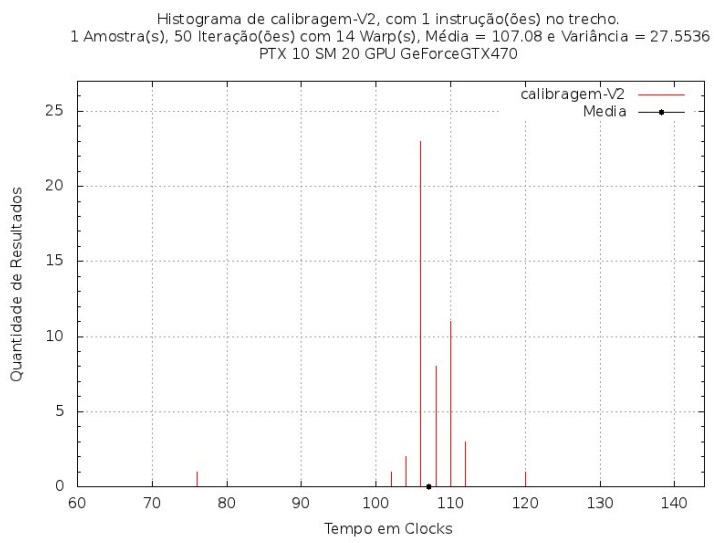

Figura 7.45: Histograma da calibragem com 448 threads (14 warps), 50 amostragens e considerando o tempo total do kernel.

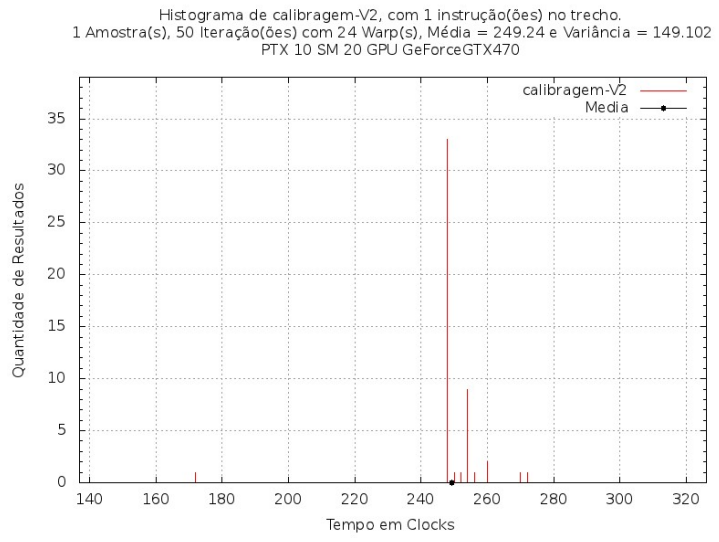

Figura 7.47: Histograma da calibragem com 768 threads (24 warps), 50 amostragens e considerando o tempo total do kernel.

execução. Isso, possivelmente, é devido ao escalonamento e contenções do registrador 。clock. Essa também pode ser a explicação para a variância zero, tão frequente nos testes com uma instrução no trecho e 12 warps, apesar dos testes com 11 warps possuírem variações.

Outra consequência dessa variação nos resultados da calibragem é a diminuição da região de precisão dos testes. Isso porque a variância da calibragem influencia na variância do resultado final de todas as instruções.

Essa situação evidencia a presença de alguns limitantes no processo de obtenção do tempo da instrução:

- Com uma quantidade pequena de instruções no trecho de teste, a precisão fica comprometida;

- Com uma quantidade grande de instruções no trecho, apesar de melhorar a precisão, constatase a presença de variação nos resultados;

- Com uma quantidade pequena de warps executando, as possíveis latências não são diluídas e existe maior dificuldade para o escalonamento encontrar um warp disponível para executar;

- Com uma quantidade grande de warps executando, o sistema de leitura de tempo influi nos resultados obtidos.

Além desses limitantes, existe outro muito significativo, que é uma característica do pipeline e trata 
da relação entre o tempo de execução e a sequência de instruções sendo executada. Veremos os detalhes na seção 7.3.

\subsubsection{Análise do Perfil da Instrução}

A análise que depende da maior quantidade de dados é o levantamento do perfil da instrução. Nele são executados testes incrementais que variam tanto a quantidade de threads quanto a quantidade de instruções no trecho.

Os valores obtidos são os valores médios segundo a descrição dada na seção 6.3.1, ou seja, descontando a calibragem e dividindo pela quantidade de instruções no trecho e pelo total de warps.

Os resultados desses testes são utilizados para gerar dois gráficos:

- um gráfico 3D de tempo médio da instrução em função da quantidade de instruções e em função das threads em execução;

- um gráfico em 2D que relaciona o tempo médio da instrução (para cada execução com quantidades diferentes no trecho de teste) com a quantidade de threads.

Na figura 7.48 temos um exemplo de gráfico 3D para a instrução add.s32. Na figura 7.49 temos o gráfico 2D para a mesma instrução.

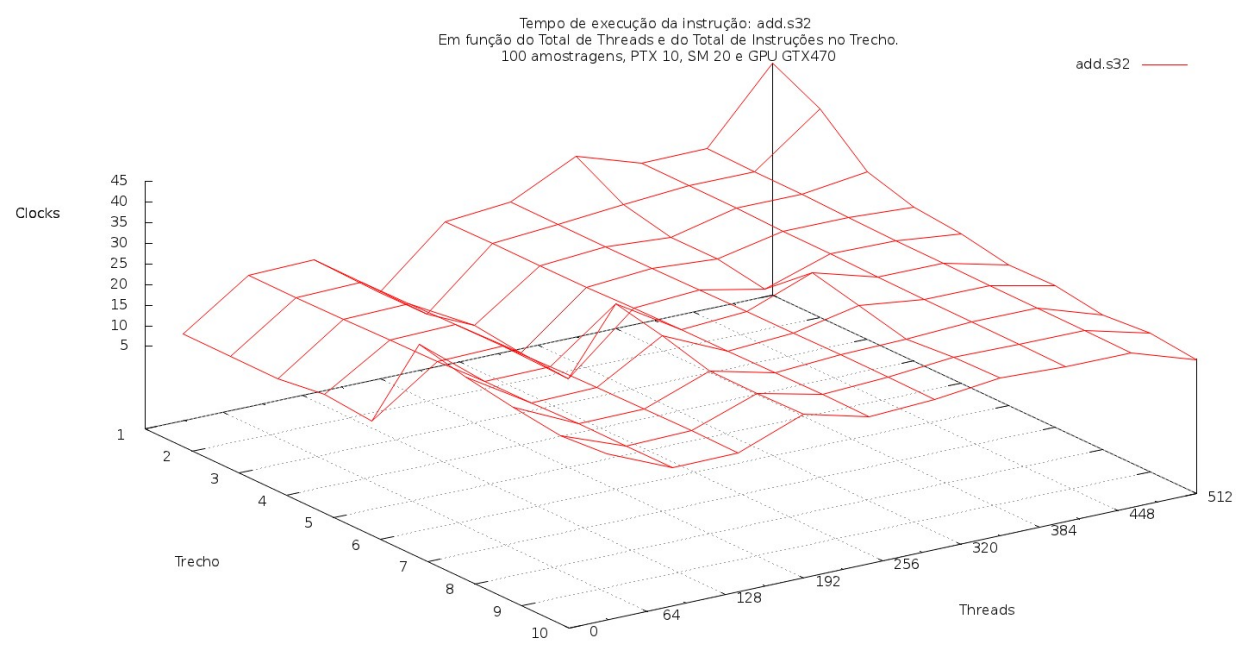

Figura 7.48: Instrução add.s32, gráfico $3 D$ do tempo médio de execução pela quantidade de instruções no trecho pela quantidade de threads. Executado na GPU GeForceGTX470 com 100 iterações, arquitetura virtual PTX 10 e arquitetura real SM 20.

A análise desses gráficos mostrou que as instruções podem ser agrupadas de acordo com as suas características de escalabilidade, considerando tanto o aumento de threads em execução quanto a quantidade de instruções no trecho de teste.

Na figura 7.49 temos o caso do add.s32, que representa o mesmo do grupo das instruções abs. f32, cvt.rm.f32.u16, mov.b16, mov.b32 e o mul.ftz.f32, entre outras. Esse grupo é caracterizado pelos resultados concentrados em dois patamares distintos, quando executado com uma pequena quantidade de threads, e a convergência para uma faixa de resultados, mais estreita, com o aumento das threads em execução.

Podemos ver na figura 7.49 que, o primeiro patamar é o agrupamento dos resultados da execução com uma a cinco instruções no trecho e o segundo são os resultados com seis a dez instruções. A convergência inicia em 192 threads e após 320 threads os valores obtidos estão confinados a uma 


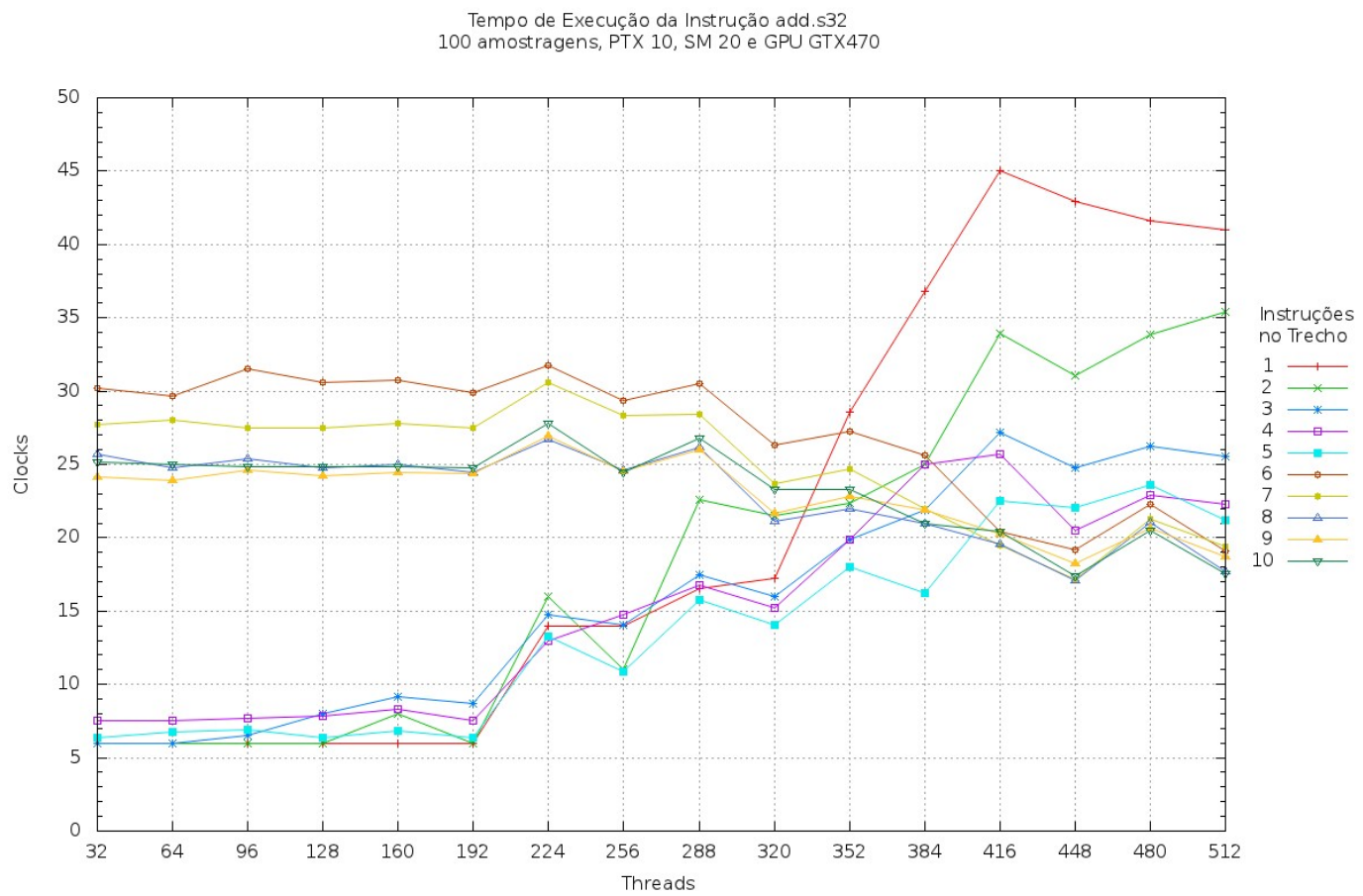

Figura 7.49: Instrução add.s32, gráfico do tempo médio de execução para cada quantidade de instruções no trecho pela quantidade de threads. Executado na GPU GeForceGTX470 com 100 iterações, arquitetura virtual PTX 10 e arquitetura real SM 20.

faixa menor. A exceção ocorre nas execuções com uma e duas instruções no trecho, que diferente das outras, divergem após 320 threads.

Uma possível explicação para esse comportamento leva em consideração a forma como a GPU escalona os warps e a disponibilidade do pipeline. Como vimos no capítulo 3, um dos fatores para o escalonador escolher qual o próximo warp a ser executado é a disponibilidade de warps em condições de execução. Dessa forma, se em um dado momento tivermos todos os warps utilizando as mesmas unidades funcionais ou recursos do pipeline, o escalonador não terá opção para execução. Assim, o pipeline não alcançará seu melhor desempenho (NVIDIA, 2011d, p. 66).

Assim, podemos supor que, até 192 threads e até cinco instruções no trecho, o pipeline executa antes da saturação. Ou seja, não há espera para o início da execução das instruções. Aparentemente, essa combinação é um ponto ótimo de execução para essa instrução. Porém, aumentando a quantidade de warps, aumenta a disputa pelos mesmos recursos de execução e alguns warps terão de esperar. O impacto dessa espera é o aumento do tempo médio de execução, até atingir a faixa de convergência dos resultados (de 384 a 512 threads).

A exceção para a execução com uma e duas instruções pode ser explicada pela pequena quantidade de instruções no trecho. Isso faz que a execução se torne, praticamente, a serialização dos trechos dos diversos warps e, dessa forma, o seu tempo aumenta com a quantidade de warps.

Por outro lado, com até 192 threads e mais do que cinco instruções no trecho, o pipeline executa dentro de uma condição de saturação, onde há espera para a execução do próximo warp. Porém, com o aumento da quantidade de warps, aparenta que há uma adequação melhor entre o ciclo de escalonamento e a disponibilidade para execução. Dessa forma, o aumento na quantidade de warps leva os resultados para a faixa de convergência (de 384 a 512 threads).

Outra característica deste padrão, que também aparece em outros padrões, é a alternância de resultados melhores (mais rápidos) para execuções com quantidade par de warps e resultados um pouco piores (mais lentos) para execuções com quantidade ímpar de warps. Uma possível explicação 
é a ocorrência de conflito de bancos de registradores, como pode ser visto na seção 6.4.4. Como indicado pela NVIDIA, o melhor resultado é obtido quando o número de threads por bloco é múltiplo de 64, ou seja, um número par de warps. Outra possibilidade é a existência de uma quantidade par de unidades funcionais que executam essa instrução. Dessa forma, quando executado com uma quantidade ímpar de warps, teremos, em algum momento, uma unidade funcional ociosa. Essa não utilização de todos os recursos de execução impacta negativamente o tempo de execução.

De forma parecida, o add. s64 mostrado na figura 7.50, em 3D, e na figura 7.51, em 2D, também apresenta os resultados se reunindo em bandas, em função da quantidade de instruções no trecho e quando executado com poucas threads. Também converge para uma faixa comum, com o aumento da quantidade de threads. Esse comportamento é similar ao das instruções cvt.s64.u16, set.eq.xor.s32.u64, set.ge.and.s32.s64, set.ge.s32.s64, sub.s64, sub.u64, entre outras. Podemos notar que temos três bandas na execução com poucos warps, ao invés de duas, como na instrução add.s32. E a convergência ocorre com uma quantidade maior de threads, quando comparada com a add.s32.

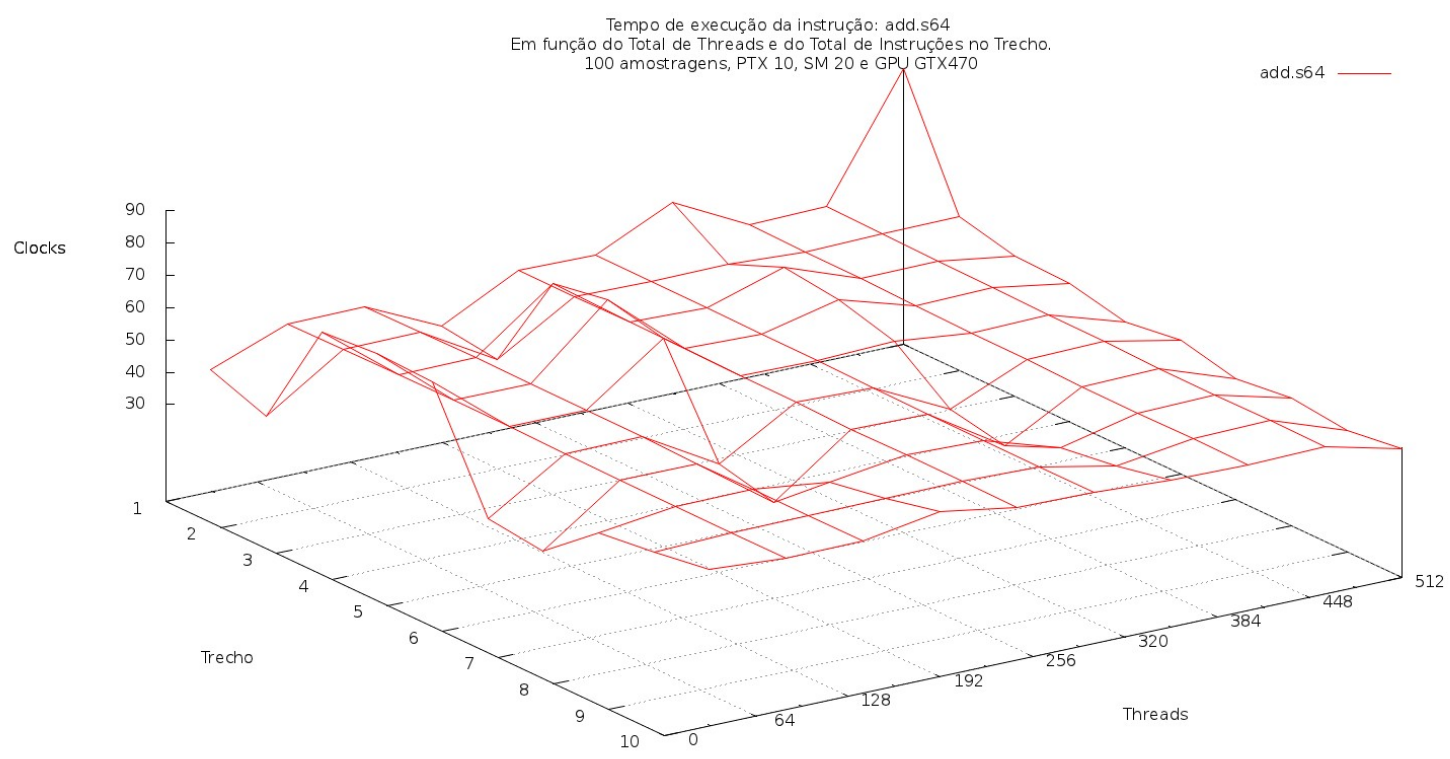

Figura 7.50: Instrução add.s64, gráfico $3 D$ do tempo médio de execução pela quantidade de instruções no trecho pela quantidade de threads. Executado na GPU GeForceGTX470 com 100 iterações, arquitetura virtual PTX 10 e arquitetura real SM 20.

Outro perfil de instrução é o formado pelo grupo do sqrt.approx. f32, ao qual pertence o ex2.approx.ftz e o div.approx.ftz. Pode ser visto na figura 7.52 (3D) e na figura 7.53 (2D). Ele apresenta um comportamento mais linear, apesar da exceção em baixas quantidades de instruções no trecho. Uma aproximação razoável para esse perfil seria uma única reta para todas as quantidades de instruções no trecho e com inclinação constante.

Para este padrão, aparenta que, os custos de escalonamento e execução são constantes e dependentes da quantidade de warps, isso, a partir de três instruções consecutivas no trecho de teste. Possivelmente, o pipeline tenha encontrado o seu limite acima desse valor e, por isso, temos tempos melhores para uma ou duas instruções no trecho.

Por sua vez, o grupo que contém o div.rn.f64, o div.s16 e outras instruções de divisão, mostrado na figura 7.54 (3D) e 7.55 (2D), apresenta uma curva de resposta para cada quantidade distinta de instruções no trecho. Essas curvas são paralelas umas às outras, com distanciamento que varia conforme a instrução executada, podendo, como no caso da div.s32, estarem restritas a uma faixa proporcionalmente menor do que a faixa do div.rn.f64. 
Tempo de Execução da Instrução add.s64 100 amostragens, PTX 10, SM 20 e GPU GTX470

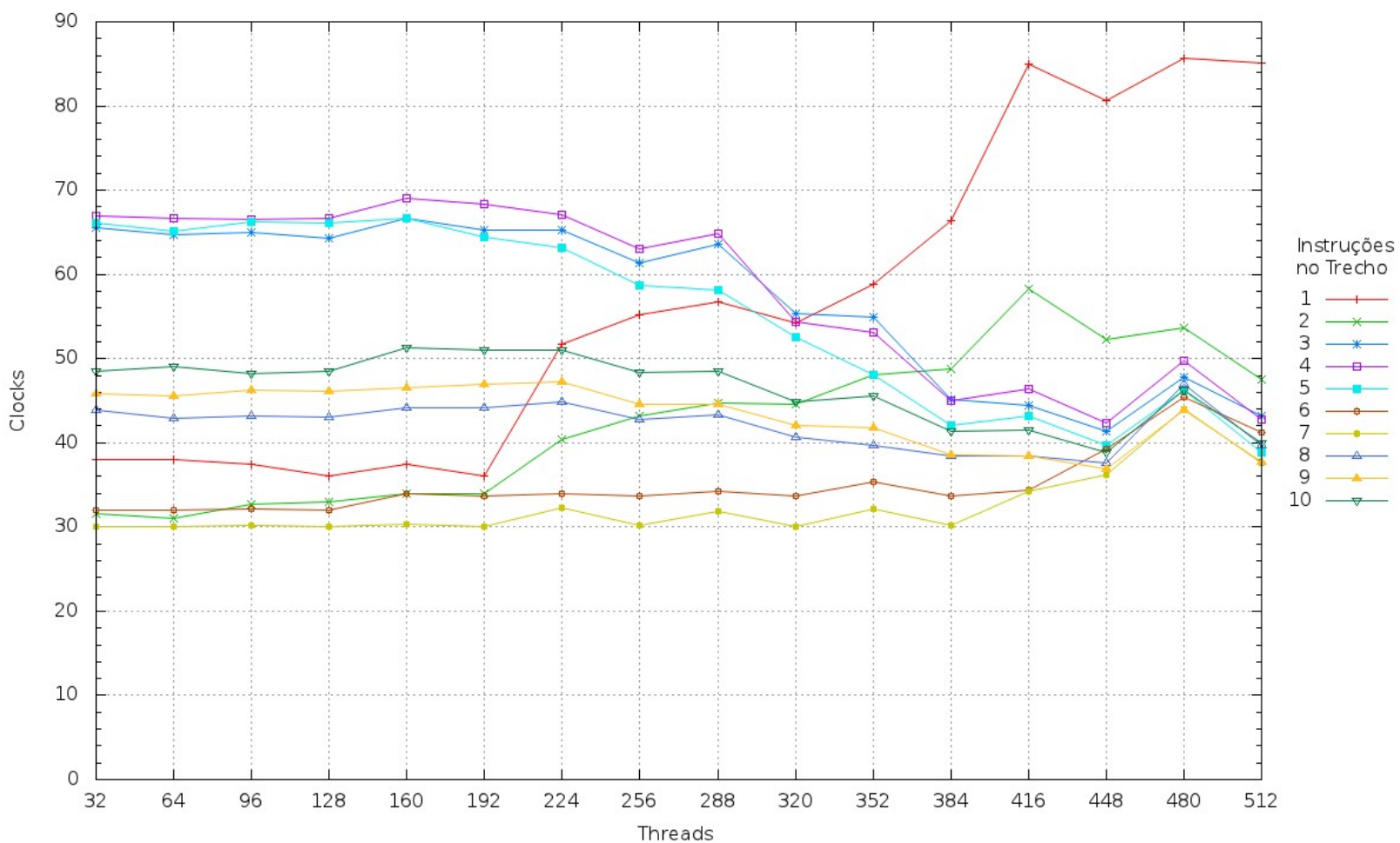

Figura 7.51: Instrução add.s64, gráfico do tempo médio de execução para cada quantidade de instruções no trecho pela quantidade de threads. Executado na GPU GeForceGTX470 com 100 iterações, arquitetura virtual PTX 10 e arquitetura real SM 20.

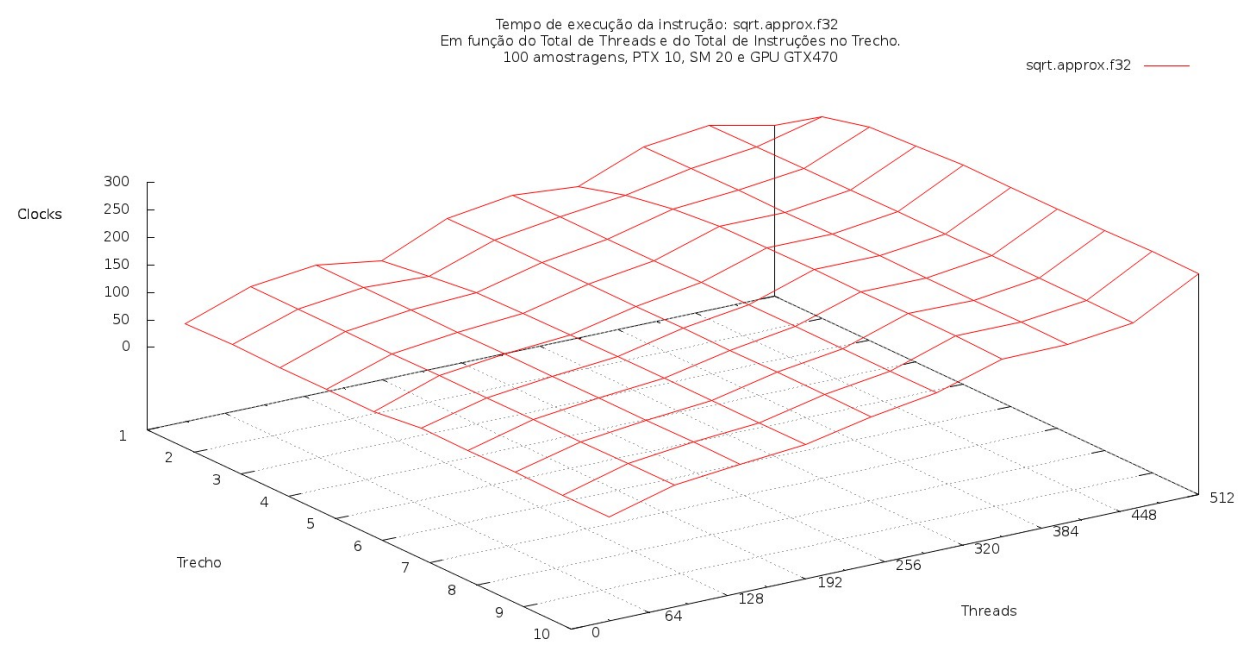

Figura 7.52: Instrução sqrt.approx.f32, gráfico 3D do tempo médio de execução pela quantidade de instruções no trecho pela quantidade de threads. Executado na GPU GeForceGTX470 com 100 iterações, arquitetura virtual PTX 10 e arquitetura real SM 20.

Neste padrão, possivelmente, temos a capacidade de execução do pipeline sendo atingida somente com nove ou dez instruções no trecho de execução (onde obtemos os menores tempos) independentemente da quantidade de warps sendo executados. A curva descrita, com o aumento de warps em execução, poderia ser explicada como o aumento dos custos de execução com o aumento dos warps. Por sua vez, os deslocamentos horizontais poderiam ser interpretados como o aumento da utilização do pipeline antes da sua saturação, uma vez que existem ganhos de desempenho. 


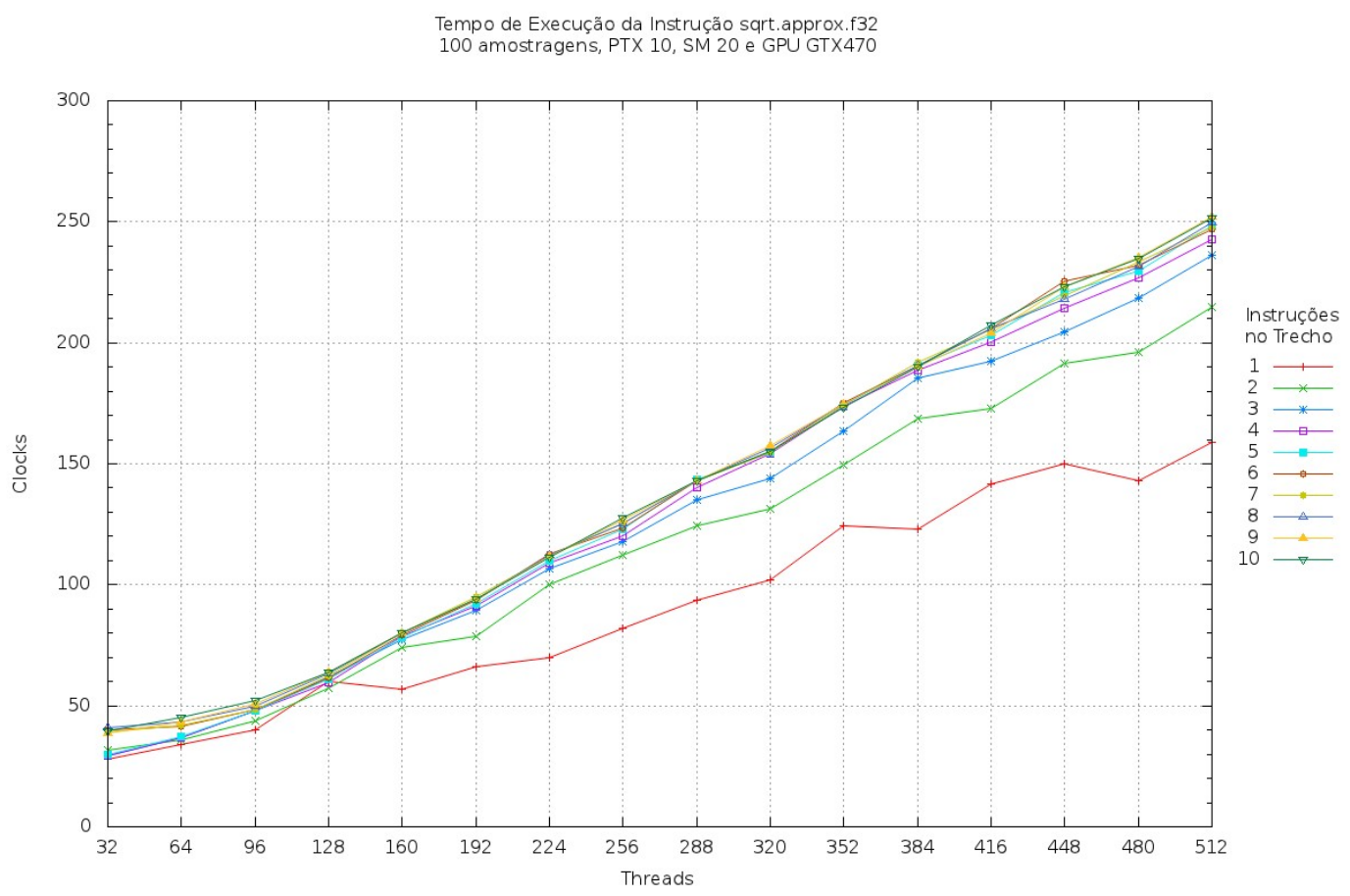

Figura 7.53: Instrução sqrt.approx.f32, gráfico do tempo médio de execução para cada quantidade de instruções no trecho pela quantidade de threads. Executado na GPU GeForceGTX470 com 100 iterações, arquitetura virtual PTX 10 e arquitetura real SM 20.

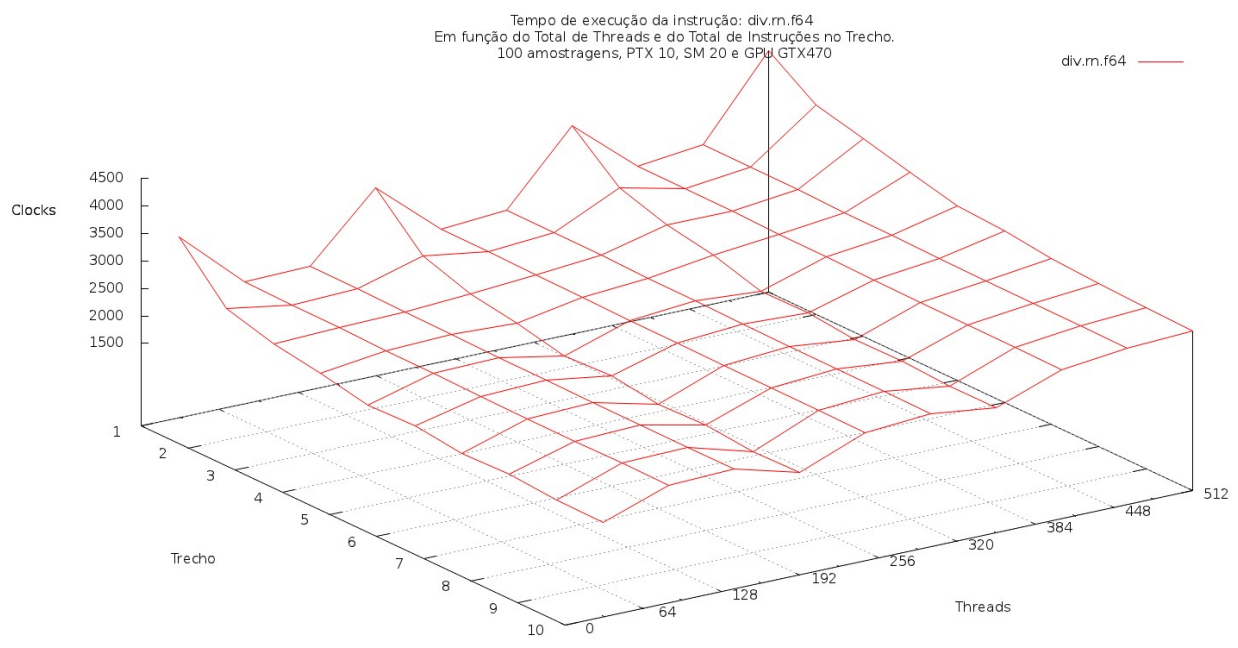

Figura 7.54: Instrução div.rn.f64, gráfico 3D do tempo médio de execução pela quantidade de instruções no trecho pela quantidade de threads. Executado na GPU GeForceGTX470 com 100 iterações, arquitetura virtual PTX 10 e arquitetura real SM 20.

O perfil de execução da instrução sub.rn.f64, que é mostrado na figura 7.56 (3D) e 7.57 (2D), é similar ao da instrução mul.rn.f64, neg.f64, min.f64 e max.f64, entre outras. Elas apresentam uma variação nos resultados para cima e para baixo (melhorando e piorando o desempenho) a cada incremento de warp em execução, formando assim, um dente de serra inclinado.

Como comentado anteriormente, uma possível explicação desse comportamento é a existência de uma quantidade par de unidades funcionais que executam essa instrução ou o conflito de bancos de registradores. Isso, somado aos custos do aumento de warps em execução. Esses fatores nos dariam a inclinação constante, juntamente com o efeito dente de serra. 


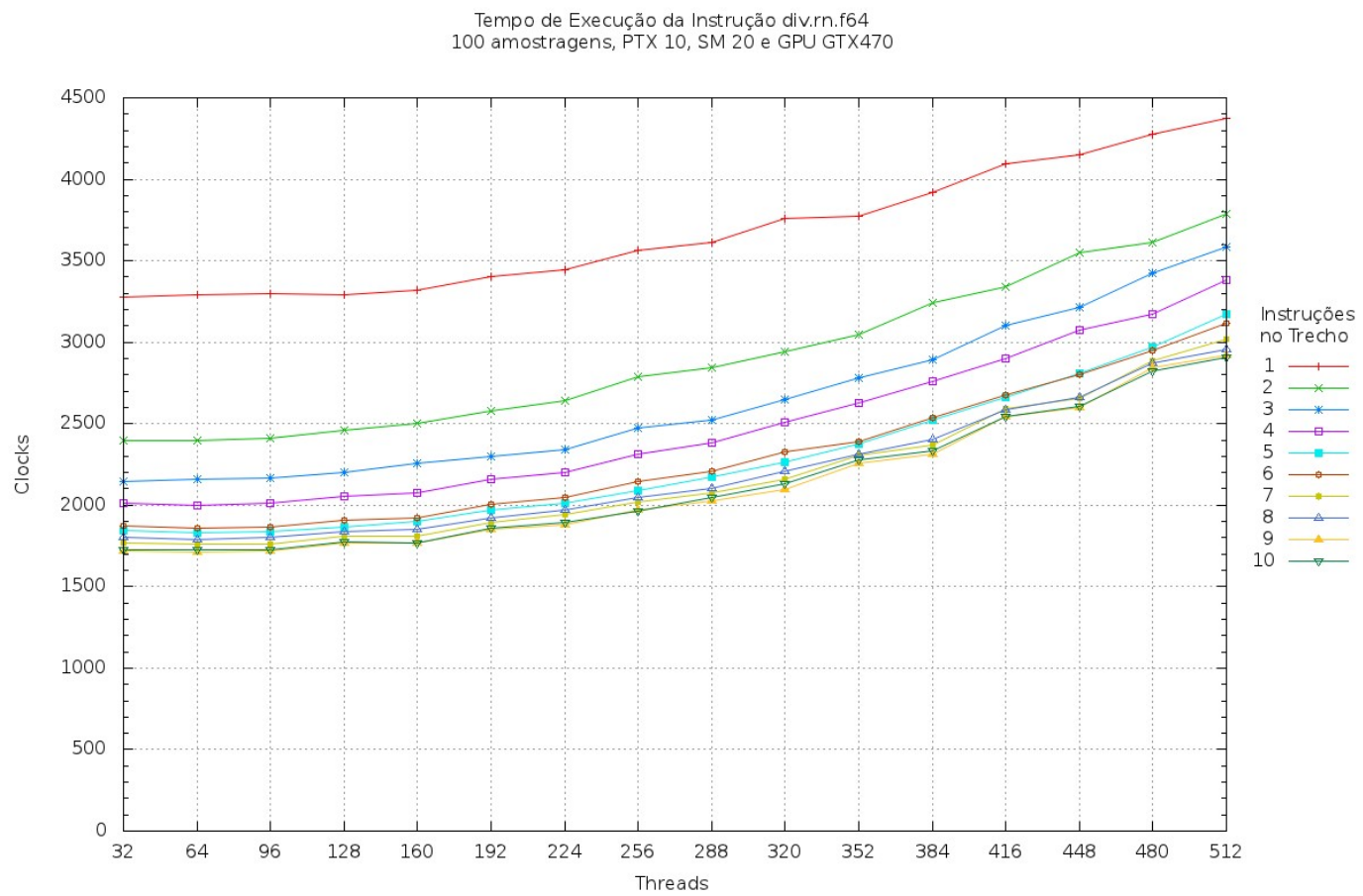

Figura 7.55: Instrução div.rn.f64, gráfico do tempo médio de execução para cada quantidade de instruções no trecho pela quantidade de threads. Executado na GPU GeForceGTX470 com 100 iterações, arquitetura virtual PTX 10 e arquitetura real SM 20.

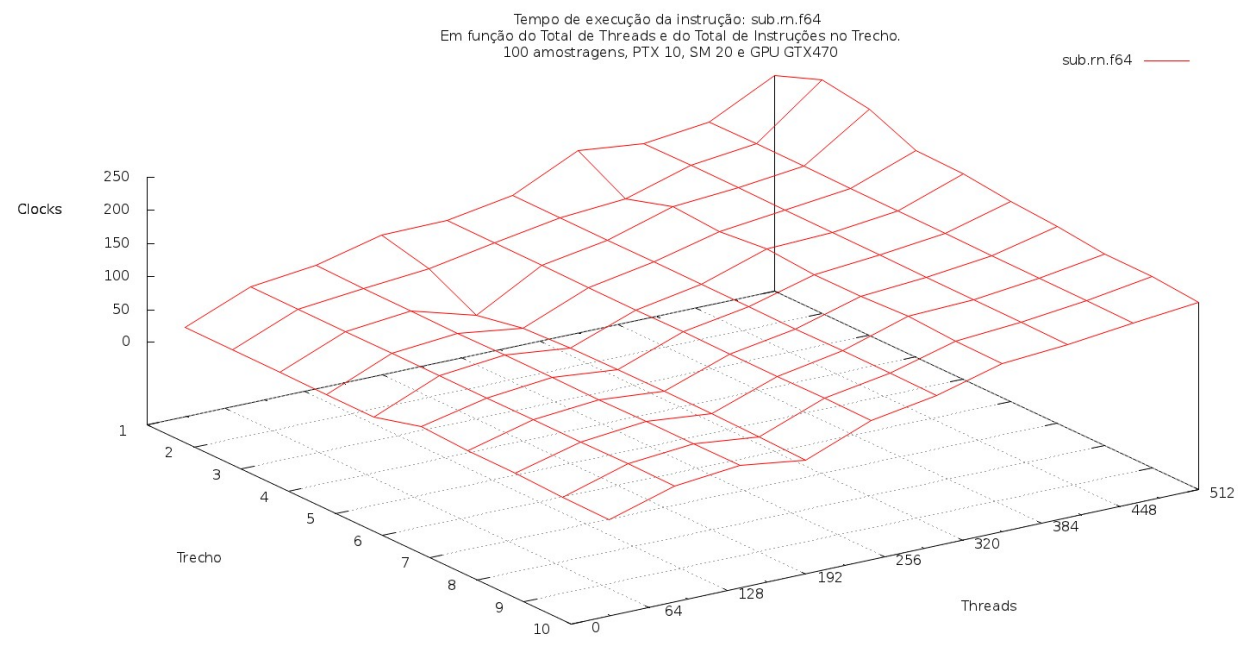

Figura 7.56: Instrução sub.rn.f64, gráfico 3D do tempo médio de execução pela quantidade de instruções no trecho pela quantidade de threads. Executado na GPU GeForceGTX470 com 100 iterações, arquitetura virtual PTX 10 e arquitetura real SM 20.

Apesar de existirem outros grupos, esses são os mais característicos e os outros grupos são uma variação desses padrões apresentados. Essas variações podem, por exemplo, ser um aumento na dispersão com o aumento das threads; a mudança na quantidade de threads onde ocorre o início da convergência (como na instrução set.eq.u32.s64), ou mesmo uma combinação de outros padrões formando um novo.

Um exemplo dessa variação está na figura 7.58 e 7.59, onde temos a instrução mul.rn.f32. Em relação aos padrões anteriores, ela apresenta uma menor concentração dos resultados nas execuções com até três instruções no trecho e acima de 256 threads; a convergência iniciando com uma quan- 


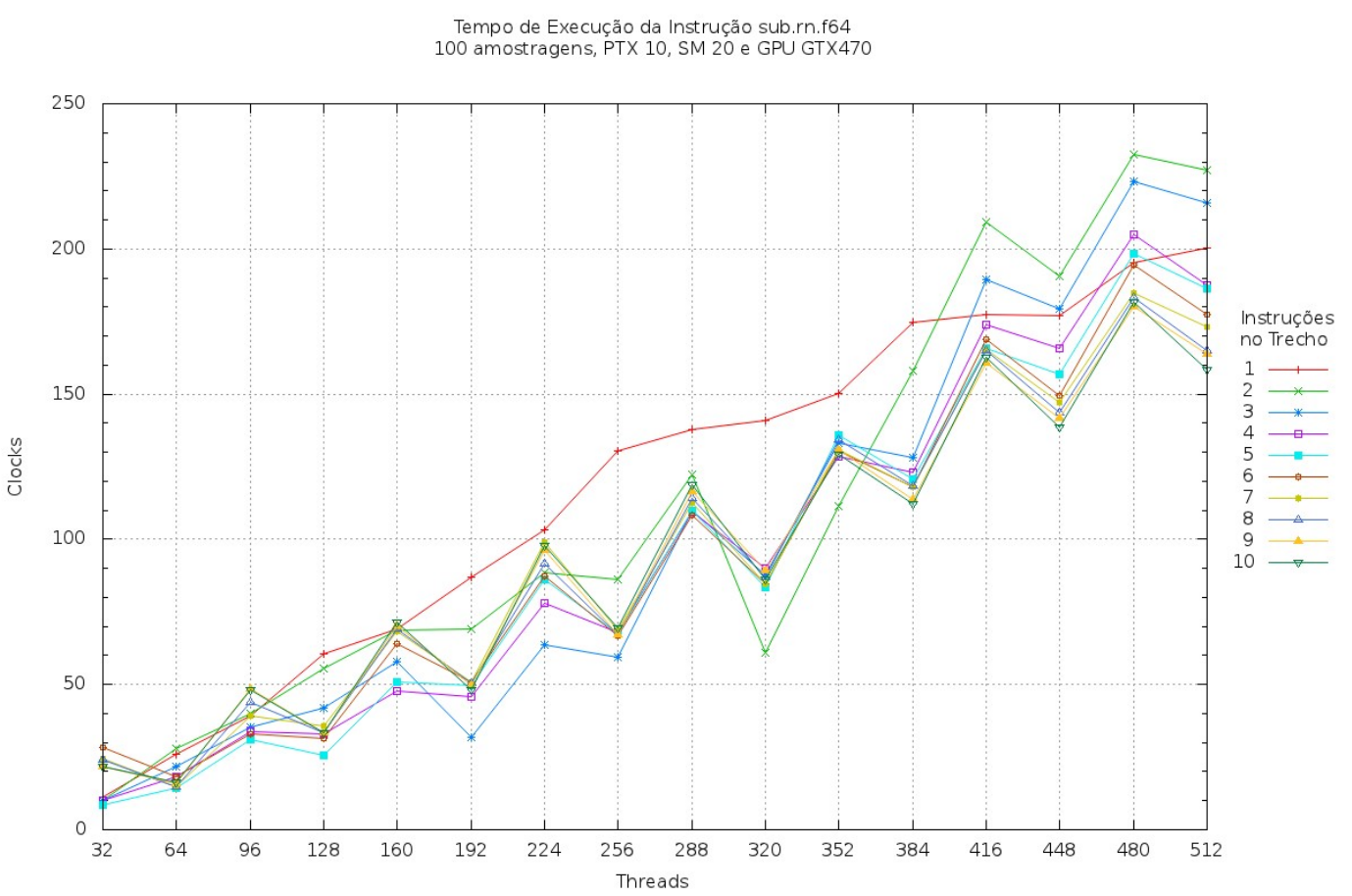

Figura 7.57: Instrução sub.rn.f64, gráfico do tempo médio de execução para cada quantidade de instruções no trecho pela quantidade de threads. Executado na GPU GeForceGTX470 com 100 iterações, arquitetura virtual PTX 10 e arquitetura real SM 20.

tidade menor de threads e o revesamento entre um desempenho maior e outro menor conforme a quantidade de warps em execução.

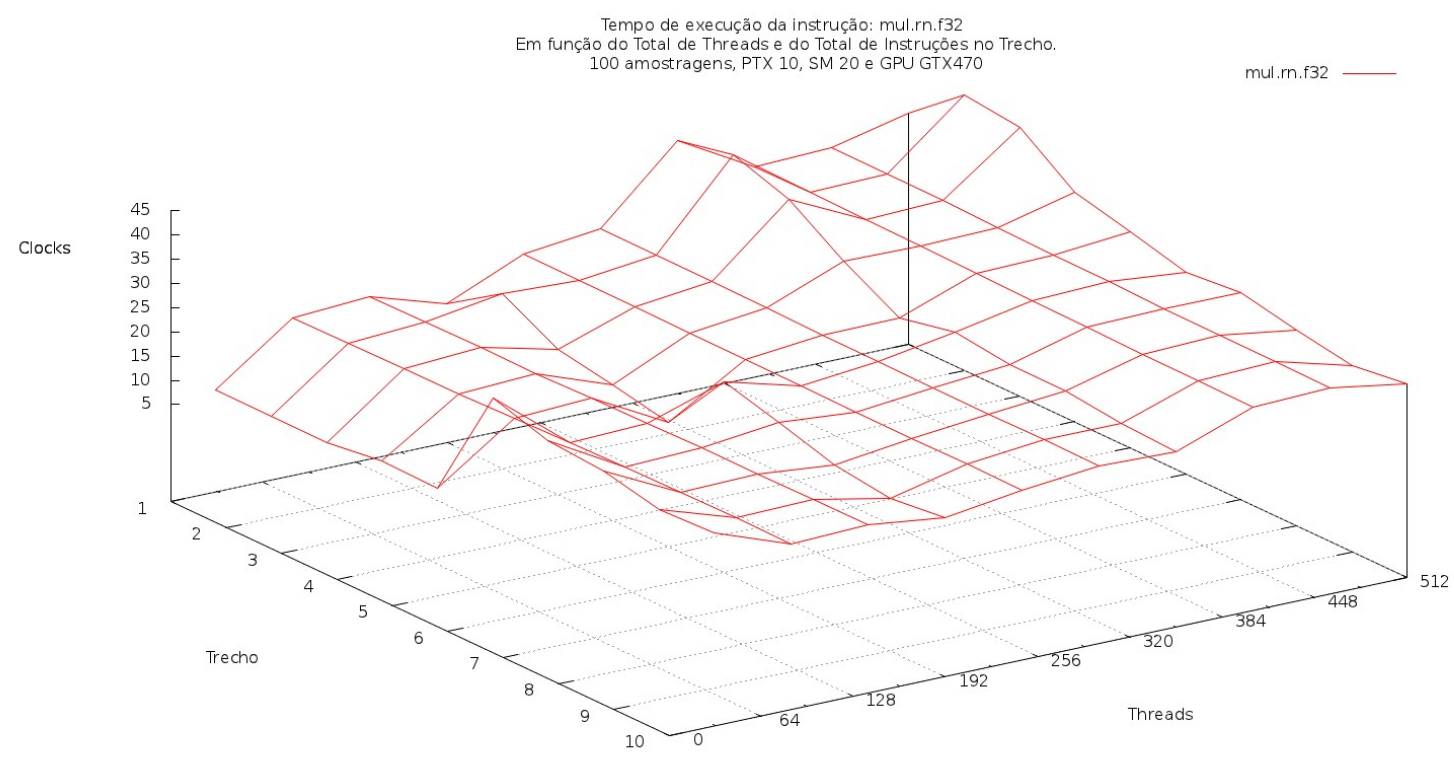

Figura 7.58: Instrução mul.rn.f32, gráfico 3D do tempo médio de execução pela quantidade de instruções no trecho pela quantidade de threads. Executado na GPU GeForceGTX470 com 100 iterações, arquitetura virtual PTX 10 e arquitetura real SM 20. 
Tempo de Execução da Instrução mul.rn. f32 100 amostragens, PTX 10, SM 20 e GPU GTX470

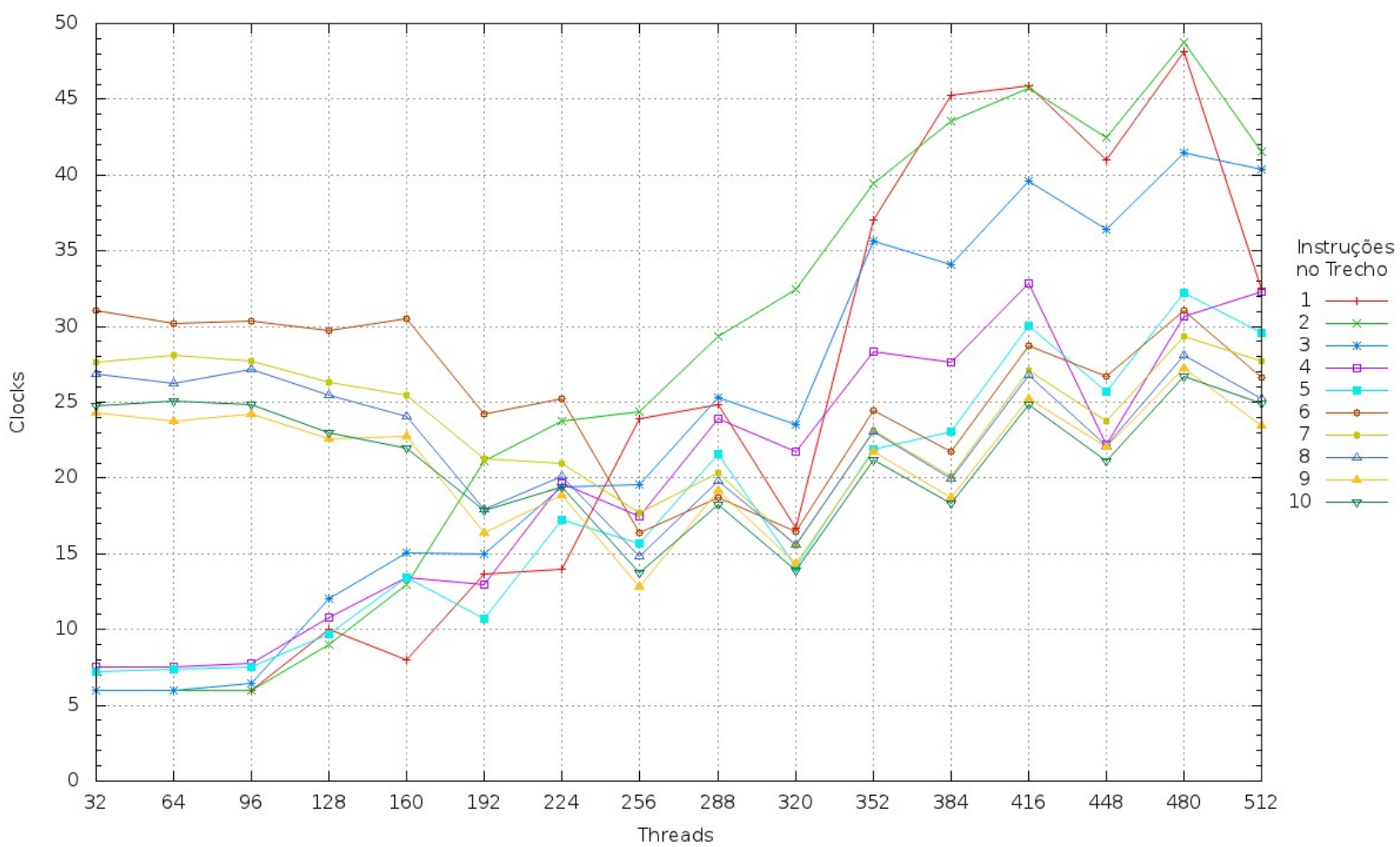

Figura 7.59: Instrução mul.rn.f32, gráfico do tempo médio de execução para cada quantidade de instruções no trecho pela quantidade de threads. Executado na GPU GeForceGTX470 com 100 iterações, arquitetura virtual PTX 10 e arquitetura real SM 20.

\section{Perfil da Calibragem}

A calibragem, mostrada nas figuras 7.60, em 3D, e 7.61, em 2D, apresenta um comportamento que pode ser dividido em dois intervalos. No primeiro, de um até dez warps, ela apresenta comportamento linear, com pequena inclinação. Já no segundo intervalo (entre 10 e 16 warps), apesar de não ser linear, pode ser aproximado por uma reta, com inclinação superior à da primeira faixa. A não linearidade do segundo intervalo é devida à execução com 12 warps, que, como comentado anteriormente (ver seção 7.1.5), possui variância zero e tempo de execução menor, parecendo ser uma condição ótima para execução.

A calibragem não possui instruções no trecho de teste e, o seu perfil é um reflexo do comportamento do sistema de contagem de ciclos de relógio, o registrador $\circ$ clock. Podemos notar que, até 10 warps em execução, o acréscimo no tempo é praticamente de 2 ciclos de relógio por warp. Como o tempo de troca de contexto é de um ciclo de relógio, podemos dizer que o acréscimo é proporcional aos custos da troca de contexto. Por outro lado, acima desse limite de 10 warps, o aumento no tempo com o acréscimo de um novo warp é muito maior que 2 ciclos, o que, possivelmente, indica contenção na leitura do registrador $\circ \mathrm{clock}$.

Como vimos anteriormente, na análise da variação dos resultados, com até 10 warps em execução não existe variação nos resultados do sistema de medição. A variação aparece acima de 10 warps em execução, da mesma forma que a possível contenção de leitura do registrador 。clock. Isso nos leva a crer que a contenção de leitura possa ser uma explicação para a variação nos resultados. 


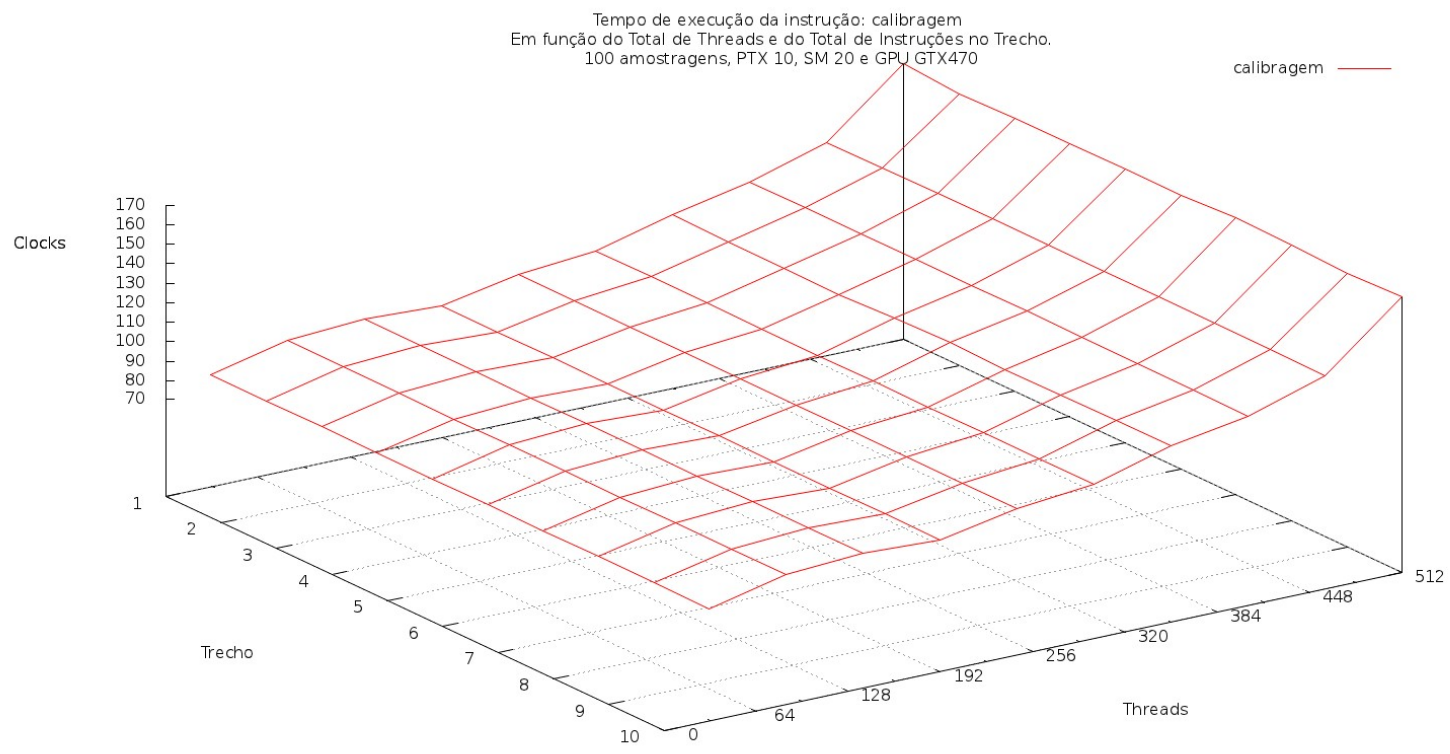

Figura 7.60: Calibragem, gráfico 3D do tempo médio de execução pela quantidade de instruções no trecho pela quantidade de threads. Executado na GPU GeForceGTX470 com 100 iterações, arquitetura virtual PTX 10 e arquitetura real SM 20.

Tempo de Execução da Instrução calibragem

100 amostragens, PTX 10, SM 20 e GPU GTX470

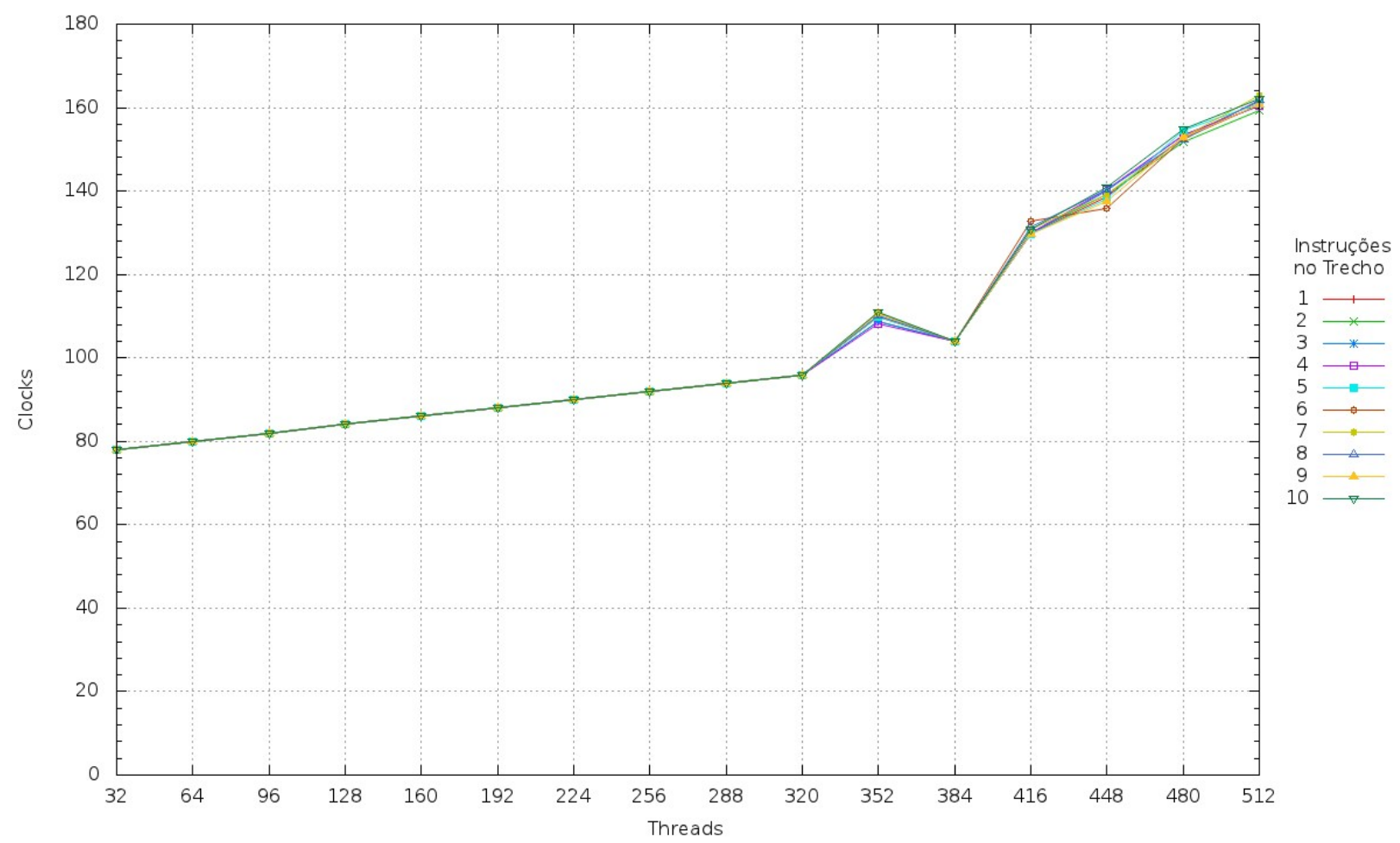

Figura 7.61: Calibragem, gráfico do tempo médio de execução para cada quantidade de instruções no trecho pela quantidade de threads. Executado na GPU GeForceGTX470 com 100 iterações, arquitetura virtual PTX 10 e arquitetura real SM 20. 


\subsubsection{Resumo e Conclusões das Análises Preliminares}

O processo de análises preliminares ajudou a alterar o microbenchmark de forma a possuir mais recursos do que os previstos inicialmente.

Com a análise da dispersão dos resultados e do escalonamento, percebemos uma forma melhor de contabilizar o tempo de execução do warp.

As análises da variância mostraram que a variação nos resultados ocorre a partir de onze warps em execução. Também percebemos que a quantidade de instruções no trecho de teste e a quantidade de warps executando criavam distribuições bimodais ou multimodais, onde a média não seria um bom indicador de tendência.

Os resultados da análise da variação do sistema de medição de tempo, registrador oclock, mostraram que a precisão está limitada pelas variações que, também, iniciam com onze warps. Uma vez que os resultados da leitura do registrador ${ }^{\circ} \mathrm{clock}$ são subtraídos de todos os resultados das instruções para obter o tempo de execução, essas variações influenciam todos os resultados.

\section{Perfil de Execução das Instruções}

As alterações feitas no microbenchmark, durante as análises preliminares, possibilitaram o levantamento do perfil de execução das instruções. E a análise desses perfis mostrou algumas características comuns entre grupos de instruções.

Dentre essas características, podemos destacar que, algumas instruções, quando executadas com baixa quantidade de warps, possuem o desempenho dividido em bandas. Essas bandas são agrupadas pela repetição da instrução e, possivelmente, expressam a capacidade de execução do pipeline quando submetido à repetição da mesma instrução. Com uma menor repetição da mesma instrução, temos um desempenho melhor.

Ainda para esse grupo de instruções, com maiores quantidades de warps, existe a convergência dessas bandas para uma faixa de resultados - isso para repetições acima de duas instruções em teste. Isso pode ser devido à maior probabilidade de existir um warp pronto para executar quando temos um conjunto maior de warps disponíveis. Dessa forma, adiciona-se o custo do escalonamento às execuções com baixa repetividade da instrução e dilui-se as esperas das execuções com grande repetividade.

Também temos situações onde o desempenho de execução da instrução depende da quantidade de warps sendo executada e é melhor em quantidades pares do que ímpares. Essa característica é, possivelmente, a ocorrência de conflito de bancos de registradores. Outra possibilidade é a existência de uma quantidade par de unidades funcionais disponível para executar essas instruções. Dessa forma, uma quantidade par de warps ocupará melhor todas as unidades funcionais do que uma quantidade ímpar, resultando em um melhor desempenho.

Os diferentes grupos de perfis escalam de forma diferente os seus resultados em relação à quantidade de warps e em relação à repetição no trecho de teste. Essa característica pode influenciar os resultados de trechos com sequências de instruções de diferentes grupos.

Notamos, durante as alterações no microbenchmark, que as instruções localizadas antes do trecho de teste influenciavam o resultado obtido no trecho de teste. Uma possível explicação é a presença dessas instruções no pipeline quando o trecho de teste iniciar a execução. Dessa forma, podemos ter a influência da utilização das unidades funcionais disponíveis e a possível existência de dependências. Também temos a execução dessas instruções anteriores ao trecho de teste, nos warps tardios, de forma entrelaçada com as instruções do trecho de teste dos warps que iniciaram a execução primeiro. 
Da mesma forma, notamos que as instruções que estão após o trecho de teste também influenciam no resultado. Isso, possivelmente, porque quando os primeiros warps terminam a execução do trecho de teste, eles passam a executar o código posterior entrelaçado com o código do trecho de teste dos outros warps. Dessa forma, as instruções após o trecho de teste, poderão influenciar no final da execução de alguns warps tardios.

Devido a esses dois últimos fatores, podemos supor que os resultados obtidos não são uma característica somente da instrução, mas, da instrução e do seu contexto de execução (código anterior e posterior a ela). Também, pelo visto anteriormente, a repetividade da instrução e a quantidade de warps influenciam os resultados obtidos. A quantidade de warps, além de esconder as latências, possui a característica de se adequar à quantidade de unidades funcionais existentes ou evitar conflitos de bancos de registradores (efeito par ou ímpar).

\section{Conclusões das Análises Preliminares}

Durante as análises preliminares, notamos que o microbenchmark possui dois limitantes na sua acurácia. O primeiro deles está relacionado com os tempos obtidos em execuções com grandes quantidades de threads. Esse tempo é influenciado pela grande variação nos resultados, que é fruto da variação do sistema de medição. Além disso, temos a impossibilidade de executar o teste de algumas instruções com grandes quantidades de threads - devido a excessiva utilização de recursos. A impossibilidade de executar todas as instruções com todas as configurações de quantidade de threads impede o levantamento completo do perfil dessas instruções.

O segundo fator que limita da acurácia do microbenchmark está na execução com poucas threads, que impede a diluição das dependências de leitura após escrita. Dessa forma, os resultados do microbenchmark podem se referir a situações um pouco diferentes das encontradas numa execução comum da mesma instrução. A opção -m do microbenchmark foi criada para tratar desse problema com relação a instrução mov.

Ainda com relação ao sistema de medição, a sua acurácia está limitada a 10 warps e acima desse limite a variação dos seus resultados influi nos resultados de todas as instruções testadas.

Nas execuções com grandes quantidades de threads e grandes quantidades de instruções no trecho de teste, aparentemente, chegamos a uma situação de congestionamento do pipeline, onde o escalonador não possui opção de execução que não utilize os recursos em uso. Nessa situação, há uma tendencia para que a distribuição dos resultados de execução se torne uma bimodal. Quando isso ocorre e a quantidade de warps em execução é impar, a distribuição bimodal fica mais evidenciada. Nesses casos, a média não é um bom indicador de tendência para o resultado.

Com relação à forma como as diferentes instruções se comportam, notamos que elas se dividem em grupos e que a sua resposta em função da quantidade de threads em execução é variada. Alguns grupos têm ganhos de desempenho com o aumento das threads em execução, enquanto que outros são mais lineares ou possuem um ganho muito discreto. A combinação dessas respostas diferentes, ou formas de escalar diferentes, pode gerar resultados diferentes, dependendo da sequência com que as instruções são executadas.

Além disso, como existe a influência das instruções anteriores e posteriores ao trecho de teste, o resultado dos tempos de uma instrução também são influenciados pelo seu contexto de execução. 


\subsection{Validação}

A forma escolhida para validar os resultados obtidos pelo microbenchmark foi compará-los com resultados da execução de programas em CUDA C. Porém, não poderíamos usar o tempo total de execução do programa, pois este inclui o tempo de acesso à memória, o que foge do escopo deste trabalho.

Para evitar esse problema, foram criados kernels em CUDA C, que executam instruções de cálculo em um determinado trecho de código, e foi medido o tempo gasto nesse trecho. Para garantir que não haveria influência do tempo de acesso à memória, fizemos com que o trecho de interesse estivesse bastante distanciado de qualquer acesso à memória.

Para poder comparar esse resultado obtido com os resultados das instruções do microbenchmark, fizemos um modelo simplificado, que levanta as instruções utilizadas no trecho de teste e, com os valores obtidos pelo microbenchmark, faz uma previsão do tempo de execução.

A seguir apresentamos alguns detalhes de como esse trabalho foi realizado e quais os resultados obtidos.

\subsubsection{Kernels de Teste}

Como a principal função de uma placa GPGPU é calcular, focamos os testes nas instruções de multiplicação, divisão, adição, subtração e raiz. Assim, criamos alguns kernels utilizando essas instruções, tanto com o tipo de dados FLOAT como INT, de acordo com o tipo de operação executado.

Para simplificar a obtenção dos resultados, não utilizamos laços em nenhum kernel e os valores computados não tinham significado específico, mas, o importante eram as operações utilizadas. Como visto anteriormente, mantivemos um distanciamento entre o trecho de teste e o acesso à memória global, para evitar a necessidade de modelar o funcionamento dessa memória.

As operações de exponenciação e logaritmo não foram utilizadas na validação porque o seu código executável possui desvio condicional ou acesso a memória.

Para determinar o trecho que seria o objetivo do teste, dentro do kernel, utilizamos as anotações //\#\#\#<INICIO>\#\#\#\# e //\#\#\#<FIM>\#\#\#\#. Os kernels foram compilados para manter as informações de depuração, de forma que esses indicadores permaneceram no programa compilado em PTX. Isso os tornou em marcadores de ínicio e fim do trecho de teste e poderiam ser utilizados por um programa que analisa o total de instruções do trecho.

Além da opção das informações de depuração, outra necessidade foi a compilação sem otimização. Para evitar que a passagem de dados causasse um acesso à memoria no início do kernel, utilizamos, no trecho de teste, uma sequência de atribuição e cálculo com as constantes atribuídas. Com a otimização ligada, essa sequência seria substituída pelo resultado pré-calculado e não teríamos o trecho de teste.

Como pode ser visto no código exemplo, mostrado na listagem 7.1, foram feitas três leituras do registrador oclock. A primeira leitura ocorre no início do trecho de teste, a segunda no fim do trecho de teste e a terceira no início da escrita na memória global. Essa terceira leitura foi utilizada para verificar que não ocorresse concomitância entre o código de teste e qualquer escrita na memória.

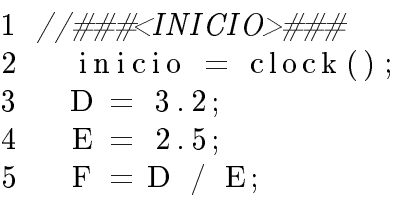




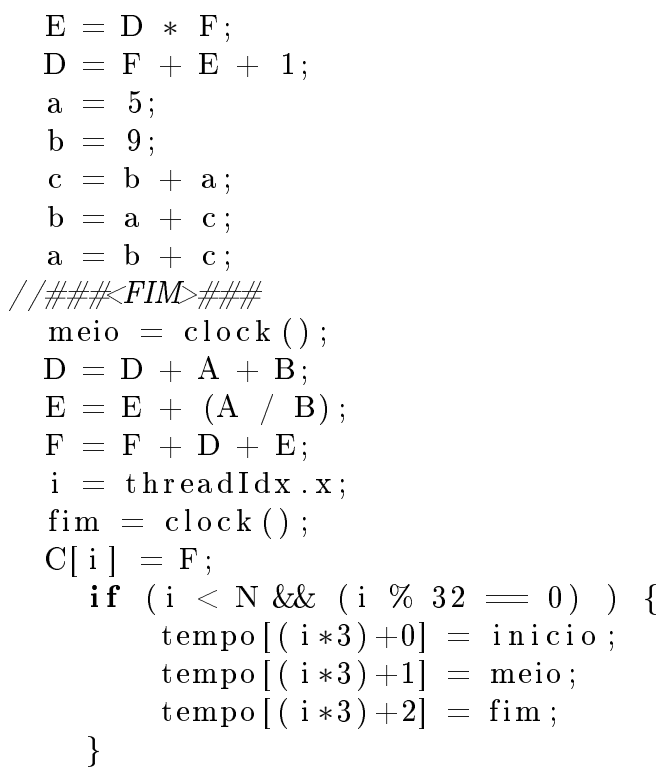

Listagem 7.1: Exemplo de um kernel de teste.

O programa que analisa o código PTX do trecho de teste, foi implementado em AWK. O resultado da sua execução é uma fórmula indicando os tipos de instruções no trecho e suas quantidades. Veremos mais detalhes na seção 7.2.2, que trata do modelo utilizado.

\subsubsection{Modelo Simplificado}

Como vimos nas análises preliminares, o tempo de execução depende da quantidade de instruções no trecho de teste e da quantidade de threads em execução. Dessa forma, utilizamos esse conhecimento para fazer um modelo aproximado do tempo de execução total de um kernel.

Como pode ser visto na figura 7.62, o processo de compilação do kernel de teste inclui a geração do código fonte em PTX, com as anotações preservadas. Esse arquivo é analisado por um programa em AWK que extrai os tipos e quantidades das instruções existentes no trecho, incluindo a quantidade de instruções iguais, repetidas em sequência. O resultado dessa análise é uma fórmula contendo os tipos de instruções, suas quantidades e repetividade.

Com esses dados das instruções existentes no trecho de validação, é feita uma consulta aos resultados do microbenchmark para obter os tempos de cada instrução, conforme a sua quantidade de repetições (as repetições da fórmula do modelo equivalem à quantidade de instruções no trecho de teste do microbenchmark) e o total de threads executadas. Com esses valores é calculada a expectativa de tempo do modelo.

Para a validação foram utilizados os valores de execução de um warp somente. Isso foi feito para evitar a modelagem do escalonamento e dos ganhos de desempenho, que existem com o aumento da quantidade de warps em execução.

Por fim, são comparados os resultados obtidos na execução com os resultados obtidos pelo modelo.

\subsubsection{Resultados}

Os resultados foram obtidos com a execução em um computador com placa GPU dedicada ao uso GPGPU (sem compartilhar a geração de vídeo). Essa máquina era equipada com uma placa mãe Intel DX58SO, com processador Intel Core i7 920 de 2,67GHz (4 cores e 8 threads) e 6GB de RAM. 


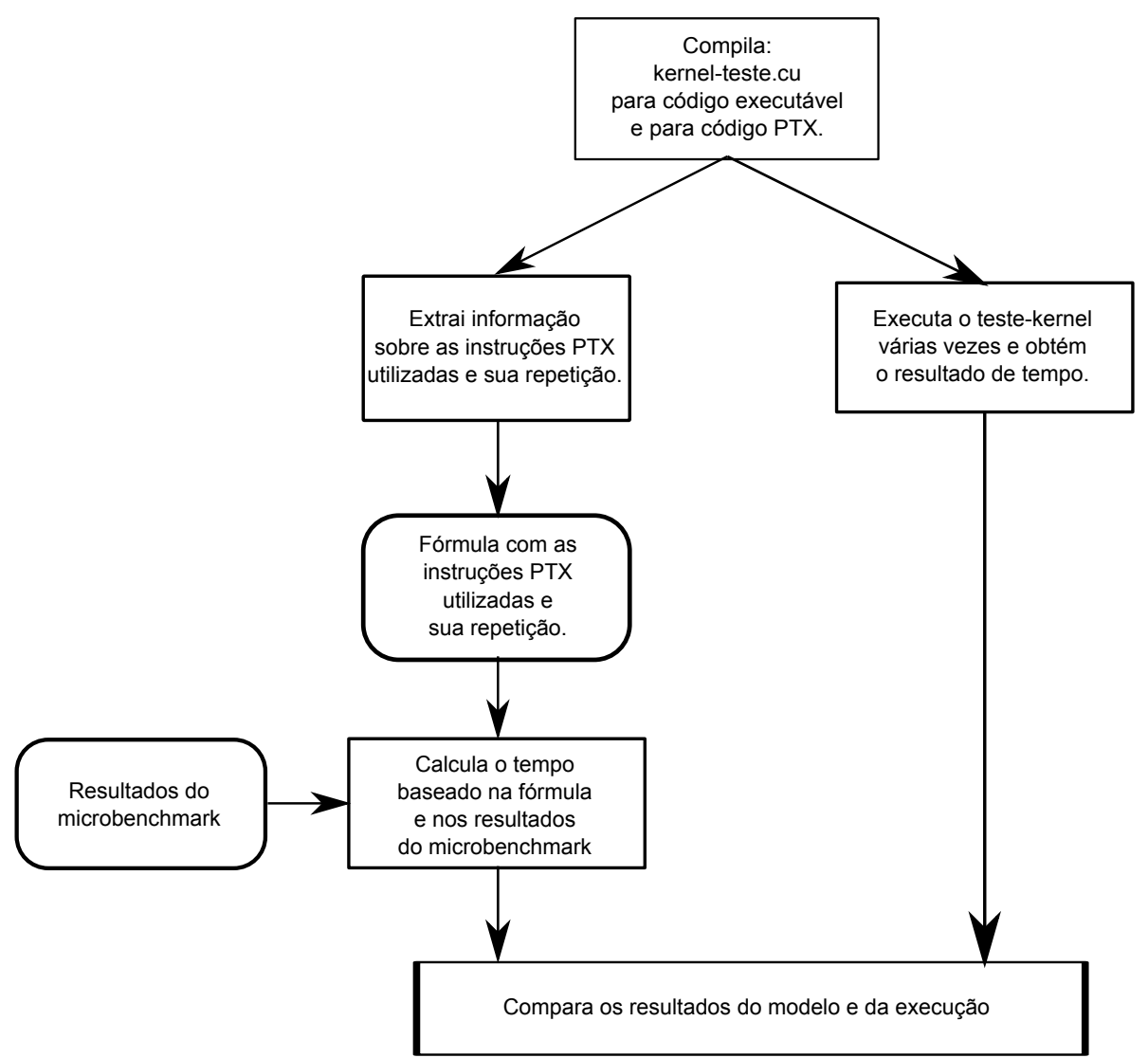

Figura 7.62: Sequência de etapas da validação.

Foi utilizada a GPU GeForce GTX 470 (compute capability 2.0) e todos os testes foram feitos utilizando o Ubuntu 11.04, CUDA driver 4.1 e SDK 4.1.

Utilizamos cinco kernels de teste contendo as seguintes instruções:

- kernel 1: atribuição de valores às variáveis e soma de tipos FLOAT;

- kernel 2: atribuição de valores às variáveis e soma de tipos FLOAT e INT;

- kernel 3: atribuição de valores às variáveis, soma, multiplicação e divisão de tipos FLOAT. Atribuição de valores e soma de tipos INT;

- kernel 4: soma, multiplicação e subtração de tipos FLOAT. Atribuição de valores, soma, subtração e divisão de tipos INT;

- kernel 5: raiz quadrada, soma, subtração, multiplicação e divisão de tipos FLOAT.

Os resultados dos kernels são referentes à média de 100 execuções de um único warp. Essa também foi a configuração de execução do microbenchmark. Os resultados iniciais estão mostrados na tabela abaixo:

Como o erro obtido foi acima do esperado, fizemos uma análise do kernel 1 e percebemos que a instrução mov era o principal fator de erro. Enquanto que no microbenchmark uma sequência de duas instruções mov. 132 obtinham um tempo de execução de 12 clocks, no kernel de teste o valor obtido era de 30 clocks.

Para entender melhor o motivo dessa diferença, comparamos a forma como a instrução mov. f32 aparece no código PTX do kernel de teste com a forma como é testada no microbenchmark. Como pode ser visto a seguir, no código PTX do microbenchmark temos a movimentação entre reg- 


\begin{tabular}{|c|c|c|c|}
\hline Kernel & Execução & Modelo & Erro \% \\
\hline \hline 1 & 361,54 & 138 & 61,83 \\
\hline 2 & 622 & 256 & 58,84 \\
\hline 3 & 968,03 & 720,06 & 25,62 \\
\hline 4 & 1249,92 & 1000,1 & 19,99 \\
\hline 5 & 768,02 & 510,12 & 33,58 \\
\hline
\end{tabular}

Tabela 7.6: Resultados da execução dos 5 kernels comparados com os valores calculados pelo modelo usando os valores do microbenchmark. Ambos com 100 execuções.

istradores de vetores distintos:

mov.f32 D2, Ax0;

mov.f32 Dx1, Ax1;

Já no kernel de teste, ocorre a movimentação de uma constante e em seguida a movimentação entre registradores de um mesmo vetor. Essa segunda movimentação possui dependência de leitura após escrita, como pode ser visto abaixo:

mov.f32 fㅣ, 0f40400000;

mov.f32 ㄷㄴ

Testamos separadamente o tempo de cada movimentação do kernel de teste e ele resultou igual ao obtido pelo microbenchmark. Para tirar a dúvida se o problema estava na sequência das instruções, analisamos o código executável gerado pelas duas sequências e como podemos ver a seguir, o código do microbenchmark, que foi criado com registradores de 32 bits, foi convertido para dois movs.

Código PTX do microbenchmark:

mov. $132 \div \mathrm{Dx} 2, \div \mathrm{Ax} 0$;

mov.f32 D1, Ax1;

Código executável do microbenchmark montado a partir do código PTX mostrado anteriormente:

MOV R5, R5;

MOV R7, R7;

O código do kernel de teste também foi criado com registradores de 32 bits, como pode ser visto a seguir:

mov.f32 Dx2, 0 f404ccccd; // valor de 3.2

mov.f32 Dx0, D2;

Porém, ele foi montado para código de máquina em uma sequência de três movs. Além disso, com dependência de leitura após escrita no registrador R5, como mostrado a seguir :

MOV32I R5, $0 \times 404 \mathrm{ccccd}$;

MOV R7, R5;

MOV R8, R5;

Essa diferença de montagem e de tempo de execução nos levou a alterar o microbenchmark, adicionando uma opção para executar o teste da instrução mov com registradores dentro do mesmo vetor (no caso o Dx) e com dependência de leitura após escrita. Essa alteração está mostrada na listagem abaixo, para um trecho com 10 instruções:

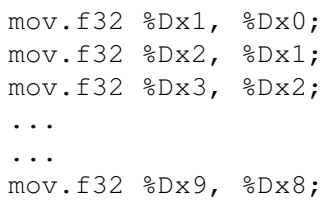

Com essa alteração executamos o microbenchmark novamente e fizemos a validação com esses valores 
obtidos. Os resultados estão na tabela a seguir:

\begin{tabular}{|c|c|c|c|}
\hline Kernel & Execução & Modelo & Erro \% \\
\hline \hline 1 & 361,54 & 408 & $-12,85$ \\
\hline 2 & 622 & 660 & $-6,11$ \\
\hline 3 & 968,03 & 1126 & $-16,32$ \\
\hline 4 & 1249,92 & 1338,16 & $-7,06$ \\
\hline 5 & 768,02 & 832,96 & $-8,46$ \\
\hline
\end{tabular}

Tabela 7.7: Resultados da execução dos 5 kernels comparados com os valores calculados pelo modelo usando os valores do microbenchmark. Ambos com 100 execuções e o microbenchmark com a modificação de teste da instrução mov.

Como esses valores foram considerados aceitáveis, não continuamos o processo de ajuste do microbenchmark. Porém, é possível que uma maior pesquisa, sobre as relações entre instruções em PTX e seu código de máquina gerado, leve a uma melhoria na forma de teste do microbenchmark e maior precisão nos resultados.

\subsubsection{Análise das Rechamadas}

Durante os testes preliminares, percebemos que um dado kernel, com poucas instruções e sem desvios condicionais, sendo executado duas vezes consecutivas dentro de um mesmo programa principal, obtinha dois valores distintos para o tempo de execução.

Porém, se esse mesmo kernel fosse chamado uma única vez dentro do programa principal, mas o programa principal fosse chamado duas vezes, teríamos o mesmo resultado nas duas vezes.

Após uma inspeção no código, notamos que a chamada de API cudaDeviceReset () era executada ao fim do programa principal, como nos exemplos do SDK da NVIDIA. Esse comando destrói e libera todos os recursos associados com o processo e a GPU correntes. Qualquer função de tempo de execução ou chamada de API subsequente criará um novo contexto de execução (NVIDIA, 2011d, p. 20)(NVIDIA, 2011c, p. 15).

Fizemos um teste executando o mesmo kernel duas vezes consecutivas, dentro do programa principal, com uma chamada ao cudaDeviceReset () entre as execuções do kernel. O tempo obtido foi sempre o mesmo.

Isso nos mostrou que o tempo de execução é sensível ao estado do contexto da GPU, porém, é prática chamar kernels consecutivos sem reinicialização. Até porque o tempo de reiniciar o contexto é significativo. Nessas condições, podemos supor que haverá variação no tempo de execução de um dado kernel quando executado mais do que uma vez, o que é contrário ao inicialmente esperado.

\subsection{Pipeline, Sequência de Instruções e Tempo de Execução}

Pelo visto durante as análises preliminares e validação, a sequência de execução das instruções pode ter um efeito considerável no tempo de execução do kernel. Isso poderia ser justificado pela disponibilidade de unidades funcionais para a execução imediata de uma dada instrução, desde que ela não fosse antecedida por instruções que ocupassem todas essas unidades funcionais. Outra possibilidade é a execução de duas instruções concomitantes, em unidades funcionais diferentes. Dessa forma, deve existir pelo menos uma sequência ótima de instruções para extrair o maior desempenho do pipeline. 
Segundo a NVIDIA, o SM utiliza o paralelismo das threads para maximizar a utilização das suas unidades funcionais e para isso depende da quantidade de warps em execução. A cada instrução o escalonador verifica a disponibilidade de execução da próxima instrução de cada warp e seleciona um dos possíveis de executar. A maior utilização dos recursos (e o melhor desempenho) ocorre quando o escalonador sempre tem alguma instrução de algum warp para ser executada (NVIDIA, 2011d, p. 66).

Para verificar se a sequência de instruções realmente influencia o tempo de execução, criamos três kernels de teste com as mesmas instruções, executando os mesmos cálculos, com os mesmos valores, porém, em sequências diferentes. Como a intenção era testar o pipeline e não a capacidade de otimização do compilador, compilamos esses três kernels sem otimização nenhuma.

Os três kernels possuem três operações básicas, uma atribuição de ponto flutuante, uma raiz quadrada e uma atribuição de inteiro. Essas operações são repetidas 23 vezes com valores e variáveis distintas para cada repetição, porém iguais para os 3 kernels. Todos os resultados dessas operações são utilizados, da mesma forma nos três kernels, após o trecho de teste, para prevenir que o compilador elimine o código morto.

Como podemos ver a seguir, o kernel 1 faz a atribuição de ponto flutuante, em seguida extrai a raiz quadrada dessa atribuição e por fim faz a atribuição de inteiros. Isso, em 23 blocos semelhantes. Vale notar que algumas letras, como $i$ e $n$, não foram utilizadas nessa sequência, pois foram reservadas para outros cálculos no kernel.

\section{Kernel 1:}

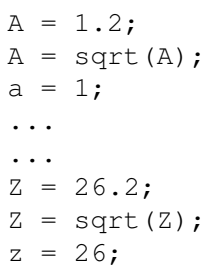

O kernel 2 faz a atribuição de ponto flutuante e em seguida extrai a raiz quadrada dessa atribuição, isso, para os 23 blocos. Por fim, faz as 23 atribuições de inteiros em um único bloco.

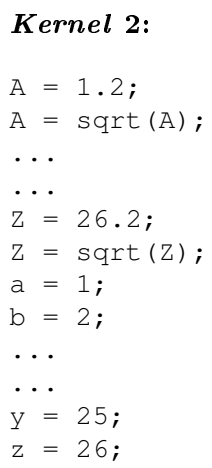

Já o kernel 3, faz as 23 atribuições de ponto flutuante, em seguida faz as 23 extrações de raiz quadrada das atribuições anteriores e, por fim, faz as 23 atribuições de inteiros.

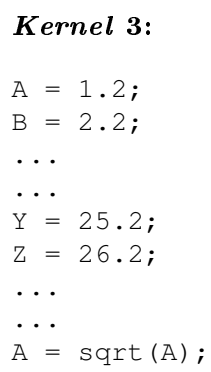




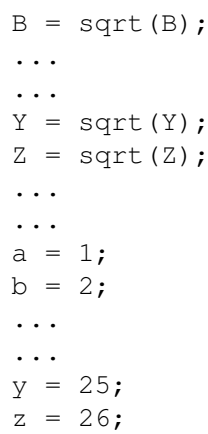

Para poder analisar melhor os resultados obtidos, verificamos a desmontagem dos três kernels e concluímos o seguinte:

- os três kernels possuem a mesma quantidade de instruções, tanto PTX quanto de máquina;

- os kernels 1 e 2 possuem o mesmo padrão de transferência de dados entre os registradores;

- o kernel 3, apesar de usar as mesmas instruções, possui um padrão de transferência de dados, entre os registradores, diferente dos kernels anteriores. Isso, porém, somente na atribuição de ponto flutuante.

\section{Análise do Teste de Pipelilne sem Otimização}

Os resultados da média de 100 execuções desses três kernels de testes está mostrado na figura 7.63. Foi verificado que não houve execução de nenhum trecho de teste concomitante com acessos à memória global.

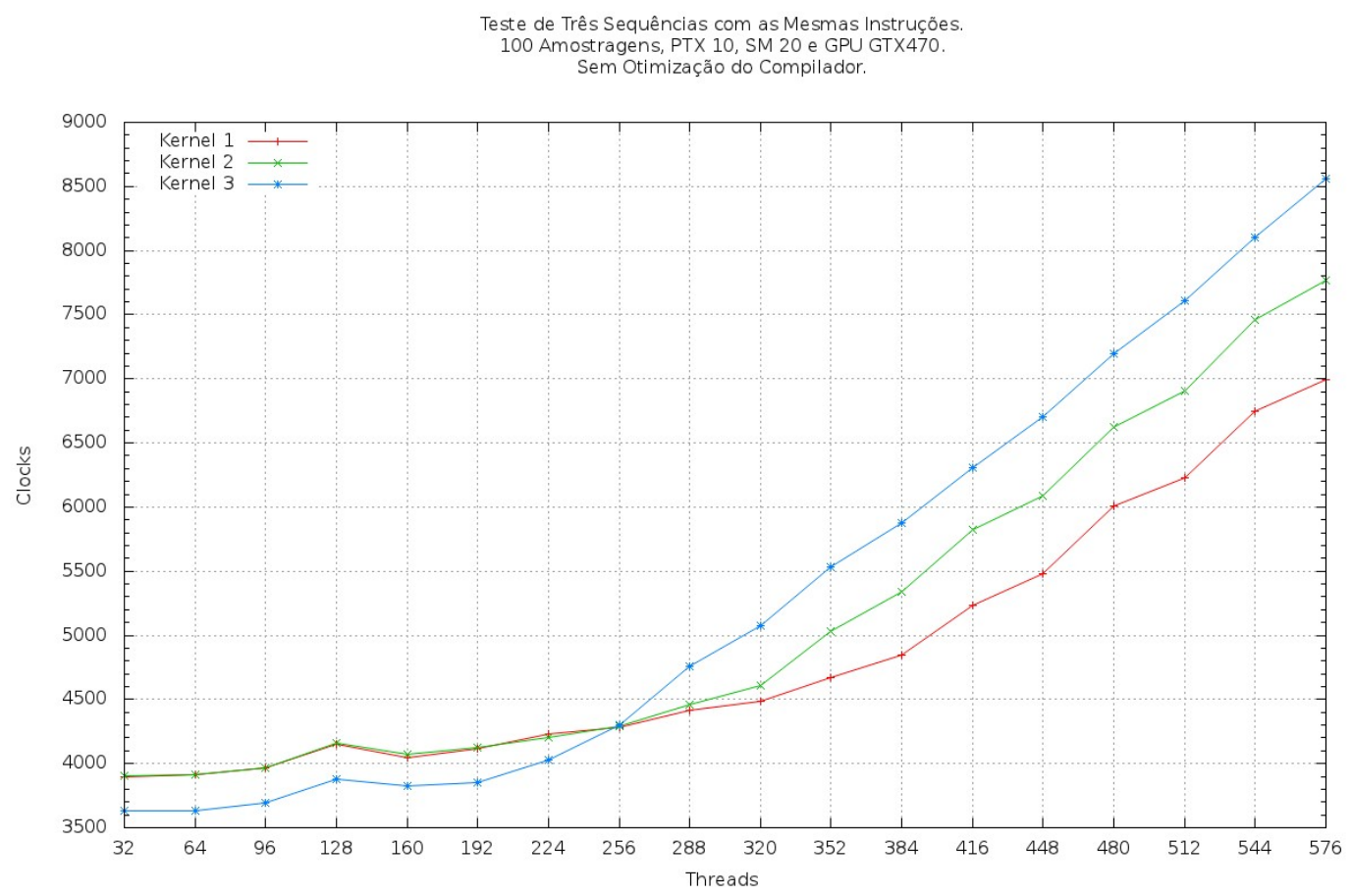

Figura 7.63: Resultado da execução de três kernels com as mesmas instruções, porém, em sequências diferentes. Compilado sem otimização e executado na GPU GeForceGTX470, com 100 iterações, arquitetura virtual PTX 10 e arquitetura real SM 20.

O kernel 1 possui uma sequência que mistura o uso de unidades funcionais e obteve o melhor desempenho para execuções acima de 256 threads. Abaixo desse patamar ele ficou em segundo 
lugar, juntamente com o kernel 2. Uma possível explicação é que a execução abaixo de 256 threads está aquém da capacidade de execução do pipeline e as dependências de leitura após escrita são mais significativas no desempenho. Acima de 256 threads temos a diluição da latência dessas dependências e o congestionamento do pipeline passa a restringir o desempenho.

Essa explicação é coerente com o desempenho do kernel 3, que após 256 threads possui o pior desempenho e possui as operações iguais mais concentradas, o que impediria o escalonador de obter um warp disponível para execução dentro desses trechos.

Entre os dois primeiros kernels a única diferença, no código de máquina, é a sequência de execução dos blocos de instruções, sendo que a o padrão de transferência de dados entre os registradores é o mesmo. Dessa forma, a diferença de desempenho pode ser, possivelmente, atribuída ao pipeline.

No kernel 3, apesar de haver diferença no uso dos registradores em seu código de máquina, isso não deveria ter consequências de desempenho na execução com grandes quantidades de warps, onde melhor ocorre a diluição das latências. Porém, são nessas execuções que as diferenças de desempenho são mais evidentes. Aqui também parece provável que a diferença seja resultado da pior utilização do pipeline feita neste kernel.

\section{Pipeline e Otimizações do Compilador}

Para verificar se o compilador resolveria a situação da concentração de instruções iguais, fizemos dois novos kernels de teste que seriam compilados com a otimização ativada. Para evitar que a otimização substituísse toda a sequência de cálculos por uma constante com o resultado, o kernel recebeu os dados para os cálculos em um vetor.

Usamos uma sequência de operações contendo atribuição de ponto flutuante e de inteiros, multiplicação de ponto flutuante e extração de raiz quadrada. Foram 24 sequências, dessas instruções, dispostas de forma agrupada ou intercalada, de acordo com cada kernel.

Como no teste anterior, todos os resultados dessas operações foram utilizados, após o trecho de teste e da mesma forma nos dois kernels. Isso, para prevenir que o compilador eliminasse o código morto.

No kernel 1 intercalamos as operações de ponto flutuante e agrupamos as atribuições de inteiros, como pode ser visto a seguir:

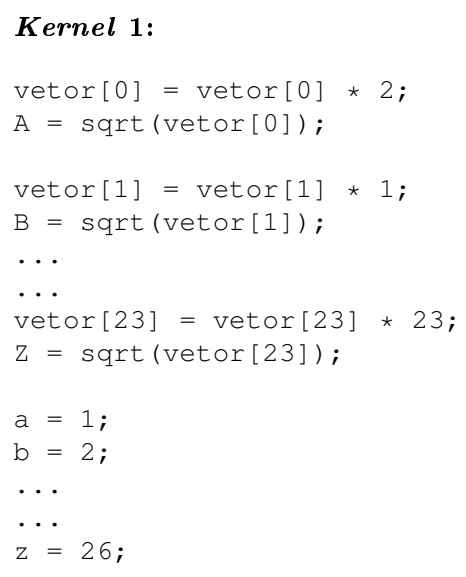

Já o kernel 2, foi feito com todas as operações iguais agrupadas, como pode ser visto no código a seguir:

\section{Kernel 2:}

vetor $[0]=\operatorname{vetor}[0] * 2$; 


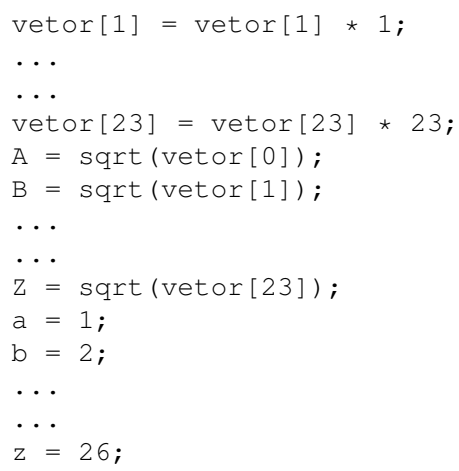

Os resultados da média de 100 execuções desses testes está mostrado na figura 7.64. No kernel 2, houve execução do trecho de teste concomitante com a escrita dos resultados na memória global. Isso ocorreu em execuções com 160 ou mais threads.

Como ambos kernels recebem as variáveis de entrada através da memória, eles possuem acessos à memória global em seu código de teste. Esses acessos não são considerados na verificação de execução concomitante entre o trecho de teste e a escrita dos resultados finais.

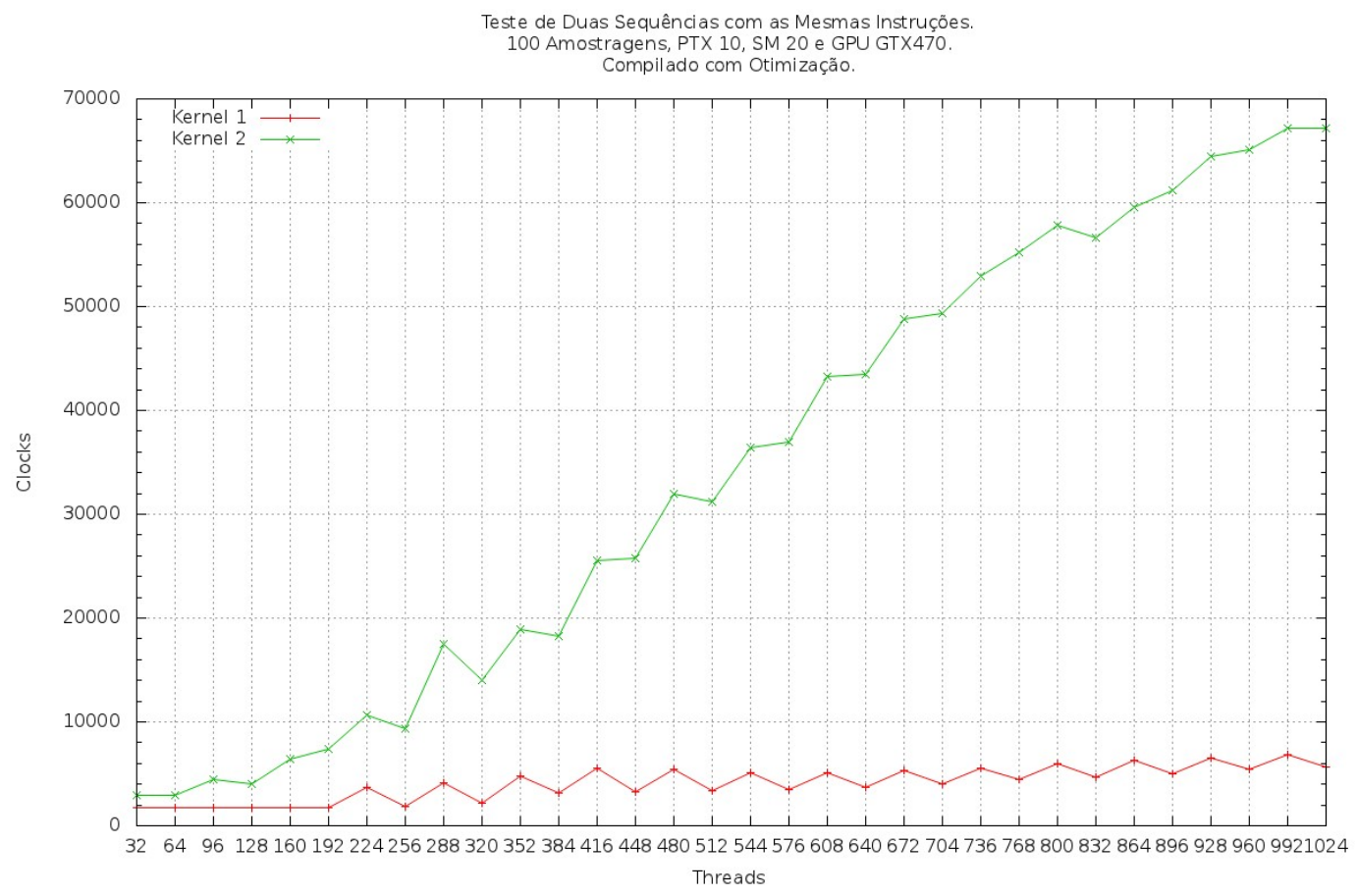

Figura 7.64: Resultado da execução de dois kernels com as mesmas instruções, porém, em sequências diferentes. Compilado com otimização e executado na GPU GeForceGTX470 com 100 iterações, arquitetura virtual PTX 10 e arquitetura real SM 20.

Pelo gráfico, podemos ver que há diferença nos desempenhos em toda a faixa de execução. Nas execuções com 160 threads e acima, como houve influência da execução do trecho de teste concomitante com a escrita dos resultados finais na memória, pelo kernel 2, o seu desempenho foi fortemente penalizado. Porém, nas execuções com 32, 64, 96 e 128 threads temos uma diferença de desempenho sem esse acesso concomitante. Ou seja, o kernel 2, que possui as operações em blocos é penalizado no seu desempenho, sem que o compilador possa resolver essa situação.

Pela análise do código de máquina desses kernels, notamos que a otimização deles foi diferente. Excetuando as instruções de acesso à memória global, para ler e escrever parâmetros, os dois kernels possuem as mesmas instruções, tanto na quantidade quanto no tipo. Com relação ao acesso à memória global, o kernel 2 tem uma maior quantidade de acessos, 67 contra 48 do kernel 1 . 
Essa diferença nos acessos é, possivelmente, a maior responsável pela diferença de desempenho nas execuções abaixo de 160 threads. Ela também deve ser o motivador da execução concomitante do trecho de teste com a escrita dos resultados, no kernel 2, quando executado com 160 ou mais threads.

Pelo que vimos neste teste, a otimização do compilador não é capaz de resolver o problema de concentração das instruções. Pelo menos quando ela ocorre com um distanciamento suficientemente grande entre os blocos de instruções.

\subsection{Comparativo com Valores de Referência da NVIDIA}

Para avaliar a utilidade dos resultados do microbenchmark, fizemos uma comparação, para os dois primeiros kernels de teste, entre os tempos de execução, os resultados do modelo e os resultados obtidos com os valores de referência fornecidos pela NVIDIA.

Não utilizamos os cinco kernels porque o terceiro, quarto e quinto kernel, possuem instruções que não estão na tabela de referência da NVIDIA. Esses valores de referência estão no apêndice B e foram retirados do guia de programação CUDA C (NVIDIA, 2011d, p. 98). Eles são dados em número de operações por ciclo de relógio, por multiprocessador. Eles se referem a instruções aritméticas que são nativas de cada compute capability.

Como os valores da NVIDIA se referem ao desempenho máximo, ajustamos o valor obtido com o modelo, que se refere a 32 threads, para refletir 1024 threads. Isso foi feito multiplicando o valor obtido na validação de cada kernel por uma constante de ajuste. Essa constante é a razão, para cada kernel, do tempo de execução com 1024 threads pelo tempo de execução com 32 threads. Utilizamos esse artifício para evitar a criação de um novo modelo, que estaria além do objetivo deste trabalho.

Os resultados da comparação estão na tabela 7.8 e mostram que o erro do microbenchmark é inferior ao erro utilizando a tabela de referência. Lembramos que esse é o tempo de computação, sem considerar os acessos à memória.

\begin{tabular}{|c|c|c|c|c|c|}
\hline Kernel & Execução & Modelo Ajustado & Tabela NVIDIA & Erro Modelo \% & Erro Tabela \% \\
\hline \hline 1 & 1014,84 & 1145,25 & 672 & $-12,85$ & 33,78 \\
\hline 2 & 1671,76 & 1773,89 & 1280 & $-6,11$ & 23,43 \\
\hline
\end{tabular}

Tabela 7.8: Comparação entre os resultados para os dois primeiros kernels de teste, utilizando os resultados obtidos com o modelo e utilizando os valores de referência da NVIDIA. O tempo de execução se refere à média de 100 execuções com 1024 threads. O valor do modelo foi ajustado para refletir a execução com 1024 threads.

\subsubsection{Resumo e Conclusões da Validação}

A validação foi composta de cinco testes que estão descritos a seguir:

- a certificação de que os resultados obtidos pelo microbenchmark eram úteis e coerentes;

- a verificação dos resultados da execução de kernels com múltiplas chamadas dentro de um mesmo programa (rechamadas);

- a verificação se a sequência de instruções realmente é significativa no desempenho do pipeline;

- a verificação da capacidade do compilador otimizar os agrupamentos de instruções iguais;

- um comparativo com os valores obtidos com o modelo simplificado e os obtidos através da tabela de referência da NVIDIA. 
No primeiro teste concluímos que os resultados obtidos com o microbenchmark podem ser utilizados na contabilização do tempo de computação de um kernel. Para isso, fizemos um modelo simplificado que previu o tempo de computação - desconsiderando os tempos de acessos à memória global - de cinco kernels, com erros dentro da faixa de $6,11 \%$ a $16,32 \%$.

O teste de rechamadas mostrou que o tempo de execução de um dado kernel varia conforme a condição em que é chamado. Utilizamos um kernel de teste com poucas instruções e sem desvios condicionais. Ao chamá-lo após um comando de cudaDevi ceReset (), obtivemos sempre o mesmo resultado. Porém, ao chamarmos algumas vezes consecutivas, dentro de um mesmo programa e sem o comando entre elas, o tempo obtido variou, mesmo que pouco, entre as diversas execuções. Uma possível explicação é que o contador de tempo utilizado para a preempção estará em posição diferente durante cada rechamada, influenciando o escalonamento e os resultados.

No terceiro teste mostramos como a sequência de instruções pode influenciar o desempenho do pipeline. Uma decorrência disso é a existência de, pelo menos, uma sequência de instruções que seja ótima para ocupar o pipeline e obter o melhor desempenho.

Dessa forma, um teste mais preciso deveria levar em consideração as combinações das instruções para verificar o desempenho. Porém, isso levaria a uma combinação onde o número de possibilidades cresceria exponencialmente e inviabilizaria a execução do teste.

Mostramos, com o quarto teste, que existe pelo menos um caso em que as otimizações do compilador não são capazes de resolver o problema de concentração de instruções.

Por fim, mostramos que os resultados do modelo simplificado se aproximam mais dos resultados de execução que os obtidos com a tabela de referência da NVIDIA. O teste foi limitado a dois kernels devido a falta de dados, na tabela da NVIDIA, referentes a instruções utilizadas nos outros três kernels. 


\section{Capítulo 8}

\section{Conclusões}

O objetivo deste trabalho foi levantar informações sobre o tempo de execução das instruções PTX, das GPUs NVIDIA, para auxiliar na confecção de um modelo de desempenho. Para tanto, foi criado um microbenchmark sintético que testa cada instrução existente, levando em consideração os tipos de dados utilizáveis.

Esse processo envolveu a criação de uma metodologia que, a partir das definições das instruções, gera todas as rotinas de teste do microbenchmark.

Durante a execução do trabalho, foi feito um estudo sobre a forma de contabilizar o tempo utilizando o registrador $\% \mathrm{clock}$ dentro das threads. Percebemos que o sistema de leitura de tempo influencia os resultados da execução e estabelece (ou delimita) uma região de teste com acurácia, ou seja, com menor variabilidade. Essa região é definida pela quantidade de threads.

Por outro lado, as análises da desmontagem do código de máquina referente ao microbenchmark, mostraram que o compilador, possivelmente, prefira gerar dependências reais ao invés de usar mais registradores. Isso pode ser justificado pela suposição de que a grande quantidade de threads e o escalonamento escondam as latências decorrentes dessas dependências. Porém, o escalonamento depende da disponibilidade de warps a serem executados e isso pode diferir muito de uma execução real para a rotina do microbenchmark.

Assim, temos duas limitações de acurácia nos resultados, sendo que pelo lado superior (da quantidade de threads executando) o sistema de leitura é o limitante e pelo lado inferior as possíveis dependências de leitura após escrita, acesso a bancos de registradores ou falta de warps para esconder latências.

Também percebemos que a chamada consecutiva (rechamada) de um mesmo kernel dentro de um programa leva a variações nos resultados que, através de alguns testes, pudemos vincular com o estado interno da GPU, ou seja, o seu contexto.

A forma de análise dos resultados de tempo de execução das instruções, utilizando a sobreposição dos gráficos de desempenho para todas as quantidades de threads e repetição da instrução, permitiu o agrupamento das instruções de acordo com alguns perfis que consideram as características de escalabilidade.

Com esses perfis, notamos que o ponto ótimo de desempenho das instruções é função da quantidade de threads e varia conforme a instrução. A característica de escalabilidade de duas instruções pode diferir e sua sequência de execução pode gerar compensações na escalabilidade. Assim, influenciando o resultado final e criando uma dependência do tempo de execução. Isso foi mostrado com os testes de pipeline e sequência de execução (ver seção 7.3). Em favor dessa conclusão, Raj Jain comenta que, nas arquiteturas com pipeline e caches seria mais interessante testar conjuntos de instruções 
ao invés de instruções separadas (Jain, 1991, p. 49-50). Porém, a utilização do microbenchmark com instruções separadas é um comprometimento entre precisão e simplicidade.

Para validar os resultados obtidos pelo microbenchmark, criamos um modelo simplificado que obteve erros entre $6,11 \%$ e $16,32 \%$ para cinco kernels de teste. Porém, os testes foram feitos sem nenhum tipo de otimização pelo compilador. Isso, para evitar as otimizações feitas nas instruções que não são nativas e sim emuladas. Essas instruções podem ter um resultado muito diferente após a otimização.

Um grande limitante na utilização do microbenchmark, baseado na linguagem PTX, é o fato que a uma instrução complexa, nessa linguagem, como exponencial ou raiz, podem incluir um desvio condicional na sua montagem. Dessa forma, o seu tempo de execução poderá possuir uma variação muito grande. Também, os efeitos da otimização podem ser significativos. Essa é uma das explicações para os trabalhos anteriores terem evitado a utilização da linguagem PTX no levantamento do tempo de execução.

Nos modelos estudados percebemos que o levantamento do tempo de execução foi feito de forma aproximada, uma vez que, na tecnologia Tesla, os tempos de acesso à memória são predominantemente mais significativos que o tempo de execução. Porém, nas novas tecnologias, com a melhoria no sistema de memória, teremos uma maior necessidade de obtenção do tempo de execução com maior precisão.

Também, os trabalhos anteriores limitaram-se a testar instruções representativas de classes de instruções e fazer o teste em linguagem de máquina. Até o limite do nosso conhecimento, este é o primeiro trabalho que faz um teste abrangente de todas as instruções e em linguagem PTX.

Por fim, foi feito um teste para avaliar a capacidade do compilador otimizar os agrupamentos de instruções e impedir a saturação do pipeline. Percebemos que, a partir de um certo distanciamento entre os blocos de instruções iguais, o compilador fica incapacitado para melhorar esse escalonamento.

\section{Contribuições}

Como a principal contribuição, podemos destacar a ferramenta de criação de microbenchmarks, que está descrita no capítulo 6, com seus detalhes de uso. Além de obter os valores de tempo de execução das instruções PTX, ela permite compreender algumas das características de execução do hardware. Ela também pode ser utilizada dentro de um modelo de desempenho, que foi a motivação inicial deste trabalho, e a sua disponibilide auxilia na tarefa de criação de modelos.

A metodologia de criação do microbenchmark, com o gerador de aplicações, a linguagem de descrição das instruções e o formato da rotina de teste, são a segunda contribuição.

O estudo sobre a utilização do registrador oclock na contabilização do tempo tem sua parcela de contribuição e difere da forma como o fabricante sugere.

Fruto da utilização do microbenchmark, a análise do perfil das instruções permitiu a organização dessas instruções em grupos. Essa organização considerou as características de repetividade da instrução e escalabilidade.

No levantamento bibliográfico não encontramos outra implementação de microbenchmark utilizando a linguagem intermediária (PTX). 


\subsection{Sugestões para Pesquisas Futuras}

Para diminuir o tempo de execução do microbenchmark poderia ser feito um pré-processador que analisasse o kernel a ser avaliado e criasse o microbenchmark somente com as instruções utilizadas nesse kernel.

Apesar de ser dependente da versão em uso, um estudo das otimizações e escalonamento feitos pelo compilador poderia levar a melhorias na precisão dos resultados das instruções emuladas no microbenchmark. De acordo com Sim et al, a otimização do PTX trata da alocação dos registradores e do escalonamento das instruções (Sim et al., 2012).

Como a sequência das instruções influencia o desempenho, em função da variação do ILP $^{1}$, um teste mais preciso necessitaria fazer as combinações das instruções e verificar o desempenho. Um estudo classificando as instruções em grupos de acordo com os recursos funcionais necessários para a execução, permitiria definir algumas sequências relevantes. Dessa forma, poderia ser feito um microbenchmark que além das instruções individuais, testasse algumas combinações de sequências de instruções, permitindo expressar o ILP nos resultados obtidos.

\footnotetext{
${ }^{1}$ Instruções de ponto flutuante e as que usam SFU podem ser executadas em paralelo, caso não exista essa sequência, o tempo de execução de instruções na SFU pode ser significativo. (Sim et al., 2012).
} 
114 CONCLUSÕES 


\section{Apêndice A}

\section{Compute Capability}

\begin{tabular}{|c|c|c|c|c|c|}
\hline \multirow{2}{*}{ Recurso } & \multicolumn{5}{|c|}{ Compute Capability } \\
\hline & 1.0 & 1.1 & 1.2 & 1.3 & $2 . x$ \\
\hline Grade 3D & \multicolumn{4}{|c|}{$\mathrm{N}$} & S \\
\hline Função atômica em inteiros de 32 bits na memória global & $\mathrm{N}$ & \multicolumn{4}{|c|}{ S } \\
\hline Função atômica em inteiros de 64 bits na memória global & \multicolumn{2}{|c|}{$\mathrm{N}$} & \multicolumn{3}{|c|}{$\mathrm{S}$} \\
\hline $\begin{array}{l}\text { Função atômica em inteiros de } 32 \text { bits na memória com- } \\
\text { partilhada }\end{array}$ & \multicolumn{2}{|c|}{$\mathrm{N}$} & \multicolumn{3}{|c|}{ S } \\
\hline Função de eleição Warp & \multicolumn{2}{|c|}{$\mathrm{N}$} & \multicolumn{3}{|c|}{ S } \\
\hline Dupla precisão em ponto flutuante & \multicolumn{3}{|c|}{$\mathrm{N}$} & \multicolumn{2}{|c|}{$\mathrm{S}$} \\
\hline $\begin{array}{l}\text { Adição atômica de ponto flutuante de } 32 \text { bits na } \\
\text { memória global e compartilhada }\end{array}$ & \multicolumn{4}{|c|}{$\mathrm{N}$} & $\mathrm{S}$ \\
\hline ballot () & \multicolumn{4}{|c|}{$\mathrm{N}$} & $\mathrm{S}$ \\
\hline _threadfence_system() & \multicolumn{4}{|c|}{$\mathrm{N}$} & $\mathrm{S}$ \\
\hline _syncthreads_count () & \multicolumn{4}{|c|}{$\mathrm{N}$} & $\mathrm{S}$ \\
\hline _syncthreads_and () & \multicolumn{4}{|c|}{$\mathrm{N}$} & $\mathrm{S}$ \\
\hline _syncthreads_or () & \multicolumn{4}{|c|}{$\mathrm{N}$} & $\mathrm{S}$ \\
\hline Funções de superfície & \multicolumn{4}{|c|}{$\mathrm{N}$} & $\mathrm{S}$ \\
\hline
\end{tabular}

Tabela A.1: Recursos e características técnicas - parte 1 (NVIDIA, 2011d, p. 158)

\begin{tabular}{|c|c|c|c|c|c|}
\hline \multirow{2}{*}{ Recurso } & \multicolumn{5}{|c|}{ Compute Capability } \\
\hline & 1.0 & 1.1 & 1.2 & 1.3 & $2 . \mathrm{x}$ \\
\hline Dimensão máxima da Grade de Blocos & \multicolumn{4}{|c|}{2} & 3 \\
\hline Dimensão máxima da Grade em x, y ou z & \multicolumn{5}{|c|}{65.535} \\
\hline Dimensão máxima do Bloco & \multicolumn{5}{|c|}{3} \\
\hline Dimensão máxima do Bloco em x ou y & & & 12 & & 1.024 \\
\hline Dimensão máxima do Bloco em z & \multicolumn{5}{|c|}{64} \\
\hline Máximo número de threads por Bloco & & & 12 & & 1.024 \\
\hline Tamanho do Warp & \multicolumn{5}{|c|}{32} \\
\hline Máximo de Blocos residentes por SM & \multicolumn{5}{|c|}{8} \\
\hline Máximo de Warps residentes & & & & & 48 \\
\hline
\end{tabular}

Tabela A.2: Recursos e características técnicas - parte 2 (NVIDIA, 2011d, p. 158) 


\begin{tabular}{|c|c|c|c|}
\hline \multirow{2}{*}{ Recurso } & \multicolumn{3}{|c|}{ Compute Capability } \\
\hline & $\mathbf{1 . 0}$ & \begin{tabular}{l|l}
1.2 & 1.3
\end{tabular} & $2 . \mathrm{x}$ \\
\hline Número máximo de threads residentes por SM & 768 & 1.024 & 1.536 \\
\hline Registradores de 32 bits por SM & $8 \mathrm{~K}$ & $16 \mathrm{~K}$ & $32 \mathrm{~K}$ \\
\hline Máximo de memória compartilhada por SM & \multicolumn{2}{|c|}{$16 \mathrm{~K}$} & $48 \mathrm{~K}$ \\
\hline Número de bancos de memória compartilhada & \multicolumn{2}{|c|}{16} & 32 \\
\hline Total de memória local por thread & \multicolumn{2}{|c|}{$16 \mathrm{~K}$} & $512 \mathrm{~K}$ \\
\hline Tamanho da memória de constantes & \multicolumn{3}{|c|}{$64 \mathrm{~K}$} \\
\hline Cache da memória de constantes por SM & \multicolumn{3}{|c|}{$8 \mathrm{~K}$} \\
\hline Cache da memória de texturas por SM & \multicolumn{3}{|c|}{ de $6 \mathrm{~K}$ a $8 \mathrm{~K}$, dependendo do equipamento } \\
\hline Número máximo de instruções por kernel & \multicolumn{3}{|c|}{2 milhões } \\
\hline
\end{tabular}

Tabela A.3: Recursos e características técnicas - parte 3 (NVIDIA, 2011d, p. 159) 


\section{Apêndice B}

\section{Desempenho Instruções fornecido pela NVIDIA}

A tabela abaixo foi retirada do CUDA C Programming Guide, V. 4.0 (NVIDIA, 2011d, p. 98). Nela, as taxas de execução são dadas em número de operações por ciclo de relógio por multiprocessador.

\begin{tabular}{|c|c|c|c|}
\hline Instrução & CC 1.X & $\mathrm{CC} 2.0$ & $\mathrm{CC} 2.1$ \\
\hline $\begin{array}{l}\text { Soma, multiplicação, multiplicação com soma } \\
\text { de ponto flutuante com } 32 \text { bits. }\end{array}$ & 8 & 32 & 48 \\
\hline $\begin{array}{l}\text { Soma, multiplicação, multiplicação com soma } \\
\text { de ponto flutuante com } 64 \text { bits. }\end{array}$ & 1 & 16 & 4 \\
\hline Soma de inteiros e operação lógica de 32 bits & 8 & 32 & 48 \\
\hline Comparação e deslocamento de inteiros de 32 bits & 8 & 16 & 16 \\
\hline $\begin{array}{l}\text { Soma, multiplicação, multiplicação com soma, } \\
\text { soma de diferença absoluta de } 32 \text { bits }\end{array}$ & $\begin{array}{l}\text { Múltiplas } \\
\text { Instruções }\end{array}$ & 16 & 16 \\
\hline Multiplicação de inteiros de 24 bits & Hovergous & $\begin{array}{l}\text { Múltiplas } \\
\text { Instruções }\end{array}$ & $\begin{array}{l}\text { Múltiplas } \\
\text { Instruções }\end{array}$ \\
\hline $\begin{array}{l}\text { Cálculo de recíproco, raiz quadrada recíproca, } \\
\text { logaritmo base } 2 \text {, exponencial base } 2 \text {, seno e cosseno }\end{array}$ & 2 & 4 & 8 \\
\hline Conversão de Tipos & 8 & 16 & 16 \\
\hline _ syncthreads () & 8 & 16 & 16 \\
\hline
\end{tabular}

Tabela B.1: Tabela de referência da NVIDIA (NVIDIA, 2011d, p. 98).

Esse mesmo manual comenta que as outras instruções e funções são implementadas sobre as instruções nativas e podem variar conforme a compute capability do equipamento. Também o número de instruções nativas após a compilação poderá variar dependendo da versão do compilador. Nas funções complicadas, dependendo do valor de entrada, poderão existir vários caminhos de execução. (NVIDIA, 2011d, p. 98).

Para que seja executada uma instrução para todas as threads de um warp, na compute capability 1.X, o escalonador deverá emitir uma instrução conforme a quantidade de ciclos de relógio informado na tabela B.2.

O escalonamento da compute capability 2.X funciona de forma diferente, já que essa família possui dois escalonadores. No momento de emitir a instrução para execução, na compute capability 2.0, o escalonador deverá emitir uma instrução, enquanto que na 2.1 deverá emitir duas instruções. O primeiro escalonador cuida dos warps impares e o segundo dos pares. Se for emitida uma instrução de ponto flutuante com precisão dupla, somente um escalonador operará. Como o escalonador emite uma instrução para cada meio warp, para executar uma instrução para todas as threads do warp, o escalonador deverá emitir a instrução por dois ciclos de relógio, tanto para aritmética de inteiros quanto para ponto flutuante (NVIDIA, 2011d, p. 166). 


\begin{tabular}{|l|c|}
\hline Instrução & $\begin{array}{c}\text { Número de ciclos para emitir } \\
\text { uma nova instrução para execução }\end{array}$ \\
\hline \hline $\begin{array}{l}\text { Instrução aritmética com inteiros ou } \\
\text { ponto flutuante de precisão simples }\end{array}$ & 4 \\
\hline $\begin{array}{l}\text { Instrução aritmética de ponto flutuante } \\
\text { com precisão dupla }\end{array}$ & 32 \\
\hline $\begin{array}{l}\text { Instrução transcendental de ponto flutuante } \\
\text { com precisão simples }\end{array}$ & 16 \\
\hline
\end{tabular}

Tabela B.2: Tabela de emissão, pelo escalonador da compute capability 1.X, de instruções para execução (NVIDIA, 2011d, p. 162). 


\section{Apêndice C}

\section{Código Fonte}

A seguir mostramos o código fonte para a opção 5 de leitura do ঃclock para o microbenchmark. Essa rotina está escrita em CUDA C e linguagem de montagem PTX.

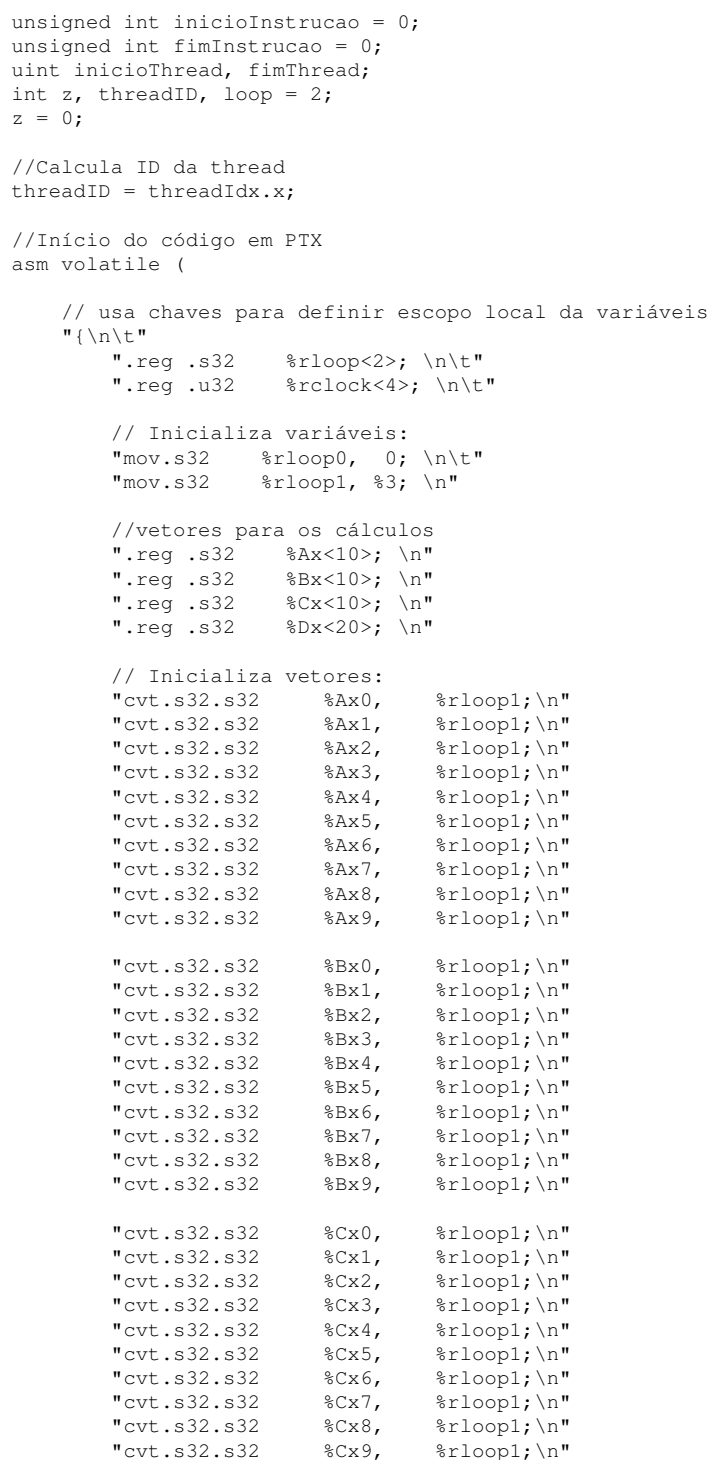




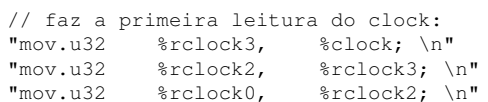

// local onde entram as instruções a serem avaliadas

\begin{tabular}{|c|c|c|c|}
\hline mov.s32 & $\because \mathrm{Dx} 0$, & $\therefore \mathrm{AxO} ;$ & $\backslash n \backslash t t^{\prime}$ \\
\hline "mov.s32 & $\frac{\circ \mathrm{Dx} 1,}{1}$ & $\frac{\circ}{0} \mathrm{Ax} 1 ;$ & $\backslash n \backslash t^{\prime}$ \\
\hline "mov.s 32 & $\because \mathrm{D} \times 2$, & $\frac{\circ}{8} \times 2 ;$ & $\backslash n \backslash t^{\prime}$ \\
\hline nov.s32 & $\because \mathrm{D} \times 3$, & $\div A \times 3 ;$ & $\mid t^{\prime}$ \\
\hline nov.s32 & $\because \mathrm{Dx} 4$, & $\div A \times 4 ;$ & $\backslash n \backslash t^{\prime}$ \\
\hline "mov.s32 & $\because \mathrm{Dx} 5$, & $\div A \times 5 ;$ & $n \backslash t^{\prime}$ \\
\hline nov.s32 & $\because \mathrm{Dx} 6$, & $\div A \times 6 ;$ & $\lambda \backslash t^{\prime}$ \\
\hline "mov.s32 & $\because \mathrm{D} \times 7$, & $\frac{\circ \mathrm{Ax} 7}{;}$ & $\mid t^{\prime}$ \\
\hline mov.s 32 & $\because \mathrm{Dx}$ & $\therefore$ Ax8; & $\mid t^{\prime}$ \\
\hline "mov.s32 & $\because \mathrm{D} \times 9$, & $\frac{\circ \times 9}{8} ;$ & \\
\hline
\end{tabular}

// fim das instruções a serem avaliadas

// faz a segunda leitura do \%clock: $\backslash n$ "

"mov.u32 \%rclock3, \%clock; \n"

"mov.u32 orclock2, 音clock3; \n"

"mov.u32 orclock1, orclock2; \n"

//Reduz todos os resultados para um único

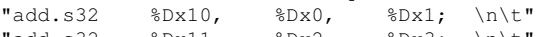

"add.s32

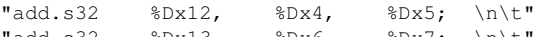

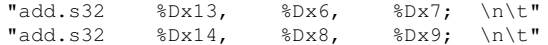

"add.s32 \%Dx15, \%Dx10, \%Dx11; $\backslash n \backslash t$

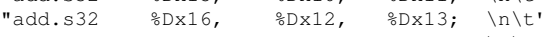

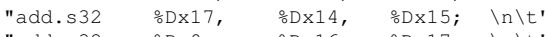

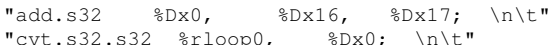

// retorna a leitura do clock inicial

"mov.u32 \%1, orclock0; \n"

// retorna a leitura do clock fina

"mov.u32 \%2, \%rclock1; \n"

// retorna o valor de saída para evitar as otimizações " \} "

// definicao dos dados de entrada e saída - sem otimizar memoria

:"=r" (z), "=r" (inicioInstrucao), "=r" (fimInstrucao)

);

: "r" (loop) : "memory"

if ( (threadID < kTotalThreads) \&\& (threadID $\% 32==0)$ )

// Salva leitura do inicio das instrucoes de teste

dev_resultado[TOTALPARAMETROS * (threadID/32) + 1] = (uint) inicioInstrucao;

// Salva leitura do fim das instrucoes de teste

dev_resultado[TOTALPARAMETROS * (threadID/32) + 2] = (uint)fimInstrucao;

$1 /$ Precisa sair com o resultado para evitar otimizaçóes

dev_resultado[TOTALPARAMETROS * $($ threadID/32) + 4] = z; 


\section{Apêndice D}

\section{Desmontagem de Instruções PTX}

Neste apêndice mostramos a desmontagem do código de máquina de uma instrução PTX, o div •s 64. Como veremos a seguir, essa instrução possui um desvio condicional e um ponto de sincronismo em seu código de máquina.

\section{D.1 Instrução de Divisão de 64 bits}

A seguir temos o código PTX para o teste do div.s64 com uma instrução no trecho.

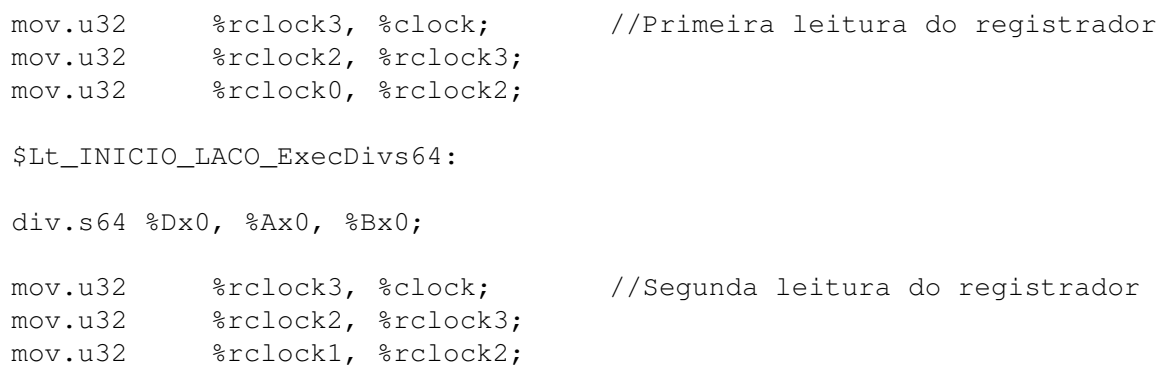

Esse código, após compilado, foi desmontado e está na listagem apresentada a seguir. Nota-se que a rotina de máquina para a divisão possui um desvio condicional, no endereço 0a38, e um ponto de sincronização, no endereço 0a30.

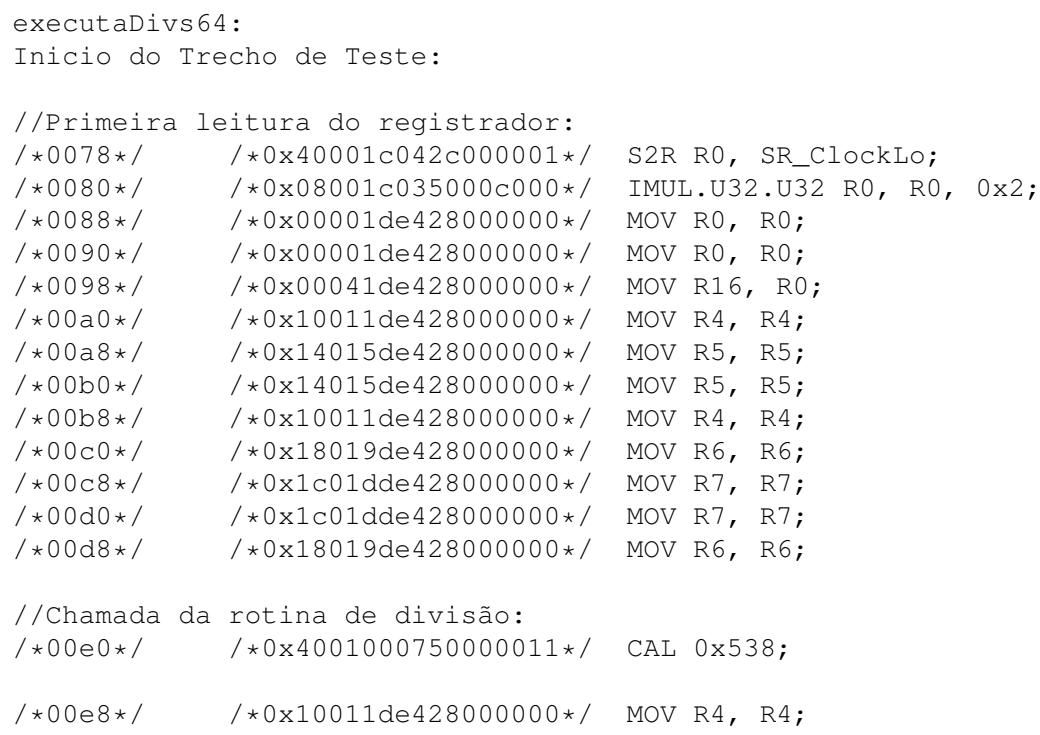




\begin{tabular}{|c|c|c|}
\hline$/ * 00 \pm 0 * /$ & $/ * 0 \times 14015$ de $428000000 * /$ & MOV R5， R5; \\
\hline $1 * 00 f 8 * 1$ & $/ * 0 \times 10011$ de $428000000 * /$ & MOV R4, R4; \\
\hline$/ * 0100 * /$ & / *0×14015de $428000000 * /$ & MOV R5, R5; \\
\hline$/ * 0108 * /$ & $/ \star 0 \times 10011$ de $428000000 * /$ & MOV R4, R4; \\
\hline$/ \star 0110 * /$ & $/ * 0 \times 14015$ de $428000000 * /$ & MOV R5, R5; \\
\hline$/ / \mathrm{Se}$ & leitura do regist & \\
\hline$/ * 0118 * /$ & $/ * 0 \times 40001 c 042 c 000001 * /$ & S2R R0, SR_ClockLo; \\
\hline$/ \star 0120 * /$ & $/ * 0 \times 08001 c 035000 c 000 * /$ & IMUL.U32.U32 R0, R0, 0x2; \\
\hline$/ \star 0128 * /$ & $/ \star 0 \times 00001$ de $428000000 * /$ & MOV RO, RO; \\
\hline$/ \star 0130 * /$ & $/ * 0 \times 00001$ de $428000000 * /$ & MOV R0, RO; \\
\hline $1 * 0138 * 1$ & / *0x00001de $428000000 * /$ & MOV RO, RO; \\
\hline
\end{tabular}

//Rotina de divisão de inteiro com sinal:

/*0538*/ / /0x14025de428000000*/ MOV R9, R5;

$/ * 0540 * / \quad / * 0 \times 10021$ de428000000*/ MOV R8, R4;

$/ * 0548 * / \quad / * 0 \times 1$ c015de428000000*/ MOV R5， R7;

$/ * 0550 * / \quad / * 0 \times 18011$ de428000000*/ MOV R4, R6;

/*0558*/ /*0*10011de428000000*/ MOV R4, R4;

$/ * 0560 * / \quad / * 0 \times 14015$ de428000000*/ MOV R5，R5;

$/ \star 0568 * / \quad / * 0 \times 10019$ de428000000*/ MOV R6, R4;

$/ * 0570 * / \quad / * 0 \times 1401$ dde428000000*/ MOV R7, R5 ;

/*0578*/ /*0xfc00dde428000000*/ MOV R3, RZ;

/*0580*/ /*0*20021de428000000*/ MOV R8, R8;

$/ \star 0588 * / \quad / * 0 \times 24025$ de428000000*/ MOV R9, R9;

/*0590*/ /*0*20021de428000000*/ MOV R8， R8;

$/ * 0598 * / \quad / * 0 \times 24025$ de428000000*/ MOV R9, R9;

$/ * 05 \mathrm{a} 0 * / \quad / * 0 \times 20029$ de428000000*/ MOV R10, R8;

$/ * 05 \mathrm{a} 8 * / \quad / * 0 \times 2402$ dde428000000*/ MOV R11，R9;

$/ * 05 \mathrm{~b} 0 * / \quad / * 0 \times 2 \mathrm{c} 001 \mathrm{de} 428000000 * /$ MOV R0, R11;

/*05b8*/ /*0*18019de428000000*/ MOV R6, R6;

$/ * 05 \mathrm{c} 0 * / \quad / * 0 \times 1 \mathrm{c} 01 \mathrm{dde} 428000000 * /$ MOV R7, R7;

/*05c8*/ / *0x18029de428000000*/ MOV R10，R6;

$/ * 05 \mathrm{~d} 0 * / / * 0 \times 1 \mathrm{c} 02 \mathrm{dde} 428000000 * /$ MOV R11，R7;

/*05d8*/ /*0*2c031de428000000*/ MOV R12，R11;

$1 * 05 e 0 * /$

/ *05e8* /

$/ * 05 \mathrm{f} 0 * /$

$/ * 05 \mathrm{f} 8 * /$

$1 * 0600 * 1$

$/ * 0608 * 1$

$/ * 0610 * /$

$/ * 0618 * /$

$/ * 0620 * /$

$1 * 0628 * /$

$1 * 0630 * /$

$1 * 0638 * 1$

$/ * 0640 * /$

$/ * 0648 * 1$

$1 * 0650 * 1$

$/ * 0658 * /$

$/ * 0660 * /$

$/ * 0668 * /$

$/ * 0670 * /$

$/ * 0678 * /$

$1 * 0680 * 1$

$/ * 0688 * /$

$/ \star 0690 * /$

$/ * 0698 * /$

$1 * 06 \mathrm{a} 0 * /$

$/ * 06 \mathrm{a} 8 * 1$

$/ * 06 \mathrm{~b} 0 * /$

$1 * 06 \mathrm{~b} 8 * 1$

$1 * 06 \mathrm{c} 0 * /$

$1 * 06 \mathrm{c} 8 * 1$

$1 * 06 \mathrm{~d} 0 * /$

$1 * 06 \mathrm{~d} 8 * /$

$1 * 06 \mathrm{e} 0 * 1$

$1 * 06 e 8 *$

$/ * 06 \mathrm{f} 0 *$

$/ * 06 \mathrm{f} 8 * /$

$1 * 0700 * 1$

$/ * 0708 * /$

/ *0x00c29c8368000000* /

$/ * 0 \times 0 \mathrm{ca} 3 \mathrm{dc} 231 \mathrm{~b} 0 \mathrm{e} 0000 * /$

$/ * 0 \times f c 629 e 0348010000 * /$

$/ * 0 \times f c 72$ de $4348000000 * /$

$/ * 0 \times f c 00$ dde $428000000 * /$

$/ * 0 \times 0 \operatorname{cc} 1 \mathrm{dc} 23188 e 0000 * /$

/ *0x18a29c0420000000*/

/ *0x1cb2dc0420000000* /

/ *0x10011de428000000*/

$/ * 0 \times 14015$ de $428000000 * /$

/ *0x10019de428000000*/

$/ * 0 \times 1401$ dde $428000000 * /$

/*0xfc811e0348010000*/

$/ * 0 \times f c 915 e 4348000000 * /$

/ *0xfc00 dde $428000000 * /$

/ *0x0c01dc23188e0000*/

/*0×20431c0420000000*/

/*0×24535c0420000000* /

/*0×29a01c0418040000*/

$/ * 0 \times 10001 \mathrm{c00c8000000*/}$

$/ * 0 \times 00001$ de $428000000 * /$

$/ * 0 x f 8001 \mathrm{c0} 02087 f f f f f * /$

$1 * 0 \times 00001$ de $428000000 * /$

$/ * 0 \times 00001$ de $428000000 * /$

$/ * 0 \times 00001$ de $428000000 * /$

$/ * 0 \times 00001$ de $428000000 * /$

$/ \star 0 \times 00001 \mathrm{c} 405800 \mathrm{cfe} 0 * /$

$1 * 0 \times 00001$ de $428000000 * /$

$/ * 0 \times 01311 c 0414060000 * /$

$/ * 0 \times 10011$ de $428000000 * /$

/*0x14015de428000000*/

$/ * 0 \times 10 a 21 \mathrm{c} 0350010000 * /$

/*0x10a01c4320ff0000*/

$1 * 0 \times 10 \mathrm{~b} 0 \mathrm{dc} 0320810000 * /$

/*0×10b01c4320fe0000*/

/*0x14a25c0320070000*/

$/ * 0 \times 14 \mathrm{a} 0 \mathrm{dc} 4320810000 * /$

$/ * 0710 * /$

$/ * 0 \times f f f 01 \mathrm{c} 4348000000 * /$

LOP. XOR R10, R12, R0;

ISETP.GE.AND P1, pt, R10, R3, pt;

IADD R10.CC, $-\mathrm{R} 6$, RZ;

IADD.X R11, -R7, RZ;

MOV R3, RZ;

ISETP.LT.AND P0, pt, R12, R3, pt;

SEL R10，R10，R6，P0;

SEL R11，R11，R7，P0;

MOV R4, R4;

MOV R5, R5;

MOV R6, R4;

MOV R7, R5;

IADD R4.CC, -R8, RZ;

IADD.X R5, -R9, RZ;

MOV R3, RZ;

ISETP.LT.AND P0, pt, R0, R3, pt;

SEL R12, R4, R8, P0;

SEL R13，R5，R9，P0;

I2F.F32.U64.RP R0, R10;

MUFU.RCP RO, RO;

MOV RO, RO :

IADD32I R0, R0, 0x1ffffffe;

MOV R0, R0;

MOV RO, RO;

MOV RO, RO;

MOV RO, RO;

FMUL.FTZ R0, R0, $0 \times 3 f 800$;

MOV R0, R0;

F2I.U64.F32.TRUNC R4, R0;

MOV R4, R4;

MOV R5, R5;

IMUL.U32.U32 R8.CC, R10, R4;

IMAD.U32.U32.HI.X R0.CC, R10, R4, RZ;

IMAD.U32.U32.X R3.CC, R11, R4, R0;

IMAD.U32.U32.HI.X R0, R11, R4, RZ;

IMAD.U32.U32 R9.CC, R10, R5, R3;

IMAD.U32.U32.HI.X R3.CC, R10, R5, R0;

IADD.X RO, RZ, RZ;

IMAD.U32.U32 R3.CC, R11，R5， R3; 


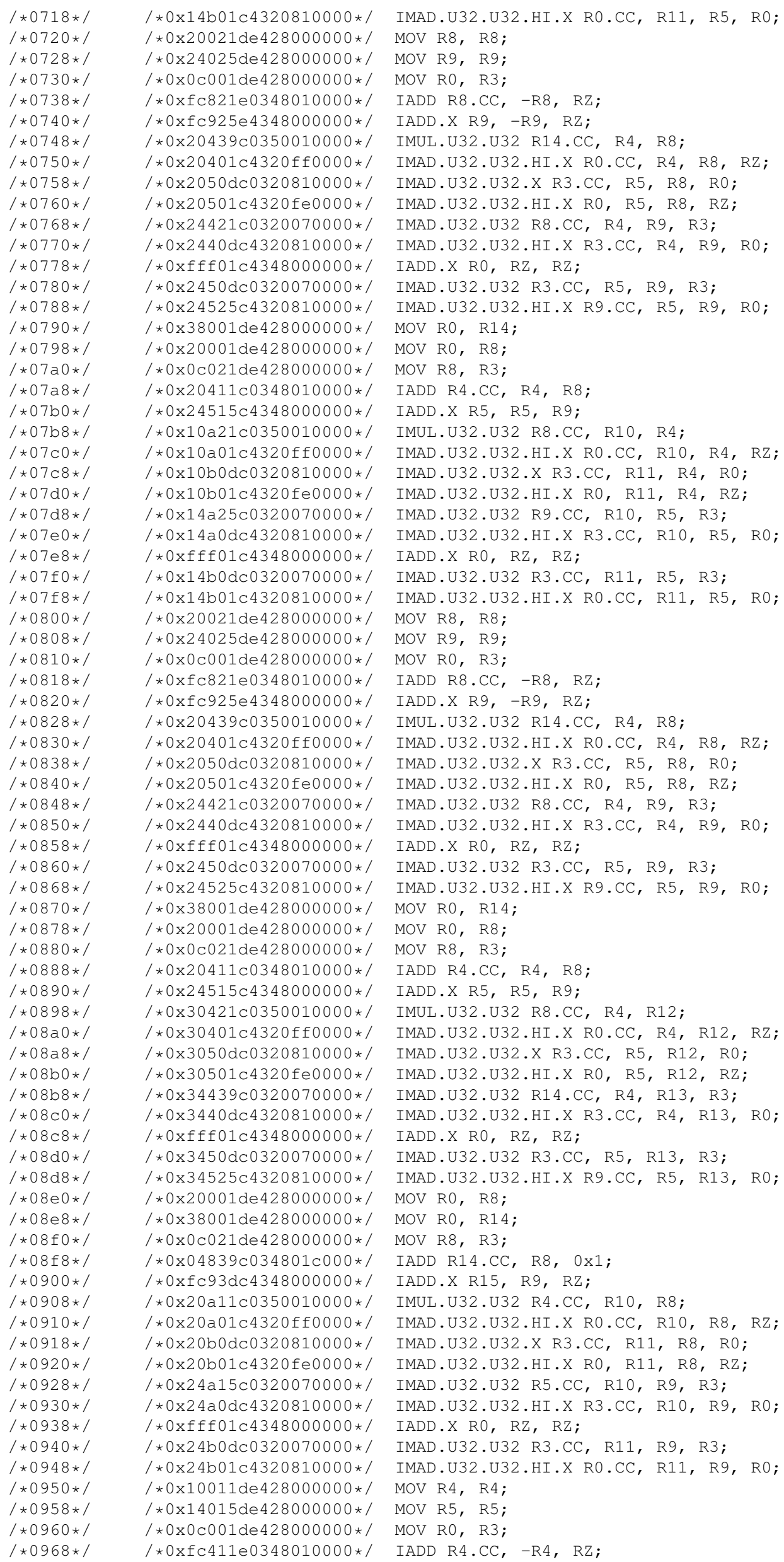

$/ * 0718 * /$ $/ * 0720 * 1$ $/ * 0728 * /$ $/ * 0730 * /$ $1 * 0738 * 1$ $/ * 0740 * /$ $/ * 0748 * 1$ $/ * 0750 * /$ $/ * 0758 * 1$ $/ * 0760 * /$ $/ * 0768 * /$ $/ \star 0770 * /$ $/ * 0778 * /$ $/ * 0780 * /$ $/ \star 0788 * /$ $/ * 0790 * /$ $/ * 0798 * 1$ $/ * 07 \mathrm{a} 0 * /$ / *07a $8 * /$ $1 * 07 \mathrm{~b} 0 * 1$ $1 * 07 \mathrm{~b} 8 * 1$ $/ * 07 \mathrm{c} 0 * /$ $/ * 07 \mathrm{c} 8 * /$ $/ * 07 \mathrm{~d} 0 * /$ $1 * 07 \mathrm{~d} 8 * 1$ $/ * 07 e 0 * /$ $/ * 07 e 8 * /$ $/ * 07 \mathrm{f} 0 * /$ $1 * 07 \mathrm{f} 8 * 1$ $1 * 0800 * /$ $/ * 0808 * /$ $/ * 0810 * /$ $/ \star 0818 * /$ $/ \star 0820 * /$ $/ * 0828 * /$ $/ * 0830 * /$ $/ * 0838 * 1$ $/ * 0840 * /$ $/ * 0848 * /$ $/ * 0850 * /$ $1 * 0858 * 1$ $/ * 0860 * /$ $/ * 0868 * 1$ $/ \star 0870 * /$ $/ * 0878 * /$ $/ * 0880 * /$ $/ * 0888 * 1$ $/ * 0890 * /$ $/ * 0898 * /$ $1 * 08 \mathrm{a} 0 * /$ $/ * 08 \mathrm{a} 8 * /$ $/ * 08 \mathrm{~b} 0 * /$ $/ \star 08 \mathrm{~b} 8 * /$ $1 * 08 \mathrm{c} 0 * /$ $/ * 08 \mathrm{c} 8 * /$ $/ \star 08 \mathrm{~d} 0 * /$ $1 * 08 \mathrm{~d} 8 * 1$ $/ * 08 e 0 * /$ $1 * 08 e 8 * 1$ $/ \star 08 \mathrm{f} 0 * /$ $/ * 08 \mathrm{f} 8 * /$ $1 * 0900 * 1$ $/ * 0908 * /$ /*0910*/ $/ * 0918 * /$ $1 * 0920 * 1$ $/ * 0928 * /$ $/ * 0930 * /$ $/ * 0938 * /$ $/ * 0940 * /$ $/ * 0948 * /$ $/ * 0950 * /$ $/ * 0958 * /$ $/ * 0960 * /$ $/ * 0968 * /$

/*0x14b01c4320810000*/ $/ * 0 \times 20021$ de $428000000 * /$ $/ * 0 \times 24025 \operatorname{de} 428000000 * /$ $/ * 0 \times 0$ c001de $428000000 * /$ $/ \star 0 x f c 821 e 0348010000 * /$ $/ * 0 x f c 925 e 4348000000 * /$ /*0×20439c0350010000* / $/ * 0 \times 20401 \mathrm{c} 4320 \mathrm{ff0} 000 * /$ / *0×2050dc0320810000* / $/ * 0 \times 20501 c 4320$ fe0000*/ /*0×24421c0320070000*/ $/ * 0 \times 2440$ dc4320810000*/ /*0xfff01c4348000000*/ $/ * 0 \times 2450 \mathrm{dc} 0320070000 * /$ $/ * 0 \times 24525 c 4320810000 * /$ /*0×38001de428000000* / $/ \star 0 \times 20001$ de $428000000 * /$ /*0x0c021de428000000* / $/ * 0 \times 20411 c 0348010000 * /$ $/ * 0 \times 24515 c 4348000000 * /$ $/ * 0 \times 10 a 21 c 0350010000 * /$ / *0x10a01c4320ff0000*/ $/ * 0 \times 10 \mathrm{~b} 0 \mathrm{dc} 0320810000 * /$ $/ * 0 \times 10 b 01$ c4320fe0000*/ /*0x14a25c0320070000* / $/ \star 0 \times 14 a 0 d c 4320810000 * /$ /*0xfff01c4348000000* / $/ * 0 \times 14 \mathrm{~b} 0 \mathrm{dc} 0320070000 * /$ /*0×14b01c4320810000* / $/ * 0 \times 20021$ de $428000000 * /$ $/ * 0 \times 24025$ de $428000000 * /$ /*0×0c001de428000000* / $/ \star 0 x f c 821 e 0348010000 * /$ /*0xfc925e4348000000*/ $/ * 0 \times 20439 c 0350010000 * /$ $/ * 0 \times 20401 c 4320$ ff0000* / $/ * 0 \times 2050$ dc0320810000*/ /*0×20501c4320fe0000*/ $/ * 0 \times 24421 c 0320070000 * /$ $/ * 0 \times 2440$ dc4320810000*/ /*0xfff01c4348000000*/ $/ * 0 \times 2450 \mathrm{dc} 0320070000 * /$ $/ * 0 \times 24525 c 4320810000 * /$ $/ * 0 \times 38001$ de428000000*/ / *0x20001de428000000*/ $/ * 0 \times 0 \mathrm{c} 021$ de $428000000 * /$ $/ * 0 \times 20411 c 0348010000 * /$ /*0×24515c4348000000*/ $/ * 0 \times 30421 c 0350010000 * /$ /*0×30401c4320ff0000* / $/ \star 0 \times 3050 \mathrm{dc} 0320810000 * /$ $/ * 0 \times 30501$ c4320fe0000*/ $/ * 0 \times 34439 c 0320070000 * /$ $/ * 0 \times 3440 \mathrm{dc} 4320810000 * /$ $/ * 0 \times f f f 01 c 4348000000 * /$ $/ * 0 \times 3450 \mathrm{dc} 0320070000 * /$ $/ * 0 \times 34525 c 4320810000 * /$ $/ \star 0 \times 20001$ de $428000000 * /$ $/ * 0 \times 38001$ de428000000*/ $/ * 0 \times 0$ c021de428000000*/ $/ * 0 \times 04839 c 034801 c 000 * /$ $/ * 0 \times f c 93 \mathrm{dc} 4348000000 * /$ /*0x20a11c0350010000*/ $/ * 0 \times 20 a 01 c 4320 f f 0000 * /$ $/ * 0 \times 20 \mathrm{~b} 0 \mathrm{dc} 0320810000 * /$ / *0×20b01c4320fe0000*/ $/ * 0 \times 24 a 15 c 0320070000 * /$ /*0x24a0dc4320810000*/ $/ * 0 x f f f 01 c 4348000000 * /$ $/ \star 0 \times 24 \mathrm{~b} 0 \mathrm{dc} 0320070000 * /$ $/ * 0 \times 24 \mathrm{~b} 01 \mathrm{c} 4320810000 * /$ $/ * 0 \times 10011$ de $428000000 * /$ /*0x14015de428000000*/ $/ * 0 \times 0$ c001de428000000*/ /*0xfc411e0348010000*/

IMAD.U32.U32.HI.X R0.CC, R11, R5, R0; MOV R8, R8; MOV R9, R9; MOV R0, R3; IADD R8.CC, $-\mathrm{R} 8, \mathrm{RZ}$; IADD.X R9, -R9, RZ; IMUL.U32.U32 R14.CC, R4, R8; IMAD.U32.U32.HI.X R0.CC, R4, R8, RZ; IMAD.U32.U32.X R3.CC, R5，R8，R0; IMAD.U32.U32.HI.X R0, R5, R8, RZ; IMAD.U32.U32 R8.CC, R4, R9, R3; IMAD.U32.U32.HI.X R3.CC, R4，R9，R0; IADD.X RO, RZ, RZ;

IMAD.U32.U32 R3.CC, R5, R9, R3; IMAD.U32.U32.HI.X R9.CC, R5, R9, R0; MOV R0, R14; MOV R0, R8; MOV R8, R3; IADD R4.CC, R4, R8; IADD.X R5, R5, R9; IMUL.U32.U32 R8.CC, R10, R4; IMAD.U32.U32.HI.X R0.CC, R10，R4，RZ; IMAD.U32.U32.X R3.CC, R11, R4, R0; IMAD.U32.U32.HI.X R0, R11, R4, RZ; IMAD.U32.U32 R9.CC, R10, R5, R3; IMAD.U32.U32.HI.X R3.CC, R10, R5, R0; IADD.X R0, RZ, RZ;

IMAD.U32.U32 R3.CC, R11, R5, R3; IMAD.U32.U32.HI.X R0.CC, R11，R5，R0; MOV R8, R8; MOV R9, R9; MOV R0, R3; IADD R8.CC, $-\mathrm{R} 8$, RZ; IADD.X R9, -R9, RZ; IMUL.U32.U32 R14.CC, R4, R8; IMAD.U32.U32.HI.X R0.CC, R4, R8, RZ; IMAD.U32.U32.X R3.CC, R5, R8, R0; IMAD.U32.U32.HI.X R0, R5, R8, RZ; IMAD.U32.U32 R8.CC, R4, R9, R3; IMAD.U32.U32.HI.X R3.CC, R4, R9, R0; IADD.X R0, RZ, RZ; IMAD.U32.U32 R3.CC, R5, R9, R3; IMAD.U32.U32.HI.X R9.CC, R5，R9， R0; MOV R0, R14; MOV R0, R8; MOV R8, R3; IADD R4.CC, R4, R8; IADD.X R5, R5, R9; IMUL.U32.U32 R8.CC, R4, R12; IMAD.U32.U32.HI.X R0.CC, R4, R12, RZ; IMAD.U32.U32.X R3.CC, R5, R12, R0; IMAD.U32.U32.HI.X R0, R5，R12，RZ; IMAD.U32.U32 R14.CC, R4, R13, R3; IMAD.U32.U32.HI.X R3.CC, R4，R13，R0; IADD.X RO, RZ, RZ; IMAD.U32.U32 R3.CC, R5, R13, R3; IMAD.U32.U32.HI.X R9.CC, R5，R13，R0; MOV R0, R8; MOV R0, R14; MOV R8, R3; IADD R14.CC, R8, 0x1; IADD.X R15，R9，RZ; IMUL.U32.U32 R4.CC, R10, R8; IMAD.U32.U32.HI.X R0.CC, R10, R8, RZ; IMAD.U32.U32.X R3.CC, R11, R8, R0; IMAD.U32.U32.HI.X R0, R11, R8, RZ; IMAD.U32.U32 R5.CC, R10, R9, R3; IMAD.U32.U32.HI.X R3.CC, R10, R9, R0; IADD.X RO, RZ, RZ; IMAD.U32.U32 R3.CC, R11, R9, R3; IMAD.U32.U32.HI.X R0.CC, R11, R9, R0; MOV R4, R4; MOV R5, R5. MOV R0, R3; IADD R4.CC, $-\mathrm{R} 4$, RZ 


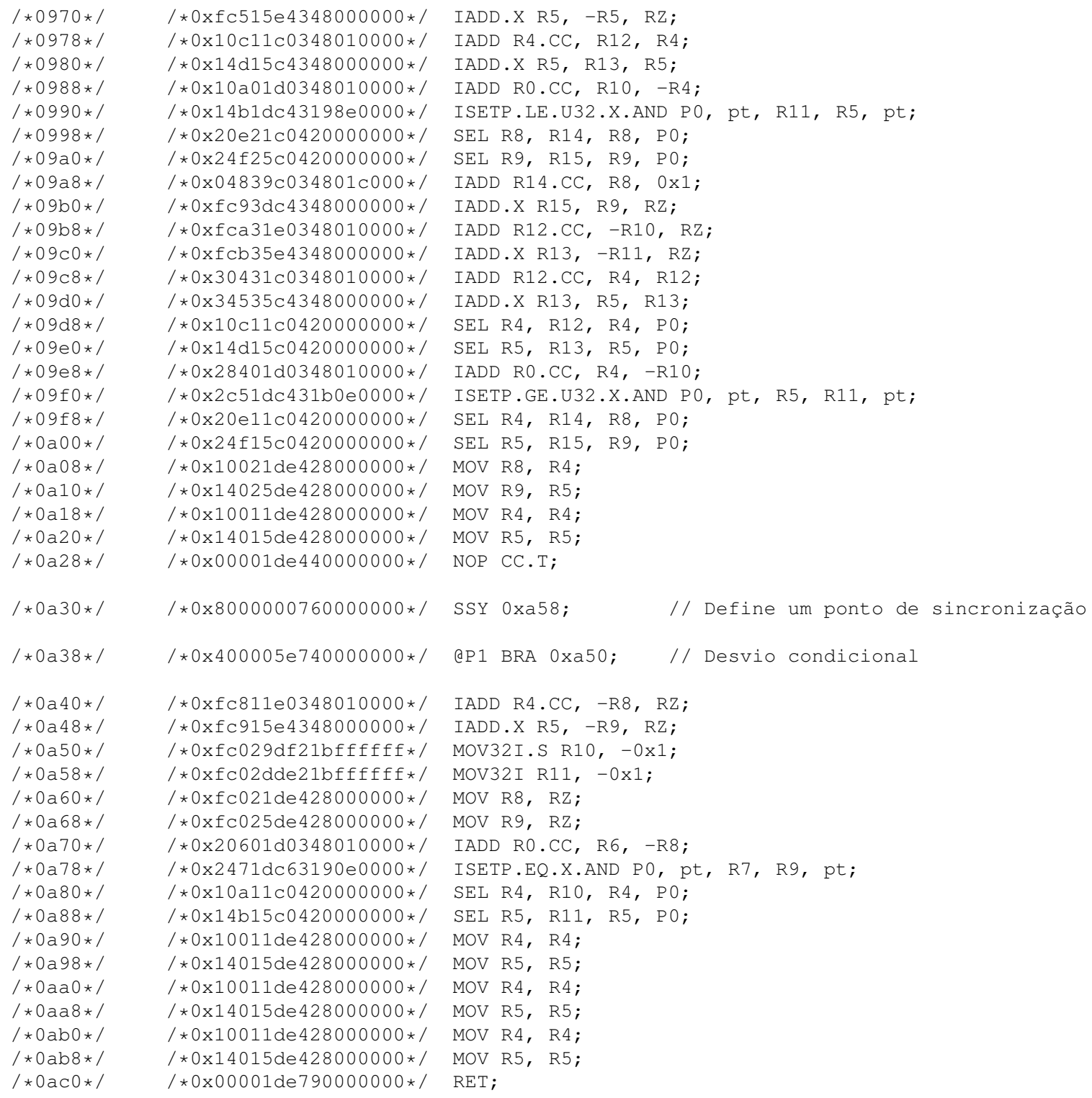




\section{Referências Bibliográficas}

DBL(2010) MASCOTS 2010, 18th Annual IEEE/ACM International Symposium on Modeling, Analysis and Simulation of Computer and Telecommunication Systems, Miami, Florida, USA, August 17-19, 2010. IEEE. ISBN 978-0-7695-4197-6. Citado na pág. 45

Abd-El-Barr e El-Rewini(2005) M. Abd-El-Barr e H. El-Rewini. Fundamentals of Computer Organization and Architecture. Wiley Series on Parallel and Distributed Computing. Wiley. ISBN 9780471478331. URL http://books.google.com.br/books?id=m6uFlL41TIIC. Citado na pág. 7, 8, 9

Aji et al.(2015) Ashwin M. Aji, Mayank Daga e Wu chun Feng. Campprof: A visual performance analysis tool for memory bound gpu kernels. Desconhecido - VERIFICAR. Citado na pág. 15

Baghsorkhi et al.(2010) Sara S. Baghsorkhi, Matthieu Delahaye, Sanjay J. Patel, William D. Gropp e Wen mei W. Hwu. An adaptive performance modeling tool for gpu architectures. Proceedings of the 15th ACM SIGPLAN Symposium on Principles and Practice of Parallel Programming (15th PPOPP'10), páginas 105-114. Citado na pág. 43, 46

Chen(2009) J.Y. Chen. Gpu technology trends and future requirements. Electron Devices Meeting (IEDM), 2009 IEEE International, páginas 1 -6. Citado na pág. 13, 15

Dasgupta(2011) Aniruddha Dasgupta. Cuda performace analyser. Dissertação de Mestrado, School of Electrical and Computer Engineering, Georgia Institute of Technology, Vancouver. Citado na pág. 41, 46

Flynn(1972) Michael J. Flynn. Some computer organizations and their effectiveness. Computers, IEEE Transactions on, C-21(9):948 -960. ISSN 0018-9340. doi: 10.1109/TC.1972.5009071. Citado na pág. 6

Fortune e Wyllie(1978) Steven Fortune e James Wyllie. Parallelism in random access machines. Em Richard J. Lipton, Walter A. Burkhard, Walter J. Savitch, Emily P. Friedman e Alfred V. Aho, editors, STOC, páginas 114-118. ACM. Citado na pág. 42

Gibbons et al.(1998) Phillip B. Gibbons, Yossi Matias e Vijaya Ramachandran. The queue-read queue-write pram model: Accounting for contention in parallel algorithms. SIAM J. Comput., 28 (2):733-769. Citado na pág. 42

Gubitoso(1996) Marco Dimas Gubitoso. Modelos analíticos de desempenho para sistemas de memória compartilhada virtual. Tese de Doutorado, Universidade de São Paulo, IME. URL http://dedalus.usp.br/F/ GPUBGPMCHLDLSAT16KNU35ISYB3AJ7KAMGNSIFMCNV4TPTRY7S- 35626? func= full-set-set\&set_number $=014509 \&$ set_entry $=000028 \&$ format $=999$. Citado na pág. 1

Halfhill(2009) Tom R. Halfhill. White paper looking beyond graphics. Relatório técnico, In-Stat. URL http://www.nvidia.com/content/PDF/fermi_white_papers/T.Halfhill_Looking_ Beyond_Graphics.pdf. Citado na pág. 13, 23, 24, 25, 26 
Hong e Kim(2010) Sunpyo Hong e Hyesoon Kim. An integrated gpu power and performance model. Em ISCA, páginas 280-289. Citado na pág. 41

Hong e Kim(2009a) Sunpyo Hong e Hyesoon Kim. Memory-level and thread-level parallelism aware gpu architecture performance analytical model. Relatório técnico, Georgia Institute of Technology. Citado na pág. 39

Hong e Kim(2009b) Sunpyo Hong e Hyesoon Kim. An analytical model for a GPU architecture with memory-level and thread-level parallelism awareness. Proc. 36th International Symposium on Computer Architecture (36th ISCA '09), páginas 152-163. GA Tech. Citado na pág. xv, 2, 18, 19, $20,21,39,46$

Jain(1991) Raj Jain. The Art of Computer Systems Performance Analysis: Techniques for Experimental Design, Measurement, Simulation, and Modeling. Wiley- Interscience. ISBN 0-47150336-3. URL http://www.cse.wustl.edu/ jain/books/perfbook.htm. Citado na pág. 86, 112

Kirk e mei W. Hwu(2010) David B. Kirk e Wen mei W. Hwu. Programming Massively Parallel Processors - A Hands-on Approach. Elsevier - Morgan Kaufmann. Citado na pág. xv, 5, 11, 12, 16, $20,22,23,28,30,31$

Kobayashi(1978) H. Kobayashi. Modeling and Analysis: An Introduction to System Performance Evaluation Methodology. Addison-Wesley Publishing Company. ISBN 0-201-14457-3. Citado na pág. 1,10

Kothapalli et al.(2009) Kishore Kothapalli, Rishabh Mukherjee, M. Suhail Rehman, Suryakant Patidar, P. J. Narayanan e Kannan Srinathan. A performance prediction model for the cuda gpgpu platform. HiPC, páginas 463-472. URL http://dx.doi.org/10.1109/HIPC.2009.5433179. Citado na pág. 19, 42, 46

Lanfear e Ziegler(2009) Tim Lanfear e Gernot Ziegler. Hpc computing with cuda and tesla hardware. Relatório técnico, NVIDIA. Citado na pág. xv, 16, 17, 33

Lindholm et al.(2008) E. Lindholm, J. Nickolls, S. Oberman e J. Montrym. Nvidia tesla: A unified graphics and computing architecture. Micro, IEEE, 28(2):39 -55. ISSN 0272-1732. URL http:// ieeexplore.iee. $. \mathrm{rg} / \mathrm{stamp} / \mathrm{stamp} . j \mathrm{sp} ? \mathrm{tp}=$ \&arnumber $=4523358$ \&isnumber $=4523348$. Citado na pág. xv $11,12,13,14,15,16,17,18,20,21,22$

Liu et al.(2007) Weiguo Liu, Wolfgang Muller-Wittig e Bertil Schmidt. Performance predictions for general-purpose computation on gpus. Proc. 2007 International Conference on Parallel Processing (36th ICPP'07), página 50. ISSN 0190-3918. Citado na pág. xv, 12

Luebke e Humphreys(2007) David Luebke e Greg Humphreys. How gpus work. Computer, 40 (2):96-100. ISSN 0018-9162. URL http://ieexplore.ieee.org/stamp/stamp.jsp?tp=\&arnumber= 4085637\&isnumber $=4085604$. Citado na pág. 11

Misel-Myrto Papadopoulou e Wong(2009) Maryam Sadooghi-Alvandi Misel-Myrto Papadopoulou e Henry Wong. Micro-benchmarking the gt200 gpu. Relatório técnico, Computer Group, ECE, University of Toronto. URL https://es100.seas.harvard.edu/download/ attachments/11043272/microbenchmark_report.pdf. Citado na pág. 45

Montrym e Moreton(2005) J. Montrym e H Moreton. The geforce 6800. Micro, IEEE, 25 (2):41-51. ISSN 0272-1732. URL http://ieeexplore.ieee.org/stamp/stamp.jsp?tp=\&arnumber= $1453487 \&$ isnumber $=31213$. Citado na pág. 11

Murphy(2008) Mike Murphy. Nvidia's experience with open64. 1st Annual Workshop on Open64. URL http://www.capsl.udel.edu/conferences/open64/2008/Papers/101.doc. Citado na pág. 34 
NVIDIA(2011a) NVIDIA. CUDA C BEST PRACTICES GUIDE v4.0, may 2011 2011a. Citado na pág. 68

NVIDIA(2009) NVIDIA. Whitepaper nvidia's next generation cuda compute architecture: Fermi v1.1. Relatório técnico, NVIDIA. URL http://www.nvidia.com/content/PDF/fermi_white papers/NVIDIA_Fermi_Compute_Architecture_Whitepaper.pdf. Citado na pág. xv, 11, 12, $2 \overline{3}$, $24,25,26$

NVIDIA(2011b) NVIDIA. Using Inline PTX Assembly in CUDA, abril 2011b. Citado na pág. 52, 53,67

NVIDIA(2011c) NVIDIA. CUDA API Reference Manual - Version 4.0, february 2011c. Citado na pág. 62,104

NVIDIA(2011d) NVIDIA. Cuda C Programming Guide 4.0. NVidia. Citado na pág. xv, xxi, 12, 13, $15,16,17,18,19,20,21,22,26,27,28,29,30,31,32,60,67,90,104,105,109,115,116,117$, 118

NVIDIA(2011e) NVIDIA. Cuobjdump - Application Note, january 2011e. Citado na pág. 35, 67, 68

NVIDIA(2011f) NVIDIA. The CUDA Compiler Driver NVCC v4.0, jan 2011 2011f. Citado na pág. $\mathrm{xv}, 27,32,33,34,35,36,37,38$

NVIDIA(2011g) NVIDIA. PTX: Parallel Thread Execution ISA Version 2.3, march 2011g. Citado na pág. $35,49,50,53$

Olukotun e Hammond(2005) Kunle Olukotun e Lance Hammond. The future of microprocessors. Queue, 3(7):26-29. ISSN 1542-7730. doi: 10.1145/1095408.1095418. URL http: //doi.acm.org/10.1145/1095408.1095418. Citado na pág. 5

Owens et al.(2007) John D. Owens, David Luebke, Naga Govindaraju, Mark Harris, Jens Kruger, Aaron E. Lefohn e Timothy J. Purcell. A survey of general-purpose computation on graphics hardware. Computer Graphics Forum, 26:80-113. ISSN 1467-8659. URL http: //www.blackwell-synergy.com/doi/abs/10.1111/j.1467-8659.2007.01012.x. Citado na pág. 12

Rau e Fisher(1992) B. Ramakrishna Rau e Joseph A. Fisher. Instruction-level parallel processing: History, overview and perspective, 1992. Citado na pág. 8, 9

Rauber e Rünger(2010) T. Rauber e G. Rünger. Parallel Programming: for Multicore and Cluster Systems. Springer. ISBN 9783642048173. URL http://books.google.com.br/books?id= wWogxOmA3wMC. Citado na pág. 6, 9, 10

Ryoo et al.(2008) Shane Ryoo, Christopher I. Rodrigues, Sam S. Stone, Sara S. Baghsorkhi, SainZee Ueng, John A. Stratton e Wen mei W. Hwu. Program optimization space pruning for a multithreaded gpu. Em Mary Lou Soffa e Evelyn Duesterwald, editors, CGO, páginas 195-204. ACM. ISBN 978-1-59593-978-4. Citado na pág. 43

Sauer e Chandy(1981) Charles H. Sauer e K. Mani Chandy. Computer systems performance modeling. Prentice-Hall. ISBN 0-13-165175-7. Citado na pág. 1, 10

Sim et al.(2012) Jaewoong Sim, Aniruddha Dasgupta, Hyesoon Kim e Richard W. Vuduc. A performance analysis framework for identifying potential benefits in gpgpu applications. Em PPOPP, páginas 11-22. Citado na pág. 41, 46, 113

Stallings(2003) William Stallings. Computer organization and architecture - designing for performance (6. ed.). Prentice Hall. ISBN 978-0-13-049307-1. Citado na pág. xv, 6, 7 
Sutter e Larus(2005) Herb Sutter e James Larus. Software and the concurrency revolution. Queue, 3(7):54-62. ISSN 1542-7730. doi: 10.1145/1095408.1095421. URL http://doi.acm.org/10. 1145/1095408.1095421. Citado na pág. 5

Valiant(1990) Leslie G. Valiant. A bridging model for parallel computation. Commun. ACM, 33 (8):103-111. Citado na pág. 42

Wong et al.(2010) Henry Wong, Misel-Myrto Papadopoulou, Maryam Sadooghi-Alvandi e Andreas Moshovos. Demystifying gpu microarchitecture through microbenchmarking. Em ISPASS, páginas 235-246. IEEE Computer Society. ISBN 978-1-4244-6022-9. Citado na pág. 45

Zhang(2012) Yao Zhang. Performance Modeling for GPU Architectures. Tese de Doutorado, University of California, Davis. URL http://search.proquest.com/docview/1023780687?accountid= 14643. Citado na pág. 44

Zhang e Owens(2011) Yao Zhang e John D. Owens. A quantitative performance analysis model for GPU architectures. Periódico Desconhecido, páginas 382-393. URL http://dx.doi.org/10. 1109/HPCA.2011.5749745. Citado na pág. 3, 44, 46 


\section{Índice Remissivo}

Apêndice

Desmontagem de Instruções PTX , 121

Conceitos de Paralelismo, 5

Conceitos GPU, 11

Arquitetura, 14

Compute Capability, 16

FERMI, 23

Conjunto de Instruções, 24

Gerenciamento de Threads, 26

ISA, 24

SM, 23

Subsistema de Memória, 26

Fundamentos, 13

Gerenciamento de Memória, 17

Otimização de Acesso à Memória, 18

SIMT, 20

Alocação, 20

Condicional Divergente, 22

Escalonamento, 20

Execução Divergente, 22

Sincronismo, 22

Stream Multi Processor, 16

CUDA, 27

Arquitetura Real, 34

Arquitetura Virtual, 34

Compilação por Demanda, 36

Emulação, 36

Etapas do Programa, 32

Just in Time Compilation, 36

Modelo de Programação, 27

NVCC, 33

Organização, 30

Repositórios, 37

Transferência, 32

Uso de Memória, 38

Experimentos e Resultados

Pipeline, Sequência de Instruções e Tempo de Execução, 104

Pipeline e Otimizações do Compilador, 107

Análises Preliminares, 71
Análise da Distribuição Após Alteração na Forma de Contabilizar o Tempo, 84

Análise das Rechamadas, 104

Análise de Dispersão, 72

Análise do Escalonamento, 72

Análise do Perfil da Instrução, 89

Análise do Sistema de Medição, 86

Análise do Teste de Pipelilne sem Otimização, 106

Análise do Trecho de Teste, 76

Perfil da Calibragem, 96

Variância em Função do Trecho de Teste e dos Warps, 84

Comparativo com Valores de Referência da NVIDIA, 109

Conclusões das Análises Preliminares, 98

Conclusões, 99

Perfil de Execução das Instruções, 98

Resumo e Conclusões da Validação, 109

Validação, 100

Kernels de Teste, 100

Modelo Simplificado, 101

Resultados, 101

experimentos e resultados, 71

Introdução, 1

microbench

Algoritmo Microbenchmark, 54

arquivo de saída, 61

funcionamento

obtenção do tempo médio, 63

pós processamento

arquivo de saída, 65

Perfil de Desempenho das Instruções, 65

Problemas Encontrados, 66

Análise de Código Morto, 67

Interferência da Geração de Vídeo, 67

variações no tempo de execução, 68

Microbenchmark

Algoritmo Execução em Rajada da Rotina de Teste de Instrução, 55

Compilação, 58 
Estrutura Básica da Rotina de Teste Executada na GPU, 53

Estrutura Básica da Rotina de Teste Executada no Hospedeiro, 55

Execução Intercalada da Rotina de Teste de Instrução, 55

Executável do Microbenchmark, 60

Formato do Arquivo de Configuração do Gerador de Microbenchmark, 57

Formato do Arquivo de Saída do Microbenchmark

Cabeçalho do Arquivo de Saída, 61

Listagem dos Tempos de Execução, 62

Gerador de Código de Teste, 52

Gerador de Instruções PTX, 48

Estrutura da Instrução PTX, 49

Gerador do Microbenchmark, 48

Linguagem para Definição de Instruções PTX, 50

Etiquetas de Definição da Arquitetura, 51

Opções de Configuração do Executável de Microbenchmark, 60

Opções de Configuração do Gerador de $M i$ crobenchmark, 55

Pós Processamento

Consistência das Leituras, 64

Perfil de Desempenho das Instruções, 65

Pós Processamento do Microbenchmark, 63

Problemas Encontrados

Código PTX e Código de Máquina, 68

paralelismo

Modelos, 9

Pipeline e ILP, 6

Taxonomia de Flynn, 6

Trabalhos Relacionados

A performance Analysis Framework for Identifying Potential Benefits in GPGPU Applications, 41

A Performance Prediction Model for the CUDA GPGPU Platform, 42

A Quantitative Performance Analysis Model for GPU Architectures, 44

An Adaptive Performance Modeling Tool for GPU Architectures, 43

An Analytical Model for a GPU Architecture with Memory-Level and Thread-Level Parallelism Awareness, 39

An Integrated GPU Power and Performance Model, 41

CUDA Performance Analyser, 41
Demystifying GPU Microarchitecture Through Microbenchmarking, 45

Resumo das Formas de Contabilizar o Tempo de Execução, 46

trabalhos relacionados, 39 